\title{
SEISMIC MOMENT TENSOR SOLUTIONS FROM GEONET DATA TO PROVIDE A MOMENT MAGNITUDE SCALE FOR NEW ZEALAND
}

\author{
Elizabeth de Joux Robertson
}

Geophysics

2008

A thesis submitted to the School of Geography, Environment and Earth Sciences,

Victoria University of Wellington, as fulfilment for the degree of Master of Science in Geophysics, 2008.

School of Geography, Environment and Earth Sciences

Victoria University of Wellington. 



\section{Abstract}

The aim of this project is to enable accurate earthquake magnitudes (moment magnitude, $\mathrm{M}_{\mathrm{W}}$ ) to be calculated routinely and in near real-time for New Zealand earthquakes. This would be done by inversion of waveform data to obtain seismic moment tensors. Seismic moment tensors also provide information on fault-type.

I use a well-established seismic moment tensor inversion method, the Time-Domain [seismic] Moment Tensor Inversion algorithm (TDMT_INVC) and apply it to GeoNet broadband waveform data to generate moment tensor solutions for New Zealand earthquakes. Some modifications to this software were made. A velocity model can now be automatically used to calculate Green's functions without having a pseudolayer boundary at the source depth. Green's functions can be calculated for multiple depths in a single step, and data are detrended and a suitable data window is selected. The seismic moment tensor solution that has either the maximum variance reduction or the maximum double-couple component is automatically selected for each depth.

Seismic moment tensors were calculated for 24 New Zealand earthquakes from 2000 to 2005. The Global CMT project has calculated CMT solutions for 22 of these, and the Global CMT project solutions are compared to the solutions obtained in this project to test the accuracy of the solutions obtained using the TDMT_INVC code.

The moment magnitude values are close to the Global CMT values for all earthquakes. The focal mechanisms could only be determined for a few of the earthquakes studied. The value of the moment magnitude appears to be less sensitive to the velocity model and earthquake location (epicentre and depth) than the focal mechanism.

Distinguishing legitimate seismic signal from background seismic noise is likely to be the biggest problem in routine inversions. 


\section{Contents}

$\begin{array}{ll}\text { Abstract } & \text { i }\end{array}$

List of Figures $\quad$ v

List of Tables $\quad$ v

Acknowledgements vi vi

Chapter One: Introduction 1

1.1. Motivation 1

1.2. New Zealand tectonics 3

1.3. Seismic moment tensor inversion 5

1.4. Previous work in New Zealand 8

1.5. Outline of this thesis 9

Chapter Two: Theory 11

2.1. Seismic moment tensor solutions 11

2.1.1. The Seismic Moment Tensor 11

2.1.1.1. Double-couple sources 11

2.1.1.2. Non-double-couple sources 14

$\begin{array}{ll}\text { 2.1.2. Seismic Moment Tensor Inversion } & 15\end{array}$

2.2. Calculation of the angle required to bring the focal planes from two focal mechanisms into coincidence 16

Step 1: Calculate P, T, and null axes 16

$\begin{array}{ll}\text { Step 2: Flip sets of vectors } & 17\end{array}$

$\begin{array}{ll}\text { Step 3: Define matrices of vectors } & 18\end{array}$

Step 4: Find the Euler vector 18

Step 5: Find a vector at right angles to the Euler vector and rotate around the

$\begin{array}{ll}\text { Euler vector } & 19\end{array}$

Step 6: Find the angle required to bring the focal planes from the two mechanisms into coincidence 19

Step 7: Find the minimum angle required $\quad 20$

The maximum angle required to rotate one mechanism into another 20

$\begin{array}{ll}\text { Chapter Three: Methodology } & 21\end{array}$

3.1. TDMT_INVC algorithm 21

3.1.1. Calculate Green's functions $\quad 21$

3.1.1.1. Modifications to calculation of Green's functions 22

$\begin{array}{ll}\text { 3.1.2. Prepare data } & 23\end{array}$

3.1.2.1. Modifications to data preparation script 23 
3.1.3. Moment tensor inversion 24

3.1.3.1. Modifications to moment tensor inversion 26

3.2. Velocity models 28

3.2.1. New Zealand velocity model 29

3.2.2. Wellington velocity model 30

3.3. Stations used 32

3.4. Earthquakes used 33

3.4.1. Earthquake locations 33

$\begin{array}{ll}\text { 3.5. Frequencies used } & 37\end{array}$

$\begin{array}{ll}\text { Chapter Four: Inversion Results } & 39\end{array}$

4.1. Summary of results $\quad 39$

Summary Table Notes $\quad 42$

4.2. Case studies 45

4.2.1. Upper Hutt $\quad 45$

4.2.2. Puysegur Trench 48

4.2.3. Fiordland $\quad 52$

4.2.4. East of Gisborne 55

4.3. Solution quality 58

4.4. Comparison with Global CMT solutions 61

4.4.1. Moment magnitude 61

4.4.2. Focal mechanisms $\quad 62$

4.5. Routine calculation of seismic moment tensors 66

4.5.1. Noise 66

4.5.2. Azimuthal coverage 66

$\begin{array}{ll}\text { Chapter Five: Conclusions } & 67\end{array}$

$\begin{array}{lr}\text { References } & \mathbf{7 0}\end{array}$

Appendix 1: Case Studies $\quad 75$

A1.1. Event 1502698 - Wairarapa 76

A1.2. Event 1597193 - Taupo 78

A1.3. Event 1737299 - King Country 82

A1.4. Event 1825324 - Haast 84

A1.5. Event 2114219 - Fiordland 86

A1.6. Event 2137041 - Fiordland 90

A1.7. Event 2137186 - Fiordland 94

A1.8. Event 2228901-Gisborne 98 
A1.9. Event $2266782-$ Bay of Plenty 102

A1.10. Event 2266243 - Bay of Plenty 104

$\begin{array}{ll}\text { A1.11. Event 2326055 - Puysegur Trench } & 108\end{array}$

A1.12. Event 2352986-Wairarapa 124

A1.13. Event 2353002 - Wairarapa 126

A1.14. Event 2354133 - Upper Hutt 128

A1.15. Event 2354877-Upper Hutt 134

A1.16. Event 2359081 - Wairarapa 136

A1.17. Event 2569288 - Wairarapa 138

A1.18. Event 2376455 - South of Taranaki 140

A1.19. Event 2376763 - Fiordland 148

A1.20. Event 2385032 - Twizel 152

A1.21. Event 2398629 - Jackson's Bay 156

A1.22. Event 2626467-Jackson's Bay 160

A1.23. Event 2403682 - East of Gisborne 162

A1.24. Event 2418019 - South of Kermadec Islands 166

$\begin{array}{ll}\text { Appendix 2: All seismic moment tensor solutions } & 168\end{array}$ 


\section{List of Figures}

Figure 1. 1. Present tectonics of the New Zealand plate boundary. ............................ 4

Figure 2. 1. The nine force couples of the seismic moment tensor. ........................... 11

Figure 2. 2. Fault geometry used in earthquake studies. ....................................... 13

Figure 2. 3. Focal mechanisms for an explosion (left) and an implosion (right)....... 14

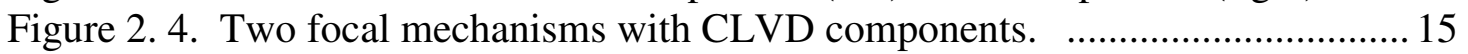

Figure 3. 1. Example of the output plot file from the TDMT_INVC code. ...............25

Figure 3. 2. A solution showing data with multiple peaks..................................... 27

Figure 3. 3. Boundaries of velocity models ............................................................... 29

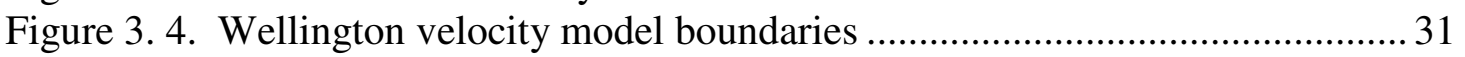

Figure 3. 5. New Zealand broadband seismograph stations..................................... 32

Figure 3. 6. 39 earthquakes recorded in March 2000 - June 2005 ............................. 34

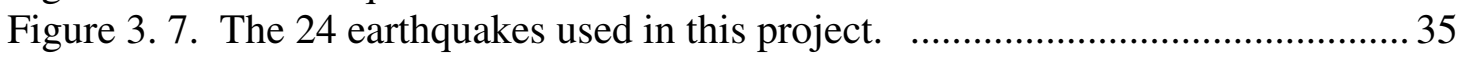

Figure 4. 1. The best solution calculated for the Upper Hutt earthquake.....................46

Figure 4. 2. One of the best solutions calculated for the Upper Hutt earthquake........ 46

Figure 4. 3. One of the best solutions calculated for the Upper Hutt earthquake........ 47

Figure 4. 4. One of the best solutions calculated for the Upper Hutt earthquake,....... 47

Figure 4. 5. The best solution produced for the Puysegur Trench earthquake, ...........50

Figure 4. 6. One of the best solutions produced for the Puysegur Trench earthquake 50

Figure 4. 7. One of the best solutions produced for the Puysegur Trench earthquake 51

Figure 4. 8. One of the best solutions produced for the Puysegur Trench earthquake 51

Figure 4. 9. The best solution produced for an earthquake in Fiordland......................53

Figure 4. 10. One of the best solutions produced for an earthquake in Fiordland ......53

Figure 4. 11. One of the best solutions produced for an earthquake in Fiordland ......54

Figure 4. 12. One of the best solutions produced for an earthquake in Fiordland. ..... 54

Figure 4. 13. One of the solutions calculated for the earthquake east of Gisborne ..... 56

Figure 4. 14. One of the solutions calculated for the earthquake east of Gisborne ..... 56

Figure 4. 15. One of the solutions calculated for the earthquake east of Gisborne ..... 57

Figure 4. 16. One of the solutions calculated for the earthquake east of Gisborne ..... 57

Figure 4. 17. Solution quality with epicentral location. ..........................................58

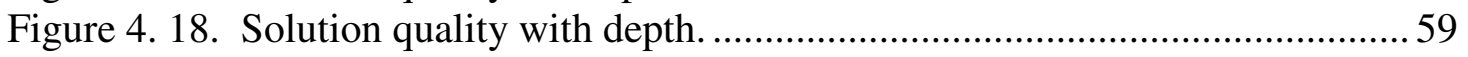

Figure 4. 19. Mw values this study compared to Global CMT project Mw values. ... 59

Figure 4. 20. Mw values this study compared to Global CMT project Mw values. ... 62

Figure 4. 21. The best mechanisms produced in this study ......................................63

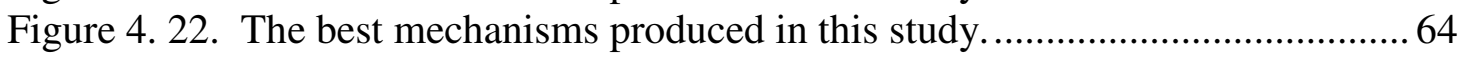

\section{List of Tables}

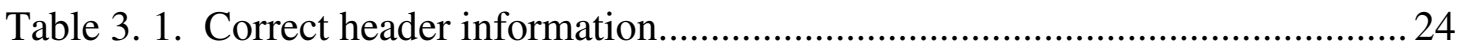

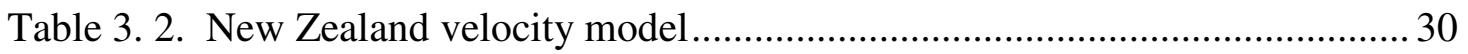

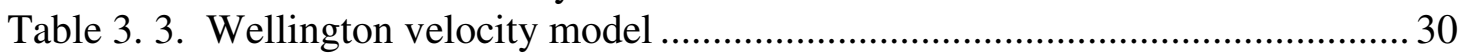

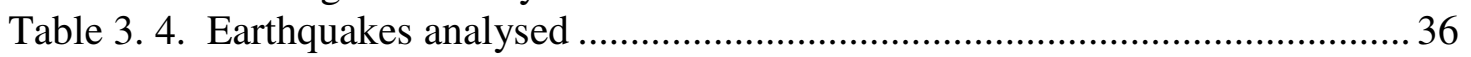

Table 4. 1. Summary of earthquakes processed ........................................................ 41

Table 4. 2. Magnitudes of A and B grade earthquakes ........................................... 42

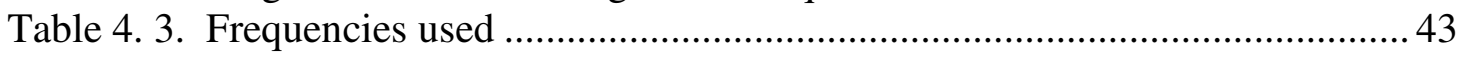




\section{Acknowledgements}

I would like to thank the many people and organisations who have helped to make this research possible.

- My primary supervisor, Prof. Euan Smith, for all of his support, assistance and advice.

- My secondary supervisor, Russell Robinson of GNS Science, for his advice.

- The Earthquake Commission, for their funding of this project.

- The Sarah Beanland Memorial Scholarship, administered by GNS Science, for their funding of this project.

- $\quad$ The New Zealand GeoNet project and its sponsors EQC, GNS Science and FRST, for providing data used in this study.

- Moment tensors were computed using the mtpackagev1.1 package developed by Douglas Dreger of the Berkeley Seismological Laboratory, and Green's functions were computed using the FKRPROG software developed by Chandan Saikia of URS.

- $\quad$ Staff and my fellow students in the Institute of Geophysics at Victoria University of Wellington and my colleagues at GNS Science; especially Mark Henderson, Stacey Dravitzki, Anya Seward and Sandra Bourguignon at the university, and John Ristau, Kevin Fenaughty, Mark Chadwick, Bryan Field, Stephen Bannister, and Paul Grimwood at GNS Science, for their help with computers, data collection, programming, figure creation, proof-reading, staying sane, and their friendship.

- $\quad$ And finally, my amazing family and my wonderful partner, Gareth Ackrill, for their support in so many ways. How can I ever thank them enough? 


\section{Chapter One: Introduction}

\subsection{Motivation}

The size, or magnitude, of an earthquake was first estimated using the local, or Richter, magnitude scale developed by Richter (1935). It was conceived for earthquakes with magnitudes between 2 and 6 recorded by a standard Wood-Anderson seismograph at distances of several tens to a few hundred kilometres (e.g. Deichmann, 2006). Other magnitude definitions include body-wave magnitude and surface-wave magnitude, which are based on measuring the dominant signal characteristics of earthquakes of different sizes and at different teleseismic distances (e.g. Stein and Wysession, 2003). Because of the narrow frequency bands in which amplitudes are measured, these magnitude scales "saturate" at large magnitudes, and the sizes of big earthquakes are sometimes unable to be determined (e.g. Stein and Wysession, 2003).

An alternative measure of an earthquake's size is the seismic moment, $M_{0}$, which is defined as

$$
M_{0}=\mu A \bar{D}
$$

where $\mu$ is the shear modulus, $A$ is the area of the fault, and $\bar{D}$ is the average slip on the fault (e.g. Stein and Wysession, 2003). Hanks and Kanamori (1979) showed that when $M_{0}$ is measured in dyne-cm,

$$
M_{W}=\frac{2}{3} \log M_{0}-10.7
$$

defines a "moment magnitude".

Scaling relations between local and moment magnitudes appear to be frequency dependent, and for both small and large events there are differences between the values of the local and moment magnitudes (e.g. Deichmann, 2006). The seismic moment is now widely regarded as the fundamental measure of the size of an earthquake (e.g. Deichmann, 2006), so it is preferable to use moment magnitude rather than other magnitude scales. 
It is also desirable to be able to quickly determine the focal mechanism of the earthquake, as this can give information on the likelihood of aftershock production, directivity (Pasyanos et al, 1996), and also on the likelihood of tsunami generation. Focal mechanisms calculated using first motions are often of dubious quality due to errors in the first motion picks (Dziewonski et al, 1981).

Calculating seismic moment tensors using the method of Dreger et al (1993) or similar methods leads to estimates of moment magnitude and the earthquake focal mechanism.

The moment magnitude and focal mechanisms currently are not routinely calculated for New Zealand earthquakes. Currently only the local magnitude is calculated routinely for New Zealand earthquakes, and this is known to significantly underestimate the size of earthquakes bigger than about $\mathrm{M}_{\mathrm{W}} 6.5$, and may also overestimate the size of small or deep earthquakes (Euan Smith, pers. comm. 2006).

This study investigates the feasibility of using the software of Dreger (2003) to automatically calculate seismic moment tensors (and hence moment magnitude and focal mechanisms) of New Zealand earthquakes. 


\subsection{New Zealand tectonics}

The New Zealand landmass lies upon the boundary between the Pacific and the Australian plates and is an area of complex continental deformation (e.g. Arnadottir et al, 1995). The Pacific Plate is subducted beneath the Australian plate along the Hikurangi subduction zone adjacent to the North Island, whereas south of the South Island, the Australian Plate subducts beneath the Pacific Plate. Between these two subduction zones there exists a transpressional boundary focussed upon the Alpine Fault in the South Island. The main tectonic features of New Zealand are shown in Figure 1. 1.

In the North Island, the Pacific and Australian Plates converge obliquely at the Hikurangi subduction zone. The rate of convergence varies from $45 \mathrm{~mm} / \mathrm{yr}$ at the Raukumara Peninsula in the north of the North Island (RP in Figure 1. 1) to $38 \mathrm{~mm} / \mathrm{yr}$ in the north of the South Island (McGinty et al, 2000; DeMets et al 1990, 1994). The convergence is accommodated by subduction of the Pacific Plate and deformation of the Australian plate (e.g. McGinty et al, 2000). The Hikurangi subduction zone includes standard subduction zone features such as a well-defined zone of intermediate depth seismicity, andesite volcanoes, a growing accretionary prism, and a fore-arc basin of low heat-flow and negative gravity anomalies (Smith et al, 1989). Back-arc rifting with extensional deformation, active volcanism and high heat-flow occurs in the Taupo Volcanic Zone (Wallace et al, 2004; Smith et al, 1989). Dextral (right-lateral) strike-slip faulting occurs in the eastern North Island (Wallace et al, 2004). The Hikurangi subduction zone extends into the Marlborough region.

The Alpine Fault, a dextral-reverse oblique-slip fault, is the main tectonic element of the South Island (e.g. Wellman and Willett, 1942; Anderson et al, 1993; Arnadottir et al, 1995). The Alpine Fault is connected to the Hikurangi subduction zone through the Marlborough Fault System, a series of several active dextral strike-slip faults that strike approximately north-east, sub-parallel to the direction of the plate motion (Lamb and Bibby, 1989). The plates are thought to be permanently locked in the north-east of the South Island, possibly as a result of subduction of the thickened crust of the Chatham Rise and Campbell Plateau (Reyners et al, 1997; Reyners 1998). In the South Island the Pacific and Australian plates converge at a rate of $\sim 40 \mathrm{~mm} / \mathrm{yr}$ in a WSW-ENE direction (Anderson et al, 1993). 


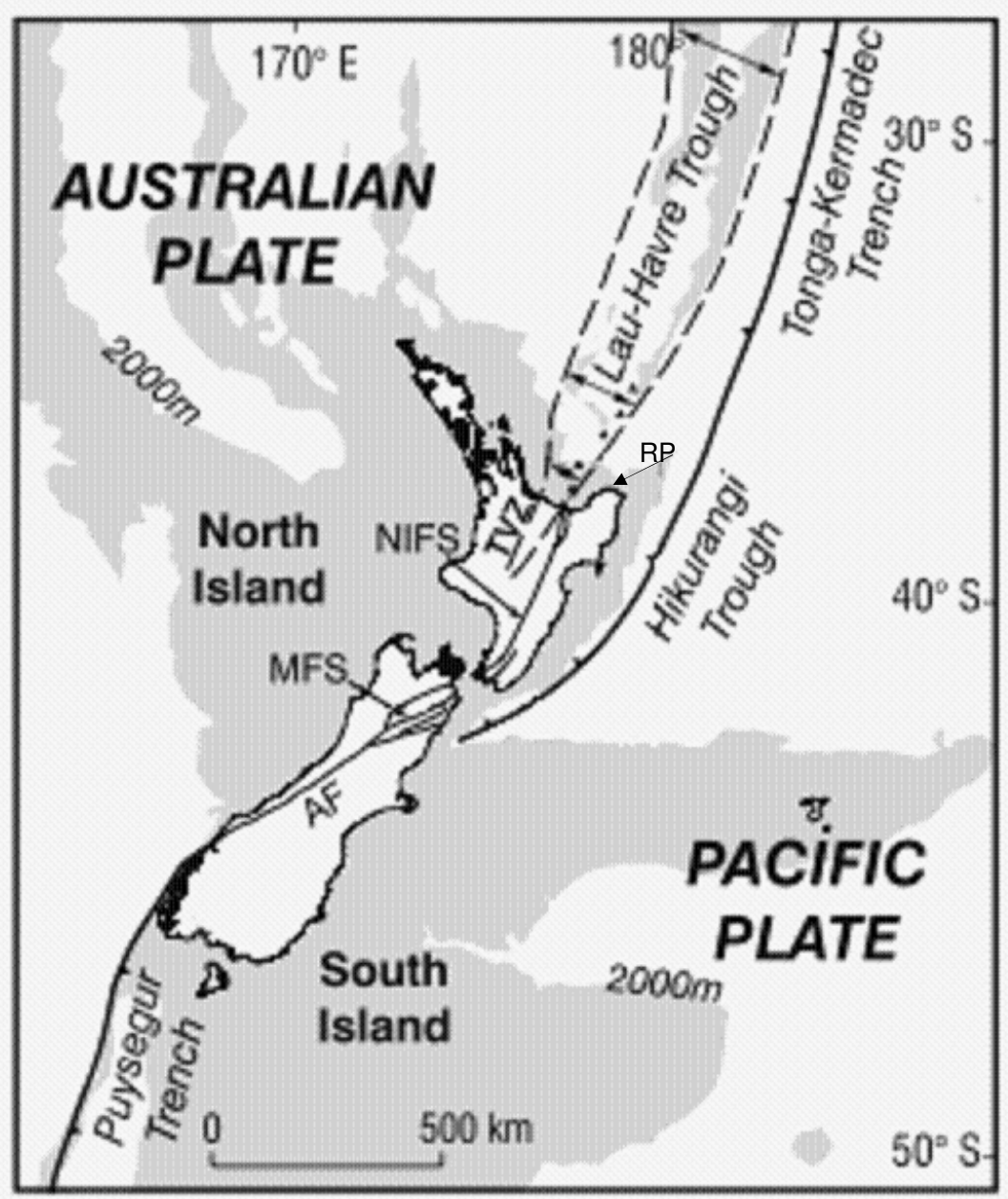

Figure 1. 1. Present tectonics of the New Zealand plate boundary. In the north, through to the south end of the North Island, the Pacific Plate subducts beneath the Australian Plate at the Tonga-Kermadec Trench and the Hikurangi Trough, and back-arc extension occurs in the Lau-Havre Trough and the Taupo Volcanic Zone (TVZ). In the South Island the plate boundary is a transform boundary at the Alpine Fault, and south of the South Island, the Australian Plate subducts beneath the Pacific Plate at the Puysegur Trench. Abbreviations: AF, Alpine Fault; MFS, Marlborough Fault System; NIFS, North Island Fault System; TVZ, Taupo Volcanic Zone; RP, Raukumara Peninsula. Figure modified from Nicol et al (2007).

As a result of these active tectonics New Zealand experiences a large number of earthquakes, mostly associated with the Hikurangi and Puysegur subduction zones. On average there are nearly 3000 earthquakes with magnitudes of M 3+ per year, and about one earthquake with a magnitude of M 6+ per year. Depths range from only a few kilometres to over $600 \mathrm{~km}$.

Earthquakes with magnitudes of M 6+ are potentially very damaging. It is therefore important to be able to rapidly determine an accurate magnitude and the faulting mechanism of the larger earthquakes so that the likelihood of possible damage can be quickly assessed. 


\subsection{Seismic moment tensor inversion}

Seismic moment tensors are calculated in near real-time for both global and local earthquakes using the method used in this study and similar methods at many institutions world-wide.

Dziewonski et al (1981) described a method of obtaining the seismic moment tensor and applied this method to 25 global events. This method uses a priori assumptions of earth structure, event location and origin time, and calculates double-couple solutions using inversion of seismic waveform data. This method is used for calculating moment tensor solutions by the Global CMT Project (previously the Harvard CMT Project). At the Earthquake Research Institute of the University of Tokyo, Japan, an automated near real-time CMT inversion procedure uses the "Harvard CMT method" of Dziewonski et al (1981) using long period body-wave data (Kawakatsu, 1995). Seismic moment tensor solutions are calculated for both local and global events (Kawakatsu, 1995).

Dreger and Helmberger described a method of calculating Green's functions from broadband data and a method of calculating the seismic moment tensor and obtaining source parameters including the focal mechanism, seismic moment, and source depth from regional data with sparse seismograph coverage (Dreger and Helmberger, 1990, 1993).

Pasyanos et al (1996) described two different methods of regional seismic moment tensor inversion, and suggest that the layered velocity models used in earthquake location programs may be used for obtaining Green's functions. The first method investigated is a regional frequency domain surface wave inversion. Intermediate period Love and Rayleigh waves are inverted using an inversion procedure adapted from one designed for global applications. An appropriate velocity model is selected for each source-receiver path to account for lateral variations in structure. Earthquakes with magnitudes $M>\sim 3.6$ can be processed using this method. The second method investigated is the time domain complete waveform method, as used in this study. Pasyanos et al (1996) processed earthquakes with a minimum magnitude of M 3.5 using this method. The minimum magnitude value reflects limits imposed by background noise in the frequency bands used in the inversion. Pasyanos et al (1996) use different frequency passbands for earthquakes with different magnitude ranges, with longer 
periods being used for bigger earthquakes. Pasyanos et al (1996) got very similar results from the two methods. Pasyanos et al (1996) concluded that the results are very insensitive to the values of the attenuation constants.

Sipkin (1994) described the method used for rapid determination of global moment tensors at the National Earthquake Information Centre of the United States Geological Survey, using only P-waveform data to minimise the time between the earthquake and the computation of the seismic moment tensor.

Ristau et al $(2003,2005)$ calculated regional seismic moment tensors for earthquakes off Canada's West Coast and in the Canadian Cordillera and Vancouver Island/Puget Sound region. The moment magnitudes calculated using this method were calibrated with local magnitudes. The regional moment tensor solutions were found to differ from those calculated using global data (e.g. by USGS or Harvard) in some cases, and this was attributed to the differences between global velocity models and region specific models (Ristau et al, 2003). It was found that for continental crust earthquakes in the Canadian Cordillera and the Vancouver Island/Puget Sound region $\mathrm{M}_{\mathrm{W}}=\mathrm{M}_{\mathrm{L}}$ for $\mathrm{M}_{\mathrm{L}} \geq 3.6$ (Ristau et al, 2005). For earthquakes in the subducting slab in the Vancouver Island/Puget Sound region $\mathrm{M}_{\mathrm{W}}$ was found to be greater than $\mathrm{M}_{\mathrm{L}}$ systematically by nearly 0.6 magnitude units (Ristau et al, 2005). Regional moment tensors could be calculated for earthquakes as small as M 3.5 (Ristau et al, 2005).

Rueda and Mezcua (2005) described automatic calculation of seismic moment tensors in Spain using the technique of Dreger and Helmberger (1993). Seismic moment tensors are calculated automatically for events with $\mathrm{m}_{\mathrm{bLg}}>3.5$ (body wave magnitude from Lb waves) as determined by the location system. Data are used from the three real-time broadband stations that are located closest to the epicentre. Results for near real-time calculations of seismic moment tensors for 22 earthquakes are discussed. The results are compared to those of other agencies, and these comparisons suggest that the results are reliable for magnitudes of $\mathrm{M}>4.5$. 
In this study the method of Dreger and Helmberger (1993) is used, by implementing the software of Dreger (2003). This method is applied to 24 recent earthquakes, which occurred between March 2000 and June 2005, onshore New Zealand and near offshore, with depths of $5-250 \mathrm{~km}$, and magnitudes of M 3.5 - M 7.2. The feasibility of implementing the method in near real-time is discussed. 


\subsection{Previous work in New Zealand}

Matcham (1999; Matcham et al, 2006) determined seismic moment tensor solutions for New Zealand earthquakes using the method of Dreger and Helmberger (1991) and an earlier version of the TDMT_INVC (Time Domain [seismic] Moment Tensor INVersion) method used in this study (Dreger, 2003). Matcham used data from the permanent broadband station SNZO, near Wellington, which was the only permanent broadband station at the time, and also from temporary deployments. Focal mechanisms were also calculated using the amplitude ratio technique and solutions obtained using both methods were compared. This study showed that the technique was feasible but data from more than one station was needed to produce satisfactory results.

Pancha et al (2005) used a determination of a 'mantle magnitude' from long period (40 - 300 seconds) surface waves to determine the moment magnitude of New Zealand earthquakes. This method can determine the moment magnitude for the large earthquakes with $M>7$ that it was intended for, but can not determine the moment magnitude of smaller events.

Since the work of Matcham (1999) the New Zealand seismograph network has been significantly upgraded, and there are now more than 40 broadband seismometers in New Zealand (see the GeoNet website, http://www.geonet.org.nz for more information). The technique may now be able to produce satisfactory results with the current permanent seismograph network. 


\subsection{Outline of this thesis}

Following this introduction, this thesis is divided into four further chapters.

Chapter Two discusses the theory of seismic moment tensors and seismic moment tensor inversion, and discusses a method to quantatively compare two focal mechanisms.

Chapter Three discusses the methodology used in this study. The TDMT_INVC code (Dreger, 2003) and the modifications made to the code for this study are discussed, followed by information on the velocity models that were used, the locations of the stations used and the earthquakes analysed, and the frequency bands used.

Chapter Four summarises the results of this project. A summary of the results is given, and the seismic moment tensor solutions calculated for four earthquakes are discussed. The quality of the solutions produced is discussed, and solutions are compared to solutions calculated by the Global CMT Project (http://www.globalcmt.org/CMTsearch.html). The feasibilty of the routine calculation of seismic moment tensor solutions in New Zealand is discussed.

The conclusions of this study are given in Chapter Five.

Following the main body of the thesis, seismic moment tensor solutions calculated for all earthquakes are discussed in Appendix 1, and all solutions produced are given in Appendix 2 (on the accompanying CD-ROM). 


\section{Chapter Two: Theory}

\subsection{Seismic moment tensor solutions}

\subsubsection{The Seismic Moment Tensor}

A seismic moment tensor is a complete description (to a first-order approximation) of the equivalent forces of a seismic point-source. (Jost and Hermann, 1989). The strike, dip and rake (or slip) of the earthquake as well as the scalar seismic moment (and hence the moment magnitude) can all be determined from the seismic moment tensor.

\subsubsection{Double-couple sources}

The seismic moment tensor is written

$$
\mathbf{M}=\left(\begin{array}{lll}
M_{x x} & M_{x y} & M_{x z} \\
M_{y x} & M_{y y} & M_{y z} \\
M_{z x} & M_{z y} & M_{z z}
\end{array}\right)
$$

(Stein and Wysession, 2003) where the elements are the force-couples shown in Figure 2. 1.
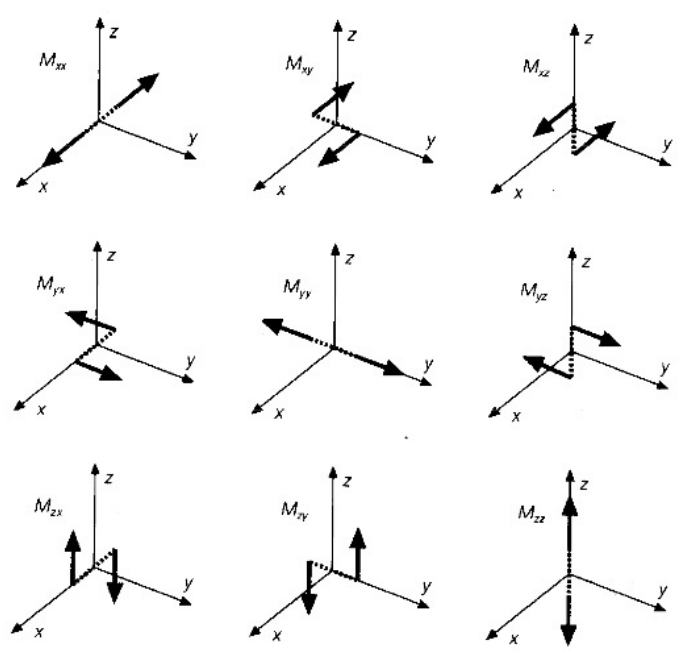

Figure 2. 1. The nine force couples which are the components of the seismic moment tensor. Each consists of two opposite forces separated by an infintesimal distance, so the net force is always zero. From Stein and Wysession (2003). 
For a double-couple earthquake the components of the seismic moment tensor are given by the scalar seismic moment $\left(M_{0}\right)$ and by the elements of the unit fault normal vector $(\underline{\hat{n}})$ and the unit slip vector $(\underline{\hat{d}})$,

$$
M_{i j}=M_{0}\left(n_{i} d_{j}+n_{j} d_{i}\right)
$$

or

$$
\mathbf{M}=M_{0}\left(\begin{array}{ccc}
2 n_{x} d_{x} & n_{x} d_{y}+n_{y} d_{x} & n_{x} d_{z}+n_{z} d_{x} \\
n_{y} d_{x}+n_{x} d_{y} & 2 n_{y} d_{y} & n_{y} d_{z}+n_{z} d_{y} \\
n_{z} d_{x}+n_{x} d_{z} & n_{z} d_{y}+n_{y} d_{z} & 2 n_{z} d_{z}
\end{array}\right)
$$

(Stein and Wysession, 2003).

It can be seen from this that the moment tensor is symmetric, i.e.

$$
M_{x y}=M_{y x}, M_{x z}=M_{z x} \text { and } M_{y z}=M_{z y} .
$$

This shows that slip either on the fault-plane or on the auxillary plane would yield the same seismic radiation patterns (Stein and Wysession, 2003).

It can also be seen that the trace (the sum of the diagonal elements) is zero. A non-zero trace would imply a volume change (e.g. an explosion or implosion) which does not exist for a pure double-couple source (Stein and Wysession, 2003).

The moment tensor can be written in terms of the seismic moment and the strike, rake and dip of the fault by using equations expressing the fault normal and slip vectors in terms of the strike $(\phi)$, rake $(\lambda)$ and $\operatorname{dip}(\delta)$ :

$$
\begin{aligned}
& \underline{\hat{n}}=\left(\begin{array}{c}
-\sin \delta \sin \phi \\
-\sin \delta \cos \phi \\
\cos \delta
\end{array}\right), \\
& \underline{\hat{d}}=\left(\begin{array}{c}
\cos \lambda \cos \phi+\sin \lambda \cos \delta \sin \phi \\
-\cos \lambda \sin \phi+\sin \lambda \cos \delta \cos \phi \\
\sin \lambda \sin \delta
\end{array}\right)
\end{aligned}
$$

(Stein and Wysession, 2003). 
From these equations and the definition of the seismic moment tensor in terms of the fault normal and slip vectors, equations can be derived for each of the moment tensor elements in terms of the strike, rake and dip. As the moment tensor is symmetric, there are only six elements to be derived.

$$
\begin{aligned}
& M_{x x}=-M_{0}\left(\sin \delta \sin 2 \phi \cos \lambda+\sin 2 \delta \sin ^{2} \phi \sin \lambda\right) \\
& M_{x y}=M_{y x}=-M_{0}\left(\sin \delta \cos 2 \phi \cos \lambda+\frac{1}{2} \sin 2 \delta \sin 2 \phi \sin \lambda\right) \\
& M_{x z}=M_{z x}=M_{0}(\cos 2 \delta \sin \phi \sin \lambda+\cos \delta \cos \phi \cos \lambda) \\
& M_{y y}=-M_{0}\left(\sin \delta \sin 2 \phi \cos \lambda-\sin 2 \delta \cos ^{2} \phi \sin \lambda\right) \\
& M_{y z}=M_{z y}=-M_{0}(\cos \delta \sin \phi \cos \lambda-\cos 2 \delta \cos \phi \sin \lambda) \\
& M_{z z}=M_{0}(\sin 2 \delta \sin \lambda)
\end{aligned}
$$

The geometrical relationship between the strike, rake and dip of the fault, and the fault normal and slip vectors is shown in Figure 2. 2.

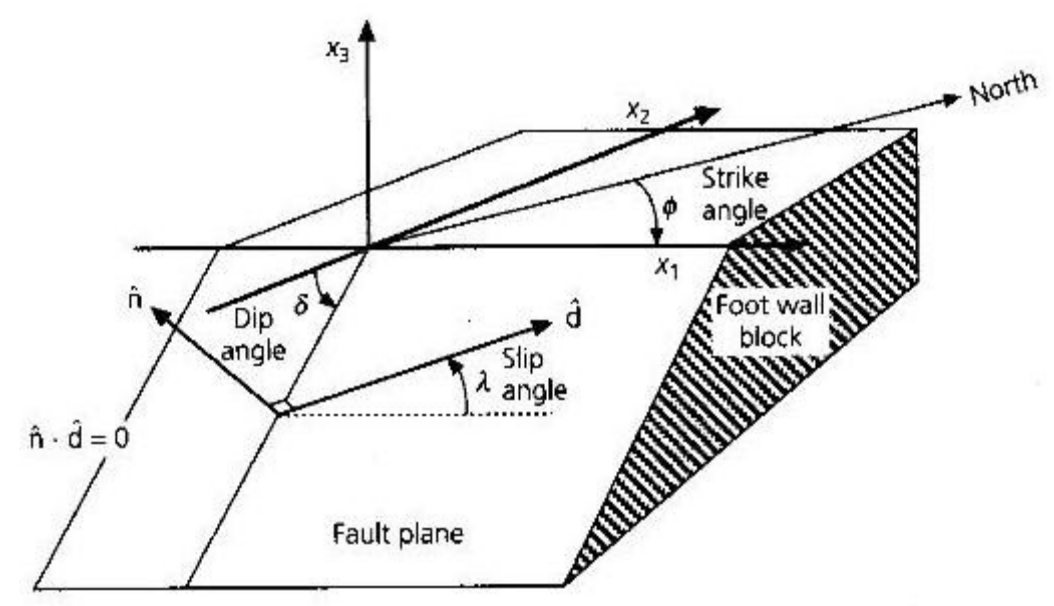

Figure 2. 2. Fault geometry used in earthquake studies. The fault plane, with normal vector $\mathrm{n}$, separates the lower footwall block from the upper hangingwall block (not shown). The slip vector, $d$, describes the motion of the hangingwall block with respect to the footwall block. The coordinate axes are chosen with $\mathrm{x}_{3}$ vertical and $\mathrm{x}_{1}$ oriented along the fault in the plane of the earth's surface, such that the fault dip angle, $\delta$, measured from the $-\mathrm{x}_{2}$ axis, is less than $90^{\circ}$. The rake or slip angle, $\lambda$, is measured between the $\mathrm{x}_{1}$ axis and $\mathrm{d}$ in the fault plane. $\phi$ is the strike of the fault, measured clockwise from north. From Stein and Wysession (2003). 
The seismic moment tensor $\mathbf{M}$ is both real and symmetric, and therefore can be rotated into the principal coordinate system, diagonalising $\mathbf{M}$, with the diagonal elements being the eigenvalues $\mathrm{m}_{i}$ of $\mathbf{M}$. The scalar seismic moment $M_{0}$, is given by

$$
M_{0}=\frac{1}{2}\left(\left|m_{1}\right|+\left|m_{2}\right|\right)
$$

where $m_{1}$ and $m_{2}$ are the largest eigenvalues in the absolute sense (Jost and Herrmann, 1989).

The seismic moment, $M_{0}$, is defined as

$$
M_{0}=\mu A \bar{D}
$$

where $\mu$ is the shear modulus, $A$ is the area of the fault, and $\bar{D}$ is the average slip on the fault (Stein and Wysession, 2003). The moment magnitude, $M_{W}$, can be found from the seismic moment,

$$
M_{w}=\frac{\log M_{0}}{1.5}-10.73
$$

where $M_{0}$ is given in dyne-cm (Stein and Wysession, 2003).

\subsubsection{Non-double-couple sources}

So far it has been assumed that the source is a double-couple earthquake. Moment tensors can also be found for non-double-couple sources. There are two main kinds of non-doublecouple seismic sources, isotropic and compensated linear vector dipoles (CLVDs).

The moment tensor for an explosion or implosion is isotropic and looks like

$$
\mathbf{M}=\left(\begin{array}{lll}
E & 0 & 0 \\
0 & E & 0 \\
0 & 0 & E
\end{array}\right)
$$

The trace is not zero, as it is for a double-couple moment tensor, and the nonzero trace represents a volume change (Stein and Wysession, 2003). Explosion mechanisms are all black (compression) and implosion mechanisms are all white (dilatation), as shown in Figure 2. 3.

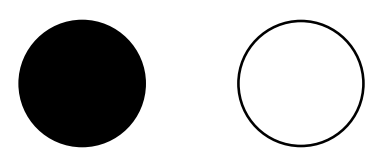

Figure 2. 3. Focal mechanisms for an explosion (left) and an implosion (right). 
CLVDs are sets of three force dipoles with one dipole -2 times the magnitude of the others:

$$
\mathbf{M}=\left(\begin{array}{ccc}
-a & 0 & 0 \\
0 & a / 2 & 0 \\
0 & 0 & a / 2
\end{array}\right)
$$

(Stein and Wysession, 2003). CLVD mechanisms look like baseballs or fried eggs, as illustrated in Figure 2. 4. CLVD mechanisms may be caused by cracks opening under tension, or two earthquakes occuring at about the same place and time on faults of different geometries (Stein and Wysession, 2003).
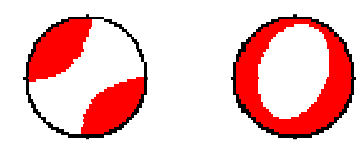

Figure 2. 4. Two focal mechanisms with CLVD components. The "baseball" mechanism on the left is for an earthquake in Southern Chile, which occurred on 3 February 2007. The "fried egg" mechanism on the right is for an earthquake which occurred on 18 January 2007 on the Northern Mid-Atlantic Ridge. Both mechanisms were computed by the Global CMT project.

\subsubsection{Seismic Moment Tensor Inversion}

The moment tensor is inverted for using observed seismograms, $d_{n}$, and Green's functions, $G_{n}$. The observed seismograms could be calculated by

\section{$\mathbf{d}=\mathbf{G m}$}

where $\mathbf{d}$ is a vector of $n$ seismograms, $\mathbf{G}$ is a $n \times 6$ matrix of Green's functions, and $\mathbf{m}$ is a vector containing the six independent elements of the moment tensor (Jost and Herrmann, 1989). We want to invert the above equation for $\mathbf{m}$. If $n$ is more than 6 the system is overdetermined, and a least-squares approach is used:

$$
\mathbf{m}=\left(\mathbf{G}^{T} \mathbf{G}\right)^{-1} \mathbf{G}^{T} \mathbf{d}
$$

(Stein and Wysession, 2003).

Preparation of data and calculation of Green's functions are discussed in Chapter 3. 


\subsection{Calculation of the angle required to bring the focal planes from two focal mechanisms into coincidence}

One method to compare two focal mechanisms, the orientations of the focal planes and the type of motion (normal, reverse, strike-slip, oblique-slip), is to find the angle that is needed to rotate the first mechanism into the second mechanism. This method is based on Euler's theorem, which says that the motion of a rigid body with one point fixed (eg. the origin) can be described as a rotation about some axis, which has to be found. This method was developed with Euan Smith (pers. comm. 2007) and is described below. Similar methods based on the same principles are discussed by Arnold and Townend (2007) and Kagan (2007).

\section{Step 1: Calculate $P, T$, and null axes}

Take the strike $(\phi)$, dip $(\delta)$ and rake $(\lambda)$ of a focal plane from each mechanism.

Calculate the fault normal vector $(\underline{\hat{n}})$ and slip vector $(\underline{\hat{d}})$ for each plane:

$$
\begin{aligned}
& \hat{\hat{n}}=\left(\begin{array}{c}
-\sin \delta \sin \phi \\
-\sin \delta \cos \phi \\
\cos \delta
\end{array}\right), \\
& \underline{\hat{d}}=\left(\begin{array}{c}
\cos \lambda \cos \phi+\sin \lambda \cos \delta \sin \phi \\
-\cos \lambda \sin \phi+\sin \lambda \cos \delta \cos \phi \\
\sin \lambda \sin \delta
\end{array}\right)
\end{aligned}
$$

(Stein \& Wysession, 2003).

Calculate the $\mathrm{P}, \mathrm{T}$ and null axes of each focal mechanism:

$$
\begin{array}{ll}
\text { P axis: } & \underline{p}=\underline{\hat{n}}-\underline{\hat{d}}, \\
\text { T axis: } & \underline{t}=\underline{\hat{n}}+\underline{\hat{d}}, \\
\text { null (B) axis: } & \underline{\hat{b}}=\underline{\hat{n}} \times \underline{\hat{d}}=\left(\begin{array}{c}
-\sin \lambda \cos \phi+\cos \lambda \cos \delta \sin \phi \\
\sin \lambda \sin \phi+\cos \lambda \cos \delta \cos \phi \\
\cos \lambda \sin \delta
\end{array}\right)
\end{array}
$$

(Stein \& Wysession, 2003).

Normalise $\mathrm{P}$ and $\mathrm{T}$ axes to get the unit vectors (the null axis is already a unit vector):

$$
\hat{p}=\frac{1}{\sqrt{p_{1}^{2}+p_{2}^{2}+p_{3}^{2}}}\left(\begin{array}{l}
p_{1} \\
p_{2} \\
p_{3}
\end{array}\right),
$$




$$
\hat{t}=\frac{1}{\sqrt{t_{1}^{2}+t_{2}^{2}+t_{3}^{2}}}\left(\begin{array}{l}
t_{1} \\
t_{2} \\
t_{3}
\end{array}\right),
$$

\section{Step 2: Flip sets of vectors}

Each focal mechanism is defined by two planes, each with a strike, rake and dip. From each plane a set of $\mathrm{P}, \mathrm{T}$ and null axes can be defined. These two sets of $\mathrm{P}, \mathrm{T}$ and null axes are not the same: one axis will be pointing in the same direction, and two axes will be pointing in opposite directions. This is illustrated below by two examples.

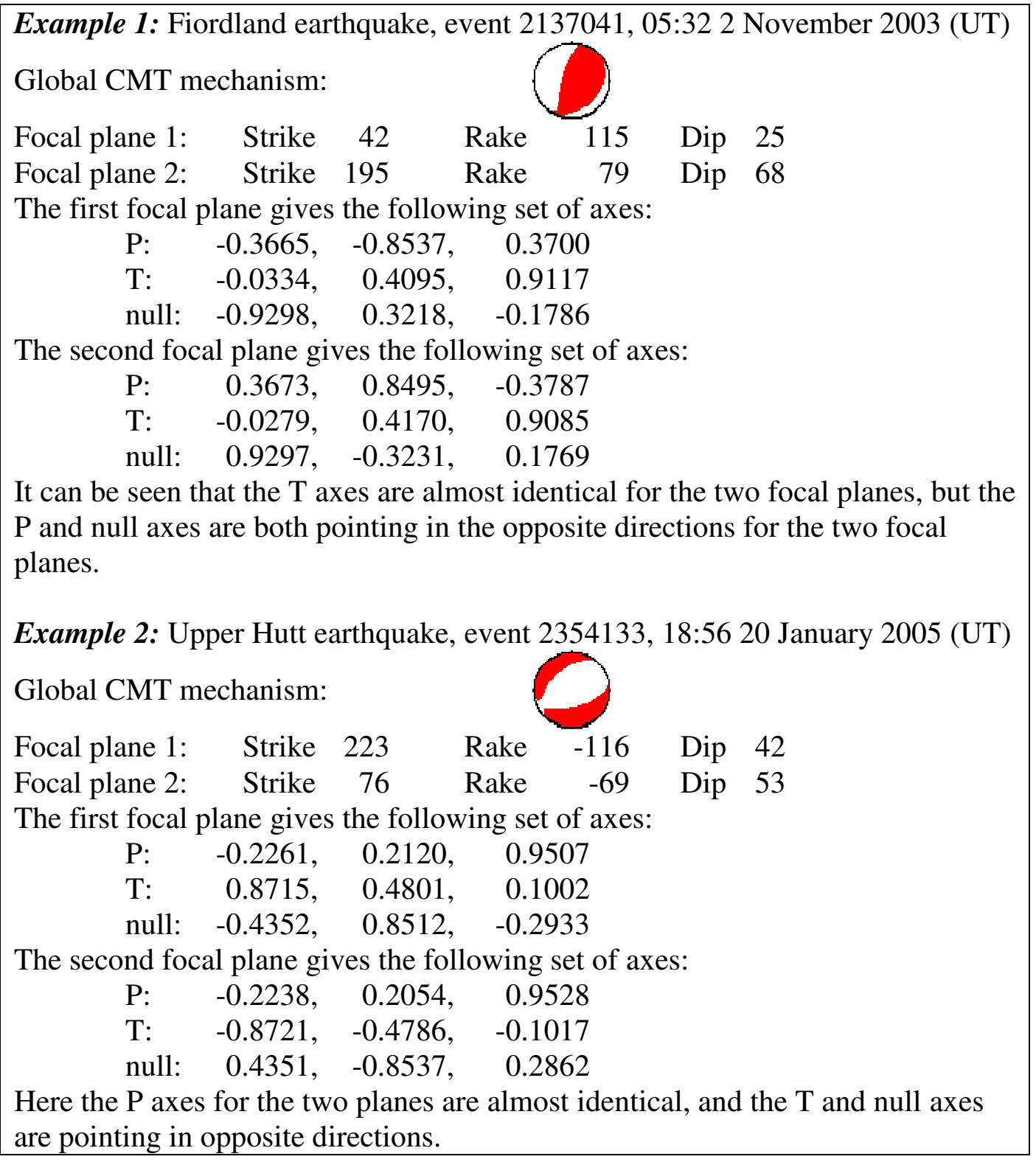

This non-uniqueness of the directions of the $\mathrm{P}, \mathrm{T}$ and null axes means that when comparing two mechanisms, each with two focal planes, there are four possible combinations of focal 
Chapter 2: Theory

2.2. Calculation of the angle required to bring two focal mechanisms into coincidence

planes to compare, and four different angles that could be used to bring the two focal planes into coincidence.

To find the minimum angle required, using just one focal plane from each mechanism, pairs of vectors are flipped, and angles calculated for each set with vectors flipped. Angles are calculated for four sets of vectors:

1. Using the $\mathrm{P}, \mathrm{T}$ and $\mathrm{B}$ (null) vectors of one plane for each mechanism;

2. Using the $\mathrm{P}, \mathrm{T}$ and $\mathrm{B}$ vectors of one plane for the first mechanism, and using $-\mathrm{P},-\mathrm{T}$, and $\mathrm{B}$ for the second mechanism;

3. Using the $\mathrm{P}, \mathrm{T}$ and $\mathrm{B}$ vectors of one plane for the first mechanism, and using $\mathrm{P},-\mathrm{T}$, and $-\mathrm{B}$ for the second mechanism;

4. Using the $\mathrm{P}, \mathrm{T}$ and $\mathrm{B}$ vectors of one plane for the first mechanism, and using $-\mathrm{P}, \mathrm{T}$, and $-\mathrm{B}$ for the second mechanism;

The minimum of the angles calculated is the angle required to bring the focal planes from the two mechanisms into coincidence.

The following steps are performed for each of the four combinations of vectors listed above.

\section{Step 3: Define matrices of vectors}

Let the $\mathrm{P}, \mathrm{T}$ and null axes for the first focal plane be represented by $\underline{\hat{p}}_{a}, \hat{t}_{a}$, and $\underline{\hat{b}}_{a}$, and let those for the second plane be represented by $\underline{\hat{p}}_{b}, \hat{t}_{b}$, and $\underline{\hat{b}}_{b}$.

Define matrices of vectors, $\mathrm{A}$ and $\mathrm{B}$ :

$$
A=\left(\begin{array}{c}
\hat{p}_{a}^{T} \\
\hat{\hat{t}}_{a}^{T} \\
\hat{\hat{b}}_{a}^{T} \\
\underline{\underline{a}}^{T}
\end{array}\right), \quad B=\left(\begin{array}{c}
\hat{\hat{p}}_{b}^{T} \\
\hat{\hat{t}}_{b}^{T} \\
\hat{\hat{b}}_{b}^{T} \\
\underline{\underline{t}}_{b}
\end{array}\right) .
$$

\section{Step 4: Find the Euler vector}

We want the Euler vector $\underline{x}$ such that $A \underline{x}=B \underline{x}$. 
Chapter 2: Theory

2.2. Calculation of the angle required to bring two focal mechanisms into coincidence

Multiply both sides on the left by the inverse of B (B is orthogonal so the inverse always exists):

$$
B^{-1} A \underline{x}=B^{-1} B \underline{x}
$$

so $\quad B^{-1} A \underline{x}=\underline{x}$.

As $\mathrm{A}$ and $\mathrm{B}$ are square matrices, and all elements of $\underline{x}$ are real, we can write this as

$$
B^{-1} A \underline{x}=\mu \underline{x} \quad \text { where } \mu=1 .
$$

We can now see that $\underline{x}$ is an eigenvector of $B^{-1} A$, with eigenvalue 1 .

\section{Step 5: Find a vector at right angles to the Euler vector and rotate around the Euler vector}

To find a vector $\underline{\hat{x}}_{r}$ at right angles to the Euler vector, we can take the cross-product of the Euler vector and another vector, and the result will be at right angles to both, i.e.

$$
\underline{x}_{r}=\underline{x} \times\left(\begin{array}{l}
0 \\
0 \\
1
\end{array}\right) \quad \text { or } \underline{x}_{r}=\underline{x} \times\left(\begin{array}{l}
0 \\
1 \\
0
\end{array}\right)
$$

and then normalise to find the unit vector

$$
\underline{\hat{x}}_{r}=\frac{1}{\sqrt{x_{r 1}^{2}+x_{r 2}^{2}+x_{r 3}^{2}}}\left(\begin{array}{c}
x_{r 1} \\
x_{r 2} \\
x_{r 3}
\end{array}\right) .
$$

In the "A" co-ordinate system, this is:

$$
\underline{\hat{x}}_{a}=A \underline{\hat{x}}_{r} .
$$

In the " $\mathrm{B}$ " co-ordinate system, this is:

$$
\underline{\hat{x}}_{b}=B \underline{\hat{x}}_{r} \text {. }
$$

\section{Step 6: Find the angle required to bring the focal planes from the two} mechanisms into coincidence

Bring $\mathrm{A}$ and $\mathrm{B}$ together by rotating about the Euler vector, so the angle required to bring the two focal mechanisms into coincidence is 


$$
\cos ^{-1}\left(\underline{\hat{x}}_{b} \bullet \underline{\hat{x}}_{a}\right) \text {. }
$$

\section{Step 7: Find the minimum angle required}

At this point steps $3-6$ should be repeated for all of the sets of vectors defined in step 2. The minimum of these angles is the angle required.

\section{The maximum angle required to rotate one mechanism into another}

If a set of axes $(\mathrm{x}, \mathrm{y}, \mathrm{z})$ is arbitrarily assigned, so that the rotation of the first focal mechanism around the z-axis by an angle $\alpha$ results in the second focal mechanism, then the rotation matrix R can be written

$$
R=\left[\begin{array}{ccc}
\cos \alpha & \sin \alpha & 0 \\
-\sin \alpha & \cos \alpha & 0 \\
0 & 0 & 1
\end{array}\right]
$$

And the trace of the rotation matrix is

$$
\operatorname{tr}(R)=1+2 \cos \alpha .
$$

So the angle can be expressed as

$$
\alpha=\cos ^{-1}\left(\frac{\operatorname{tr}(R)-1}{2}\right) \text {. }
$$

When there is no rotation required to rotate one focal mechanism into another (i.e. the two focal mechanisms are the same) the rotation matrix is the identity matrix, and the trace has a value of 3 . The angle required to rotate one mechanism into the other is

$$
\alpha=\cos ^{-1}\left(\frac{3-1}{2}\right)=\cos ^{-1}(1)=0 \text { as expected. }
$$

The maximum absolute departure from no rotation occurs when the trace is zero, so the maximum angle that could be required to rotate one focal mechanism into another is

$$
\alpha=\cos ^{-1}\left(\frac{0-1}{2}\right)=\cos ^{-1}\left(-\frac{1}{2}\right)=120^{\circ} \text {. }
$$

Grid searches over selected mechanisms revealed angles of up to $119.83^{\circ}$. 


\section{Chapter Three: Methodology}

Seismic moment tensor solutions were calculated for New Zealand earthquakes using GeoNet data and the TDMT_INVC algorithm (Dreger, 2003). Information about the earthquakes chosen for inversion is given in Section 3.4. Some modifications were made to the TDMT_INVC software. The TDMT_INVC software and the modifications made to it are described in Section 3.1.

\subsection{TDMT_INVC algorithm}

The TDMT_INVC algorithm was developed by Dreger (2003). The software uses subroutines from Numerical Recipes in C (Press et al, 1988) and SAC (Seismic Analysis Code; Goldstein et al, 2003), which are not included with the TDMT_INVC software (Dreger, 2003). The following sections describe how Green's functions are calculated and filtered, how the data are prepared for inversion, how the seismic moment tensor inversions are performed, and the modifications made to the TDMT_INVC software for this study.

\subsubsection{Calculate Green's functions}

Displacement Green's functions (with $\mathrm{cm}$ amplitude units) were calculated by applying a delta source-time function to a 1D "velocity" model (how velocity, density and attenuation vary with depth) for various source depths and source-seismograph distances. The velocity models used are described in Section 3.2.

The first 200 seconds of each Green's function were filtered using one pass of a frequency band-pass Butterworth filter with two poles, and then resampled at 1 sample per second. The frequency ranges used are described in Section 3.5.

Because a 1D velocity model is used, the Green's functions are dependent on source depth and source-seismograph distance, but not on the azimuth between the source and seismograph. This means that the Green's functions calculated for particular depths, sourceseismograph distances and velocity models can be saved as a library and used again later for other earthquakes. Calculating Green's functions is the most time-consuming part of computing seismic moment tensors, so having libraries of Green's functions computed for particular depths, velocity models and source-seismograph distances significantly reduces the 
computing time. Using libraries of pre-filtered Green's functions having particular bandpass frequency filters also speeds up the calculation of seismic moment tensors.

\subsubsection{Modifications to calculation of Green's functions}

The TDMT_INVC code calculates Green's functions for several source-seismograph distances at $5 \mathrm{~km}$ intervals using a velocity model with a pseudo-boundary at the source depth. Seismic velocities, density and attenuation constants must be the same in the layers above and below the source. The velocity model must be altered to calculate Green's functions for different depths.

The original velocity model also has two unset parameters, $\mathrm{X}$ and $\mathrm{Y}$, which relate to the number of computer CPUs used to generate the Green's functions. Up to four CPUs may be used. A script, run_parallel, is used to write a number of new velocity models equal to the number of CPUs used, and then to use these new velocity models and the FKRPROG program to calculate the Green's functions. $\mathrm{X}$ in each new velocity model is replaced with the current CPU number, and $\mathrm{Y}$ is changed to the total number of CPUs.

For this project only one CPU was used to generate the Green's functions, so both X and Y were set to 1 .

There were some problems with the run_parallel script, and sometimes Green's functions were generated properly and sometimes they were not. Manually changing the values of $X$ and $\mathrm{Y}$ and running FKRPROG directly meant that the Green's functions were generated correctly.

There were problems with using SAC commands to filter the Green's functions directly, so the commands were written to a file, which was then called in SAC.

A program called depth_loop was developed by John Ristau (pers. comm. 2007) and was used to generate and filter Green's functions. Depth_loop runs the FKRPROG program and the run_filter script from the TDMT_INVC code to generate and filter the Green's functions. Depth_loop uses a simple velocity model without the pseudo-boundary at the source depth and with $\mathrm{X}$ and Y both replaced with 1. Depth_loop calculates and filters Green's functions for various source depths and source-seismograph distances using a given frequency band. 
Minimum and maximum depths and source-seismograph distances and the depth interval can be set. The source-seismograph distance interval is set to $5 \mathrm{~km}$.

Only one pass of the butterworth filter used to filter out high and low frequencies was used, rather than the two used in the original script. Since both the data and the Green's functions are filtered using one pass of the same filter, any phase shift caused by only using one pass is common, and so does not affect the results.

\subsubsection{Prepare data}

Velocity seismograms (with amplitude units of $\mathrm{m} / \mathrm{s}$ ) were used from 3-component broadband instruments. These seismograms were prepared for moment tensor inversion. The data were trimmed to begin four seconds before the arrival of the P-wave and end 200 seconds after the P-wave arrival. Data for the Puysegur Trench event were also prepared using different amounts of data before the P-wave arrival. 10 second, 30 second, 60 second, and 120 second lengths were also used for the Puysegur Trench earthquake. The linear trend of the data was removed from each component. The instrument response (poles and zeros that convert from digital units to $\mathrm{m} / \mathrm{s}$ ) was deconvolved. The two horizontal (North and East) components were rotated into the radial and transverse components. All three components were integrated using the trapezoidal rule to give displacement seismograms (in $\mathrm{cm}$ ). The data were filtered using the same frequency band-pass filter that was applied to the Green's functions (see section 3.1.1), and finally the data were resampled at one sample per second.

\subsubsection{Modifications to data preparation script}

The time of the P-wave arrival was not originally included in the data preparation script, and the length of data was not cut. Originally there was no option to use data from broadband seismometers with broadband $\mathrm{HH}$ component code prefixes, so the script had to be modified to include this. This also had to be changed in the configuration file that specifies which component code prefix is to be used. There were problems with using the SAC commands directly, so the commands were written to a file that was then called in SAC. The original script removed only the mean from the data, this was modified so that the linear trend was removed. The component azimuths and incident angles were not properly set in the SAC header information so data could not be rotated. This may be due to a problem with GeoNet header information. The script was modified to change the component information to the correct values, shown in Table 3. 1. 
Table 3. 1. Correct header information

\begin{tabular}{|l|c|c|}
\hline Component & $\begin{array}{c}\text { Azimuth } \\
\text { (degrees clockwise from North) }\end{array}$ & $\begin{array}{c}\text { Incident angle } \\
\text { (degrees from vertical) }\end{array}$ \\
\hline North & $0^{\circ}$ & $90^{\circ}$ \\
\hline East & $90^{\circ}$ & $90^{\circ}$ \\
\hline Vertical & $0^{\circ}$ & $0^{\circ}$ \\
\hline
\end{tabular}

A script, mprepdata, was written so that data from lots of stations could be prepared for moment tensor inversion with a single command. An additional input file is required. This input file contains the codes of all the required stations and the time of the P-wave arrivals at each station. The other information required by the original data preparation script (data filename prefix, the year and Julian day of the earthquake, earthquake latitude and longitude, and the frequency range of the filter) is still required in the command line as well as the name of the input file containing the station names and P-wave arrival times.

\subsubsection{Moment tensor inversion}

To invert for the seismic moment tensor, an input file with the relevant information is required. The first line of this input file, $m t_{-} i n v . i n$, gives the number of three component broadband stations to be used $(n)$, the source depth, the distance weighting flag (set to 1) and the plotting flag (also set to 1 ). The next $n$ lines give the data filename, the distance (in $\mathrm{km}$ ) from the earthquake, the azimuth (degrees from North), the sample offset (zcor, see below) and the number of samples (set at 120) for each station; and the final $n$ lines give the name of the filtered Green's function to be used for each station (in the same order as the data files), the zero-offset (always set at zero), and the number of samples to be used (also 120). (Dreger, 2003).

The zcor parameter is used to align the data with the Green's functions. This is usually set at zero initially, and the inversion script modifies this value before inversion by crosscorrelating the data with the Green's functions to obtain the value of zcor that gives the best variance reduction for each station. The inversion can then be re-performed adjusting the value of zcor from the automatically obtained value until the best solution is found. It was found to be necessary to change the zcor value to match the length (in seconds) of pre-Pwave data used.

When the moment tensor inversion is run a plot file is generated which is then converted to the Postscript image format. An example of the plot file generated is shown in Figure 3. 1. 


\subsection{TDMT_INVC algorithm}

The output plot file shows the alignment of the data and the Green's functions (data are shown with solid lines and Green's functions with dashed lines) and the resulting focal mechanism. For each station the name of the data file used, the azimuth, the maximum amplitude, and the station variance reduction (VR), are given beneath the tangential traces.

On the right of the figure information is given about the solution, the moment tensor decomposition, and the fitting parameters. The solution information given is the strike, dip and rake of the fault plane and the auxilary plane (though it is not known which is which), the scalar seismic moment, and the moment magnitude. Information is given about the moment tensor decomposition in terms of the percentage double-couple (DC), CLVD, and isotropic (ISO, which is constrained to be zero) components. The fitting parameters variance, variance reduction (Var. Red), and the variance modulated by the percentage double-couple (RES/Pdc) are also given.

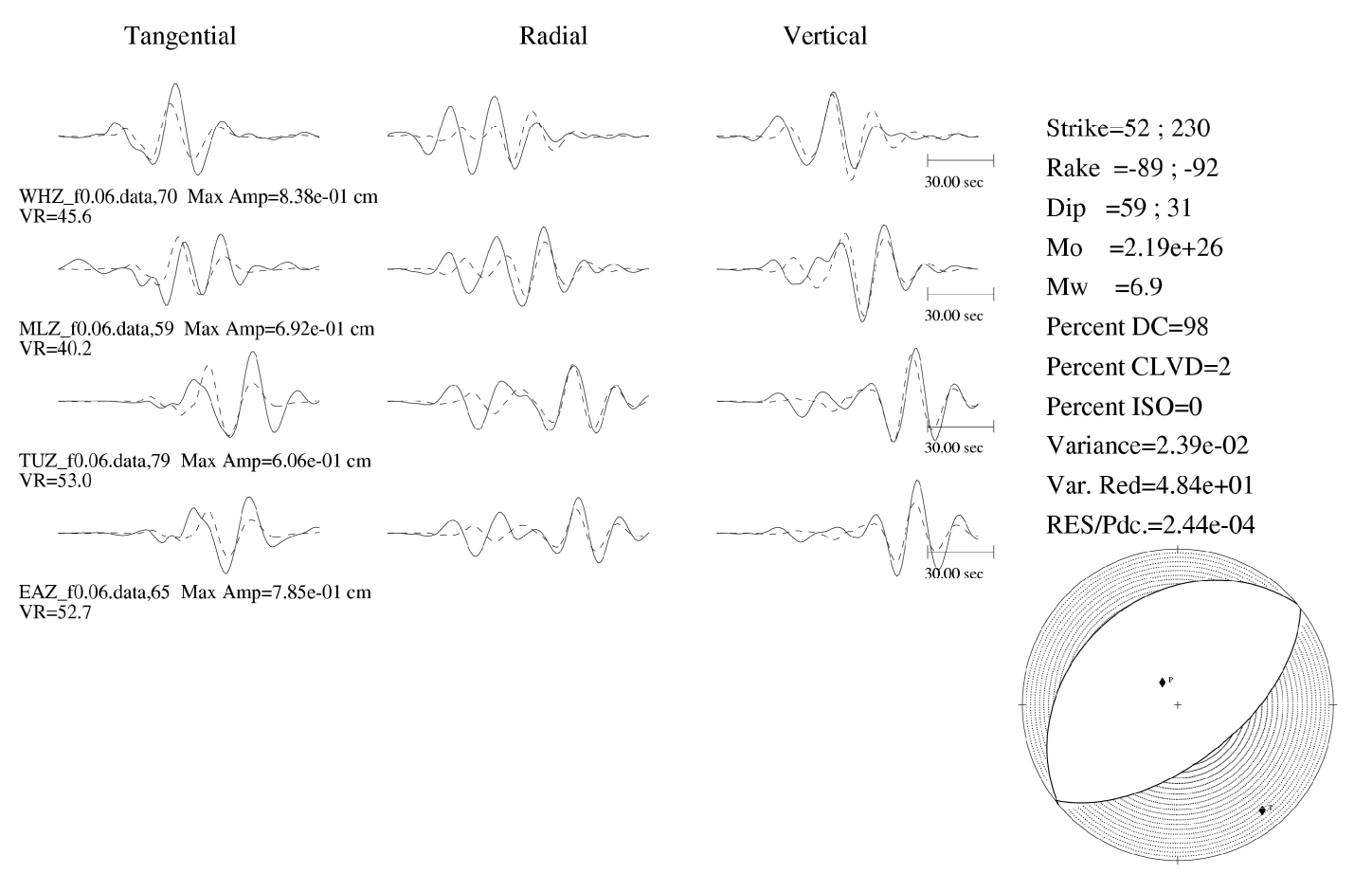

Figure 3. 1. Example of the output plot file from the TDMT_INVC code. Best solution for the Puysegur Trench earthquake, event 2326055.

The variance is calculated as

$$
\text { Variance }=\frac{\text { Sum of squares of residuals (summed over all stations and samples) }}{\text { Number of traces }-6}
$$


where the residual is the value of the data minus the value of the Green's function for each sample, and the number 6 represents the number of independent elements of the moment tensor.

The variance reduction is defined as

$$
\begin{aligned}
& \text { Variance } \\
& \text { reduction }
\end{aligned}=1-\left(\frac{\begin{array}{c}
\text { Station-weighted sum of squares of residuals summed over } \\
\text { stations and samples }
\end{array}}{\begin{array}{c}
\text { Station-weighted sum of squares of data summed over } \\
\text { stations and samples }
\end{array}}\right) \text {. }
$$

\subsubsection{Modifications to moment tensor inversion}

Calculating and recalculating the seismic moment tensor using various values of $z$ cor to change the alignment of the data and the Green's functions is a time consuming business, and a script (invert) was written by John Ristau (pers. comm., 2007) to calculate and recalculate the moment tensor optimising the variance reduction.

New Zealand seismic data are fairly noisy and often have multiple peaks of similar amplitudes, as seen in Figure 3. 2. This means that there is a potential to fit the Green's functions to the data with a considerable phase (zcor) error and to obtain a good (high) value for the variance reduction. Figure 3. 2 was obtained using the invert code, and shows the solution with the largest variance reduction. Solutions were also calculated over a range of depths. The solution shown in Figure 3. 2 has a very high percentage CLVD component, which is physically unrealistic.

For this reason the invert code was modified (and renamed einvert), which maximises the percentage double-couple component instead of the variance reduction. This script was later modified again so that the source depth is included in the information displayed on the solution plot.

Seismic moment tensor solutions for some earthquakes were calculated using the invert code, which optimises the variance reduction, and solutions for other earthquakes were calculated using einvert, which optimises the double-couple component. For a few earthquakes, solutions were calculated using both invert and einvert. For the earthquakes with solutions calculated using both invert and einvert, einvert produced solutions that appeared to have better fits between the data and the synthetic seismograms. Details about which code was used to produce solutions for each earthquake can be found in Section 4.1 and Appendix 1. 

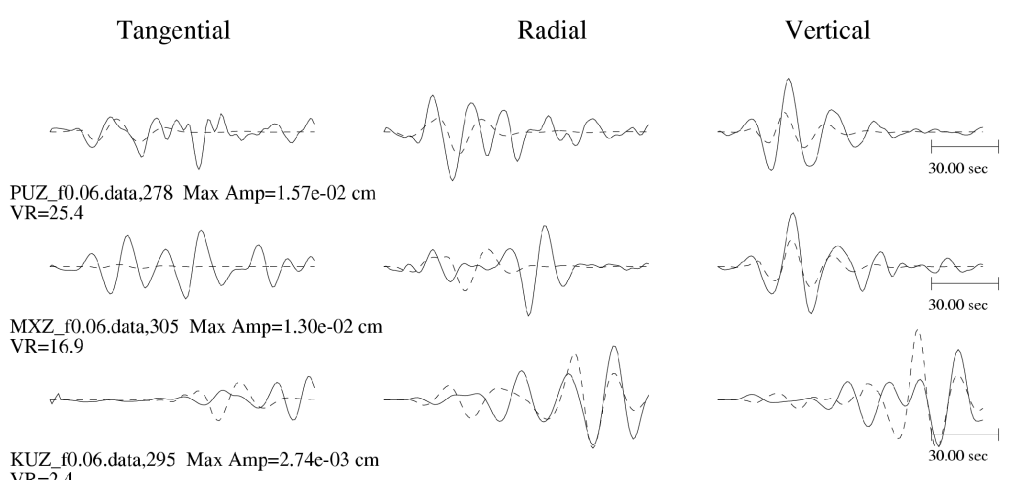

Strike $=29 ; 249$

Rake $=80 ; 129$

Dip $=78 ; 15$

Mo $=7.71 \mathrm{e}+23$

$\mathrm{Mw}=5.2$

Percent $\mathrm{DC}=28$

Percent $\mathrm{CLVD}=72$

Percent $\mathrm{ISO}=0$

Variance $=8.41 \mathrm{e}-06$

Var. Red $=2.03 \mathrm{e}+01$

RES/Pdc. $=3.05 \mathrm{e}-07$

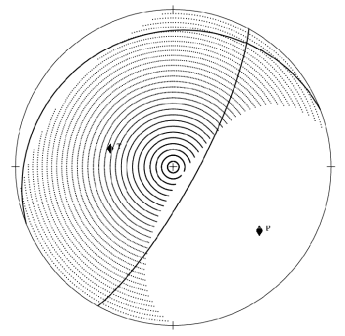

Figure 3. 2. A solution from an earthquake east of Gisborne, event 2403682, showing data (solid lines) with multiple peaks. 


\subsection{Velocity models}

The TDMT_INVC code calculates Green's functions based on 1D velocity models which contain information about how P- and S-wave velocities, density, and P- and S-wave attenuation vary with depth. The velocity model also contains the phase velocity window for integration and a reduction velocity.

The velocity models used are based on the models used by GNS Science for locating earthquakes. Figure 3.3 shows the boundaries of the regions the models used to locate earthquakes (co-ordinates from http://www.geonet.org.nz/resources/earthquake/hypocentrederivation.html). These boundaries are not sharp as shown in the figure, but use gradual transitions (Euan Smith, pers. comm. 2007).

The New Zealand standard velocity model given in Section 3.2.1 was used to compute moment tensor solutions for all earthquakes used in this study. The Wellington velocity model (Section 3.2.2) was also used to compute solutions for an earthquake in Upper Hutt.

A velocity model with a water layer was trialled but was unable to be used. S-waves can not travel through water, therefore the S-wave velocity is zero in the water layer. The TDMT_INVC code was unable to calculate Green's functions with an S-wave velocity of zero.

The same attenuation constants, phase velocities and reduction velocity were used in both models. A P-wave attenuation constant $\left(\mathrm{Q}_{\mathrm{p}}\right)$ of 400 was taken as an average value from Eberhart-Philips and McVerry (2003). It was assumed that the $\mathrm{S}$-wave attenuation, $\mathrm{Q}_{\mathrm{s}}$, is equal to half the P-wave attenuation $\left(\mathrm{Q}_{\mathrm{s}}=200\right)$, and that the attenuation does not vary with depth, consistent with the Californian velocity models SoCal and Gil7 included with the TDMT_INVC algorithm (Dreger, 2003). Velocities of 10,000.0 km/s, 30.0 km/s, $2.3 \mathrm{~km} / \mathrm{s}$ and $1.9 \mathrm{~km} / \mathrm{s}$ were used to define the phase velocity window of the integration. The first two phase velocity values are the same as are given in the Californian SoCal and Gil7 velocity models (Dreger, 2003). The third and fourth phase velocity values must be less than the Rayleigh wave velocity of the model (Dreger, 2003). The SoCal model has values of 2.9 $\mathrm{km} / \mathrm{s}$ and $2.5 \mathrm{~km} / \mathrm{s}$, and the Gil7 model uses values of $1.2 \mathrm{~km} / \mathrm{s}$ and $1.0 \mathrm{~km} / \mathrm{s}$ (Dreger, 2003). Values of $2.3 \mathrm{~km} / \mathrm{s}$ and $1.9 \mathrm{~km} / \mathrm{s}$ were chosen as appropriate for New Zealand. The reduction 
velocity defines the time at which the Green's functions start; $t_{0}=$ distance/reduction velocity. A reduction velocity of $8.0 \mathrm{~km} / \mathrm{s}$ was used, as recommended by Dreger (2003), and consistent with the New Zealand velocity model.

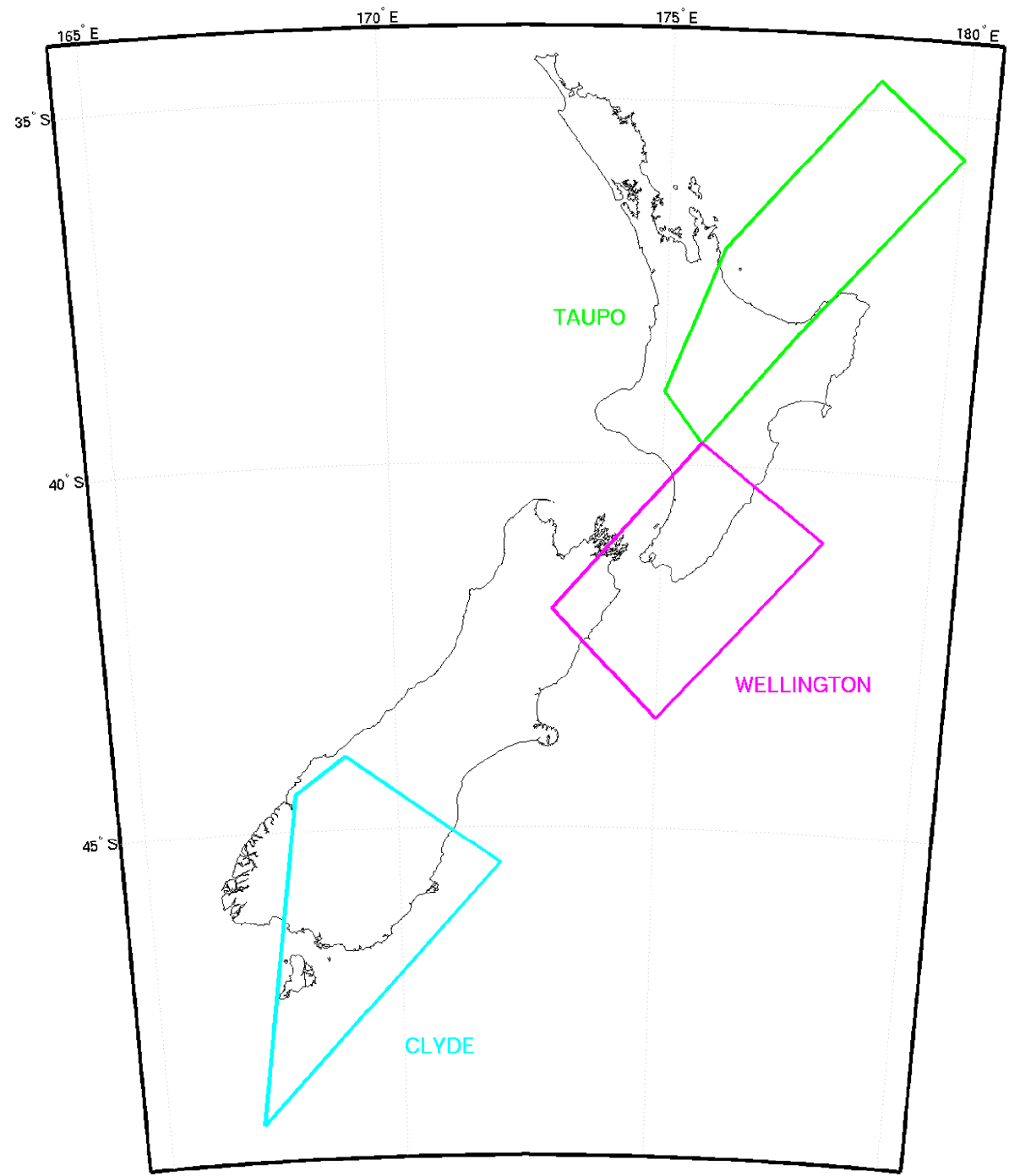

Figure 3. 3. Boundaries of velocity models used by GNS Science for locating earthquakes. Outside these boundaries the New Zealand standard velocity model is used.

\subsubsection{New Zealand velocity model}

The New Zealand velocity model, shown in Table 3. 1, was used to produce moment tensor solutions for all earthquakes used. 
Table 3. 2. New Zealand velocity model

\begin{tabular}{|c|c|c|c|c|c|}
\hline $\begin{array}{c}\text { Depth to base of } \\
\text { layer }(\mathrm{km})\end{array}$ & $\begin{array}{c}\mathrm{v}_{\mathrm{p}} \\
(\mathrm{km} / \mathrm{s})\end{array}$ & $\begin{array}{c}\mathrm{v}_{\mathrm{s}} \\
(\mathrm{km} / \mathrm{s})\end{array}$ & $\begin{array}{c}\text { Density } \\
\left(\mathrm{Mg} / \mathrm{m}^{3}\right)\end{array}$ & $\mathrm{Q}_{\mathrm{p}}$ & $\mathrm{Q}_{\mathrm{s}}$ \\
\hline 12 & 5.5 & 3.2 & 2.6 & 400 & 200 \\
\hline 33 & 6.5 & 3.8 & 2.7 & 400 & 200 \\
\hline 433 & 8.1 & 4.7 & 3.4 & 400 & 200 \\
\hline
\end{tabular}

The thicknesses of the first two layers and the P-wave velocities $\left(\mathrm{v}_{\mathrm{p}}\right)$ are from the New Zealand standard velocity model used by GNS Science to locate earthquakes (see http://www.geonet.org.nz/resources/earthquake/hypocentre-derivation.html). The thickness of the bottom layer is not given, and is taken as $400 \mathrm{~km}$, consistent with that of the SoCal model given in the TDMT_INVC examples (Dreger, 2003). A $\mathrm{v}_{\mathrm{p}} / \mathrm{v}_{\mathrm{s}}$ ratio of 1.7 was used, and the densities are from Euan Smith (pers. comm. 2007).

\subsubsection{Wellington velocity model}

The Wellington velocity model, shown in Table 3. 3, was used to produce seismic moment tensor solutions for an Upper Hutt earthquake.

Table 3. 3. Wellington velocity model

\begin{tabular}{|c|c|c|c|c|c|}
\hline $\begin{array}{c}\text { Depth to base of } \\
\text { layer }(\mathrm{km})\end{array}$ & $\begin{array}{c}\mathrm{v}_{\mathrm{p}} \\
(\mathrm{km} / \mathrm{s})\end{array}$ & $\begin{array}{c}\mathrm{v}_{\mathrm{s}} \\
(\mathrm{km} / \mathrm{s})\end{array}$ & $\begin{array}{c}\text { Density } \\
\left(\mathrm{Mg} / \mathrm{m}^{3}\right)\end{array}$ & $\mathrm{Q}_{\mathrm{p}}$ & $\mathrm{Q}_{\mathrm{s}}$ \\
\hline 0.4 & 4.40 & 2.54 & 2.46 & 400 & 200 \\
\hline 5.01 & 5.63 & 3.16 & 2.61 & 400 & 200 \\
\hline 15.01 & 5.77 & 3.49 & 2.69 & 400 & 200 \\
\hline 25.01 & 6.39 & 3.50 & 2.76 & 400 & 200 \\
\hline 35.01 & 6.79 & 3.92 & 2.93 & 400 & 200 \\
\hline 45.01 & 8.07 & 4.80 & 3.39 & 400 & 200 \\
\hline 445.01 & 8.77 & 4.86 & 3.55 & 400 & 200 \\
\hline
\end{tabular}

The depths to the base of each layer are adapted from Robinson (1986). Robinson uses depths of $0.4,5,15$, etc. An extra $0.01 \mathrm{~km}$ is added to each depth to prevent the earthquake depth matching the layer boundary depth. The TDMT_INVC code accepts source depths given to the nearest $\mathrm{km}$. The depth of the base of the bottom layer is not given by Robinson, and is taken as $400 \mathrm{~km}$, consistent with that of the SoCal model given in the TDMT_INVC examples (Dreger, 2003). The velocities $\left(\mathrm{v}_{\mathrm{p}}\right.$ and $\mathrm{v}_{\mathrm{s}}$ ) used are from Robinson (1986), and the densities from Matcham (1999). 
Figure 3. 4 shows the boundaries of the Wellington model used for locating earthquakes, the 20 January 2005 Upper Hutt earthquake, and the stations used to compute moment tensor solutions for this earthquake.

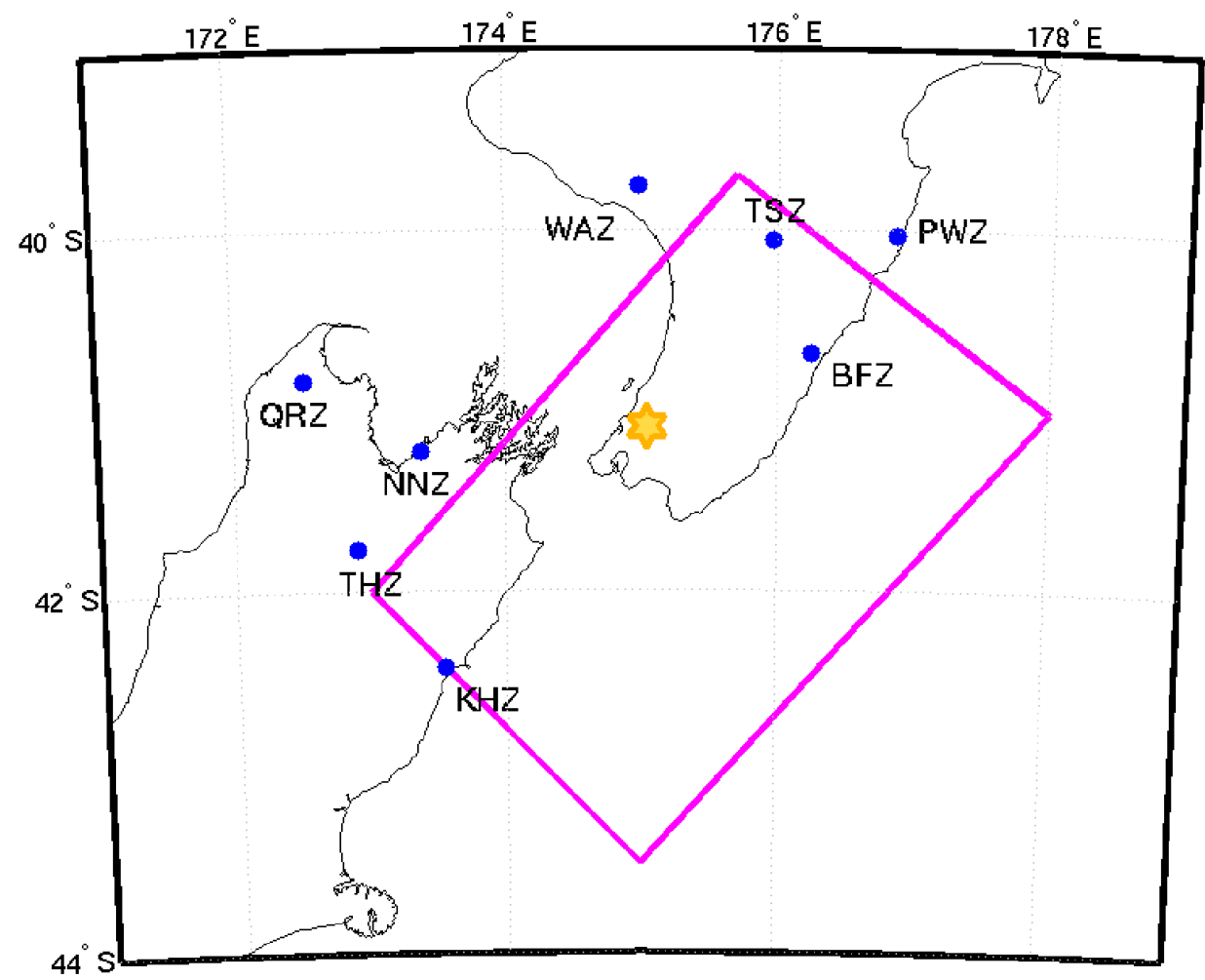

Figure 3. 4. Wellington velocity model boundaries shown in pink, Upper Hutt earthquake location (yellow star), and stations used to calculate solutions for the Upper Hutt earthquake, (blue dots). 


\subsection{Stations used}

The New Zealand broadband seismograph stations are shown in Figure 3. 5. Sites marked in red and blue had operational broadband seismographs at the time of the occurrences of the earthquakes analysed in this study. Sets of these stations were used to compute seismic moment tensor solutions. Details about which stations were used for each earthquake can be found in Appendix 1.

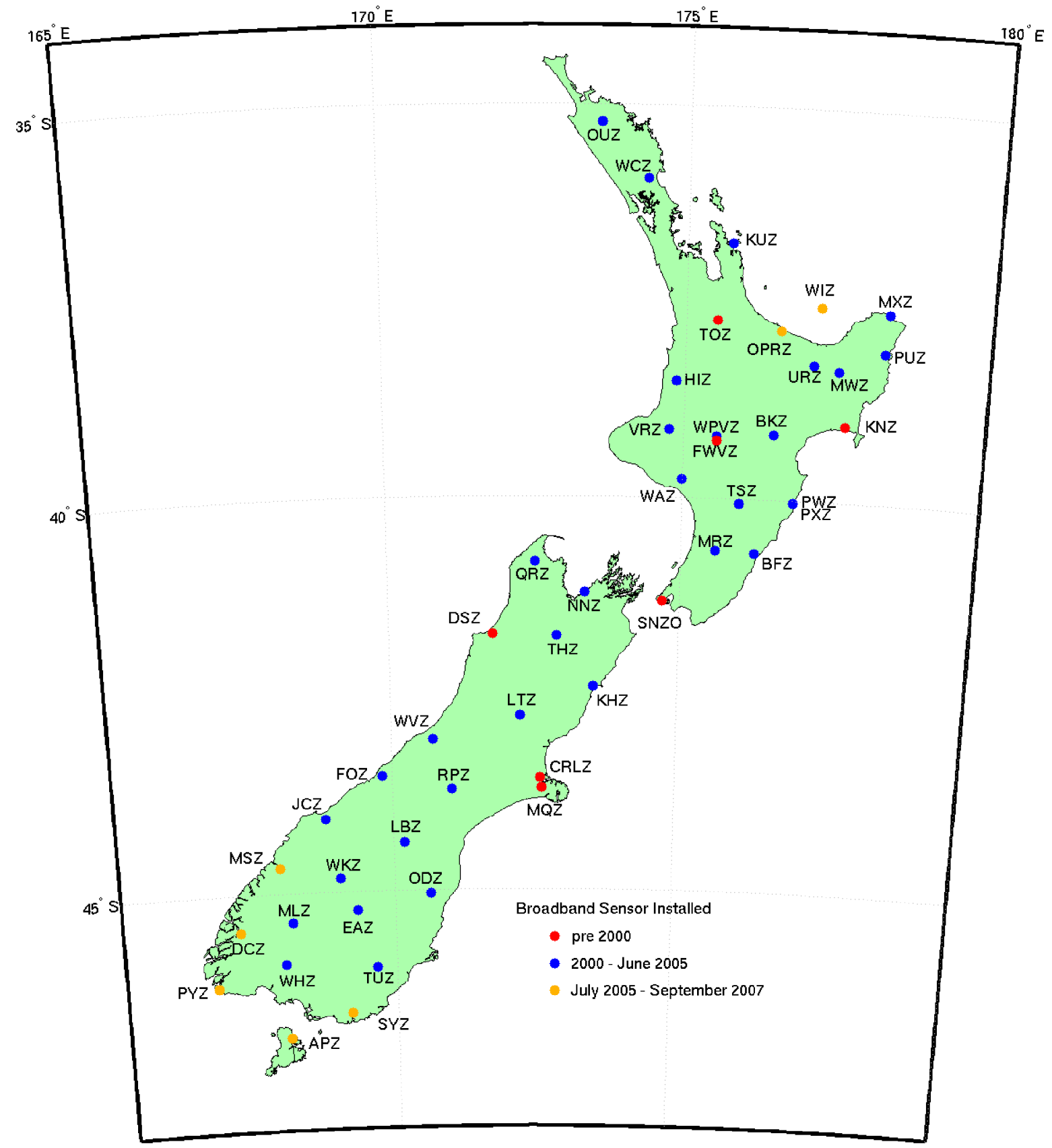

Figure 3. 5. New Zealand broadband seismograph stations (as at September 2007). 


\subsection{Earthquakes used}

A test set of 39 earthquakes that occurred between March 2000 and June 2005 were selected and are shown in Figure 3. 6. These earthquakes have GeoNet broadband data from at least three stations and CMT solutions have been calculated by the Global CMT project.

Data recorded at particular distances from the earthquake are preferred to avoid poor signalto-noise ratios at greater distances (Dreger and Helmberger, 1993) and contamination with Pnl waves at shorter distances (Romanowicz et al, 1993). Dreger and Helmberger (1993) suggest using data at distances of $1^{\circ}-12^{\circ}$ (approximately $110-1320 \mathrm{~km}$ ) from the earthquake, Tajima et al (2002) suggest distances of $30-700 \mathrm{~km}$, Gee et al (2003) and Rueda and Mezcua (2005) suggest distances of 40 - 400 km, Pasyanos et al (1996) suggest distances of $50-400 \mathrm{~km}$, and Romanowicz et al (1993) suggest distances of $100-500 \mathrm{~km}$. Distances of $100-400 \mathrm{~km}$ are preferred in this study, and there were 20 earthquakes of the original 39 that met this criteria. Moment tensor solutions were also produced for two earthquakes using data at distances greater than $400 \mathrm{~km}$.

Two earthquakes without Global CMT solutions were also analysed. The 24 earthquakes analysed in this study are shown in Figure 3. 7. A list of the 41 earthquakes considered is given in Table 3. 4, along with information on whether a Global CMT solution had been produced for each earthquake, whether there were data in the $100-400 \mathrm{~km}$ distance range, and whether the earthquake was analysed in this study. More information about the 24 earthquakes used is given in Chapter 4 and Appendix 1.

\subsubsection{Earthquake locations}

Earthquake epicentres were obtained from GNS Science. Distances between the earthquakes and the stations used were rounded to the nearest $5 \mathrm{~km}$, as the synthetic seismograms were calculated for distance intervals of $5 \mathrm{~km}$. Moment tensor solutions were calculated for each earthquake over a range of depths, usually at 5 or $10 \mathrm{~km}$ intervals. Solutions were calculated for depths both higher and lower than the depths obtained from GNS Science and the Global CMT project. 


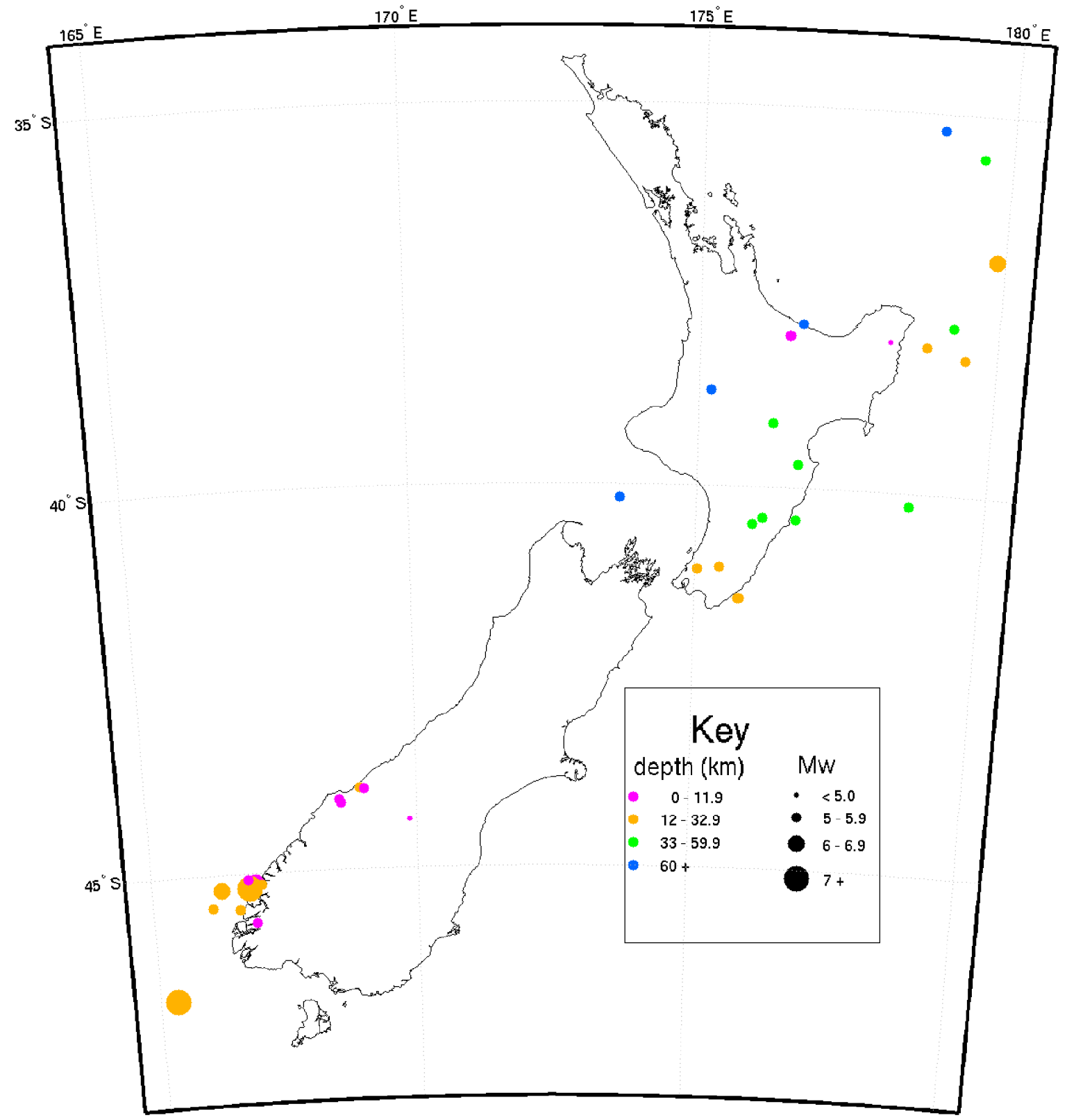

Figure 3. 6. 39 earthquakes recorded in March 2000 - June 2005 with New Zealand broadband data and Global CMT solutions. Locations (epicentres and depths) from GNS Science, moment magnitudes from the Global CMT project. Note that there are a few dots representing multiple earthquakes with very similar locations. 


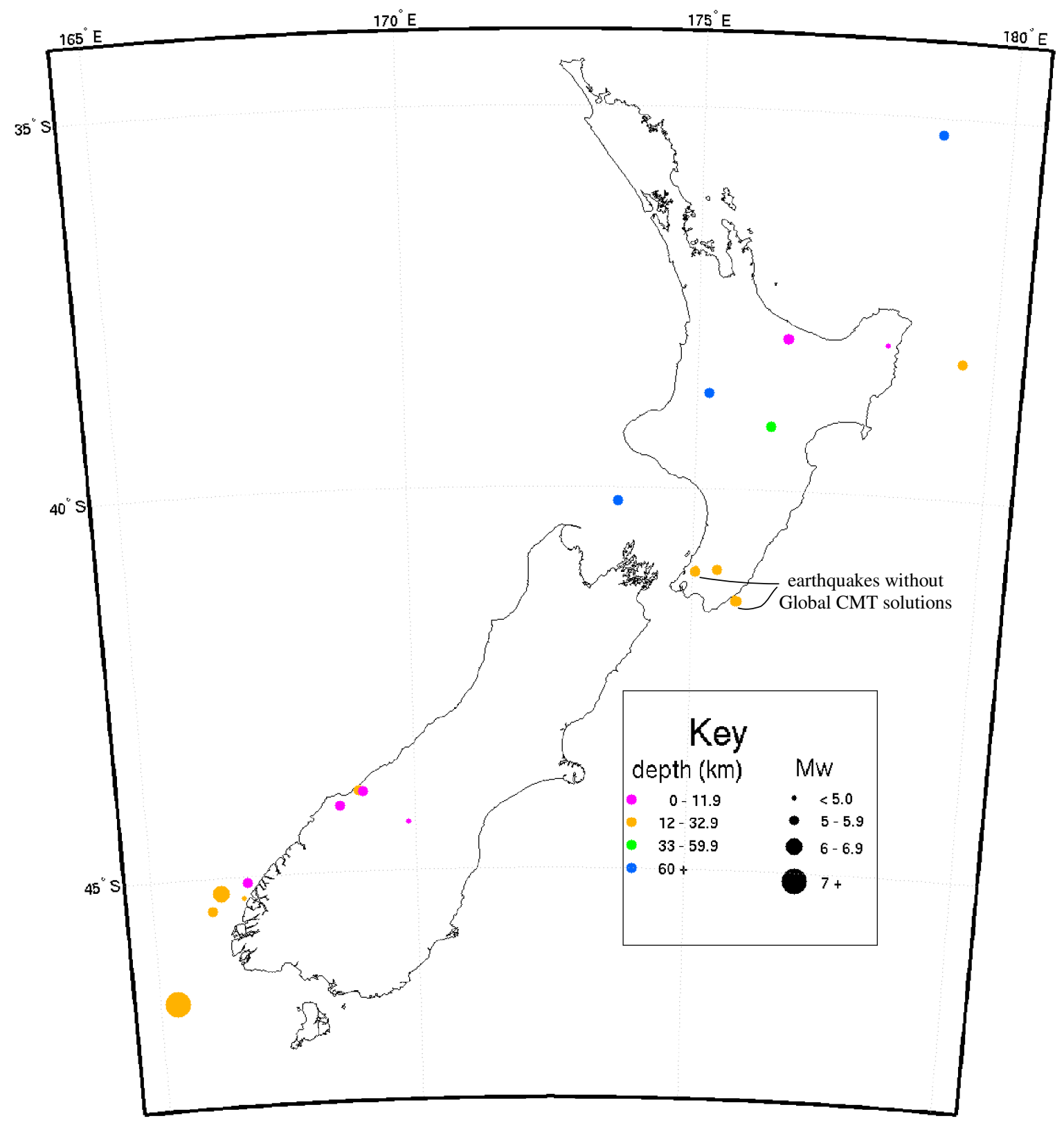

Figure 3. 7. The 24 earthquakes used in this project. Locations (epicentres and depths) from GNS Science, moment magnitudes from the Global CMT project, except for the two earthquakes without Global CMT solutions, whose moment magnitudes are from this project. Note that there are a few dots representing multiple earthquakes with very similar locations, including the locations of the two earthquakes without Global CMT solutions. 
Table 3. 4. Earthquakes considered for analysis

\begin{tabular}{|c|c|c|c|c|c|c|}
\hline Cusp ID & $\begin{array}{l}\text { Date } \\
\text { (yyyymmdd) }\end{array}$ & Time & Where & $\begin{array}{l}\text { Global } \\
\text { CMT }\end{array}$ & $\begin{array}{c}\text { Data within } \\
400 \mathrm{~km} ?\end{array}$ & Analysed? \\
\hline 1502698 & 20000329 & 1430 & Wairarapa & $\checkmark$ & $\checkmark$ & $\checkmark$ \\
\hline 1597193 & 20000808 & 1031 & Taupo & $\checkmark$ & & $\checkmark$ \\
\hline 1635267 & 20001101 & 1035 & Thompson Sound & $\checkmark$ & & \\
\hline 1638170 & 20001112 & 1149 & Fiordland & $\checkmark$ & & \\
\hline 1663531 & 20001231 & 2156 & near Gisborne & $\checkmark$ & & \\
\hline 1737299 & 20010524 & 1807 & King Country & $\checkmark$ & & $\checkmark$ \\
\hline 1793707 & 20010924 & 0449 & Wairarapa & $\checkmark$ & & \\
\hline 1803016 & 20011015 & 0349 & S. Hawkes Bay & $\checkmark$ & & \\
\hline 2060807 & 20011021 & 0029 & N.E. of New Zealand & $\checkmark$ & & \\
\hline 1825324 & 20011207 & 1927 & Haast & $\checkmark$ & $\checkmark$ & $\checkmark$ \\
\hline 1984532 & 20020224 & 0637 & Haast & $\checkmark$ & & \\
\hline 1893015 & 20020625 & 0702 & Hikurangi Trough & $\checkmark$ & & \\
\hline 1909352 & 20020817 & 0821 & Bay of Plenty & $\checkmark$ & & \\
\hline 2016026 & 20030118 & 0210 & Raukumara Plain & $\checkmark$ & & \\
\hline 2019057 & 20030125 & 2130 & Wairarapa & $\checkmark$ & & \\
\hline 2024675 & 20030212 & 1143 & N.E. of New Zealand & $\checkmark$ & & \\
\hline 2095626 & 20030803 & 1146 & Wairarapa & $\checkmark$ & & \\
\hline 2103645 & 20030821 & 1212 & Fiordland & $\checkmark$ & & \\
\hline 2214737 & 20030826 & 2356 & Fiordland & $\checkmark$ & & \\
\hline 2110611 & 20030904 & 0840 & Fiordland & $\checkmark$ & & \\
\hline 2114219 & 20030911 & 1756 & Fiordland & $\checkmark$ & $\checkmark$ & $\checkmark$ \\
\hline 2123248 & 20030930 & 1937 & Fiordland & $\checkmark$ & & \\
\hline 2137041 & 20031102 & 0532 & Fiordland & $\checkmark$ & $\checkmark$ & $\checkmark$ \\
\hline 2137186 & 20031102 & 1358 & Fiordland & $\checkmark$ & $\checkmark$ & $\checkmark$ \\
\hline 2228901 & 20040511 & 2322 & Gisborne & $\checkmark$ & $\checkmark$ & $\checkmark$ \\
\hline 2266782 & 20040718 & 0358 & Bay of Plenty & $\checkmark$ & $\checkmark$ & $\checkmark$ \\
\hline 2266243 & 20040718 & 0422 & Bay of Plenty & $\checkmark$ & $\checkmark$ & $\checkmark$ \\
\hline 2326055 & 20041122 & 2026 & Puysegur Trench & $\checkmark$ & $\checkmark$ & $\checkmark$ \\
\hline 2352986 & 20050118 & 0836 & Wairarapa & $\checkmark$ & $\checkmark$ & $\checkmark$ \\
\hline 2353002 & 20050118 & 0926 & Wairarapa & $\checkmark$ & $\checkmark$ & $\checkmark$ \\
\hline 2354133 & 20050120 & 1856 & Upper Hutt & $\checkmark$ & $\checkmark$ & $\checkmark$ \\
\hline 2354877 & 20050122 & 0814 & Upper Hutt & & $\checkmark$ & $\checkmark$ \\
\hline 2359081 & 20050131 & 1731 & Wairarapa & $\checkmark$ & $\checkmark$ & $\checkmark$ \\
\hline 2569288 & 20050131 & 1734 & Wairarapa & & $\checkmark$ & $\checkmark$ \\
\hline 2376455 & 20050313 & 1508 & S. of Taranaki & $\checkmark$ & $\checkmark$ & $\checkmark$ \\
\hline 2376763 & 20050314 & 0804 & Fiordland & $\checkmark$ & $\checkmark$ & $\checkmark$ \\
\hline 2385032 & 20050402 & 0207 & Twizel & $\checkmark$ & $\sqrt{ }$ & $\sqrt{ }$ \\
\hline 2398629 & 20050502 & 1535 & Jackson's Bay & $\checkmark$ & $\checkmark$ & $\checkmark$ \\
\hline 2626467 & 20050502 & 1540 & Jackson's Bay & $\checkmark$ & $\checkmark$ & $\checkmark$ \\
\hline 2403682 & 20050513 & 1707 & E. of Gisborne & $\checkmark$ & $\checkmark$ & $\checkmark$ \\
\hline 2418019 & 20050614 & 2233 & S. of Kermadec Is. & $\checkmark$ & $\checkmark$ & $\checkmark$ \\
\hline
\end{tabular}




\subsection{Frequencies used}

In California the frequency passband filter is magnitude dependent: a passband of $0.02-0.10$ $\mathrm{Hz}$ is used for $\mathrm{M}<4.0,0.02-0.05 \mathrm{~Hz}$ for $4.0 \leq \mathrm{M}<5.0,0.01-0.05 \mathrm{~Hz}$ for $5.0 \leq \mathrm{M} \leq 7.5$, and $0.005-0.02 \mathrm{~Hz}$ for $\mathrm{M}>7.5$ (Dreger, 2003).

The frequency range chosen for the passband filters must be appropriate for the frequency responses of the instruments that recorded the data.

Broadband seismometers used in New Zealand between 2000 and 2005 were Streckeisen STS-2 and Guralp CMG-3ESP, CMG-3ESP-Z, CMG-40T-30s, and CMG-40T-60s instruments. The GeoNet DELTA database (http://magma.geonet.org.nz/delta/app) has information about the instruments installed at individual sites.

The Streckeisen instruments have a natural frequency of 120 seconds and a flat velocity response for frequencies of $0.02-10 \mathrm{~Hz}$ (www.kinemetrics.com/PDFs/sts2-1.pdf). The Guralp CMG-40T-30s instruments have a response of $30 \mathrm{~s}-100 \mathrm{~Hz}(0.0333-100 \mathrm{~Hz}$, www.guralp.net/products/40T/), and it is assumed that the CMG-40T-60s instruments have a response of $60 \mathrm{~s}-100 \mathrm{~Hz}(0.01666-100 \mathrm{~Hz})$. The Guralp CMG-3ESP instruments have a standard response of $120 \mathrm{~s}-50 \mathrm{~Hz}(0.008333-50 \mathrm{~Hz})$ and low self-noise at $40 \mathrm{~s}-16 \mathrm{~Hz}$ $(0.025-16 \mathrm{~Hz})$ (www.guralp.net/products/3ESP/). It is assumed that the CMG-ESP-Z instruments have a similar response to the CMG-3ESP instruments.

The responses of the instruments suggests that frequencies of $0.02 \mathrm{~Hz}$ and higher should be used. Moment tensor solutions were calculated using frequency passbands of $0.02-0.05 \mathrm{~Hz}$, $0.02-0.10 \mathrm{~Hz}, 0.03-0.06 \mathrm{~Hz}, 0.04-0.10 \mathrm{~Hz}$, and $0.05-0.10 \mathrm{~Hz}$. A frequency passband of $0.01-0.05 \mathrm{~Hz}$ was used to calculate solutions for an earthquake in the Puysegur Trench, but this passband did not produce good solutions.

The solutions produced using the TDMT_INVC algorithm described in Section 3.1 (using the velocity models described in Section 3.2 and the frequency band-pass filters described in this section) for the earthquakes mentioned in Section 3.4 are described in Chapter 4 and Appendix 1. A full set of the solutions produced is given in Appendix 2. 


\section{Chapter Four: Inversion Results}

Solutions were calculated for the twenty-four earthquakes listed in Section 3.4 using the TDMT_INVC algorithm described in Section 3.1. Multiple solutions were calculated for each earthquake by varying the source depth and the frequency passband filter used (see Section 3.5). The New Zealand velocity model was used to calculate solutions for all earthquakes, and the Wellington velocity model was also used for one earthquake (see Section 3.2). For each depth, filter and velocity model used the best solution was chosen to be either the solution with the maximum variance reduction or the solution with the highest double-couple component. For some earthquakes solutions were generated using both methods.

These results are summarised here and described in more detail in Appendix 1. All solutions calculated are given in Appendix 2. The best seismic moment tensor solutions are compared with the solutions obtained by the Global CMT Project (previously the Harvard CMT Project, http://www.globalcmt.org/CMTsearch.html).

\subsection{Summary of results}

The multiple solutions generated for each earthquake give a range of possible values of the moment magnitude and a range of possible focal mechanisms. A best solution for each earthquake was chosen, if possible, using both the variance reduction and the percentage double-couple component. For some earthquakes all solutions were poor and a best solution could not be obtained.

Each earthquake was assigned a solution quality based on whether either the moment magnitude or the focal mechanism could be constrained by the solutions produced. If there is a clear best focal mechanism and other solutions show similar focal mechanisms then the focal mechanism is considered to be constrained. If slight changes in the source depth produce very different mechanisms then the mechanism is considered to be unconstrained. The moment magnitude is considered to be constrained if many good solutions for an earthquake give similar moment magnitudes with a range of up to 0.4 magnitude units. If both the moment magnitude and the focal mechanism could be constrained the earthquake 
was assigned an A grade. If the moment magnitude could be constrained but the focal mechanism could not, the earthquake was assigned a B grade. If neither the moment magnitude nor the focal mechanism could be constrained a $\mathrm{C}$ grade was assigned. Of the 24 earthquakes analysed, eight were assigned A grades (33\%), seven were assigned B grades (29\%), and nine were assigned C grades (38\%).

For $\mathrm{A}$ and $\mathrm{B}$ grade solutions the angle required to rotate the chosen best solution into the Global CMT solution was calculated using the method described in Section 2.2.

Table 4. 1 gives the range of moment magnitudes calculated for each earthquake, the best moment magnitude, the magnitude and depth of the best solution (if applicable), the best-fit method (maximum variance reduction or maximum percentage double-couple component) used and preferred, the solution quality assigned, the mechanism and angle required to rotate into the Global CMT solution for A and B grade earthquakes, as well as the depths given by GNS Science and the Global CMT Project and the moment magnitudes given by the Global CMT Project.

For A and B grade earthquakes the range of moment magnitudes that the magnitude is considered constrained between is also given in Table 4. 2 .

Twenty of the 24 events analysed had GeoNet data from stations with epicentral distances of $100-400 \mathrm{~km}$, and Global CMT solutions. For two of the events studied, data at distances of greater than $400 \mathrm{~km}$ were included (see Section 3.4). The moment magnitude could be constrained for these earthquakes but not the focal mechanisms. There were two events studied without Global CMT solutions. These events both had magnitudes of $\mathrm{M}_{\mathrm{L}} 4.2$ (GNS Science). These were the smallest events analysed, and good solutions were not obtained. Neither the moment magnitudes nor the focal mechanisms could be constrained for these events. 
Table 4. 1. Summary of earthquakes processed

\begin{tabular}{|c|c|c|c|c|c|c|c|c|c|c|c|c|c|c|c|c|}
\hline & \multicolumn{4}{|c|}{ earthquake information } & \multicolumn{3}{|c|}{ depths $(\mathbf{k m})$} & \multirow[b]{2}{*}{$\begin{array}{c}\text { Global } \\
\text { CMT } \\
\text { Mw (1) }\end{array}$} & \multicolumn{3}{|c|}{ Mw this study } & \multicolumn{2}{|c|}{ best fit (4) } & \multirow[b]{2}{*}{$\begin{array}{c}\text { Solution } \\
\text { Quality } \\
\text { (5) }\end{array}$} & \multirow[b]{2}{*}{$\begin{array}{c}\text { mechanism } \\
\text { (6) }\end{array}$} & \multirow[b]{2}{*}{$\begin{array}{c}\text { angle } \\
(7)\end{array}$} \\
\hline$\#$ & CUSP ID & date & time & location & $\begin{array}{c}\text { Global } \\
\text { CMT } \\
\text { (1) }\end{array}$ & $\begin{array}{c}\text { GNS } \\
\text { Sci. } \\
(2)\end{array}$ & $\begin{array}{c}\text { this } \\
\text { study } \\
(3)\end{array}$ & & $\min$ & $\begin{array}{l}\max \\
M w\end{array}$ & $\begin{array}{c}\text { best } \\
\text { Mw } \\
(3)\end{array}$ & $\begin{array}{c}\max \\
V R\end{array}$ & $\begin{array}{c}\max \\
\% \\
\text { DC }\end{array}$ & & & \\
\hline 1 & 1502698 & 20000329 & 1430 & Wairarapa & 46.4 & 30.7 & 32 & 5.2 & 5.0 & 5.3 & 5.2 & 1 & & B & strike-slip & 88 \\
\hline 2 & 1597193 & 20000808 & 1031 & Taupo & 67.8 & 50.2 & 70 & 5.3 & 4.9 & 5.5 & 5.4 & 1 & & $\mathrm{~B}$ & reverse/ss & 85 \\
\hline 3 & 1737299 & 20010524 & 1807 & King Country & 248.1 & 234.3 & 250 & 5.4 & 5.4 & 5.4 & 5.4 & 1 & & $\mathrm{~B}$ & normal & 77 \\
\hline 4 & 1825324 & 20011207 & 1927 & Haast & 15.0 & $5 \mathrm{R}$ & 5 & 5.8 & 5.5 & 5.8 & 5.7 & & 1 & B & normal & 61 \\
\hline 5 & 2114219 & 20030911 & 1756 & Fiordland & 40.4 & 22.6 & 10 & 4.9 & 4.1 & 4.8 & 4.4 & & 1 & $\mathrm{C}$ & & \\
\hline 6 & 2137041 & 20031102 & 0532 & Fiordland & 15.0 & 17.1 & 30 & 6.4 & 5.7 & 6.4 & 6.3 & & 1 & $\mathrm{~B}$ & reverse/ss & 82 \\
\hline 7 & 2137186 & 20031102 & 1358 & Fiordland & 15.0 & $20 \mathrm{R}$ & 5 & 5.2 & 4.7 & 5.4 & 5.1 & & 1 & $\mathrm{~B}$ & reverse & 18 \\
\hline 8 & 2228901 & 20040511 & 2322 & Gisborne & 21.1 & $5 \mathrm{R}$ & 25 & 4.9 & 4.4 & 4.9 & 4.8 & 2 & 1 & A & normal/ss & 10 \\
\hline 9 & 2266782 & 20040718 & 0358 & Bay of Plenty & 12.0 & $5 \mathrm{R}$ & & 5.0 & 4.4 & 5.1 & & & 1 & $\mathrm{C}$ & & \\
\hline 10 & 2266243 & 20040718 & 0422 & Bay of Plenty & 12.0 & $5 \mathrm{R}$ & 15 & 5.4 & 5.1 & 5.6 & 5.4 & & 1 & $\mathrm{C}$ & & \\
\hline 11 & 2326055 & 20041122 & 2026 & Puysegur Tr. & 40.0 & $12 \mathrm{R}$ & 35 & 7.1 & 5.1 & 7.2 & 7.0 & 2 & 1 & $\mathrm{~A}$ & normal/ss & 64 \\
\hline 12 & 2352986 & 20050118 & 0836 & Wairarapa & 18.7 & 18.8 & 10 & 5.2 & 4.4 & 5.1 & 4.9 & & 1 & $\mathrm{C}$ & & \\
\hline 13 & 2353002 & 20050118 & 0926 & Wairarapa & 26.6 & 18.0 & & 5.0 & 4.5 & 5.1 & & & 1 & $\mathrm{C}$ & & \\
\hline 14 & 2354133 & 20050120 & 1856 & Upper Hutt & 30.9 & 30.8 & 31 & 5.3 & 4.6 & 5.4 & 5.3 & & 1 & A & normal/ss & 18 \\
\hline 15 & 2354877 & 20050122 & 0814 & Upper Hutt & & 29.1 & & & 3.5 & 4.1 & & & 1 & $\mathrm{C}$ & & \\
\hline 16 & 2359081 & 20050131 & 1731 & Wairarapa & 17.7 & 19.9 & 24 & 5.0 & 5.1 & 5.3 & 5.1 & 1 & & A & strike-slip & 85 \\
\hline 17 & 2569288 & 20050131 & 1734 & Wairarapa & & 12.4 & & & 4.0 & 4.2 & & & 1 & $\mathrm{C}$ & & \\
\hline 18 & 2376455 & 20050313 & 1508 & S. of Taranaki & 152.9 & 142.9 & 130 & 5.4 & 4.7 & 5.8 & 5.2 & & 1 & $\mathrm{~B}$ & normal/ss & 0 \\
\hline 19 & 2376763 & 20050314 & 0804 & Fiordland & 12.0 & $5 \mathrm{R}$ & 15 & 5.2 & 4.8 & 5.3 & 5.1 & & 1 & A & reverse/ss & 0 \\
\hline 20 & 2385032 & 20050402 & 0207 & Twizel & 12.0 & 10.9 & 5 & 4.9 & 4.1 & 4.7 & 4.6 & & 1 & $\mathrm{~A}$ & reverse/ss & 46 \\
\hline 21 & 2398629 & 20050502 & 1535 & Jackson's Bay & 12.0 & 15.0 & 5 & 5.4 & 4.8 & 5.5 & 5.2 & & 1 & A & reverse/ss & 34 \\
\hline 22 & 2626467 & 20050502 & 1540 & Jackson's Bay & 12.0 & 10.1 & 7 & 5.0 & 4.8 & 5.0 & 4.9 & 1 & & A & strike-slip & 32 \\
\hline 23 & 2403682 & 20050513 & 1707 & E. of Gisborne & 12.0 & $12 \mathrm{R}$ & & 5.1 & 5.0 & 5.5 & & 1 & 1 & $\mathrm{C}$ & & \\
\hline 24 & 2418019 & 20050614 & 2233 & $\begin{array}{l}\text { S. of Kermadec } \\
\text { Is. }\end{array}$ & 219.8 & 218.0 & & 5.3 & 4.8 & 5.1 & & 1 & & $\mathrm{C}$ & & \\
\hline
\end{tabular}




\section{Summary Table Notes}

(1) Global CMT depth and Mw: from the Global CMT project. Gaps in these columns indicate that CMT solutions were not calculated for the earthquake.

(2) GNS Sci. depth: from GNS Science. An "R" following the depth indicates that the depth has been restricted.

(3) Depth this study and best Mw this study: The best depth and Mw value obtained from this study are given where determined.

(4) Best fit: two ways of choosing the best solution for each depth were experimented with, choosing the solution with the maximum variance reduction (max VR) or the solution with the highest double-couple component ( $\max \% \mathrm{DC}$ ). When solutions were calculated using both methods, the results are ranked, $1=$ best.

(5) Solution quality: three grades of solution quality were assigned. $\mathrm{A}=\mathrm{Mw}$ and focal mechanism can be determined, $\mathrm{B}=\mathrm{Mw}$ determined, focal mechanism uncertain, $\mathrm{C}=$ neither Mw nor focal mechanism can be determined.

(6) Mechanism: ss = strike-slip.

(7) Angle: The angle that the best solution obtained must be rotated by to rotate it into the mechanism obtained by the Global CMT project. Calculated for solutions of quality A and $\mathrm{B}$.

Table 4. 2. Magnitudes of A and B grade earthquakes

\begin{tabular}{|c|c|c|c|c|c|c|c|c|}
\hline \multirow[b]{2}{*}{ \# } & \multirow[b]{2}{*}{ Cusp ID } & \multirow[b]{2}{*}{ Location } & \multirow[b]{2}{*}{ Quality } & \multirow{2}{*}{$\begin{array}{c}\text { Global } \\
\text { CMT } \\
\text { Mw }\end{array}$} & \multicolumn{4}{|c|}{ Mw this study } \\
\hline & & & & & $\min$ & $\max$ & Good range & best \\
\hline 1 & 1502698 & Wairarapa & $\mathrm{B}$ & 5.2 & 5.0 & 5.3 & $5.0-5.3$ & 5.2 \\
\hline 2 & 1597193 & Taupo & $\mathrm{B}$ & 5.3 & 4.9 & 5.5 & $5.2-5.4$ & 5.4 \\
\hline 3 & 1737299 & King Country & $\mathrm{B}$ & 5.4 & 5.4 & 5.4 & 5.4 & 5.4 \\
\hline 4 & 1825324 & Haast & $\mathrm{B}$ & 5.8 & 5.5 & 5.8 & $5.5-5.8$ & 5.7 \\
\hline 6 & 2137041 & Fiordland & $\mathrm{B}$ & 6.4 & 5.7 & 6.4 & $6.2-6.4$ & 6.3 \\
\hline 7 & 2137186 & Fiordland & $\mathrm{B}$ & 5.2 & 4.7 & 5.4 & $5.0-5.1$ & 5.1 \\
\hline 8 & 2228901 & Gisborne & $\mathrm{A}$ & 4.9 & 4.4 & 4.9 & $4.6-4.9$ & 4.8 \\
\hline 11 & 2326055 & Puysegur Trench & $\mathrm{A}$ & 7.1 & 5.1 & 7.2 & $6.8-7.2$ & 7.0 \\
\hline 14 & 2354133 & Upper Hutt & $\mathrm{A}$ & 5.3 & 4.6 & 5.4 & $5.2-5.4$ & 5.3 \\
\hline 16 & 2359081 & Wairarapa & $\mathrm{A}$ & 5.0 & 5.1 & 5.3 & $5.1-5.3$ & 5.1 \\
\hline 18 & 2376455 & S. of Taranaki & B & 5.4 & 4.7 & 5.8 & $5.2-5.3$ & 5.2 \\
\hline 19 & 2376763 & Fiordland & $\mathrm{A}$ & 5.2 & 4.8 & 5.3 & $5.0-5.1$ & 5.1 \\
\hline 20 & 2385032 & Twizel & $\mathrm{A}$ & 4.9 & 4.1 & 4.7 & $4.5-4.6$ & 4.6 \\
\hline 21 & 2398629 & Jackson's Bay & $\mathrm{A}$ & 5.4 & 4.8 & 5.5 & $5.2-5.3$ & 5.2 \\
\hline 22 & 2626467 & Jackson's Bay & $\mathrm{A}$ & 5.0 & 4.8 & 5.0 & $4.8-5.0$ & 4.9 \\
\hline
\end{tabular}

Table 4. 3 shows the frequency bands used to analyse each earthquake, and ranks which ones gave the best solutions for each earthquake. The frequencies used were ranked on the results given by those frequencies: $1=$ good, $2=$ okay, $3=$ bad. 
Table 4. 3. Frequencies used

\begin{tabular}{|c|c|c|c|c|c|c|c|}
\hline \multicolumn{2}{|c|}{ Earthquake } & \multicolumn{6}{|c|}{ Frequencies used (1) } \\
\hline$\#$ & cusp ID & $\begin{array}{c}0.0 \\
1- \\
0.0 \\
5 \\
\text { Hz }\end{array}$ & $\begin{array}{c}0.02 \\
- \\
0.05 \\
\mathrm{~Hz}\end{array}$ & $\begin{array}{c}0.02 \\
- \\
0.10 \\
\mathrm{~Hz}\end{array}$ & \begin{tabular}{|c|}
$\mathbf{0 . 0}$ \\
$\mathbf{3}-$ \\
$\mathbf{0 . 0}$ \\
6 \\
$\mathrm{~Hz}$
\end{tabular} & $\begin{array}{c}0.04 \\
- \\
0.10 \\
\text { Hz }\end{array}$ & \begin{tabular}{|c}
0.0 \\
$5-$ \\
0.1 \\
0 \\
$\mathrm{~Hz}$
\end{tabular} \\
\hline 1 & 1502698 & & & & 1 & & \\
\hline 2 & 1597193 & & & & 1 & & \\
\hline 3 & 1737299 & & & & 1 & & \\
\hline 4 & 1825324 & & & & 1 & & \\
\hline 5 & 2114219 & & & & 3 & & 1 \\
\hline 6 & 2137041 & & 1 & & 2 & & \\
\hline 7 & 2137186 & & & & 1 & & \\
\hline 8 & 2228901 & & & & 2 & & 1 \\
\hline 9 & 2266782 & & & & 1 & & \\
\hline 10 & 2266243 & & & & 1 & & \\
\hline 11 & 2326055 & 3 & 2 & & 1 & & \\
\hline 12 & 2352986 & & 3 & 3 & 3 & 2 & \\
\hline 13 & 2353002 & & 3 & 3 & 3 & 3 & \\
\hline 14 & 2354133 & & 1 & & 2 & & \\
\hline 15 & 2354877 & & 3 & & 3 & 3 & \\
\hline 16 & 2359081 & & & & 1 & & \\
\hline 17 & 2569288 & & & & 1 & & \\
\hline 18 & 2376455 & & & & 1 & & \\
\hline 19 & 2376763 & & & & 1 & & \\
\hline 20 & 2385032 & & & & 1 & & \\
\hline 21 & 2398629 & & & & 1 & & \\
\hline 22 & 2626467 & & & & 1 & & \\
\hline 23 & 2403682 & & & & 1 & & \\
\hline 24 & 2418019 & & & & 1 & & \\
\hline
\end{tabular}

The Upper Hutt earthquake (event 2354133) was processed with both the New Zealand and the Wellington velocity models (see section 3.2). The New Zealand velocity model gave better results. 
The Puysegur Trench earthquake (event 2326055) was processed using several different intervals of data before the P-wave arrival. Intervals of 4 seconds, 10 seconds, 30 seconds, one minute and two minutes were used. The two minute interval gave the best results. It is important to make sure that the value of the initial offset between the real seismograms and the synthetic seismograms was set to be the same as the amount of pre-P-wave data used. 


\subsection{Case studies}

Results for four of the earthquakes analysed are briefly discussed in this section. More information about the results obtained for these earthquakes and for the other earthquakes analysed can be found in Appendix 1. All solutions calculated are given in Appendix 2. The four case studies chosen for study here are a $M_{W} 5.3$ in Upper Hutt (quality $A$ ), a $M_{W} 7.0$ in the Puysegur Trench (quality A), a $\mathrm{M}_{\mathrm{W}} 5.1$ in Fiordland (quality B) and a $\mathrm{M}_{\mathrm{W}} \sim 5$ east of Gisborne (quality C).

\subsubsection{Upper Hutt}

Event 2354133

20 January 2005, 1856 UT depth $30.8 \mathrm{~km}$ (GNS Science), $30.9 \mathrm{~km}$ (Global CMT Project) $\mathrm{M}_{\mathrm{L}} 5.6$ (GNS Science), $\mathrm{M}_{\mathrm{W}} 5.3$ (Global CMT Project)

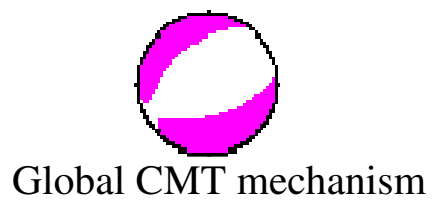

This Upper Hutt event was analysed using the New Zealand and Wellington velocity models. Frequency band-pass filters of $0.02-0.05 \mathrm{~Hz}$ and $0.03-0.06 \mathrm{~Hz}$ were used. Source depths of $5-50 \mathrm{~km}$ were tested. Data were used from sets of three to eight stations at distances of $110-215 \mathrm{~km}$. The solution with the highest double-couple component was chosen as the best solution for each source depth, velocity model, station set and filter combination.

Moment magnitudes of $\mathrm{M}_{\mathrm{W}} 4.6$ - 5.4 were calculated for this earthquake. Solutions with reasonable fits between the data and the synthetic seismograms have magnitudes of $\mathrm{M}_{\mathrm{W}} 4.8$ 5.4, and the best solutions have magnitudes of $\mathrm{M}_{\mathrm{W}} 5.2$ - 5.4. Most of the good solutions and all of the best solutions have normal/strike-slip focal mechanisms. A selection of the best mechanisms is shown in Figures 4. 1 - 4. 4.

The best solution was calculated using the New Zealand velocity model, the $0.02-0.05 \mathrm{~Hz}$ frequency band-pass filter, the three stations BFZ, TSZ, and NNZ, and a source-depth of 31 $\mathrm{km}$. This solution has a magnitude of $\mathrm{M}_{\mathrm{W}} 5.3$ and a normal/strike-slip mechanism. This solution is shown in Figure 4. 1.

From this analysis the moment magnitude of this earthquake is $M_{\mathrm{W}} 5.2-5.4$ and the mechanism is a normal/strike-slip mechanism. 


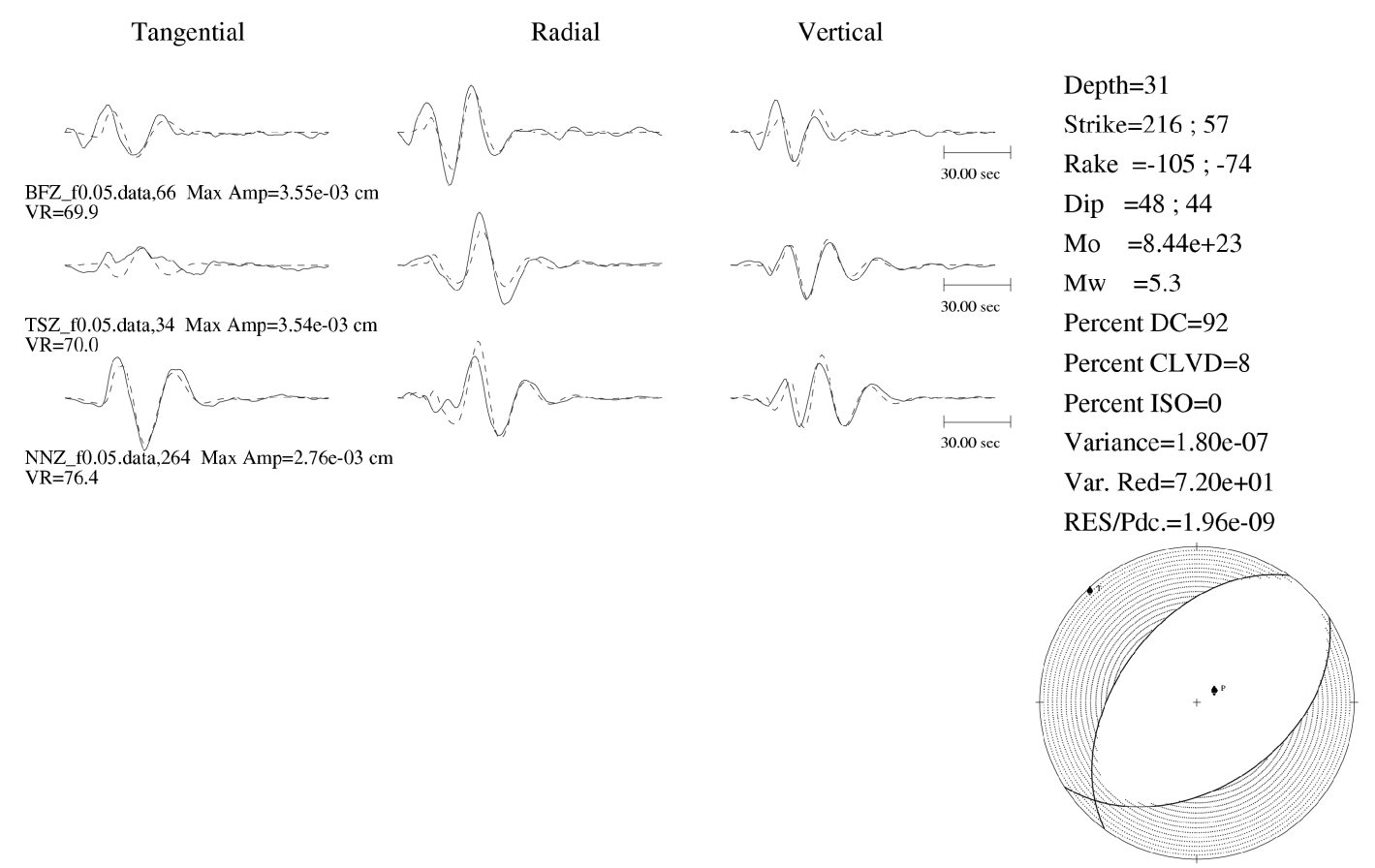

Figure 4. 1. The best solution calculated for the Upper Hutt earthquake, event 2354133. Calculated using the New Zealand velocity model, the $0.02-0.05 \mathrm{~Hz}$ frequency band-pass filter, and a source depth of $31 \mathrm{~km}$.

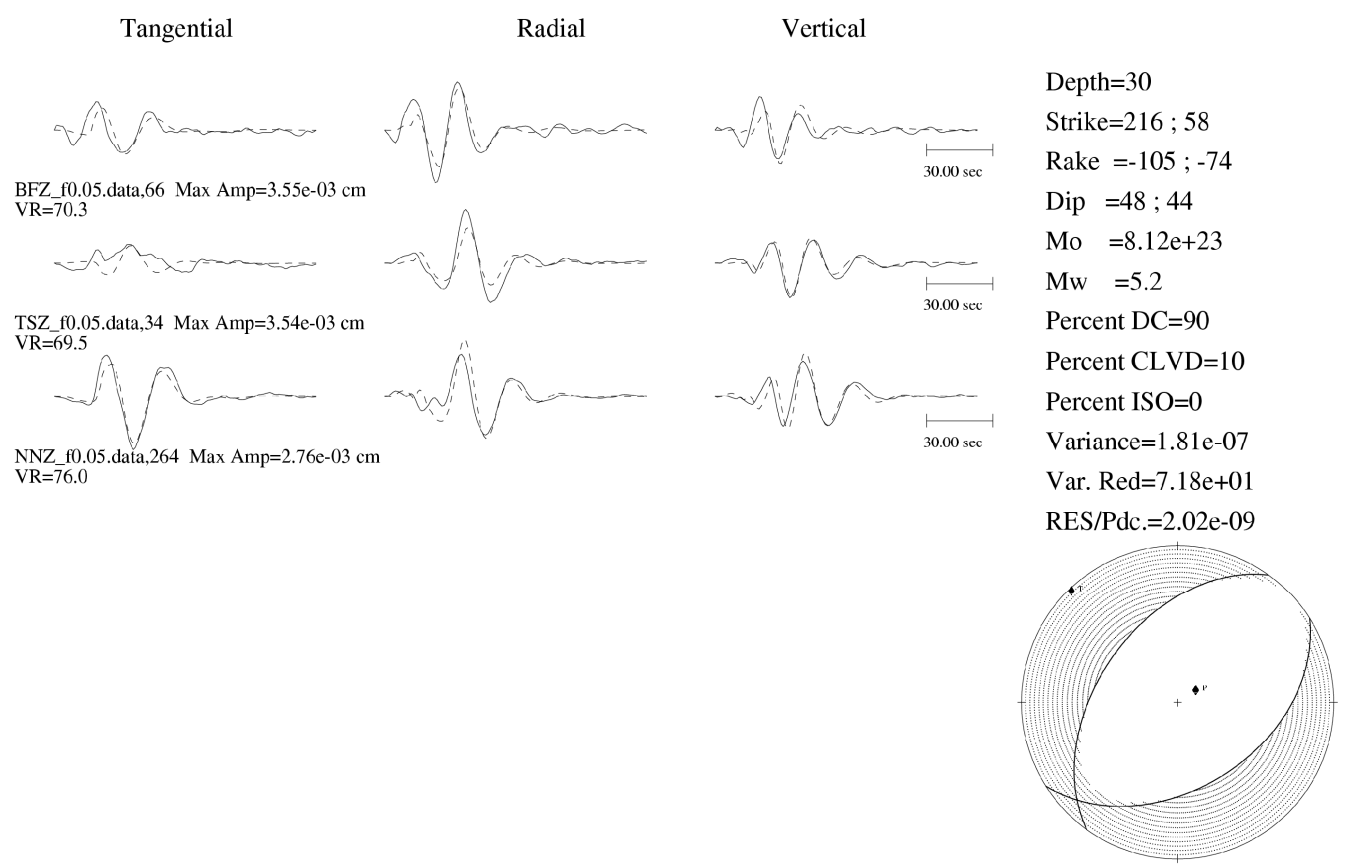

Figure 4. 2. One of the best solutions calculated for the Upper Hutt earthquake, event 2354133. Calculated using the New Zealand velocity model, the $0.02-0.05 \mathrm{~Hz}$ frequency band-pass filter, and a source depth of $30 \mathrm{~km}$. 


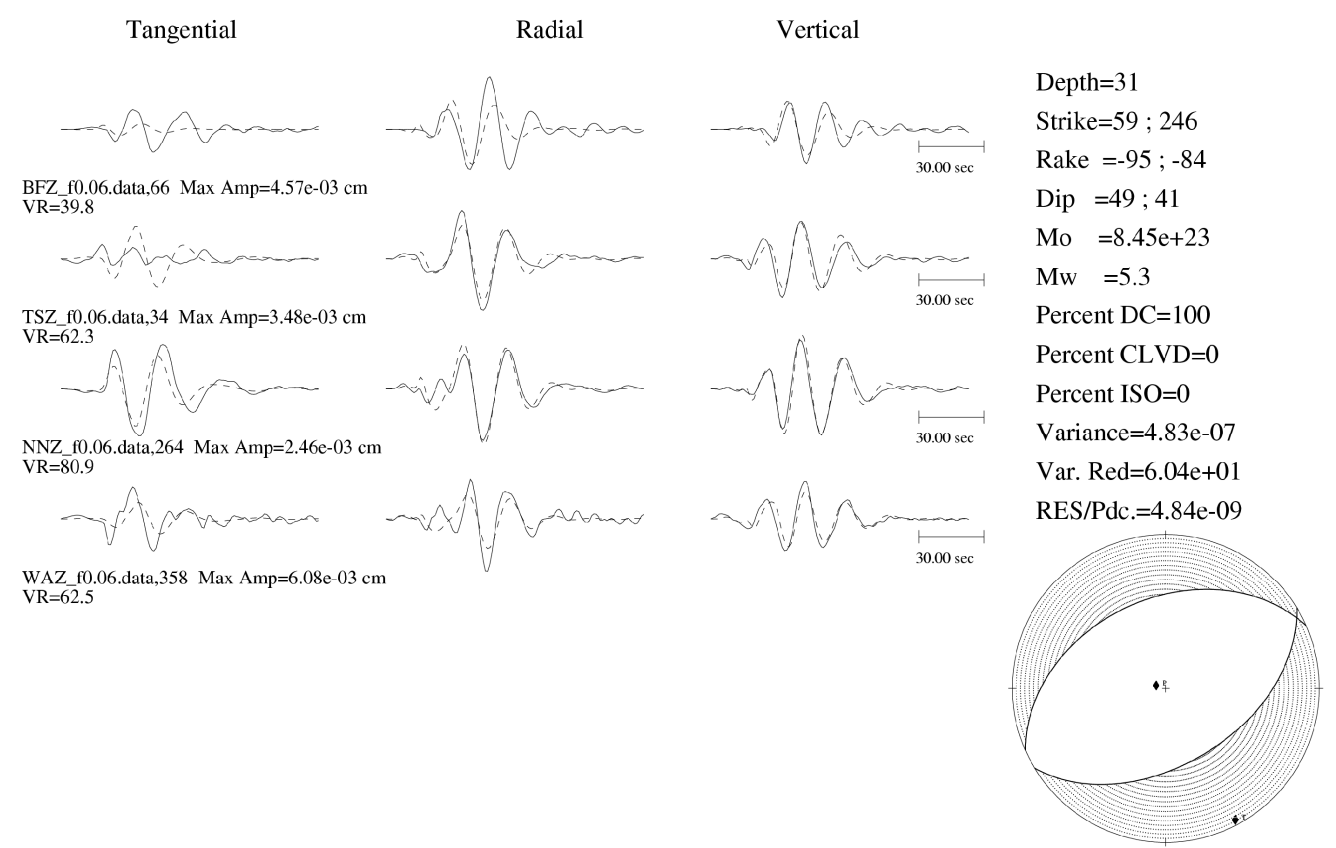

Figure 4. 3. One of the best solutions calculated for the Upper Hutt earthquake, event 2354133. Calculated using the Wellington velocity model, the $0.03-0.06 \mathrm{~Hz}$ frequency band-pass filter, and a source depth of $31 \mathrm{~km}$.

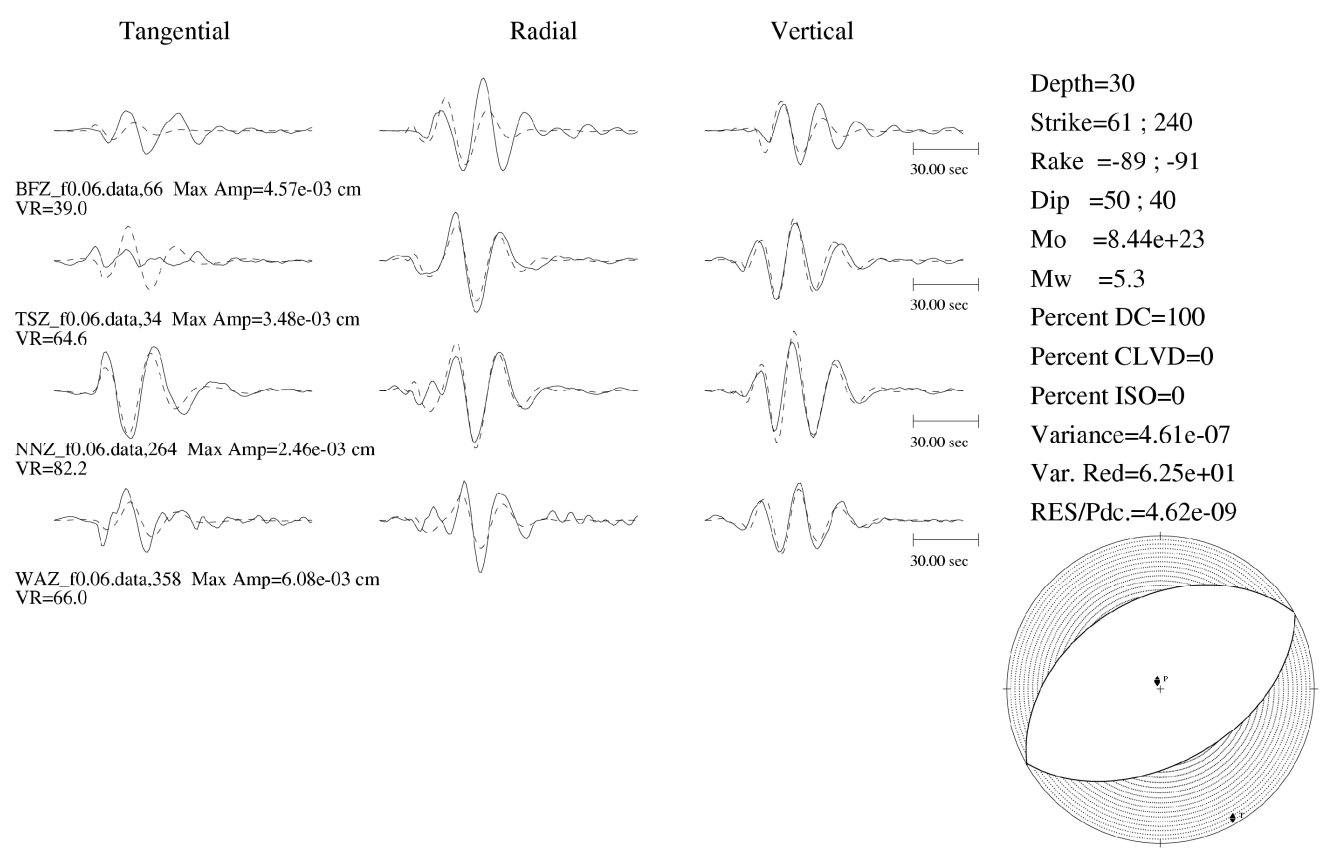

Figure 4. 4. One of the best solutions calculated for the Upper Hutt earthquake, event 2354133. Calculated using the New Zealand velocity model, the $0.03-0.06 \mathrm{~Hz}$ frequency band-pass filter, and a source depth of $30 \mathrm{~km}$. 


\subsubsection{Puysegur Trench}

\section{Event 2326055}

22 November 2004, 2026 UT

depth $12 \mathrm{~km}$ (restricted, GNS Science), $40 \mathrm{~km}$ (Global CMT Project)

ML 7.1 (GNS), Mw 7.1 (Global CMT Project)

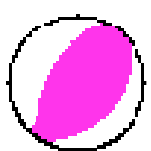

Global CMT mechanism

The Puysegur Trench earthquake was analysed with the New Zealand Standard velocity model and frequency pass-band filters of $0.01-0.05 \mathrm{~Hz}, 0.02-0.05 \mathrm{~Hz}$ and $0.03-0.06 \mathrm{~Hz}$.

The amount of pre-P-wave data was varied, pre-P-wave data lengths of 4 seconds, 10 seconds, 30 seconds, 60 seconds, and 120 seconds were tested. Altering the value of the zcor parameter, which is used to align the data with the Green's functions, was tested, solutions were calculated using an initial zcor of zero, and matching the initial zcor parameter to the amount of pre-P-wave data used (in seconds). It was found that changing the initial zcor parameter gave better results. Data from three to six stations at distances of $220-390 \mathrm{~km}$ from the earthquake were used. Source distances of 5-60 km were tested. For the solutions calculated with 4 seconds of data before the P-wave arrival both the maximum variance reduction and the highest double-couple component were used to select the best solution for each depth, station set and frequency filter combination. For solutions calculated with more than 4 seconds of data, the best solutions were chosen to be those with the highest doublecouple components.

Moment magnitudes of $\mathrm{M}_{\mathrm{W}} 5.1-7.2$ were calculated for this earthquake. The best solutions have magnitudes of $\mathrm{M}_{\mathrm{W}} 6.8$ - 7.2. The best solutions have normal/strike-slip focal mechanisms. Examples of some of the best solutions calculated for this earthquake are shown in Figures 4. 5 - 4. 8.

The best solution calculated for the Puysegur Trench earthquake was calculated using a 0.03 $0.06 \mathrm{~Hz}$ frequency band-pass filter, a pre-P-wave data length of 2 minutes, and an initial offset of 2 minutes between the real and the synthetic seismograms, maximising the doublecouple component, data from the four stations WHZ, MLZ, TUZ and EAZ, and a source depth of $35 \mathrm{~km}$. This solution is shown in Figure 4. 5, and has a moment magnitude of $\mathrm{M}_{\mathrm{W}}$ 7.0 and a normal/strike-slip focal mechanism. 
Chapter 4: Inversion Results

4.2. Case studies

The best results were obtained by increasing the amount of pre-P-wave data used in the modelling. It was necessary to increase the offset between the real and synthetic seismograms to match the amount of extra data included before the arrival of the P-wave. 


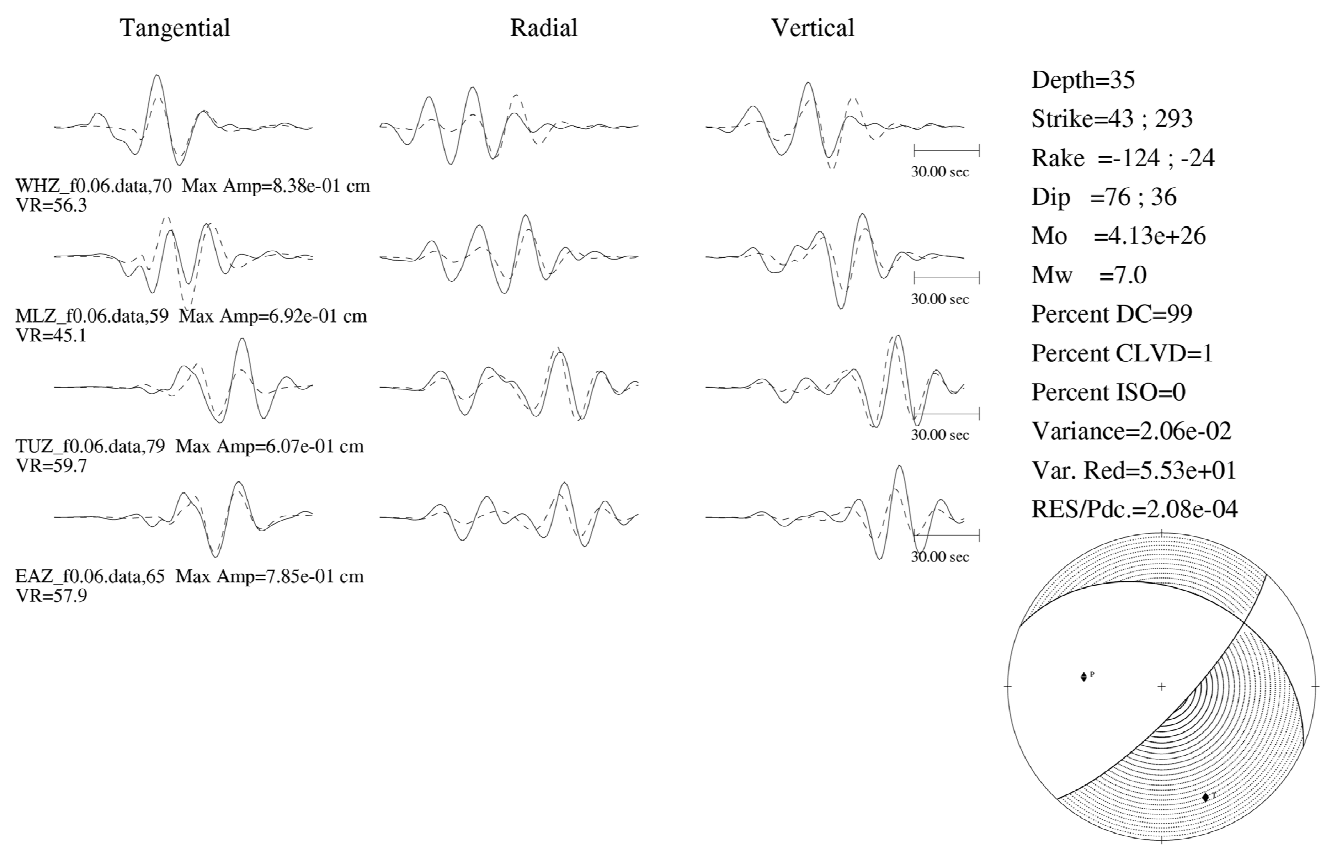

Figure 4. 5. The best solution produced for the Puysegur Trench earthquake, event 2326055. Calculated using the New Zealand velocity model, a $0.03-0.06 \mathrm{~Hz}$ frequency band-pass filter, a pre-P-wave data length of 2 minutes, and an initial offset of 2 minutes between the real and the synthetic seismograms, a source depth of $35 \mathrm{~km}$, and maximising the doublecouple component.
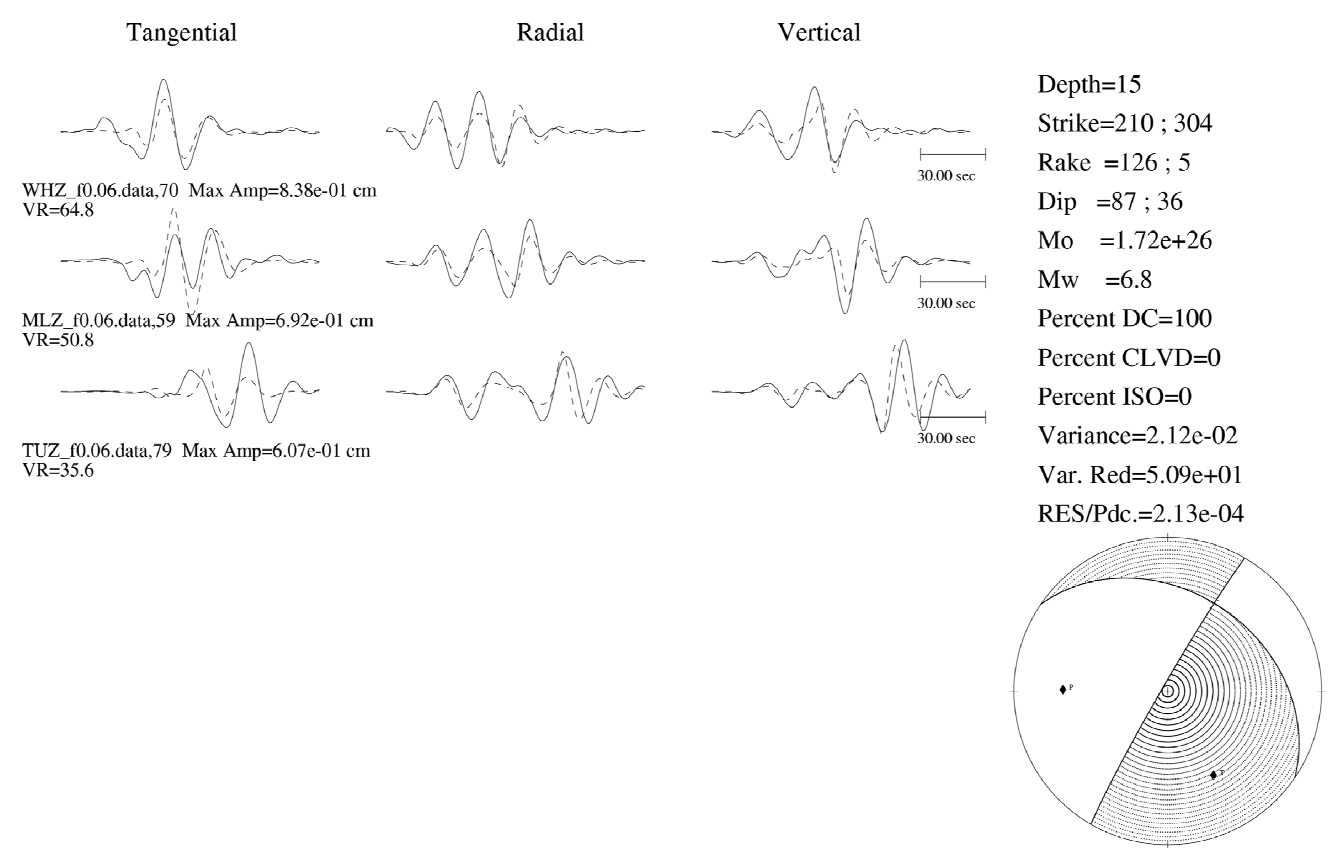

Figure 4. 6. One of the best solutions produced for the Puysegur Trench earthquake, event 2326055. Calculated using the New Zealand velocity model, a $0.03-0.06 \mathrm{~Hz}$ frequency band-pass filter, a pre-P-wave data length of 2 minutes, and an initial offset of 2 minutes between the real and the synthetic seismograms, a source depth of $15 \mathrm{~km}$, and maximising the double-couple component. 


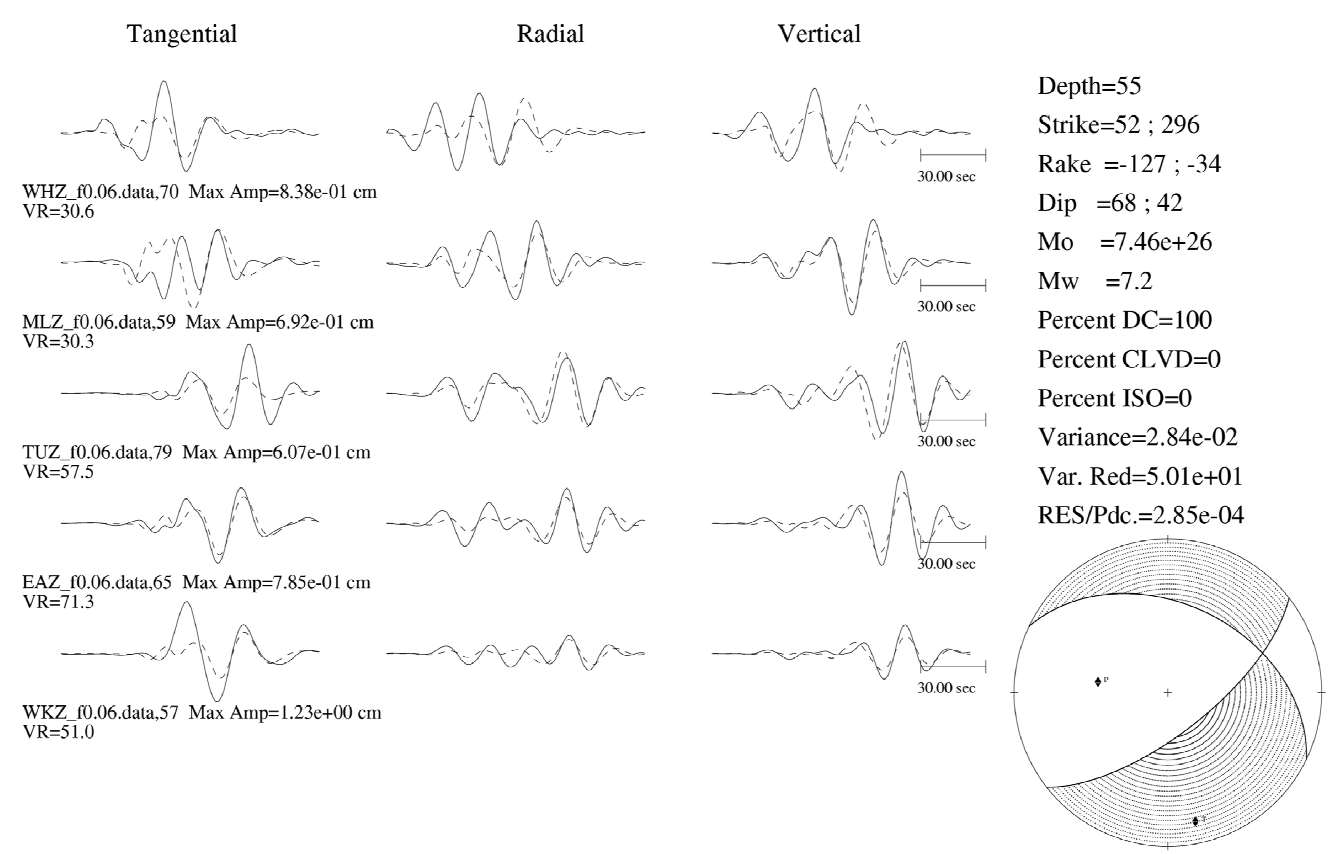

Figure 4. 7. One of the best solutions produced for the Puysegur Trench earthquake, event 2326055. Calculated using the New Zealand velocity model, a $0.03-0.06 \mathrm{~Hz}$ frequency band-pass filter, a pre-P-wave data length of 2 minutes, and an initial offset of 2 minutes between the real and the synthetic seismograms, a source depth of $55 \mathrm{~km}$, and maximising the double-couple component.
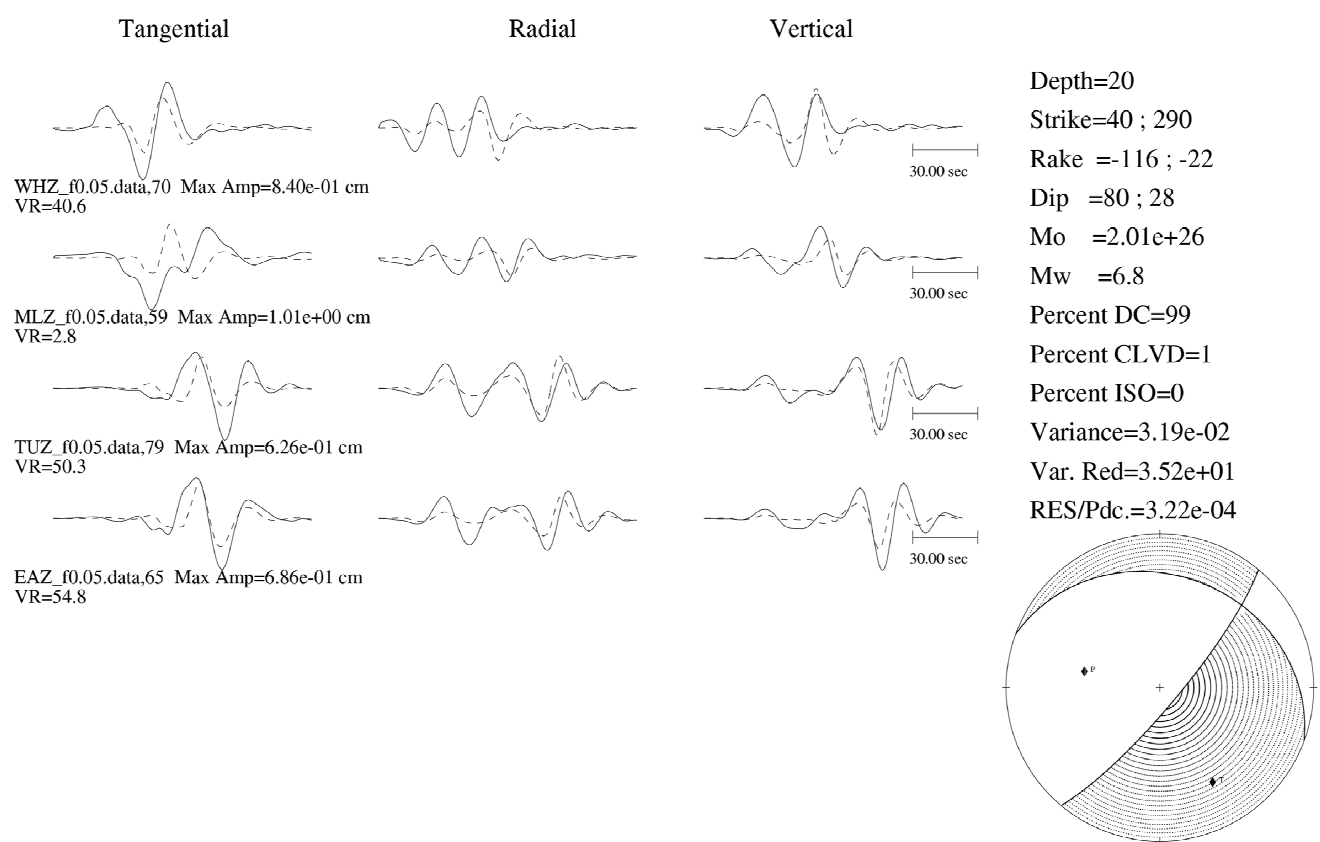

Figure 4. 8. One of the best solutions produced for the Puysegur Trench earthquake, event 2326055. Calculated using the New Zealand velocity model, a $0.02-0.05 \mathrm{~Hz}$ frequency band-pass filter, a pre-P-wave data length of 2 minutes, and an initial offset of 2 minutes between the real and the synthetic seismograms, a source depth of $20 \mathrm{~km}$, and maximising the double-couple component. 


\subsubsection{Fiordland}

Event 2137186

2 November 2003, 1358 UT

depth $20 \mathrm{~km}$ (restricted, GNS Science), $15 \mathrm{~km}$ (Global CMT Project)

ML 5.2 (GNS), Mw 5.2 (Global CMT Project)

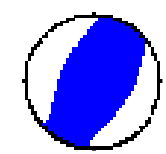

Global CMT mechanism

This Fiordland earthquake was analysed using the New Zealand Standard velocity model and a frequency band-pass filter of $0.03-0.06 \mathrm{~Hz}$. Data from four stations at distances of $150-$ $360 \mathrm{~km}$ from the earthquake were used, with various combinations of three to four stations Source depths of $5-45 \mathrm{~km}$ with intervals of $5 \mathrm{~km}$ were tested. The best solution for each depth and station combination was chosen as the solution with the highest double-couple component.

Moment magnitudes of $\mathrm{M}_{\mathrm{W}} 4.7$ - 5.4 were calculated for this earthquake. The best solutions have magnitudes of $\mathrm{M}_{\mathrm{W}} 4.9$ - 5.3. Many different focal mechanisms were calculated for this earthquake and the correct focal mechanism could not be constrained. Examples of some of the best solutions calculated for this Fiordland earthquake are shown in Figures 4. 9-4. 12 .

The best solution calculated for this earthquake was calculated using data from the three stations MLZ, TUZ and ODZ, and a source depth of $5 \mathrm{~km}$. This solution has a moment magnitude of $\mathrm{M}_{\mathrm{W}}$ 5.1, and a reverse-slip mechanism. This solution is shown in Figure 4. 9. 


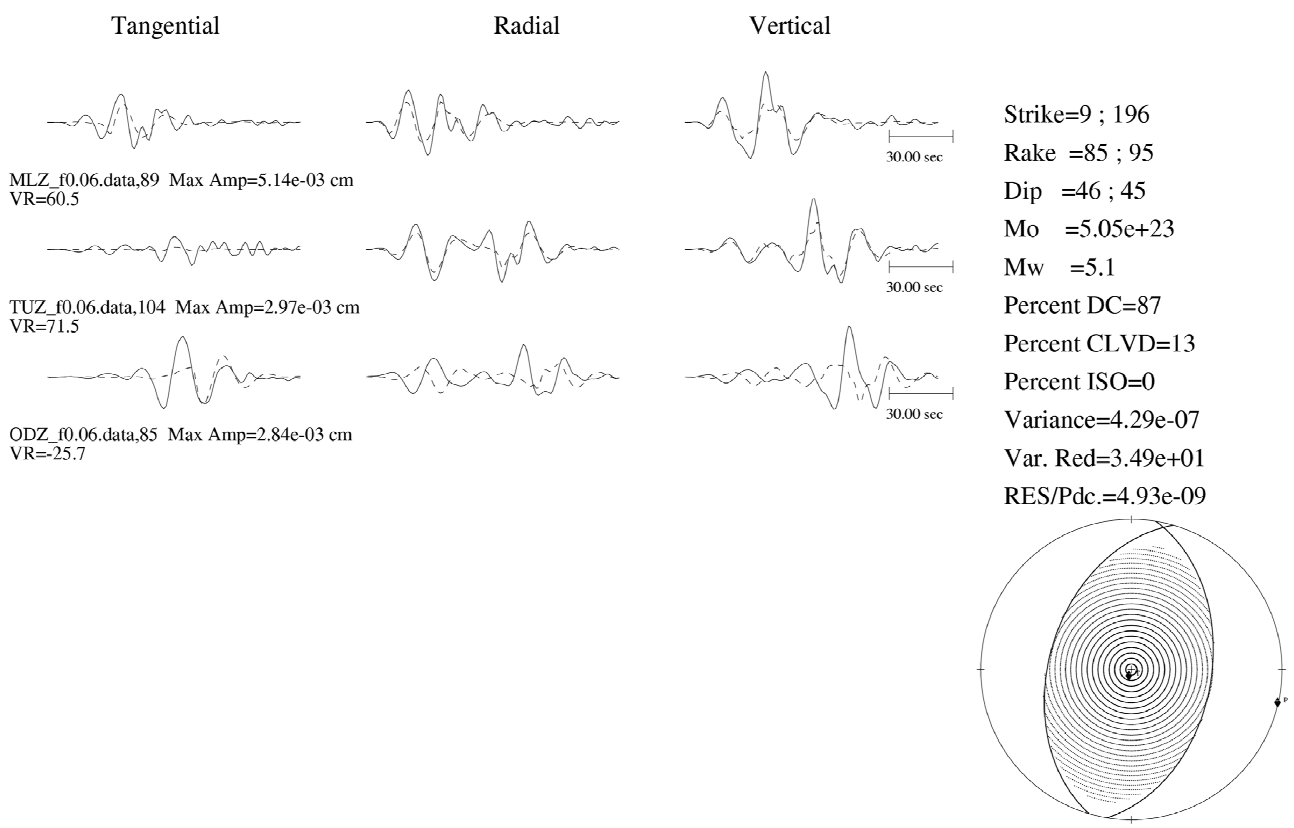

Figure 4. 9. The best solution produced for this earthquake in Fiordland, event 2137186. Calculated using the New Zealand velocity model, a $0.03-0.06 \mathrm{~Hz}$ frequency band-pass filter, a source depth of $5 \mathrm{~km}$, and maximising the double-couple component.

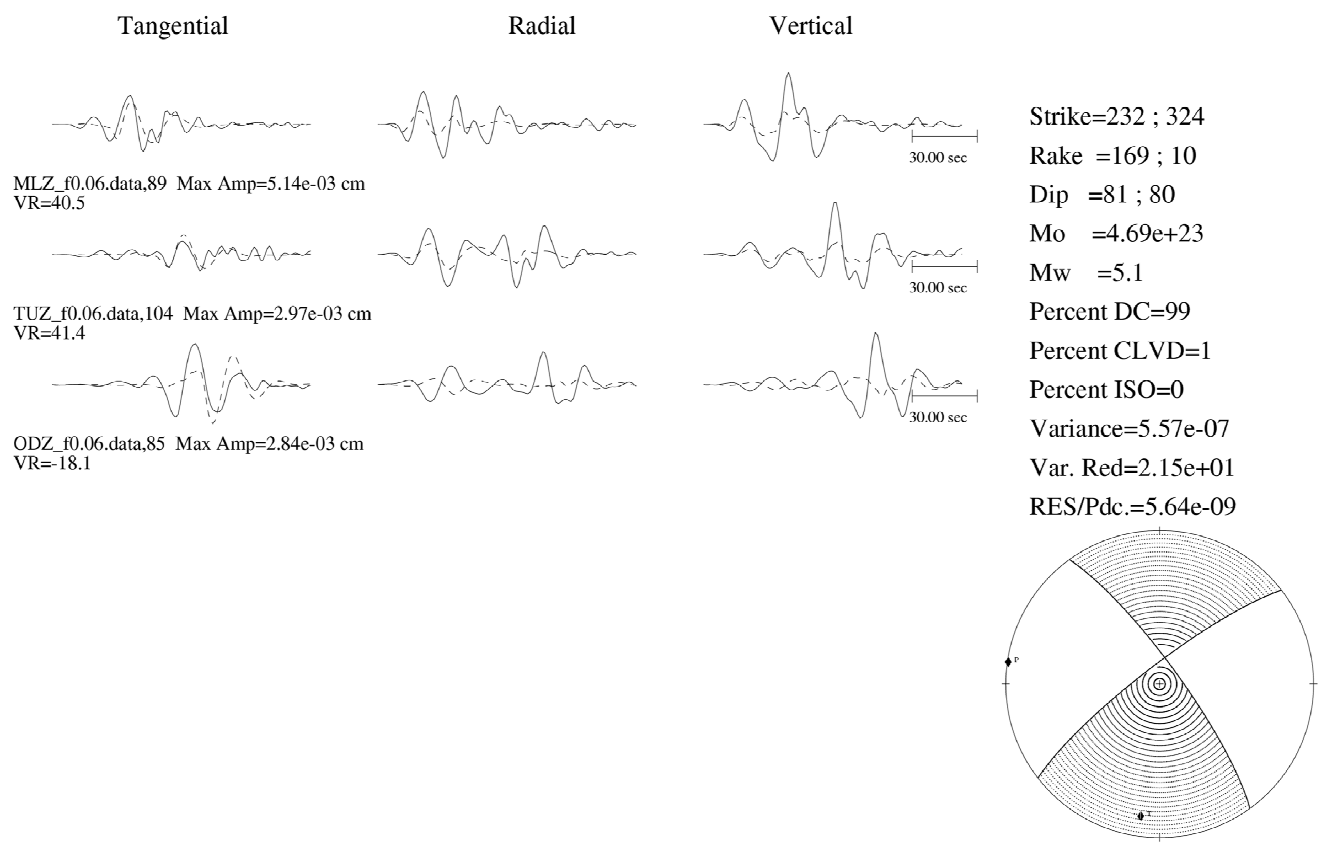

Figure 4. 10. One of the best solutions produced for this earthquake in Fiordland, event 2137186. Calculated using the New Zealand velocity model, a $0.03-0.06 \mathrm{~Hz}$ frequency band-pass filter, a source depth of $10 \mathrm{~km}$, and maximising the double-couple component. 


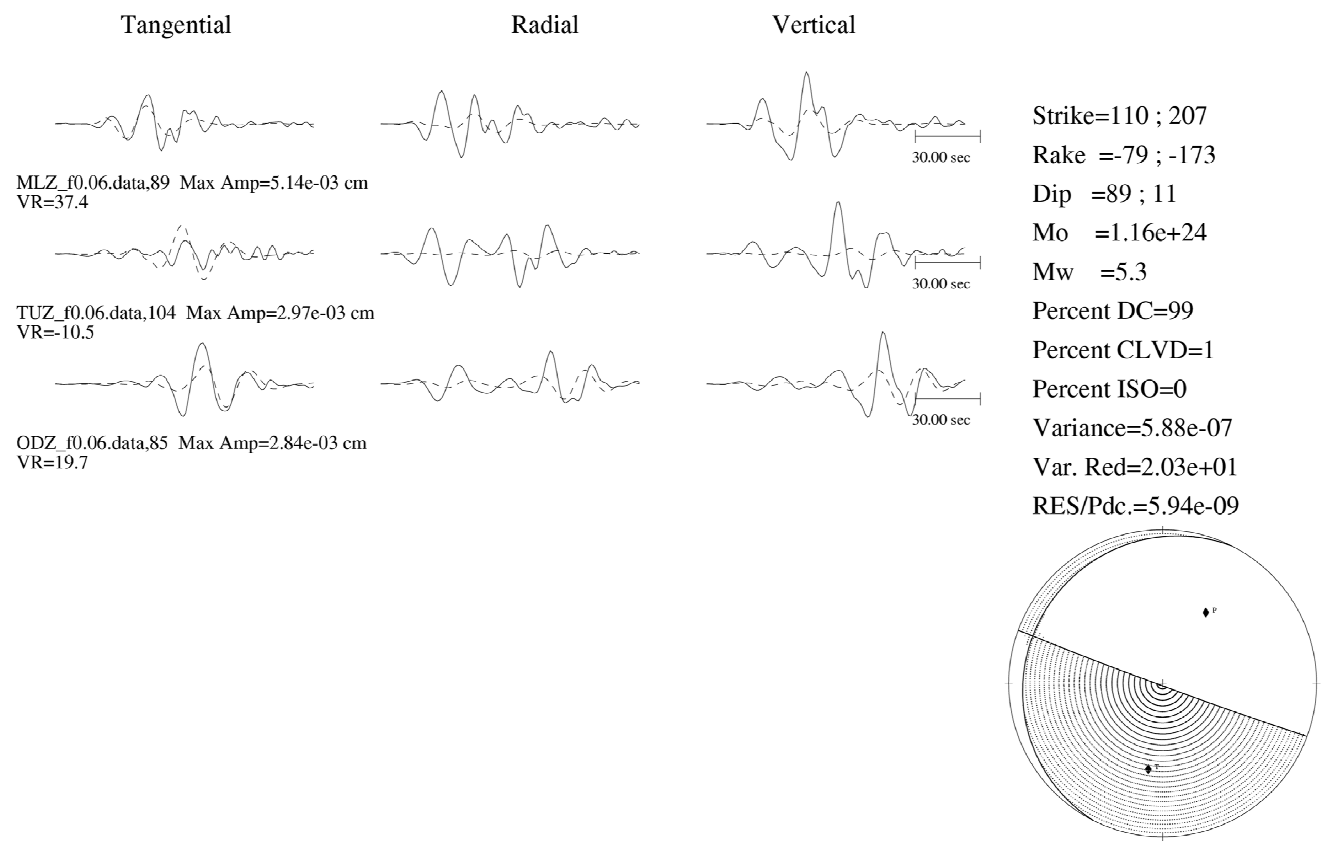

Figure 4. 11. One of the best solutions produced for this earthquake in Fiordland, event 2137186. Calculated using the New Zealand velocity model, a $0.03-0.06 \mathrm{~Hz}$ frequency band-pass filter, a source depth of $40 \mathrm{~km}$, and maximising the double-couple component.
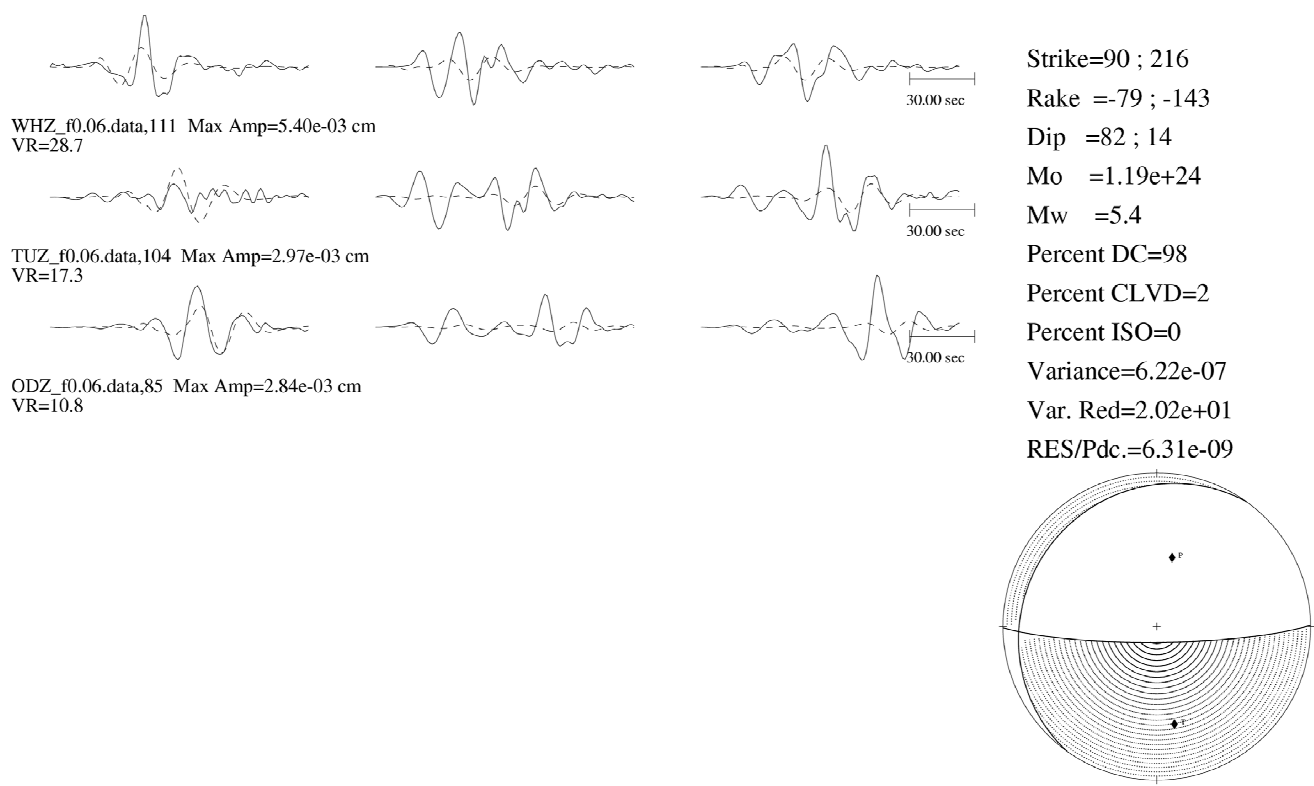

Figure 4. 12. One of the best solutions produced for this earthquake in Fiordland, event 2137186. Calculated using the New Zealand velocity model, a $0.03-0.06 \mathrm{~Hz}$ frequency band-pass filter, a source depth of $40 \mathrm{~km}$, and maximising the double-couple component. 


\subsubsection{East of Gisborne}

Event 2403682

13 May 2005, 1707 UT

depth $12 \mathrm{~km}$ (restricted, GNS Science), $12 \mathrm{~km}$ (Global CMT Project)

$\mathrm{M}_{\mathrm{L}} 4.8$ (GNS Science), $\mathrm{M}_{\mathrm{W}} 5.1$ (Global CMT Project)

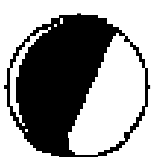

Global CMT mechanism

This earthquake east of Gisborne was analysed using the New Zealand velocity model and a $0.03-0.06 \mathrm{~Hz}$ frequency band-pass filter. Data from three to eight stations at distances of $105-370 \mathrm{~km}$ was used, and source depths of $5-35 \mathrm{~km}$ were tested. Both the maximum variance reduction and the highest double-couple component were used to select the best solution for each depth and station set combination.

None of the solutions produced good fits between the synthetic seismograms and the data, and a best solution was not chosen. Various focal mechanisms were computed. Magnitudes of $\mathrm{M}_{\mathrm{W}} 5.0-\mathrm{M}_{\mathrm{W}} 5.5$ were calculated.

Examples of some of the solutions calculated for this earthquake are given in Figures 4. 13 4. 16. 


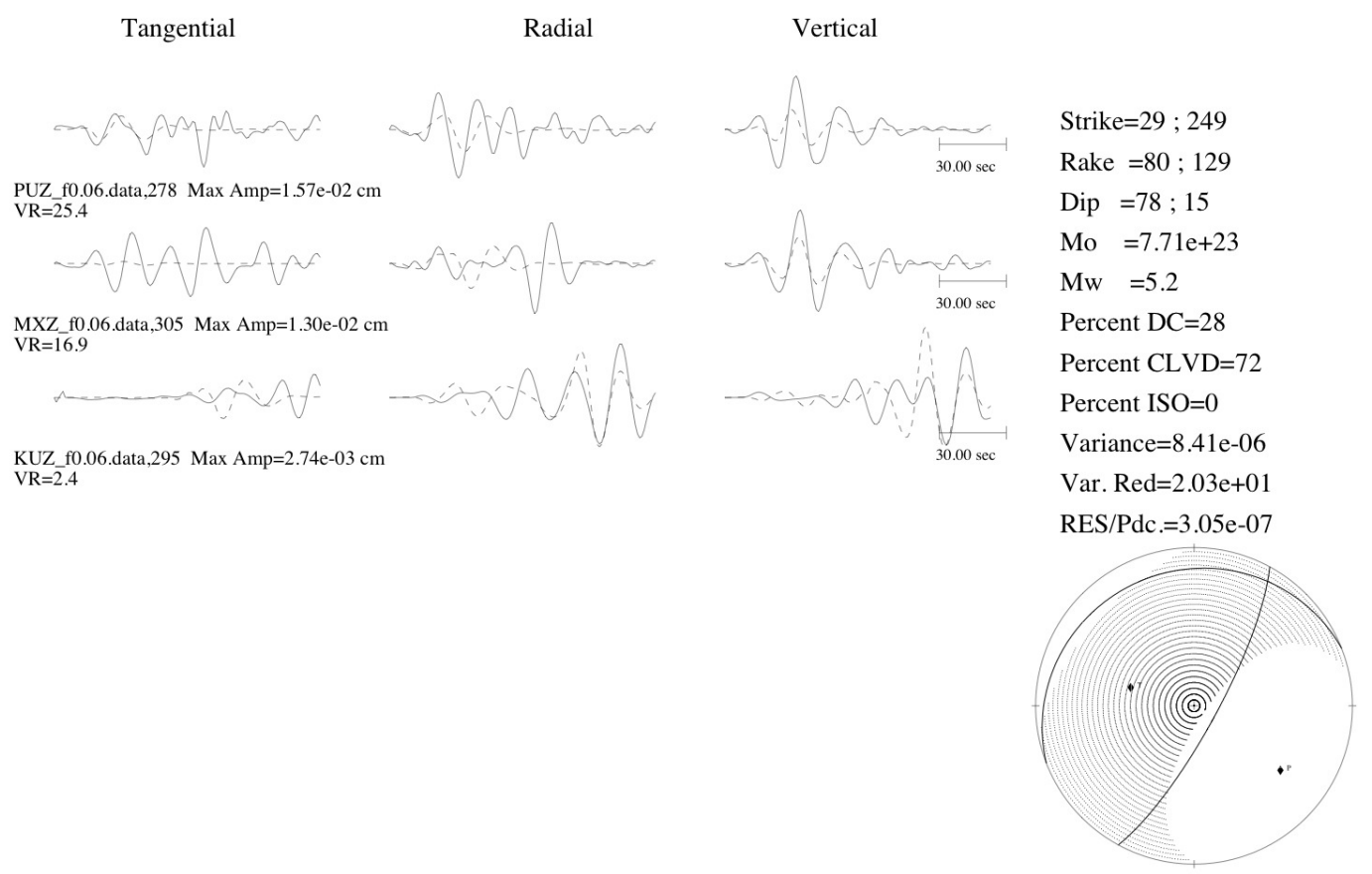

Figure 4. 13. One of the solutions calculated for the earthquake east of Gisborne, event 2403682. Calculated using the New Zealand velocity model, the $0.03-0.06 \mathrm{~Hz}$ frequency band-pass filter, a source depth of $25 \mathrm{~km}$, and optimising the variance reduction.

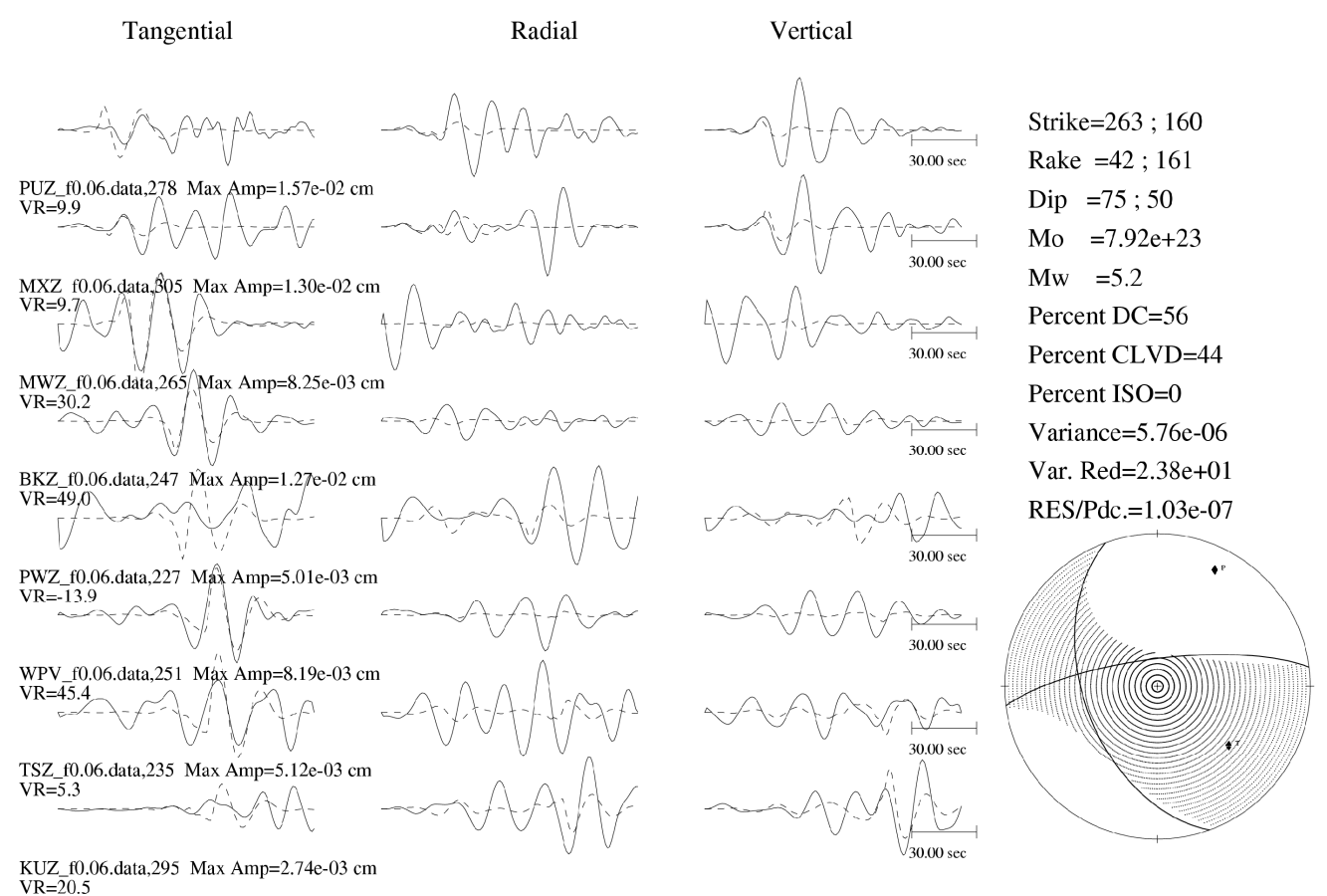

Figure 4. 14. One of the solutions calculated for the earthquake east of Gisborne, event 2403682. Calculated using the New Zealand velocity model, the $0.03-0.06 \mathrm{~Hz}$ frequency band-pass filter, a source depth of $5 \mathrm{~km}$, and optimising the variance reduction. 


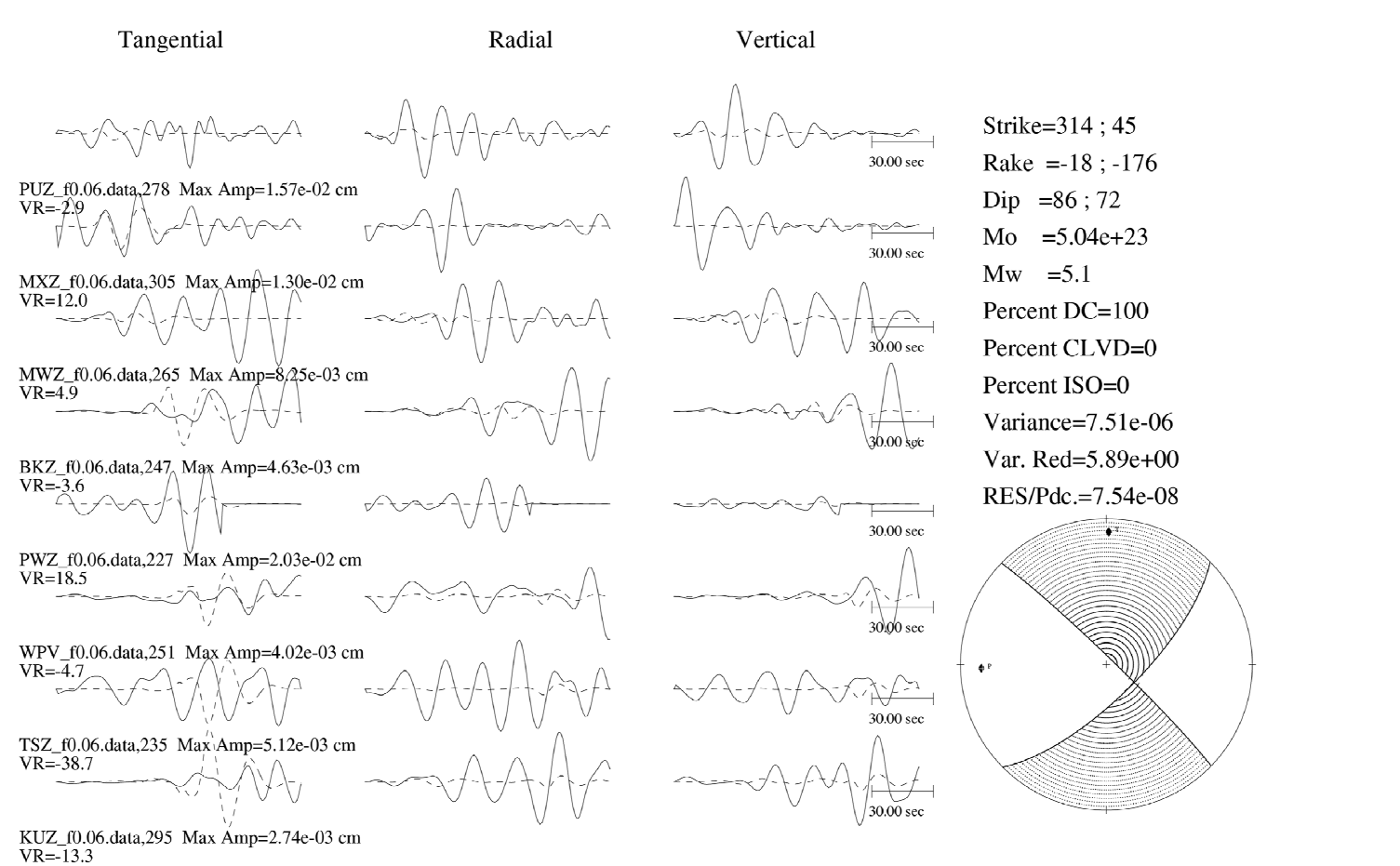

Figure 4. 15. One of the solutions calculated for the earthquake east of Gisborne, event 2403682. Calculated using the New Zealand velocity model, the $0.03-0.06 \mathrm{~Hz}$ frequency band-pass filter, a source depth of $15 \mathrm{~km}$, and optimising the double-couple component.
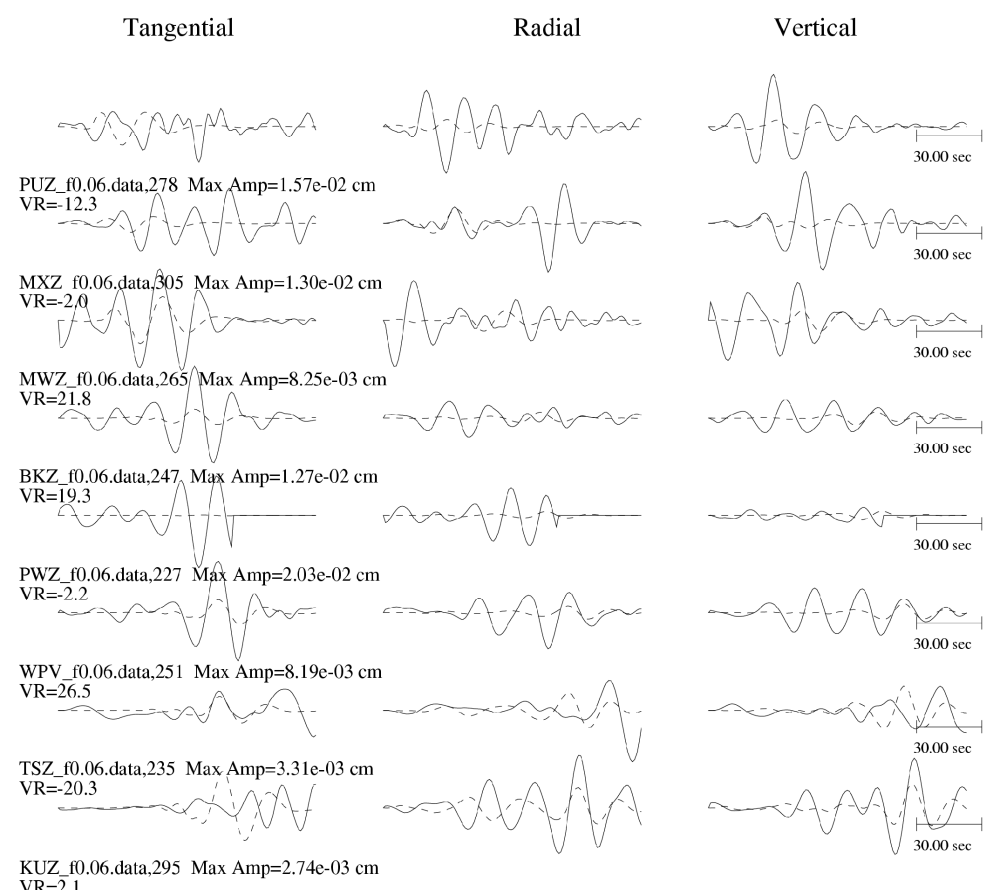
Strike $=80 ; 190$ Rake $=-37 ;-145$ Dip $=61 ; 59$ Mo $=1.21 \mathrm{e}+24$ $\mathrm{Mw}=5.4$ Percent DC $=100$ Percent CLVD $=0$ Percent ISO $=0$ Variance $=8.64 \mathrm{e}-06$ Var. Red $=4.97 \mathrm{e}+00$ RES/Pdc. $=8.66 \mathrm{e}-08$

Figure 4. 16. One of the solutions calculated for the earthquake east of Gisborne, event 2403682. Calculated using the New Zealand velocity model, the $0.03-0.06 \mathrm{~Hz}$ frequency band-pass filter, a source depth of $35 \mathrm{~km}$, and optimising the double-couple component. 


\subsection{Solution quality}

Figures 4. 17 and 4. 18 show how the solution quality varies with epicentral location and depth, and Figure 4. 19 shows how the quality varies with magnitude. Solutions of quality A have both the moment magnitude and the focal mechanism constrained, solutions of quality $\mathrm{B}$ have only the moment magnitude constrained, and solutions of quality $\mathrm{C}$ have neither the moment magnitude nor the focal mechanism constrained.

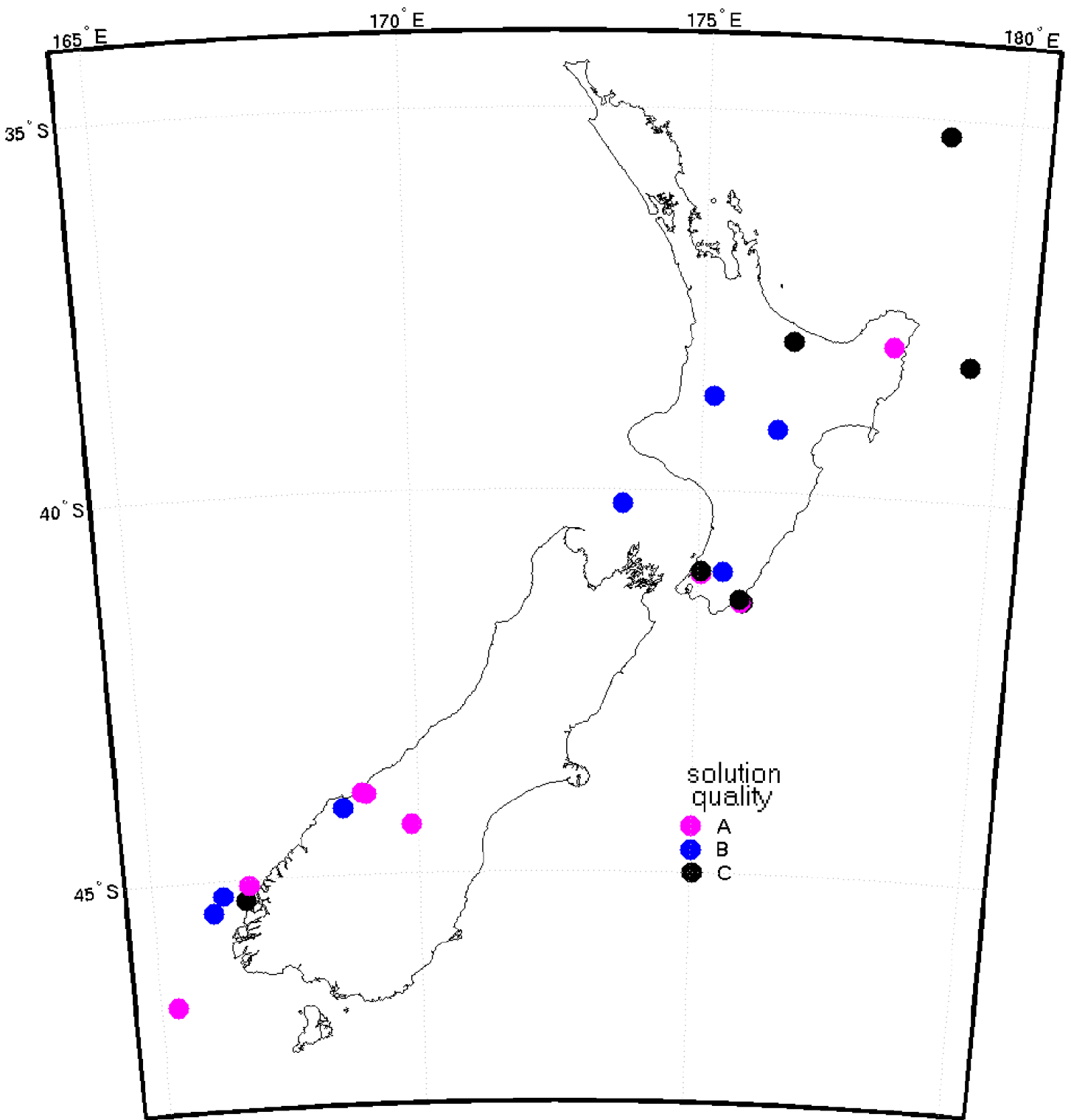

Figure 4. 17. Solution quality with epicentral location. 


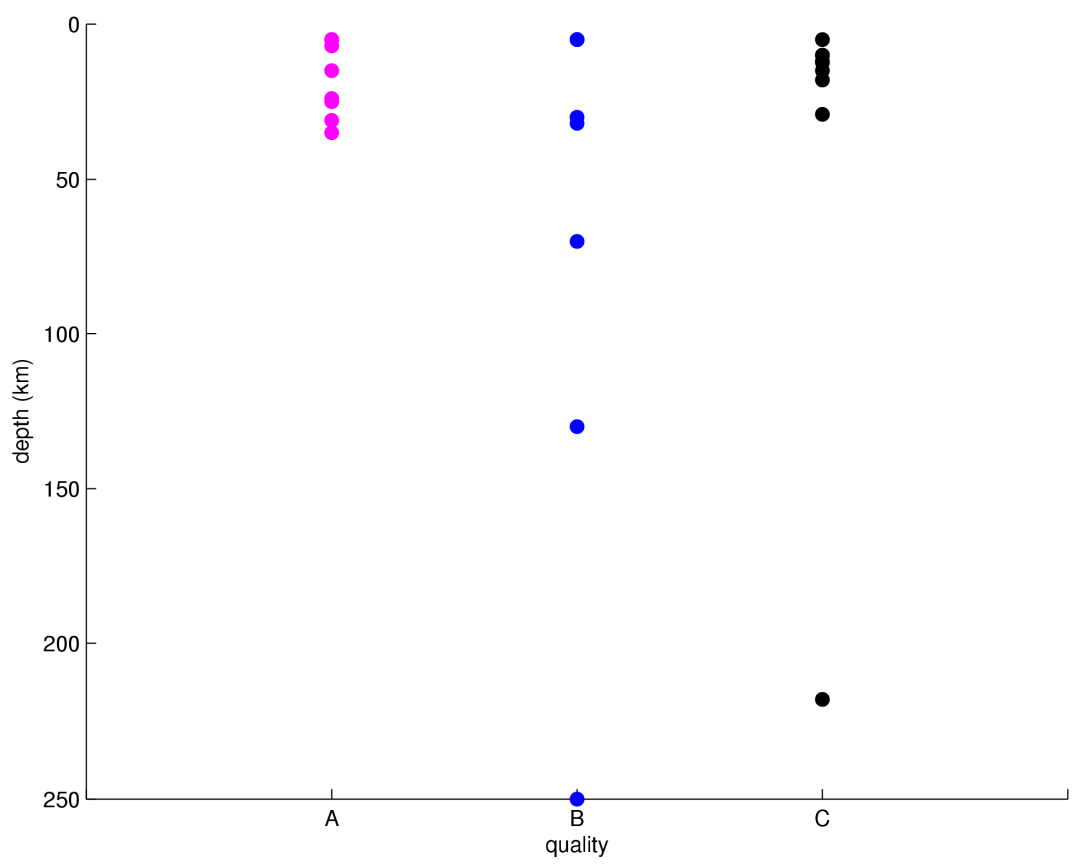

Figure 4. 18. Solution quality with depth - depth is the best depth determined from this study, where applicable, otherwise it is the depth determined by GNS Science.

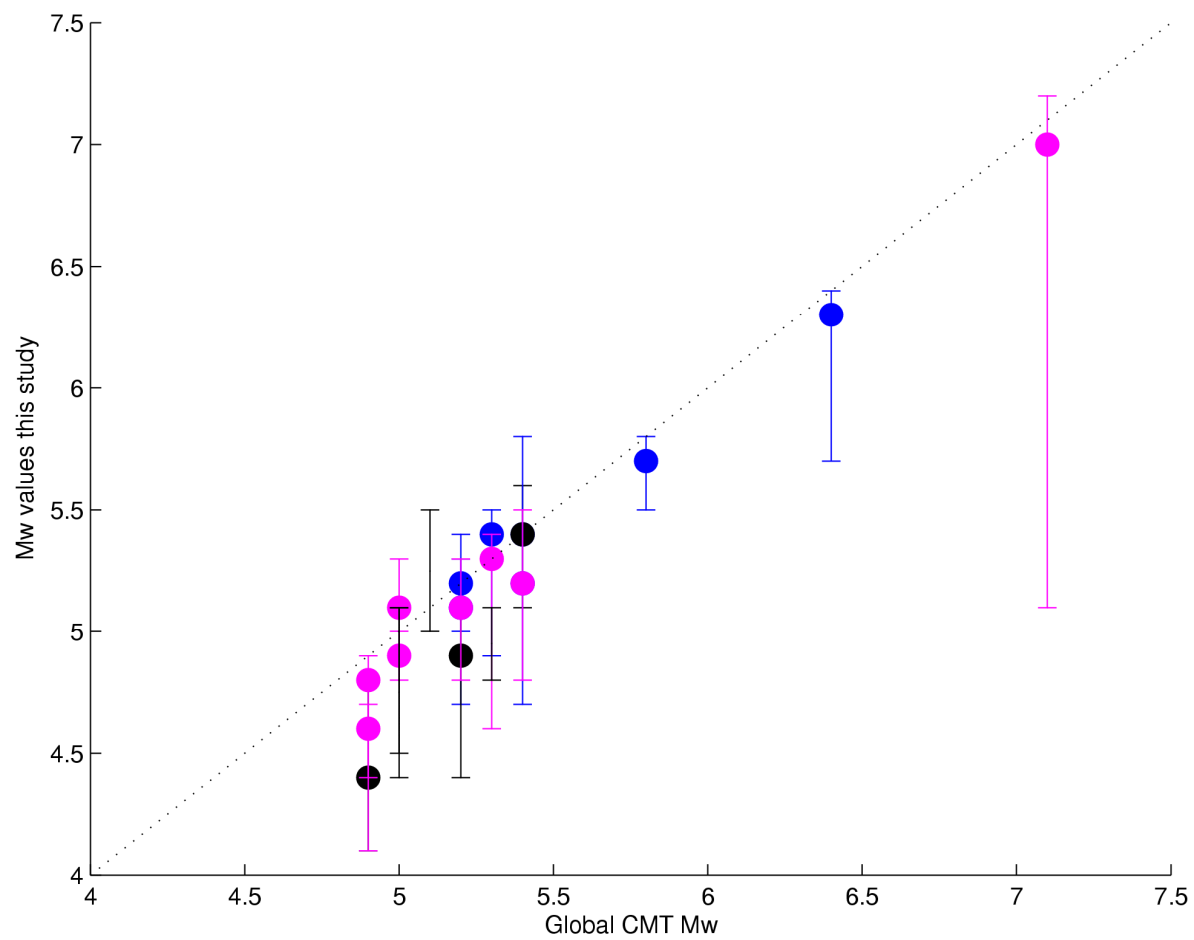

Figure 4. 19. Mw values calculated in this study compared to those calculated by the Global $\mathrm{CMT}$ project. Bars show the ranges of values calculated, with the best Mw value (if determined) shown by the dot. Pink = 'A' quality solutions, Blue = 'B' quality, Black = 'C' quality. The dotted line is the line of equal magnitude. The comparison with the Global CMT values will be discussed in Section 4.4. 
There are no major patterns of how solution quality varies with either the location or the size of the earthquake.

The A, B, and C solutions are all spread throughout New Zealand. There are places (eg. Upper Hutt and Wairarapa) where there are both A and C quality solutions. This is probably due to different magnitudes, with the earthquakes with lower magnitudes having the $\mathrm{C}$ quality solutions and the bigger earthquakes having the A quality solutions.

Shallow earthquakes have solutions of qualities A, B and C, while the three deep earthquakes have qualities of $\mathrm{B}$ and $\mathrm{C}$.

Smaller earthquakes have solutions of qualities A, B, and C, while the larger earthquakes have B quality solutions.

The twenty-four earthquakes studied are not enough to draw conclusions about the location, depth or size of earthquakes for which either the moment magnitudes or the focal mechanisms can be constrained.

It is likely that the qualities of the solutions depend on several things, including the magnitude, depth, azimuthal coverage, distance to the subducting slabs, and distances to the seismograph stations used. With only twenty-four earthquakes it is not possible to draw conclusions about how the many variables affect the solutions. 


\subsection{Comparison with Global CMT solutions}

\subsubsection{Moment magnitude}

Figure 4. 19 shows the ranges of values of moment magnitude calculated in this study compared with those calculated by the Global CMT project. Generally the moment magnitudes calculated in this study are slightly lower than those calculated by the Global CMT project.

The magnitudes produced in this study have not been calibrated to magnitudes determined by any other method (e.g. the Global CMT project). It may be that there are parameters in the velocity model that need adjusting, and these have not been tested in this study. For example, if the attenuation constants $(\mathrm{Q})$ used are too high then the magnitudes produced would also be too low. In this study it has been assumed that the attenuation does not vary with depth. In fact, the attenuation may vary with depth, in particular the subducting slab is likely to have a higher value of Q than the crust.

Figure 4. 19 shows the full range of magnitudes calculated for each earthquake. For the earthquakes that the magnitude could be constrained, the range of likely magnitudes can be considerably lower. Figure 4.20 shows the ranges of magnitudes that the magnitude is considered to be constrained between. The linear best-fit line is also plotted on this graph, showing how the best solutions calculated in this study relate to the solutions calculated by the Global CMT project. The slope of this line is 1.039, and the intercept on the 'Mw values this study' axis is -0.322 . This says that for all values of $\mathrm{M}_{\mathrm{W}}$, the values calculated by this study are on average 0.322 magnitude units lower than the value calculated by the Global CMT project. There is quite a bit of scatter about this line. 


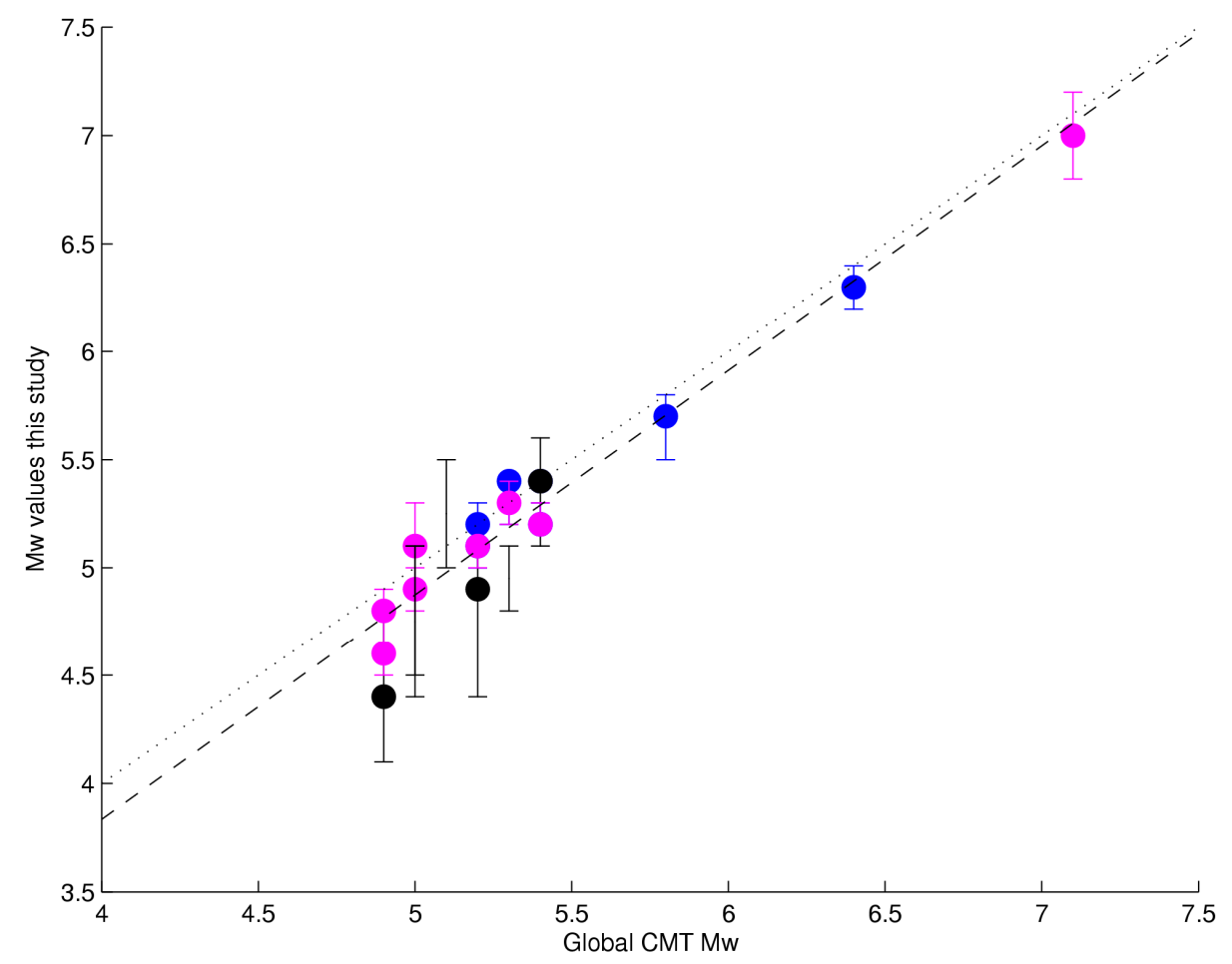

Figure 4. 20. Values of moment magnitude from this study compared to the values calculated by the Global CMT project. The dots show the best values obtained, and the bars show the magnitudes that the magnitude is considered to be constrained between. The colours represent the quality of the solutions; pink = quality $\mathrm{A}$, blue $=$ quality $\mathrm{B}$, black $=$ quality C. Also shown are the line of equal magnitude (dotted line) and the linear best-fit line (dashed line).

\subsubsection{Focal mechanisms}

Figures 4. 21 and 4. 22 show the best focal mechanisms calculated in this study, the Global CMT Project mechanisms, and the angles required to rotate one into the other, as calculated using the method described in Section 2.2. Mechanisms from this study and the angles are shown only for quality A and B solutions. 


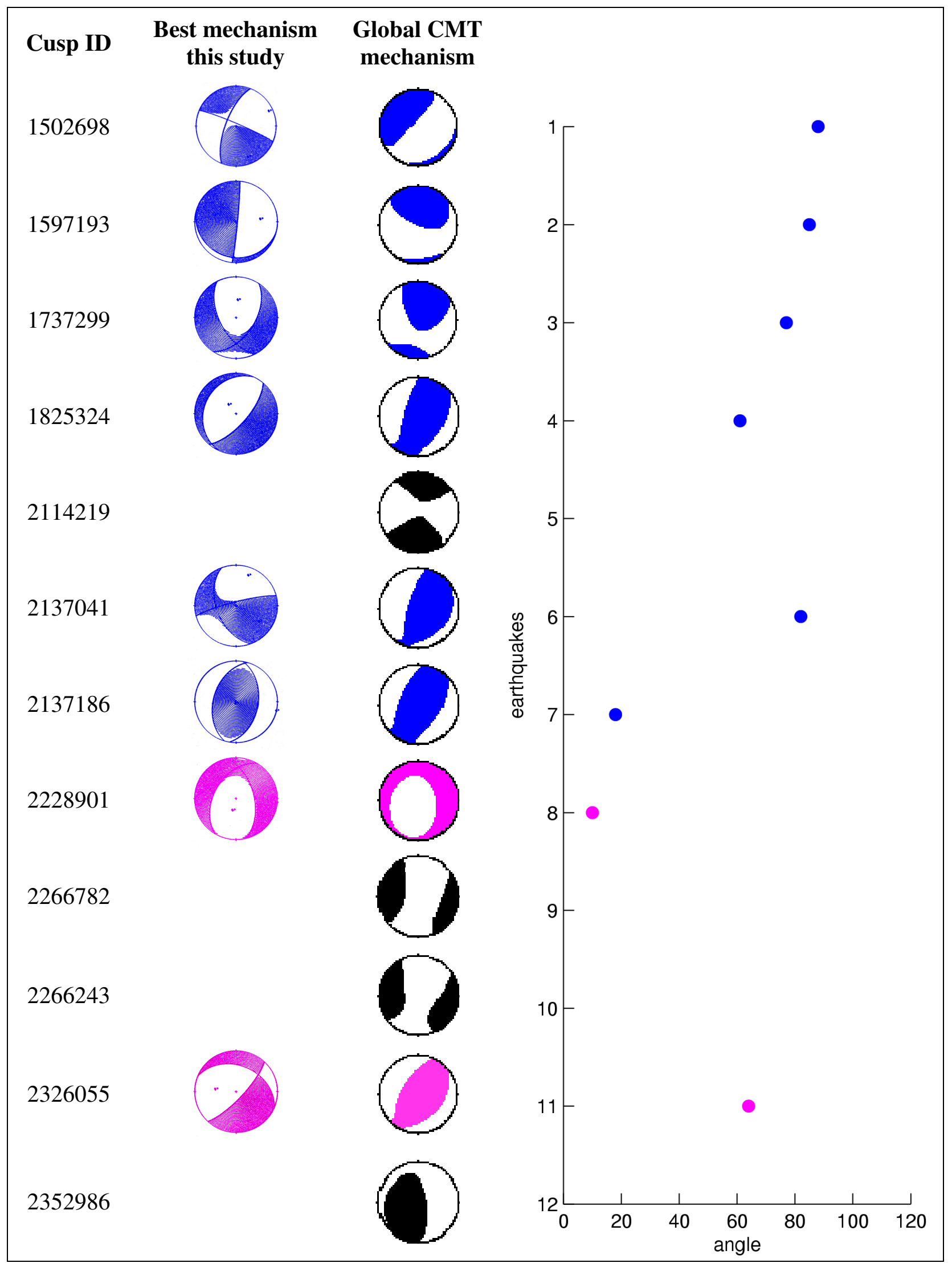

Figure 4. 21. The best mechanisms produced in this study (left), the Global CMT mechanisms (middle) and the angle required to rotate one into the other (right). The colours represent the quality of the solutions produced in this study. Pink: Mw and focal mechanism constrained, Blue: Mw constrained, Black: neither constrained. 


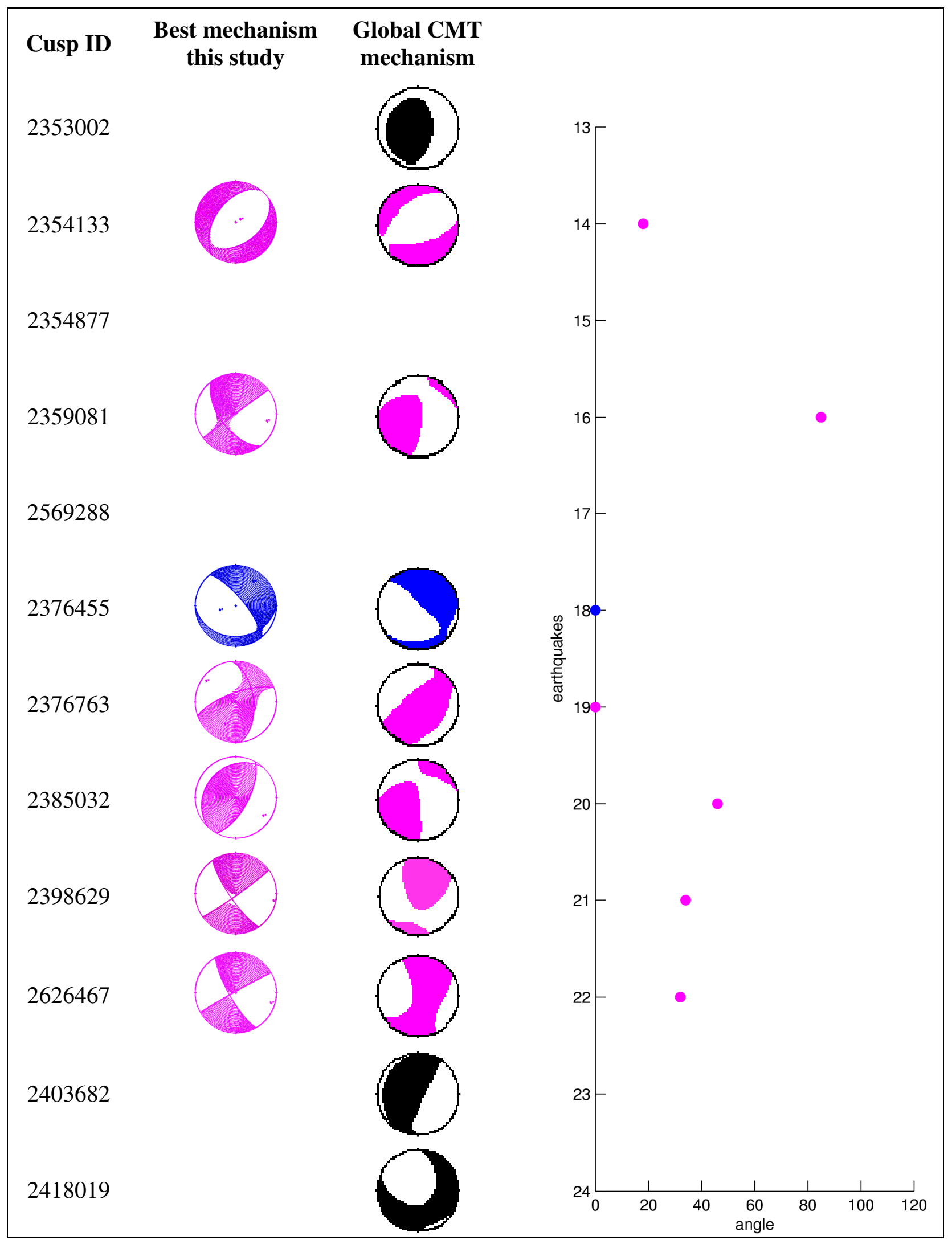

Figure 4. 22. The best mechanisms produced in this study (left), the Global CMT mechanisms (middle) and the angle required to rotate one into the other (right). The colours represent the quality of the solutions produced in this study. Pink: Mw and focal mechanism constrained, Blue: Mw constrained, Black: neither constrained. 
The best mechanisms for the earthquakes with A grade solutions, where the mechanism is constrained, can mostly be rotated into the Global CMT solution with angles of less than $50^{\circ}$. The exceptions are the Puysegur Trench earthquake (event 2326055), and a Wairarapa earthquake (event 2359081). The best mechanisms for earthquakes with B grade solutions, where the mechanism can not be constrained, mostly need angles of over $60^{\circ}$ to rotate into the Global CMT solutions. Events 2137186 and 2376455 can be rotated into the Global CMT solutions using smaller angles. The best solution for many of the earthquakes with $\mathrm{C}$ grade solutions could not be determined, so the $\mathrm{C}$ grade solutions are not compared to the Global CMT solutions.

The best solutions produced for the Puysegur Trench earthquake (event 2326055) are all very similar to the solution shown in Figure 4. 21.

The solutions produced for the Wairarapa earthquake (event 2359081) are all very similar to the best solution chosen and shown in Figure 4. 22. There were no solutions produced that looked like the solution produced by the Global CMT Project.

Although the best solutions for events 2137186 (Fiordland) and 2376455 (South of Taranaki) are very similar to the solutions calculated by the Global CMT project, there were lots of other good solutions calculated for these earthquakes in this study and there was not enough evidence to suggest that the best solution was definitely the correct solution.

Most of the best B grade solutions are quite different from the Global CMT Project solutions, which enforces the idea that the focal mechanisms for these earthquakes could not be constrained. 


\subsection{Routine calculation of seismic moment tensors}

In this project many different seismic moment tensor solutions have been calculated for each earthquake by varying the source depth, the frequency passband used, the set of stations used, and the measure of fit used (maximum variance reduction or maximum double-couple component). The solutions calculated were compared, and the best solution determined if possible. It was then decided whether it was possible to constrain the moment magnitude or the focal mechanism from the solutions calculated. It was not possible to constrain either the moment magnitude or the focal mechanism for some of the events analysed. This fact could only be determined by comparing a number of possible solutions. The need to calculate and analyse many solutions for each earthquake would make it difficult to calculate seismic moment tensors routinely. Other factors that would make it difficult include the level of microseism (ocean) noise present in New Zealand seismic data, and the azimuthal coverage of the data. These are discussed in the following sections.

\subsubsection{Noise}

Because of the level of noise present in New Zealand seismic data and the fact that the data often has multiple peaks with similar amplitudes (see Section 3.1.3.1), the variance reduction seems to be an inappropriate measure of the quality of a seismic moment tensor solution. The percentage double-couple component appears to be a more appropriate measure, but this does not always lead to the best solution. The problem with picking a way to determine the best solution will make it difficult to determine seismic moment tensor solutions routinely.

\subsubsection{Azimuthal coverage}

New Zealand is long and narrow, and many earthquakes occur in locations where the azimuthal coverage of seismic stations is poor (See Appendix 1 for details of the azimuthal coverage for each earthquake). Often all stations are either to the north-east and/or southwest of the earthquake, with no stations to the north-west or south-east. Even in the middle of the islands, stations to the east and west are likely to be less than $100 \mathrm{~km}$ away, making them unsuitable for using to calculate seismic moment tensors. This very poor azimuthal coverage may lead to some errors in the calculation of seismic moment tensors. 


\section{Chapter Five: Conclusions}

Seismic moment tensor solutions were calculated for twenty-four New Zealand earthquakes using the TDMT_INVC algorithm and GeoNet data. From the analysis of these solutions the following conclusions are drawn:

- Of the twenty-four earthquakes studied, moment magnitudes could be determined to within 0.3 magnitude units for fifteen earthquakes (62.5\%), and the focal mechanisms could be determined for nine earthquakes $(37.5 \%)$.

- The best solutions compare well with the Global CMT solutions. The average magnitude difference is 0.15 magnitude units, and the ratio is 1.007 . This means that calibrating the results of this study should be reasonably straight-forward. The focal mechanisms of the earthquakes for which the focal mechanism could be determined were mostly very similar to the Global CMT solutions.

- The solutions calculated do not appear to be sensitive to the velocity model. Further work could be done to confirm this.

- The solutions are sensitive to the amount of noise in the data. Because of the high level of microseism noise present in the data the variance reduction appears to be an inappropriate measure of the quality of the seismic moment tensor solution, and the percentage double-couple component appears to be a better indicator of the solution quality.

- The high level of noise, the lack of azimuthal coverage of New Zealand seismograph stations (constrained by New Zealand's physical narrowness), the large number of input parameters (source depth, frequency filter range, number and selection of stations), and the large number of steps required to generate a seismic moment tensor solution, will make it difficult for the TDMT_INVC code to be implemented automatically in New Zealand.

- How the quality of the solutions (whether or not either the moment magnitude or the focal mechanism could be determined) depends on the earthquake magnitude or location could not be determined from the analysis in this study. 
- No relation between the magnitudes of the earthquakes and the appropriate frequency band-pass filter was discovered in this study.

- Increasing the amount of pre-P-wave data used in the modelling produces better results. It is also necessary to increase the offset between the real and synthetic seismograms to match the amount of extra data included before the arrival of the P-wave.

- Further work could include further investigation on sensitivity of the solutions to the velocity models (including the values of the attenuation constants and 3D velocity models). Further work could also be done to investigate appropriate frequency ranges for different magnitudes. Further work should be done on investigating alternative methods of wave-form matching and determining the solution quality. The relationship between individual stations and the noise levels could also be investigated. Investigation of more earthquakes should lead to some conclusions about the sizes and location of earthquakes that produce the best solutions. A large amount of further work would be needed to further modify the algorithm for inclusion with automatic procedures. 


\section{References}

Anderson, H., Webb, T. and Jackson, J. (1993): Focal mechanisms of large earthquakes in the South Island of New Zealand, implications for the accommodation of Pacific-Australia plate motion. Geophysical Journal International, 115: 1032 - 1054.

Arnadottir, T., Beavan, J. and Pearson, C. (1995): Deformation associated with the 18 June 1994 Arthur's Pass earthquake, New Zealand. New Zealand Journal of Geology and Geophysics, 38: 553-558.

Arnold, R. and Townend, J. (2007): A Bayesian approach to estimating tectonic stress from seismological data. Geophysical Journal International, 170: 1336 - 1356., doi: 10.1111/j.1365-246X.2007.03485.x.

Deichmann, N. (2006): Local magnitude, a Moment Revisited. Bulletin of the Seismological Society of America, 96(4A): 1267 - 1277, doi: 10.1785/0120050115.

DeMets, C., Gordon, R.G., Argus, D.F., and Stein, S. (1990): Current plate motions. Geophysical Journal International, 101: 425-478.

DeMets, C., Gordon, R.G., Argus, D.F., and Stein, S. (1994): Effect of the recent revisions to the geomagnetic reversal time scale on estimates of current plate motions. Geophysical research letters, 21: 2191-2194.

Dreger, D.S. (2003): TDMT_INV: Time Domain Seismic Moment Tensor INVersion. International Handbook of Earthquake and Engineering Seismology, 81B: 1627.

Dreger, D.S. and Helmberger, D. V. (1993): Determination of Source Parameters at Regional Distances With Three-Component Sparse Network Data. Journal of Geophyiscal Research, 98(B5): 8107 - 8125 .

Dreger, D.S. and Helmberger, D.V. (1990): Broadband Modeling of Local Earthquakes. Bulletin of the Seismological Society of America, 80(5): 1162 - 1179. 
Dreger, D.S. and Helmberger, D.V. (1991): Source parameters of the Sierra Madre earthquake from regional and local body waves. Geophysical Research Letters, 18: 2015 2018.

Dziewonski, A.M., Chou, T.-A. and Woodhouse, J.H. (1981): Determination of Earthquake Source Parameters from Waveform Data for Studies of Global and Regional Seismicity. Journal of Geophysical Research, 86(B4): 2825 - 2852.

Eberhart-Phillips, D. and McVerry, G. (2003): Estimating Slab Earthquake Response Spectra from a 3D Q Model. Bulletin of the Seismological Society of America, 93(6): 2649 2663.

Gee, L., Neuhauser, D., Dreger, D., Uhrhammer, R., Romanowicz, B. and Pasyanos, M. (2003): The Rapid Data Integration Project. International Handbook of Earthquake and Engineering Seismology, 81B: 1261 - 1273.

GeoNet: DELTA. http://magma.geonet.org.nz/delta/app, downloaded 3 October 2007.

GeoNet: Hypocentre derivation. http://www.geonet.org.nz/resources/earthquake/hypocentrederivation.html, downloaded 1 October 2007.

Global CMT Project: Global CMT Catalog. http://www.globalcmt.org/CMTsearch.html, downloaded 2006, 2007.

GNS Science: GeoNet Quake Search. http://magma.geonet.org.nz/resources/quakesearch/index.jsp, downloaded 2006,2007.

Goldstein, P., Dodge, D., Firpo. M. and Minner, L. (2003): SAC2000: Signal Processing and Analysis Tools for Seismologists and Engineers. International Handbook of Earthquake and Engineering Seismology, 81B: 1613 - 1614.

Guralp Systems: CMG-3ESP. www.guralp.net/products/3ESP/, downloaded 13 July 2007. Guralp Systems: CMG-40T. www.guralp.net/products/40T/, downloaded 13 July 2007. 
Hanks, T.C. and Kanamori, H. (1979): A Moment Magnitude Scale. Journal of Geophysical Research, 84(B5): $2348-2350$.

Jost, M.L. and Hermann, R.B. (1989): A student's guide to and review of moment tensors. Seismological Research Letters, 60(2): 37 - 57.

Kagan, Y.Y. (2007): Simplified algorithms for calculating double-couple rotation. Geophysical Journal International, 171: 411 - 418, doi: 10.1111/j.1365-246X.2007.03438.x.

Kawakatsu, H. (1995): Automated near-realtime CMT inversion. Geophysical Research Letters, 22(19): 2569 - 2572.

Lamb, S.H. and Bibby, H.M. (1989): The last 25 Ma of rotational deformation in part of the New Zealand plate boundary zone. Journal of Structural Geology, 11: 473 - 492.

Matcham, I. (1999): Source mechanism determination using broadband data in the New Zealand seismic environment. MSc thesis, Victoria University of Wellington, New Zealand.

Matcham, I., Savage, M.K., Taber, J.J. and Reyners, M. (2006): Earthquake source mechanism analysis for events between 1992 and 1997 using sparse New Zealand broadband data. New Zealand Journal of Geology \& Geophysics, 49: 75 - 89.

McGinty, P., Reyners, M. and Robinson, R. (2000): Stress directions in the shallow part of the Hikurangi subduction zone, New Zealand, from the inversion of earthquake first motions. Geophysical Journal International, 142: 339 - 350.

Nicol, A., Mazengarb, C., Chanier, F., Rait, G., Uruski, C. and Wallace, L. (2007): Tectonic evolution of the active Hikurangi subduction margin, New Zealand, since the Oligocene. Tectonics, 26: TC4002, doi:1029/2006TC002090.

Pancha, A., Webb, T., Chadwick, M. (2005): Rapid size estimation of very large New Zealand earthquakes for damage assessment and tsunami warning. In press, New Zealand Journal of Geology \& Geophysics. 
Pasyanos, M.E., Dreger, D.S. and Romanowicz, B. (1996): Toward Real-Time Estimation of Regional Moment Tensors. Bulletin of the Seismological Society of America, 86(5): 1255 1269.

Press, W.H., Teukolsky, S.A., Vetterling, W.T. and Flannery, B.P. (1988): Numerical Recipes in C. Cambridge University Press, Cambridge.

Reyners, M. (1998): Plate coupling and the hazard of large subduction thrust earthquakes at the Hikurangi subduction zone, New Zealand. New Zealand Journal of Geology \& Geophysics, 41: 343 - 354.

Reyners. M., Robinson, R. and McGinty, P. (1997): Plate coupling in the northern South Island and southernmost North Island, New Zealand, as illuminated by earthquake focal mechanisms. Journal of Geophysical Research, 102(B7): 15197 - 15210.

Richter, C.F. (1935): An instrumental magnitude scale. Bulletin of the Seismological Society of America, 25: 1 - 32.

Ristau, J., Rodgers, G.C. and Cassidy, J.F. (2003): Moment Magnitude - Local Magnitude Calibration for Earthquakes off Canada's West Coast. Bulletin of the Seismological Society of America, 93(5): 2296 - 2300.

Ristau, J., Rodgers, G.C. and Cassidy, J.F. (2005): Moment Magnitude - Local Magnitude Calibration for Earthquakes in Western Canada. Bulletin of the Seismological Society of America, 95(5): 1994 - 2000, doi: 10.1785/0120050028.

Robinson, R. (1986): Seismicity, structure and tectonics of the Wellington region, New Zealand. Geophysical Journal of the Royal Astronomical Society, 87: 379 - 409.

Romanowicz, B., Dreger, D., Pasyanos, M. and Uhrhammer, R. (1993): Monitoring of strain release in central and northern California using broadband data. Geophysical Research Letters, 20(15): 1643 - 1646.

Rueda, J. and Mezcua, J. (2005): Near real-time Seismic Moment-tensor Determination in Spain. Seismological Research Letters, 76(4): 455 - 465. 
Sipkin, S.A. (1994): Rapid determination of global moment-tensor solutions. Geophysical Research Letters, 21(16): 1667 - 1670.

Smith. E.G.C, Stern, T. and Reyners, M. (1989): Subduction and Back-Arc Activity at the Hikurangi Convergent Margin, New Zealand. Pure and Applied Geophysics, 129: 203 - 231.

Stein, S. and Wysession, M. (2003): An Introduction to Seismology, Earthquakes, and Earth Structure. Blackwell Publishing, 498 pp.

Streckeisen: Streckeisen STS-2. www.kinemetrics.com/PDFs/sts2-1.pdf, downloaded 1 October 2007.

Tajima, F., Mégnin, C., Dreger, D.S. and Romanowicz, B. (2002): Feasibility of Real-Time Broadband Waveform Inversion for Simultaneous Moment Tensor and Centroid Location Determination. Bulletin of the Seismological Society of America, 92(2): 739 - 750.

Wallace, L.M., Beavan, J., McCaffrey, R. and Darby, D. (2004): Subduction zone coupling and tectonic block rotations in the North Island, New Zealand. Journal of Geophysical Research, 109: B12406, doi:10.1029/2004JB003241.

Wellman, H.W. and Willett, R.W. (1942): The geology of the west coast from Abut Head to Milford Sound, Part I. Transactions of the Royal Society of New Zealand, 71: 282 - 306. 


\section{Appendix 1: Case Studies}

Results for the twenty-four earthquakes analysed are discussed fully in this section. Twentytwo earthquakes had Global CMT solutions, and two did not. The locations of the earthquakes discussed are shown in Figure A1.1. A variety of magnitudes and focal mechanisms were calculated for each earthquake, and the best were determined where possible.

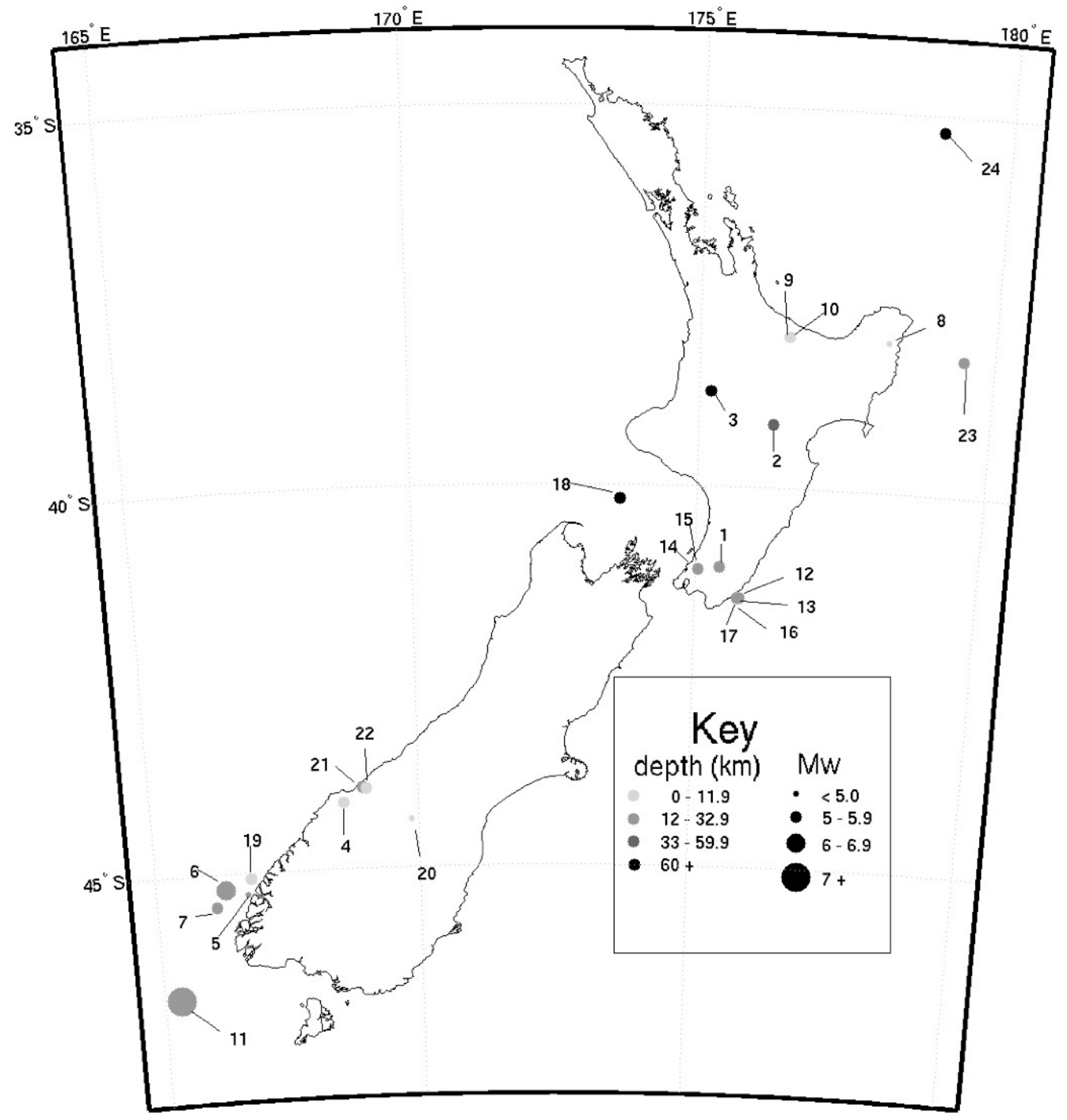

Figure A1.1. The locations of events discussed in this appendix. Locations and depths from GNS Science, Mw from the Global CMT project. The two events without Global CMT solutions show Mw values from this study. Earthquakes are numbered in chronological order, and are discussed in the appendix in this order. 


\section{A1.1. Event 1502698 - Wairarapa}

29 March 2000, 1430 UT

Latitude -41.06 , Longitude: 175.43, depth: $30.7 \pm 0.8 \mathrm{~km}(\mathrm{GNS})$

Depth $46.4 \mathrm{~km}$ (Global CMT)

ML 5.4 (GNS), Mw 5.2 (Global CMT)

$\begin{array}{llllll}\text { Global CMT focal plane 1: } & \text { strike } 54 \text { rake } & -76 & \text { dip } & 14\end{array}$

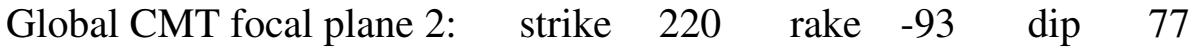

Data from three stations, at distances of $315-370 \mathrm{~km}$ and azimuths of $1^{\circ}-255^{\circ}$ from the epicentre, and listed in Table A1.1, were used to compute seismic moment tensor solutions for this earthquake.

Table A1.1:

\begin{tabular}{|l|l|c|c|}
\hline $\begin{array}{l}\text { Station } \\
\text { code }\end{array}$ & Station name & $\begin{array}{l}\text { Distance from } \\
\text { earthquake }\end{array}$ & $\begin{array}{l}\text { Azimuth from } \\
\text { earthquake }\end{array}$ \\
\hline DSZ & Denniston North & $315 \mathrm{~km}$ & $255^{\circ}$ \\
\hline TOZ & Tahuroa Road & $370 \mathrm{~km}$ & $1^{\circ}$ \\
\hline MQZ & McQueen's Valley & $370 \mathrm{~km}$ & $220^{\circ}$ \\
\hline
\end{tabular}

This event was processed with the New Zealand standard velocity model and with a frequency pass-band filter of $0.03-0.06 \mathrm{~Hz}$. Various depths between $15 \mathrm{~km}$ and $40 \mathrm{~km}$ were tested. For each depth, the solution with the highest variance reduction was chosen as the best solution for that depth.

The calculated magnitudes range from Mw 5.0 for solutions at depths of 15 and $20 \mathrm{~km}$, to Mw 5.3 for solutions with depths of $33-40 \mathrm{~km}$. The solution with the highest double-couple component has a depth of $32 \mathrm{~km}$, with a magnitude of Mw 5.2 and a double-couple component of $86 \%$.

The focal mechanisms are mostly strike-slip for the solutions with depths of 15 and $20 \mathrm{~km}$, are normal slip for solutions with depths of $25-31 \mathrm{~km}$, and are mostly strike-slip for solutions with depths of $32-40 \mathrm{~km}$. The Global CMT solution is normal-slip, similar to the $25-31 \mathrm{~km}$ deep solutions. The solution with the highest double-couple component, with a depth of $32 \mathrm{~km}$, is strike-slip. The mechanism is not constrained by these solutions.

The best depth is chosen as the depth with the highest double-couple component, at $32 \mathrm{~km}$ depth. The moment magnitude calculated for this solution matches the moment magnitude of the Global CMT solution, but the mechanism does not. The best solution is shown in Figure A1.2. 


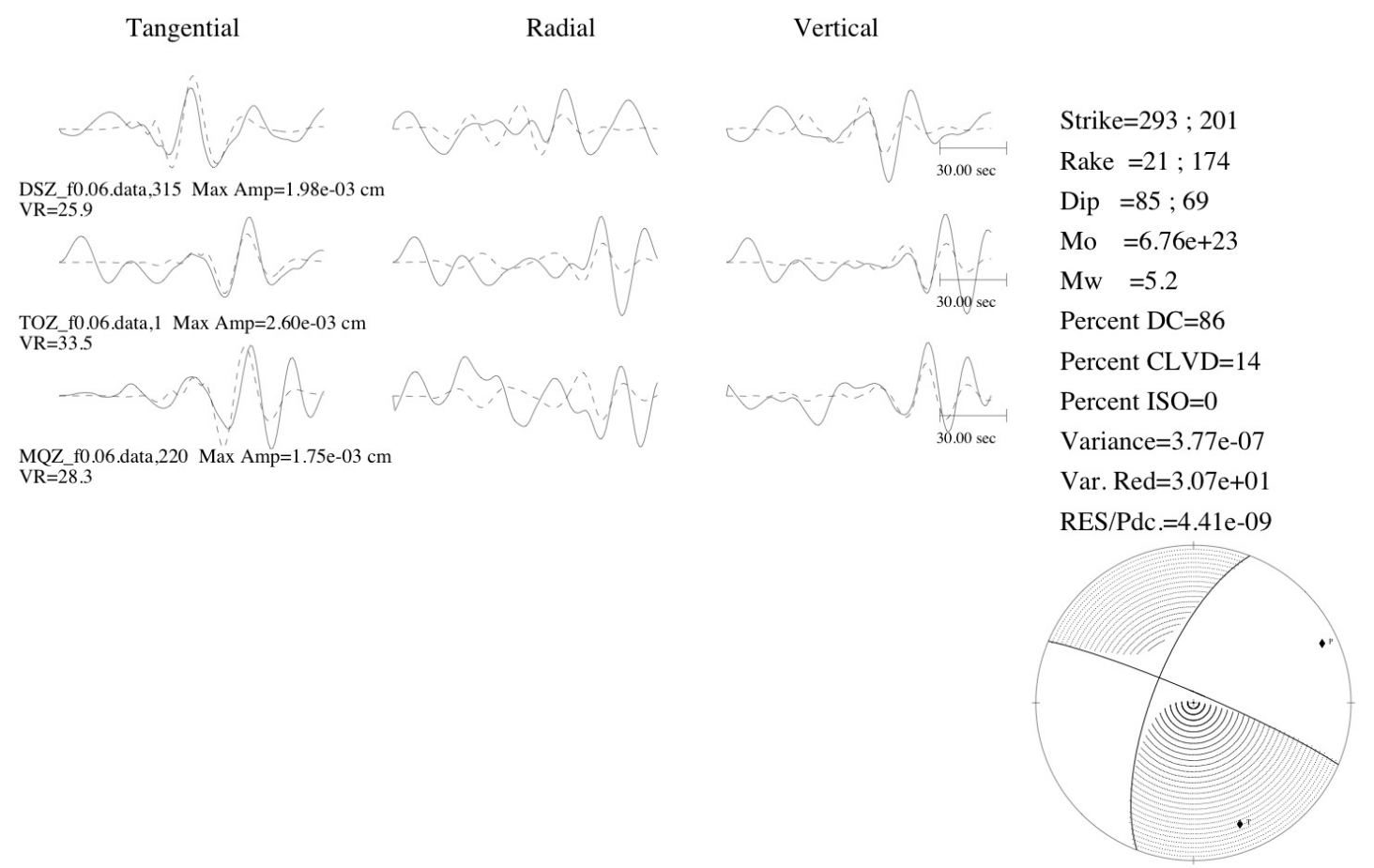

Figure A1.2. The best solution calculated for event 1502698, depth $32 \mathrm{~km}$. 


\section{A1.2. Event 1597193 - Taupo}

8 August 2000, 1031 UT

Latitude -39.16, Longitude 176.28, depth: $50.2 \pm 2.5 \mathrm{~km}$ (GNS)

Depth $67.8 \mathrm{~km}$ (Global CMT)

ML 6.2 (GNS), Mw 5.3 (Global CMT)

Global CMT focal plane 1: $\quad$ strike 32 rake 179 dip 25

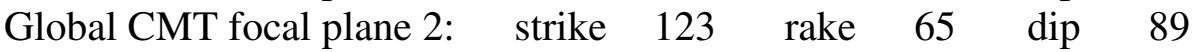

Data from four stations, at distances of $120-590 \mathrm{~km}$ and azimuths of $83^{\circ}-337^{\circ}$ from the epicentre, and listed in Table A1.2, were used to compute seismic moment tensor solutions for this earthquake.

Table A1.2:

\begin{tabular}{|l|l|c|c|}
\hline $\begin{array}{l}\text { Station } \\
\text { code }\end{array}$ & Station name & $\begin{array}{l}\text { Distance from } \\
\text { earthquake }\end{array}$ & $\begin{array}{l}\text { Azimuth from } \\
\text { earthquake }\end{array}$ \\
\hline KNZ & Kokohu & $120 \mathrm{~km}$ & $83^{\circ}$ \\
\hline TOZ & Tahuroa Road & $170 \mathrm{~km}$ & $337^{\circ}$ \\
\hline DSZ & Denniston North & $475 \mathrm{~km}$ & $231^{\circ}$ \\
\hline MQZ & McQueen's Valley & $590 \mathrm{~km}$ & $210^{\circ}$ \\
\hline
\end{tabular}

This event was processed with the New Zealand standard velocity model and with a frequency pass-band filter of $0.03-0.06 \mathrm{~Hz}$. Solutions were calculated for various depths between $20 \mathrm{~km}$ and $80 \mathrm{~km}$. For each depth, the solution with the highest variance reduction was chosen as the best solution for that depth. The event was processed with data from the four stations KNZ, TOZ, DSZ, and MQZ, and also with data from the three stations KNZ, TOZ, and DSZ. The best solution calculated was calculated with three stations, has a magnitude of Mw 5.4, a depth of $70 \mathrm{~km}$, shows reverse/strike-slip faulting, and is shown in Figure A1.3.

\section{Four stations}

Moment magnitudes calculated using data from the four stations in Table A1.2 range from Mw 5.0 (at depths of $20 \mathrm{~km}, 25 \mathrm{~km}$, and $32 \mathrm{~km}$ ) to Mw 5.5 (at a depth of $80 \mathrm{~km}$ ). Focal mechanisms are strike-slip/reverse for solutions with depths of $20-25 \mathrm{~km}$, normal/strike-slip for the solution with a depth of $30 \mathrm{~km}$, reverse/strike-slip for the $32 \mathrm{~km}$ deep solution, normal-slip for solutions with depths of $34-37 \mathrm{~km}$, reverse-slip for solutions with depths of $40-53 \mathrm{~km}$, reverse/strike-slip for solutions with depths of $54-55 \mathrm{~km}$, normal-slip for solutions with depths of $56-60 \mathrm{~km}$, reverse/strike-slip for solutions with depths of $65-70$ $\mathrm{km}$, and normal-slip for solutions with depths of $75-80 \mathrm{~km}$. The solution with the highest double-couple component has a depth of $37 \mathrm{~km}$, a magnitude of Mw 5.2, and a normal faulting mechanism. Another solution with a very high double-couple component occurs at a depth of $55 \mathrm{~km}$. This solution has a magnitude of Mw 5.4, and the focal mechanism shows reverse/strike-slip faulting. None of the fits of the synthetics seismograms to the data are very good. Neither the earthquake depth nor the focal mechanism can be constrained by this analysis, and the variation in values of $\mathrm{Mw}$ is fairly high. 


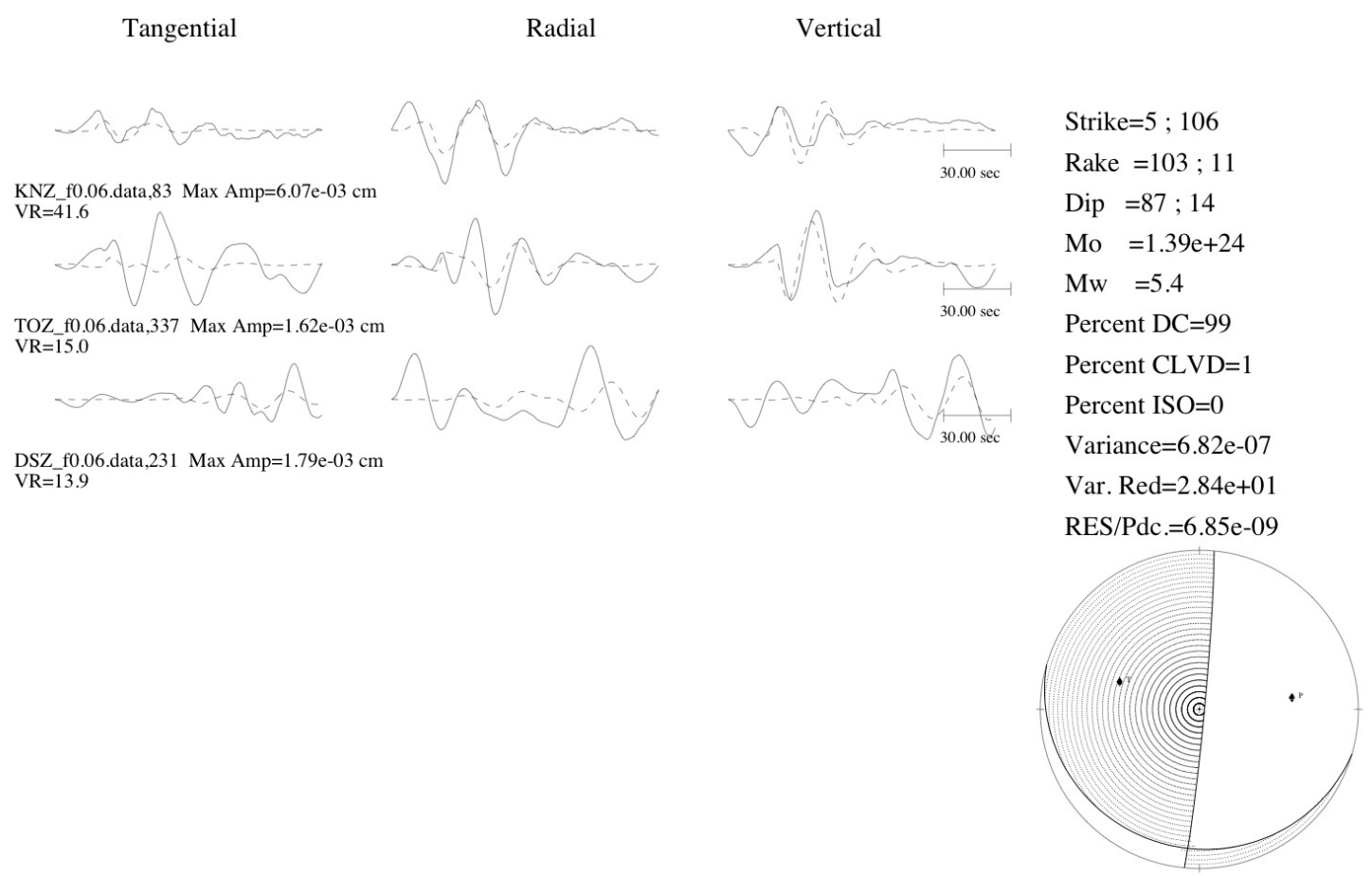

Figure A1.3. The best solution calculated for event 1597193, depth $70 \mathrm{~km}$.

\section{Three stations}

The three stations KNZ, TOZ, and DSZ lie at distances of $120 \mathrm{~km}$ to $475 \mathrm{~km}$ from the earthquake epicentre, with an azimuthal range of $254^{\circ}$. The calculated moment magnitudes are from Mw 4.9 (at a depth of $20 \mathrm{~km}$ ) to $\mathrm{Mw} 5.4$ (at depths of $60-80 \mathrm{~km}$ ). Focal mechanisms are mostly normal-slip for the $20-28 \mathrm{~km}$ deep solutions, strike-slip/normal-slip for the $30 \mathrm{~km}$ deep solution, reverse-strike-slip for the $32 \mathrm{~km}$ deep solution, mostly normalslip for the $35 \mathrm{~km}$ deep solution, vertical dip-slip for the $40-52 \mathrm{~km}$ deep solutions, reverse/strike-slip for the $55-68 \mathrm{~km}$ deep solutions, and mostly reverse-slip for the $70-80$ $\mathrm{km}$ deep solutions. The solution with the highest double-couple component (the best solution, shown in Figure A1.3) has a depth of $70 \mathrm{~km}$, magnitude Mw 5.4, and the focal mechanism shows reverse faulting. The fits of the synthetic seismograms to the data are all fairly poor.

\section{Summary}

Magnitudes of Mw 4.9 - Mw 5.5 were calculated for this event. The best solution (calculated with three stations) has a magnitude of Mw 5.4. These agree with the Mw 5.3 calculated by the Global CMT project.

The depth of the best solution is $70 \mathrm{~km}$, which agrees with the depth calculated by the Global CMT project.

The best solution has a reverse/strike-slip faulting mechanism, but the fits of the synthetic seismograms to the data were poor, so this can not be constrained. The reverse/strike-slip mechanisms do not match the Global CMT project mechanism. 
Appendix 1: Case studies

A1.2 Event 1597193 - Taupo

The poor fits of the synthetic seismograms to the data are not surprising, as two of the stations used (DSZ at $475 \mathrm{~km}$ and MQZ at $590 \mathrm{~km}$ ) are outside the recommended distance range of $100 \mathrm{~km}$ to $400 \mathrm{~km}$. 
Appendix 1: Case studies 


\section{A1.3. Event 1737299 - King Country}

24 May 2001, 1807 UT

Latitude -38.77 , Longitude 175.20, depth $234.3 \pm 1.6 \mathrm{~km}$ (GNS)

Depth $248.1 \mathrm{~km}$ (Global CMT)

ML 6.5 (GNS), Mw 5.4 (Global CMT)

Global CMT focal plane 1: $\quad$ strike 56 rake $158 \quad$ dip 57

Global CMT focal plane 2: $\quad$ strike 158 rake 35 dip 72

There were two suitable stations in the $100 \mathrm{~km}-400 \mathrm{~km}$ suitable distance range for this event, TOZ and PWZ. A third station, DSZ, at $440 \mathrm{~km}$ from the earthquake, was also used. These stations are listed in Table A1.3. The azimuthal coverage was $207^{\circ}$.

Table A1.3:

\begin{tabular}{|l|l|c|c|}
\hline $\begin{array}{l}\text { Station } \\
\text { code }\end{array}$ & Station name & $\begin{array}{l}\text { Distance from } \\
\text { earthquake }\end{array}$ & $\begin{array}{l}\text { Azimuth from } \\
\text { earthquake }\end{array}$ \\
\hline TOZ & Tahuroa Road & $120 \mathrm{~km}$ & $13^{\circ}$ \\
\hline PWZ & Pawanui & $200 \mathrm{~km}$ & $135^{\circ}$ \\
\hline DSZ & Denniston North & $440 \mathrm{~km}$ & $220^{\circ}$ \\
\hline
\end{tabular}

This event was processed using the New Zealand standard velocity model, and a frequency pass-band filter of $0.03-0.06 \mathrm{~Hz}$. Seismic moment tensor solutions were calculated for depths $200 \mathrm{~km}, 230 \mathrm{~km}, 240-260 \mathrm{~km}$ at $5 \mathrm{~km}$ intervals, and $300 \mathrm{~km}$. For each depth the solution with the highest variance reduction was chosen as the best solution for that depth.

For all depths the calculated moment magnitude was Mw 5.4, the same as the magnitude calculated by the Global CMT project. Focal mechanisms are strike-slip/reverse for the 200 and $230 \mathrm{~km}$ deep solutions, strike-slip/normal for the $240 \mathrm{~km}$ deep solution, mostly strikeslip for the $245 \mathrm{~km}$ deep solution, normal/strike-slip for the $250 \mathrm{~km}$ deep solution, mostly strike-slip for the $255-260 \mathrm{~km}$ deep solutions, and reverse/strike-slip for the $300 \mathrm{~km}$ deep solution. The fits of the synthetic seismograms to the data are generally poor, with a few traces fitting reasonably.

The best solution, with the maximum double-couple component of $79 \%$, was the $250 \mathrm{~km}$ deep solution. The depth agrees with the depth calculated by the Global CMT Project. The mechanisms do not agree. The best solution is shown in Figure A1.4.

The match between the best solution calculated using the TDMT_INVC algorithm and the Global CMT solution is surprisingly good, especially as one of the stations was outside the distance range recommended. The faulting mechanism was not constrained by the solutions calculated. 


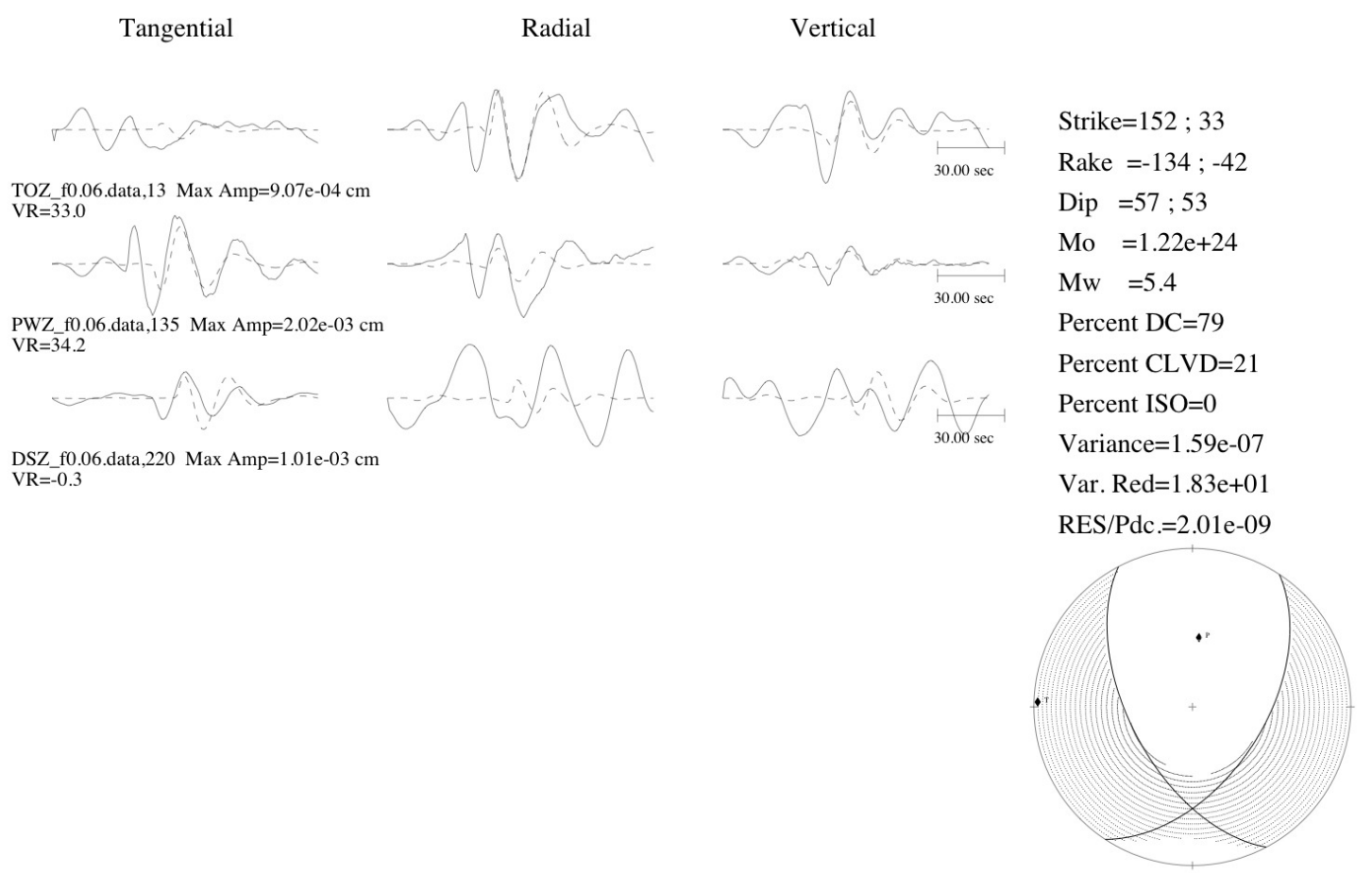

Figure A1.4. The best solution calculated for event 1737299, depth $250 \mathrm{~km}$. 


\section{A1.4. Event 1825324 - Haast}

7 December 2001, 1927 UT

Latitude -44.13, Longitude 168.61, depth $5 \mathrm{~km}$ (restricted) (GNS)

Depth $15.0 \mathrm{~km}$ (Global CMT)

ML 6.2 (GNS), Mw 5.8 (Global CMT)

Global CMT focal plane 1: $\quad$ strike 41 rake $116 \quad$ dip 35

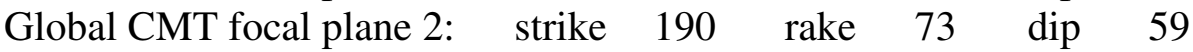

Data from three stations, at distances of $200-370 \mathrm{~km}$ and azimuths of $46^{\circ}-195^{\circ}$ from the epicentre, and listed in Table A1.4, were used to compute seismic moment tensor solutions for this earthquake.

Table A1.4:

\begin{tabular}{|l|l|c|c|}
\hline $\begin{array}{l}\text { Station } \\
\text { code }\end{array}$ & Station name & $\begin{array}{l}\text { Distance from } \\
\text { earthquake }\end{array}$ & $\begin{array}{l}\text { Azimuth from } \\
\text { earthquake }\end{array}$ \\
\hline WHZ & Wether Hill Road & $200 \mathrm{~km}$ & $195^{\circ}$ \\
\hline MQZ & McQueen's Valley & $330 \mathrm{~km}$ & $83^{\circ}$ \\
\hline DSZ & Denniston North & $370 \mathrm{~km}$ & $46^{\circ}$ \\
\hline
\end{tabular}

This earthquake was processed using the New Zealand standard velocity model and a frequency band-pass filter of $0.03-0.06 \mathrm{~Hz}$. Solutions were calculated for depths of $5-35$ $\mathrm{km}$, with a depth increment of $5 \mathrm{~km}$. The solution with the highest double-couple component was chosen as the best solution for each depth.

The calculated moment magnitudes range from Mw 5.5 (with depths of $10 \mathrm{~km}$ and $25 \mathrm{~km}$ ) to Mw 5.8 (with a depth of $35 \mathrm{~km}$ ). The $5 \mathrm{~km}$ deep solution shows normal faulting, the $10 \mathrm{~km}$ deep solution shows strike-slip reverse faulting, the $15 \mathrm{~km}$ deep solution shows normal/strike-slip faulting, and the $20-35 \mathrm{~km}$ deep solutions show reverse/strike-slip faulting. The fits of the synthetic seismograms to the data are fairly poor for all solutions. The solution with the highest variance reduction has a depth of $5 \mathrm{~km}$ and a moment magnitude of $\mathrm{Mw}$ 5.7. This is the best solution, and is shown in Figure A1.5.

The best solution calculated had a moment magnitude of Mw 5.7, slightly less than the Global CMT moment magnitude of Mw 5.8. The value Mw 5.8 is the maximum Mw calculated using the TDMT_INVC method. The focal mechanism was not accurately resolved. 


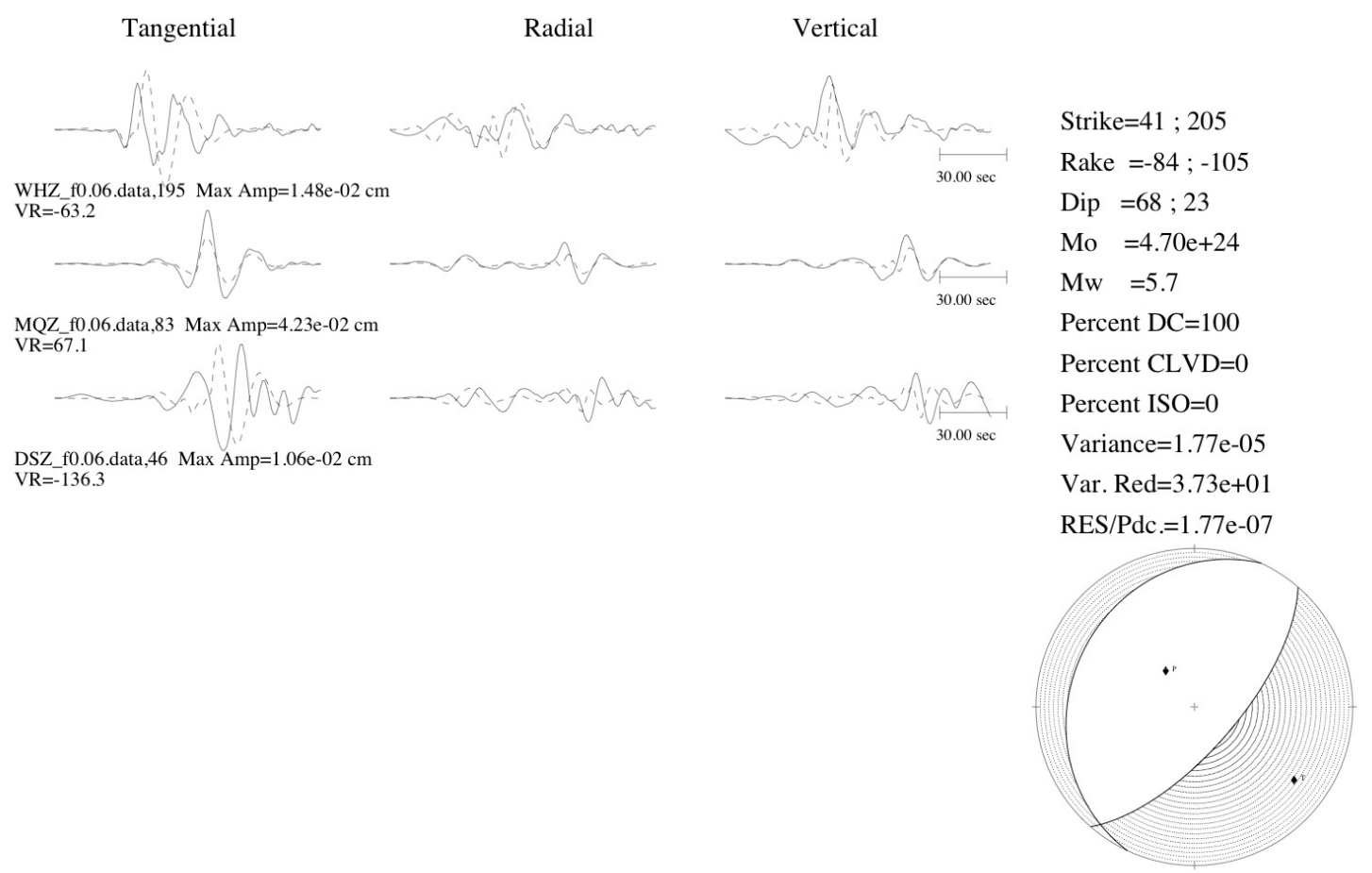

Figure A1.5 The best solution calculated for event 1825324, $5 \mathrm{~km}$ deep. 


\section{A1.5. Event 2114219 - Fiordland}

11 September 2003, 1756 UT

Latitude -45.27 , Longitude 166.73, depth $22.6 \pm 1.0 \mathrm{~km}(\mathrm{GNS})$

Depth $40.4 \mathrm{~km}$ (Global CMT)

ML 4.7 (GNS), Mw 4.9 (Global CMT)

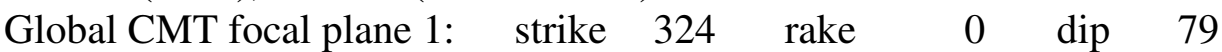

Global CMT focal plane 2: $\begin{array}{llllll}\text { strike } & 54 & \text { rake } & -169 & \text { dip } & 90\end{array}$

Data from four stations, at distances of $110-310 \mathrm{~km}$ and azimuths of $87^{\circ}-126^{\circ}$ from the epicentre, and listed in Table A1.5, were used to compute seismic moment tensor solutions for this earthquake.

\section{Table A1.5:}

\begin{tabular}{|l|l|c|c|}
\hline $\begin{array}{l}\text { Station } \\
\text { code }\end{array}$ & Station name & $\begin{array}{l}\text { Distance from } \\
\text { earthquake }\end{array}$ & $\begin{array}{l}\text { Azimuth from } \\
\text { earthquake }\end{array}$ \\
\hline MLZ & Mavora Lakes & $110 \mathrm{~km}$ & $96^{\circ}$ \\
\hline WHZ & Wether Hill Road & $120 \mathrm{~km}$ & $126^{\circ}$ \\
\hline TUZ & Tuapeka & $240 \mathrm{~km}$ & $109^{\circ}$ \\
\hline ODZ & Otahua Downs & $310 \mathrm{~km}$ & $87^{\circ}$ \\
\hline
\end{tabular}

This event was processed with the New Zealand standard velocity model and with a 0.03 $0.06 \mathrm{~Hz}$ frequency pass-band filter. Solutions were calculated for several depths using all four stations, and with sets of three stations. Seismic moment tensor solutions were also calculated using a $0.05-0.10 \mathrm{~Hz}$ frequency pass-band filter, with all four stations and one set of three stations. For each depth, the solution with the highest double-couple component was chosen as the best solution for that depth.

The best solution was calculated with the three stations WHZ, TUZ, and ODZ, the 0.03 $0.06 \mathrm{~Hz}$ frequency band-pass filter, and a depth of $10 \mathrm{~km}$. The solution has a magnitude of Mw 4.4, a normal faulting mechanism, and is shown in Figure A1.6.

\section{Four stations MLZ, WHZ, TUZ \& ODZ, 0.03 - 0.06 Hz filter}

The four stations MLZ, WHZ, TUZ and ODZ lie at distances of $110-310 \mathrm{~km}$ from the earthquake epicentre, and with an azimuthal range of $39^{\circ}$. Using the $0.03-0.06 \mathrm{~Hz}$ frequency pass-band filter seismic moment tensor solutions were calculated for depths of 20 $-50 \mathrm{~km}$ with an increment of $5 \mathrm{~km}$. The calculated magnitudes range from $\mathrm{Mw} 4.3$ (with a depth of $30 \mathrm{~km}$ ) to $\mathrm{Mw} 4.7$ (with a depth of $50 \mathrm{~km}$ ). Focal mechanisms are strike-slip for a depth of $20 \mathrm{~km}$, reverse for depths of $25-35 \mathrm{~km}$, and mostly strike-slip for depths of $40-50$ $\mathrm{km}$. The fits of the synthetic seismograms to the data are all poor. There is no large peak in the variance reduction, and no way to pick a best depth, moment magnitude or focal mechanism.

\section{Four stations MLZ, WHZ, TUZ \& ODZ, 0.05 - $0.10 \mathrm{~Hz}$ filter}

Solutions were also calculated using the four stations MLZ, WHZ, TUZ and ODZ and a 0.05 $-0.10 \mathrm{~Hz}$ frequency pass-band filter. Solutions were calculated for depths of $0-50 \mathrm{~km}$ with an increment of $10 \mathrm{~km}$. Moment magnitudes range from $\mathrm{Mw} 4.2$ (for the $10 \mathrm{~km}$ depth solution) to $\mathrm{Mw} 4.7$ (for the $50 \mathrm{~km}$ depth solution). The $0 \mathrm{~km}$ deep solution has a reverse 
faulting mechanism, the $10-30 \mathrm{~km}$ deep solutions have mostly strike-slip faulting mechanisms, the $40 \mathrm{~km}$ deep solution has a reverse/strike-slip faulting mechanism, and the $50 \mathrm{~km}$ deep solution has a strike-slip/normal faulting mechanism. Again, the fits of the synthetic seismograms to the data are fairly poor, there is no large peak in the variance reduction, and no way to pick a best depth, moment magnitude or focal mechanism.

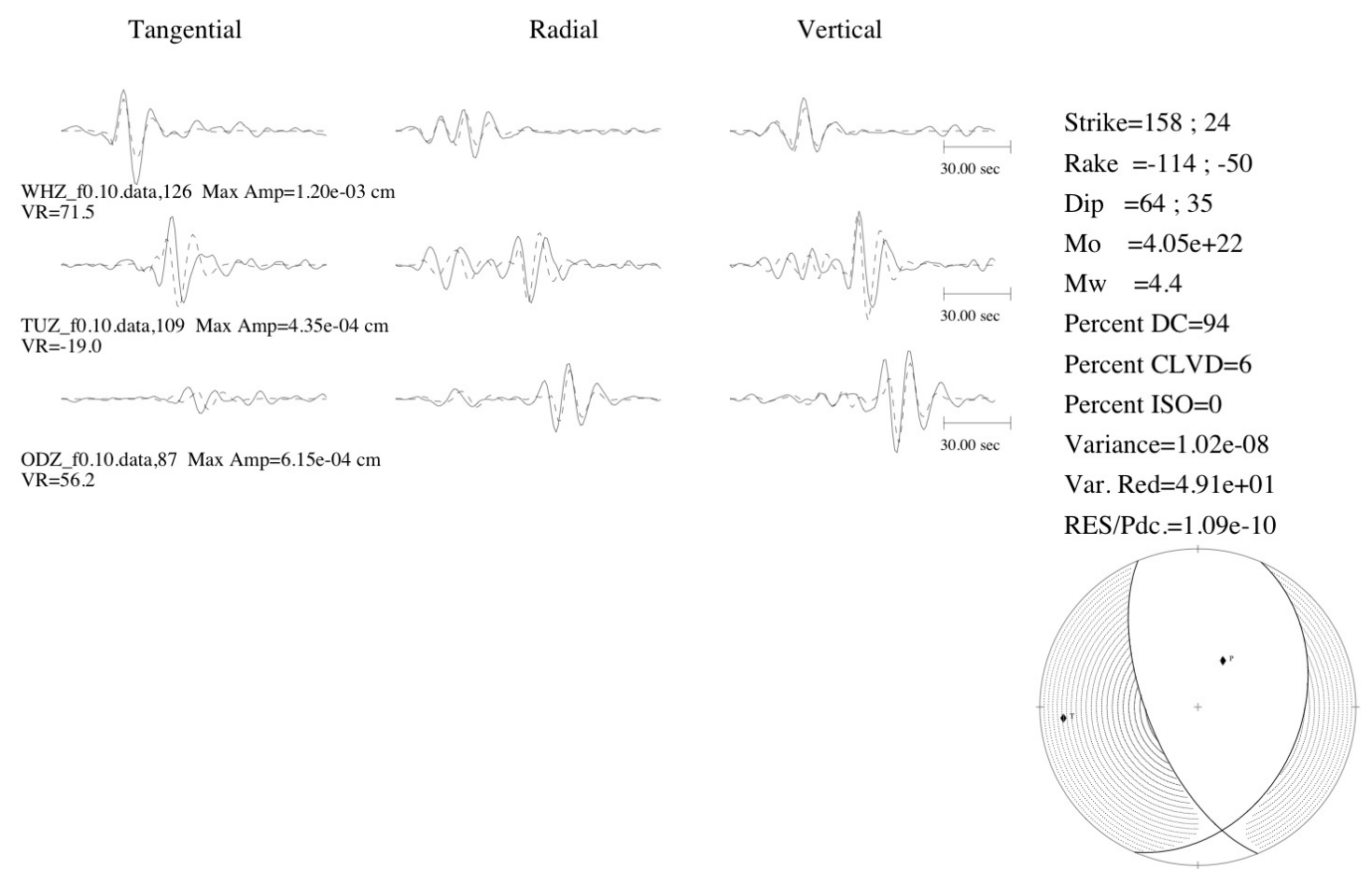

Figure A1.6. The best solution calculated for event 2114219, using a frequency filter of 0.03 $-0.06 \mathrm{~Hz}$ and a source depth of $10 \mathrm{~km}$.

\section{Three stations MLZ, WHZ \& TUZ, $0.03-0.06 \mathrm{~Hz}$ filter}

The three stations MLZ, WHZ and TUZ lie at distances of $110-240 \mathrm{~km}$ from the earthquake epicentre, and with an azimuthal range of $30^{\circ}$. Using the $0.03-0.06 \mathrm{~Hz}$ frequency pass-band filter seismic moment tensor solutions were calculated for depths of $25-55 \mathrm{~km}$ with an increment of $5 \mathrm{~km}$. The calculated magnitudes range from Mw 4.1 (with a depth of $35 \mathrm{~km}$ ) to Mw 4.8 (with a depth of $50 \mathrm{~km}$ ). Focal mechanisms are strike-slip at $25-30 \mathrm{~km}$ depth, reverse at $35 \mathrm{~km}$, reverse/strike-slip at $40 \mathrm{~km}$, and strike-slip at $45-55 \mathrm{~km}$. The fits of the synthetic seismograms to the data are all fairly poor. There is no large peak in the variance reduction, and no way to pick a best depth, moment magnitude or focal mechanism.

\section{Three stations MLZ, WHZ \& ODZ, $0.03-0.06 \mathrm{~Hz}$ filter}

The three stations MLZ, WHZ and ODZ lie at distances of $110-310 \mathrm{~km}$ from the earthquake epicentre, and with an azimuthal range of $39^{\circ}$. Using the $0.03-0.06 \mathrm{~Hz}$ frequency pass-band filter seismic moment tensor solutions were calculated for depths of $30-50 \mathrm{~km}$ with an increment of $5 \mathrm{~km}$. The calculated magnitudes range from $\mathrm{Mw} 4.3$ (with a depth of $30 \mathrm{~km}$ ) to $\mathrm{Mw} 4.7$ (at depths of 45 and $50 \mathrm{~km}$ ). Focal mechanisms are strike-slip at $30 \mathrm{~km}$ depth, reverse/strike-slip at $35 \mathrm{~km}$, and strike-slip at $40-50 \mathrm{~km}$. The fits of the synthetic 
seismograms to the data are all poor. There is no large peak in the variance reduction, and no way to pick a best depth, moment magnitude or focal mechanism.

\section{Three stations MLZ, TUZ \& ODZ, $0.03-0.06 \mathrm{~Hz}$ filter}

The three stations MLZ, TUZ and ODZ lie at distances of $110-310 \mathrm{~km}$ from the earthquake epicentre, and with an azimuthal range of $22^{\circ}$. Using the $0.03-0.06 \mathrm{~Hz}$ frequency pass-band filter seismic moment tensor solutions were calculated for depths of $30-50 \mathrm{~km}$ with an increment of $5 \mathrm{~km}$. The calculated magnitudes range from $\mathrm{Mw} 4.3$ (with a depth of $30 \mathrm{~km}$ ) to Mw 4.5 (with depths of $35-45 \mathrm{~km}$ ). Focal mechanisms are strike-slip at $30 \mathrm{~km}$ depth, reverse-slip at $35-45 \mathrm{~km}$, and strike-slip at $50 \mathrm{~km}$. The fits of the synthetic seismograms to the data are all poor. There is no large peak in the variance reduction, and no way to pick a best depth, moment magnitude or focal mechanism.

\section{Three stations WHZ, TUZ \& ODZ, $0.03-0.06 \mathrm{~Hz}$ filter}

The three stations WHZ, TUZ and ODZ lie at distances of $120-310 \mathrm{~km}$ from the earthquake epicentre, and with an azimuthal range of $39^{\circ}$. Using the $0.03-0.06 \mathrm{~Hz}$ frequency pass-band filter seismic moment tensor solutions were calculated for depths of $30-50 \mathrm{~km}$ with an increment of $5 \mathrm{~km}$. The calculated magnitudes range from $\mathrm{Mw} 4.3$ (with a depth of $30 \mathrm{~km}$ ) to $\mathrm{Mw} 4.7$ (at depths of $40-45 \mathrm{~km}$ ). Focal mechanisms are reverse-slip at $30-35 \mathrm{~km}$ depth, strike-slip at $40-45 \mathrm{~km}$, and normal/strike-slip at $50 \mathrm{~km}$. The fits of the synthetic seismograms to the data are all poor. There is no large peak in the variance reduction, and no way to pick a best depth, moment magnitude or focal mechanism.

\section{Three stations WHZ, TUZ \& ODZ, $0.05-0.10 \mathrm{~Hz}$ filter}

Solutions were also calculated using the three stations WHZ, TUZ and ODZ and a $0.05-$ $0.10 \mathrm{~Hz}$ frequency pass-band filter for depths of $0-50 \mathrm{~km}$ with an increment of $10 \mathrm{~km}$. Moment magnitudes range from Mw 4.3 (for the $30 \mathrm{~km}$ depth solution) to $\mathrm{Mw} 4.8$ (for the 50 $\mathrm{km}$ deep solution). The $0 \mathrm{~km}$ depth solution has a reverse faulting mechanism, the $10 \mathrm{~km}$ deep solution have a normal/strike-slip faulting mechanism, the $20 \mathrm{~km}$ deep solution has a reverse faulting mechanism, the $30 \mathrm{~km}$ deep solution has a strike-slip faulting mechanism, and the $40-50 \mathrm{~km}$ deep solutions have strike-slip/normal faulting mechanisms. Again, the fits of the synthetic seismograms to the data are mostly fairly poor. The variance reduction peaks at $10 \mathrm{~km}$, with a magnitude of $\mathrm{Mw} 4.4$ and a normal faulting mechanism. This suggests that this is the most accurate solution, and the synthetics and the data match up reasonably well for this solution. This solution is shown in Figure A1.6.

\section{Summary}

Magnitudes of Mw 4.1 - Mw 4.8 were calculated for this event.

Using the $0.03-0.06 \mathrm{~Hz}$ frequency band-pass filter the moment magnitude, depth or focal mechanism of the earthquake were not able to be constrained using any of the station sets, and none of the solutions obtained had good matches between the synthetic seismograms and the data.

Using the $0.05-0.10 \mathrm{~Hz}$ frequency band-pass filter and the four stations, none of the moment magnitude, depth or focal mechanism of the earthquake were able to be constrained, and none of the solutions obtained had good matches between the synthetic seismograms and the data. 
Using the $0.05-0.10 \mathrm{~Hz}$ frequency band-pass filter and the three stations WHZ, TUZ and ODZ, there was one solution with a reasonable match between the synthetic seismograms and the data, with a depth of $10 \mathrm{~km}$, a moment magnitude of Mw 4.4 and a normal faulting mechanism. The moment magnitude obtained by the Global CMT project is Mw 4.9, quite a lot higher than that obtained here. The normal-faulting mechanism obtained using this data is also quite different from the strike-slip solution obtained by the Global CMT project. 


\section{A1.6. Event 2137041 - Fiordland}

2 November 2003, 0532 UT

Latitude -45.20, Longitude 166.31, depth $17.1 \pm 3.7 \mathrm{~km}$ (GNS)

Depth $15 \mathrm{~km}$ (Global CMT)

ML 5.9 (GNS), Mw 6.4 (Global CMT)

Global CMT focal plane 1: $\quad$ strike 42 rake 115 dip 25

Global CMT focal plane 2: $\quad$ strike $195 \quad$ rake $79 \quad$ dip 68

Data from four stations, at distances of $145-340 \mathrm{~km}$ and azimuths of $89^{\circ}-122^{\circ}$ from the epicentre, and listed in Table A1.6, were used to compute seismic moment tensor solutions for this earthquake. Solutions were calculated using all four stations, and with sets of three stations, with azimuthal ranges of $20^{\circ}$ to $33^{\circ}$.

Table A1.6:

\begin{tabular}{|l|l|c|c|}
\hline $\begin{array}{l}\text { Station } \\
\text { code }\end{array}$ & Station name & $\begin{array}{l}\text { Distance from } \\
\text { earthquake }\end{array}$ & $\begin{array}{l}\text { Azimuth from } \\
\text { earthquake }\end{array}$ \\
\hline MLZ & Mavora Lakes & $145 \mathrm{~km}$ & $98^{\circ}$ \\
\hline WHZ & Wether Hill Road & $150 \mathrm{~km}$ & $122^{\circ}$ \\
\hline TUZ & Tuapeka & $270 \mathrm{~km}$ & $109^{\circ}$ \\
\hline ODZ & Otahua Downs & $340 \mathrm{~km}$ & $89^{\circ}$ \\
\hline
\end{tabular}

Solutions for this event were calculated using all four stations and with sets of three stations. The event was analysed using the New Zealand standard velocity model and a $0.03-0.06 \mathrm{~Hz}$ frequency band-pass filter. Using all four stations, and one set of three stations, a $0.02-0.05$ $\mathrm{Hz}$ frequency band-pass filter was also used. Seismic moment tensor solutions were calculated for depths of $5-35 \mathrm{~km}$ with a $5 \mathrm{~km}$ increment, and the best solution for each depth was chosen to be the solution with the highest double-couple component.

The best solution, shown in Figure A1.7, was calculated using the three stations WHZ, TUZ and ODZ, a $0.02-0.05 \mathrm{~Hz}$ frequency band-pass filter, and a depth of $30 \mathrm{~km}$. This solution has a magnitude of Mw 6.3 and a strike-slip/reverse faulting mechanism.

\section{Four Stations MLZ, WHZ, TUZ \& 0DZ, 0.03 - 0.06 Hz filter}

With the four stations MLZ, WHZ, TUZ, and ODZ and using the $0.03-0.06 \mathrm{~Hz}$ frequency band-pass filter, calculated moment magnitudes range from Mw 5.7 (at depths of 10 and 15 $\mathrm{km}$ ) to Mw 6.3 (at $35 \mathrm{~km}$ deep). Focal mechanisms are reverse for the $5 \mathrm{~km}$ deep solution, strike-slip for the $10 \mathrm{~km}$ deep solution, reverse/strike-slip for the $15 \mathrm{~km}$ deep solution, vertical dip-slip for the $20-25 \mathrm{~km}$ deep solutions, and reverse/strike-slip for the $30-35 \mathrm{~km}$ deep solutions. The fits of the synthetic seismograms to the data are all relatively poor. There are no large peaks in the variance reduction, and no obvious depth at which the best solution occurs.

\section{Four stations MLZ, WHZ, TUZ \& ODZ, 0.02 - 0.05 Hz filter}

Using all four stations and a $0.02-0.05 \mathrm{~Hz}$ frequency band-pass filter, calculated moment magnitudes range from Mw 5.9 (for depths of $10 \mathrm{~km}$ and $25 \mathrm{~km}$ ) to Mw 6.4 (with a depth of $35 \mathrm{~km}$ ). The fits of the synthetic seismograms to the data are all fairly poor, with some reasonably fitting traces. Focal mechanisms are reverse-slip for a depth of $5 \mathrm{~km}$, strike-slip for depths of $10-15 \mathrm{~km}$, strike-slip/reverse-slip for a depth of $20 \mathrm{~km}$, vertical dip-slip for 
depths of $25-30 \mathrm{~km}$, and reverse/strike-slip for a depth of $35 \mathrm{~km}$. The stations WHZ, TUZ and ODZ have the best fits. These stations were also tested with this frequency filter.

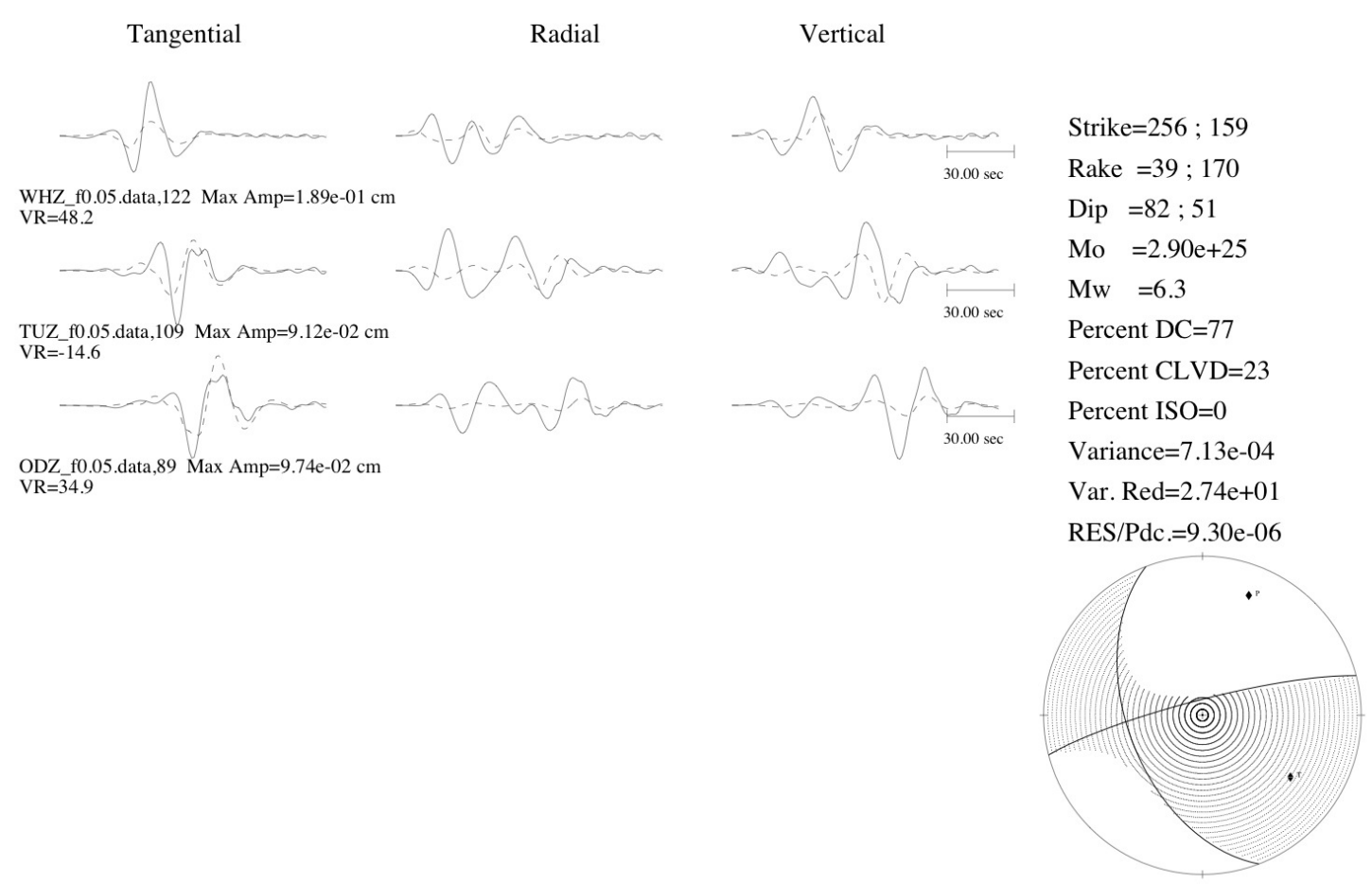

Figure A1.7. The best solution calculated for event 2137041. Calculated using a $0.02-0.05$ $\mathrm{Hz}$ frequency band-pass filter and a depth of $30 \mathrm{~km}$.

\section{Three stations MLZ, WHZ \& TUZ, 0.03 - 0.06 Hz filter}

The closest three stations in the $100-400 \mathrm{~km}$ distance range are MLZ, WHZ, and TUZ. These stations lie at distances of $145-270 \mathrm{~km}$ from the earthquake, and have an azimuthal range of $24^{\circ}$. Magnitudes calculated using the $0.03-0.06 \mathrm{~Hz}$ frequency band-pass filter range from $\mathrm{Mw} 5.8$ (at a depth of $10 \mathrm{~km}$ ) to $\mathrm{Mw} 6.4$ (at a depth of $35 \mathrm{~km}$ ). Again, there are a large variety of focal mechanisms, with reverse faulting at $5 \mathrm{~km}$, strike-slip/normal faulting at $10-20 \mathrm{~km}$ depths, strike-slip faulting at $25-30 \mathrm{~km}$ depths, and normal faulting at a depth of $35 \mathrm{~km}$. Again, the fits of the synthetic seismograms to the data are all reasonably poor, there is no major peak in the variance reduction, and no depth that is obviously the best.

\section{Three stations MLZ, WHZ \& ODZ, 0.03 - 0.06 Hz filter}

The stations MLZ, WHZ and ODZ lie at distance of $145-340 \mathrm{~km}$ from the epicentre, with an azimuthal range of $33^{\circ}$. Calculated moment magnitudes range from $\mathrm{Mw} 6.0$ (at $5 \mathrm{~km}$ deep) to Mw 6.4 (at $35 \mathrm{~km}$ deep). Focal mechanisms are strike-slip/normal for a depth of $5 \mathrm{~km}$, strike-slip for the $10 \mathrm{~km}$ deep solution, and normal/strike-slip for the $15-35 \mathrm{~km}$ deep solutions. Again, the fits of the synthetic seismograms to the data are all poor, there is no major peak in the variance reduction, and no best depth.

\section{Three stations MLZ, TUZ \& 0DZ, 0.03 - 0.06 Hz filter}

The stations MLZ, TUZ, and ODZ lie at distances of $145 \mathrm{~km}-340 \mathrm{~km}$ from the earthquake epicentre, with an azimuthal range of $20^{\circ}$. Calculated moment magnitudes range from $\mathrm{Mw}$ 
5.9 (at a depth of $25 \mathrm{~km}$ ) to Mw 6.3 (at a depth of $35 \mathrm{~km}$ ). Focal mechanisms range from reverse faulting at $5 \mathrm{~km}$ deep, to strike-slip at $10 \mathrm{~km}$ deep, to reverse at $15 \mathrm{~km}$ deep, to strikeslip/reverse at depths of $20-35 \mathrm{~km}$. There is no large peak in the variance reduction, no depths for which the synthetics fit the data well, and no best depth.

\section{Three stations WHZ, TUZ \& 0DZ, 0.03 - $0.06 \mathrm{~Hz}$ filter}

The stations WHZ, TUZ, and ODZ lie at distances of $150 \mathrm{~km}-340 \mathrm{~km}$ from the earthquake, with an azimuthal range of $33^{\circ}$. Moment magnitudes calculated using the $0.03-0.06 \mathrm{~Hz}$ frequency band-pass filter range from $\mathrm{Mw} 6.0$ (with a depth of $5 \mathrm{~km}$ ) to $\mathrm{Mw} 6.4$ (with a depth of $35 \mathrm{~km}$ ). Focal mechanisms are strike-slip for the $5 \mathrm{~km}$ deep solution and reverse/strike-slip for $10-35 \mathrm{~km}$ deep solutions. The fits of the synthetic seismograms to the data are poor for all depths; there is no major peak in the variance reduction, and no best depth.

\section{Three stations WHZ, TUZ \& ODZ, 0.02 - 0.05 Hz filter}

The stations WHZ, TUZ and ODZ had the best fits of the synthetic seismograms to the data when the four stations MLZ, WHZ, TUZ and ODZ were analysed with the $0.02-0.05 \mathrm{~Hz}$ frequency band-pass filter, so moment tensor solutions were also calculated using these three stations and the $0.02-0.05 \mathrm{~Hz}$ frequency band-pass filter. Calculated moment magnitudes range from Mw 6.1 (with a depth of $10 \mathrm{~km}$ ) to Mw 6.4 (with a depth of $35 \mathrm{~km}$ ). Focal mechanisms are reverse/strike-slip for all solutions. The best-fitting solution, with the highest variance reduction, has a depth of $30 \mathrm{~km}$, a moment magnitude of $\mathrm{Mw} 6.3$, shows strike-slip/reverse faulting, and is shown in Figure A1.7.

\section{Summary}

Magnitudes of Mw 5.7 - Mw 6.4 were calculated for this earthquake.

None of the computed solutions using the $0.03-0.06 \mathrm{~Hz}$ frequency band-pass filter show a good fit of the synthetic seismograms to the data. For none of the five sets of stations used are either the earthquake depth or moment magnitude able to be determined. There is quite a large range of possible magnitudes, from $\mathrm{Mw} 5.7$ to $\mathrm{Mw}$ 6.4. The magnitude calculated by the Global CMT project is Mw 6.4, which is high compared to those calculated using the TDMT_INVC method. Results from the MLZ, WHZ and ODZ and the WHZ, TUZ and ODZ solution sets suggest that the focal mechanism is mostly strike-slip with some reverseslip, which is different to the reverse-slip mechanism calculated by the Global CMT project. None of the other station sets were able to constrain the focal mechanism, and none were able to constrain the orientations of the fault planes.

The solutions computed using the $0.02-0.05 \mathrm{~Hz}$ frequency band-pass filter show better fits of the synthetic seismograms to the data and a magnitude range of Mw 5.9-Mw 6.4. With four stations none of the depth, magnitude, and focal mechanism can be constrained. Results from the three stations WHZ, TUZ and ODZ suggest that the earthquake had reverse/strikeslip faulting, a magnitude of Mw 6.3 and a depth of $30 \mathrm{~km}$. The focal mechanism is quite different from the Global CMT project mechanism, the magnitude is the same, and the depth is deeper than either that calculated by the Global CMT project or by GNS Science.

The focal mechanism was not constrained by this analysis. 
Appendix 1: Case studies 


\section{A1.7. Event 2137186 - Fiordland}

2 November 2003, 1358 UT

Latitude -45.42, Longitude 166.12, depth $20 \mathrm{~km}$ (restricted) (GNS)

Depth $15 \mathrm{~km}$ (Global CMT)

ML 5.2 (GNS), Mw 5.2 (Global CMT)

Global CMT focal plane 1: $\quad$ strike 35 rake 102 dip 43

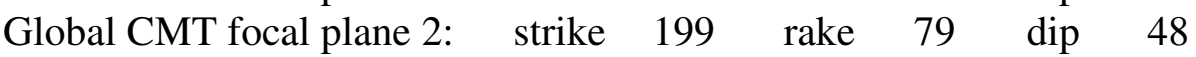

Data from four stations, at distances of $150-360 \mathrm{~km}$ and azimuths of $85^{\circ}-111^{\circ}$ from the epicentre, and listed in Table A1.7, were used to compute seismic moment tensor solutions for this earthquake.

\section{Table A1.7:}

\begin{tabular}{|l|l|c|c|}
\hline $\begin{array}{l}\text { Station } \\
\text { code }\end{array}$ & Station name & $\begin{array}{l}\text { Distance from } \\
\text { earthquake }\end{array}$ & $\begin{array}{l}\text { Azimuth from } \\
\text { earthquake }\end{array}$ \\
\hline WHZ & Wether Hill Road & $150 \mathrm{~km}$ & $111^{\circ}$ \\
\hline MLZ & Mavora Lakes & $155 \mathrm{~km}$ & $89^{\circ}$ \\
\hline TUZ & Tuapeka & $280 \mathrm{~km}$ & $104^{\circ}$ \\
\hline ODZ & Otahua Downs & $360 \mathrm{~km}$ & $85^{\circ}$ \\
\hline
\end{tabular}

This earthquake was processed using the New Zealand standard velocity model and a frequency pass-band filter of $0.03-0.06 \mathrm{~Hz}$. Solutions were calculated for depths of $5-45$ $\mathrm{km}$ at intervals of $5 \mathrm{~km}$, and the solution with the highest double-couple component was chosen as the best solution for each depth. Solutions were calculated using all four stations, and the four combinations of three stations.

The best calculated solution was calculated using the three stations MLZ, TUZ and ODZ and a depth of $5 \mathrm{~km}$. This solution has a magnitude of $\mathrm{Mw}$ 5.1, a reverse-slip mechanism, and is shown in Figure A1.8.

\section{Four stations: WHZ, MLZ, TUZ \& ODZ}

The four stations WHZ, MLZ, TUZ and ODZ lie at distances of $150-360 \mathrm{~km}$ and at azimuths of $85^{\circ}-111^{\circ}$ from the earthquake epicentre. Magnitudes calculated using these stations range from $\mathrm{Mw} 4.7$ (for a depth of $25 \mathrm{~km}$ ) to $\mathrm{Mw} 5.3$ (for a depth of $40 \mathrm{~km}$ ). Focal mechanisms are reverse/strike-slip for the $5 \mathrm{~km}$ deep solution, strike-slip/reverse for the 10 $15 \mathrm{~km}$ deep solutions, normal/strike-slip for the $20 \mathrm{~km}$ deep solution, strike-slip for the 25 $\mathrm{km}$ deep solution, reverse/strike-slip for the $30 \mathrm{~km}$ deep solution, strike-slip/normal for the $35 \mathrm{~km}$ deep solution, reverse/strike-slip for the $40 \mathrm{~km}$ deep solution, and normal/strike-slip for the $45 \mathrm{~km}$ deep solution. The fits of the synthetic seismograms to the data are fairly poor for all solutions.

\section{Three stations: WHZ, MLZ \& TUZ}

The three stations WHZ, MLZ and TUZ lie at distances of $150-280 \mathrm{~km}$ and at azimuths of $89^{\circ}-111^{\circ}$ from the earthquake epicentre. Magnitudes calculated using these stations range from $\mathrm{Mw} 4.9$ (for depths of $10-20 \mathrm{~km}$ ) to Mw 5.3 (for depths of $40-45 \mathrm{~km}$ ). Focal mechanisms are reverse for the $5 \mathrm{~km}$ deep solution, normal/strike-slip for the $10 \mathrm{~km}$ deep solution, reverse/strike-slip for the $15 \mathrm{~km}$ deep solution, normal/strike-slip for the $20-30 \mathrm{~km}$ 
deep solutions, and reverse/strike-slip for the $35-45 \mathrm{~km}$ deep solutions. The fits of the synthetic seismograms to the data are mostly reasonable, but there is no best solution.

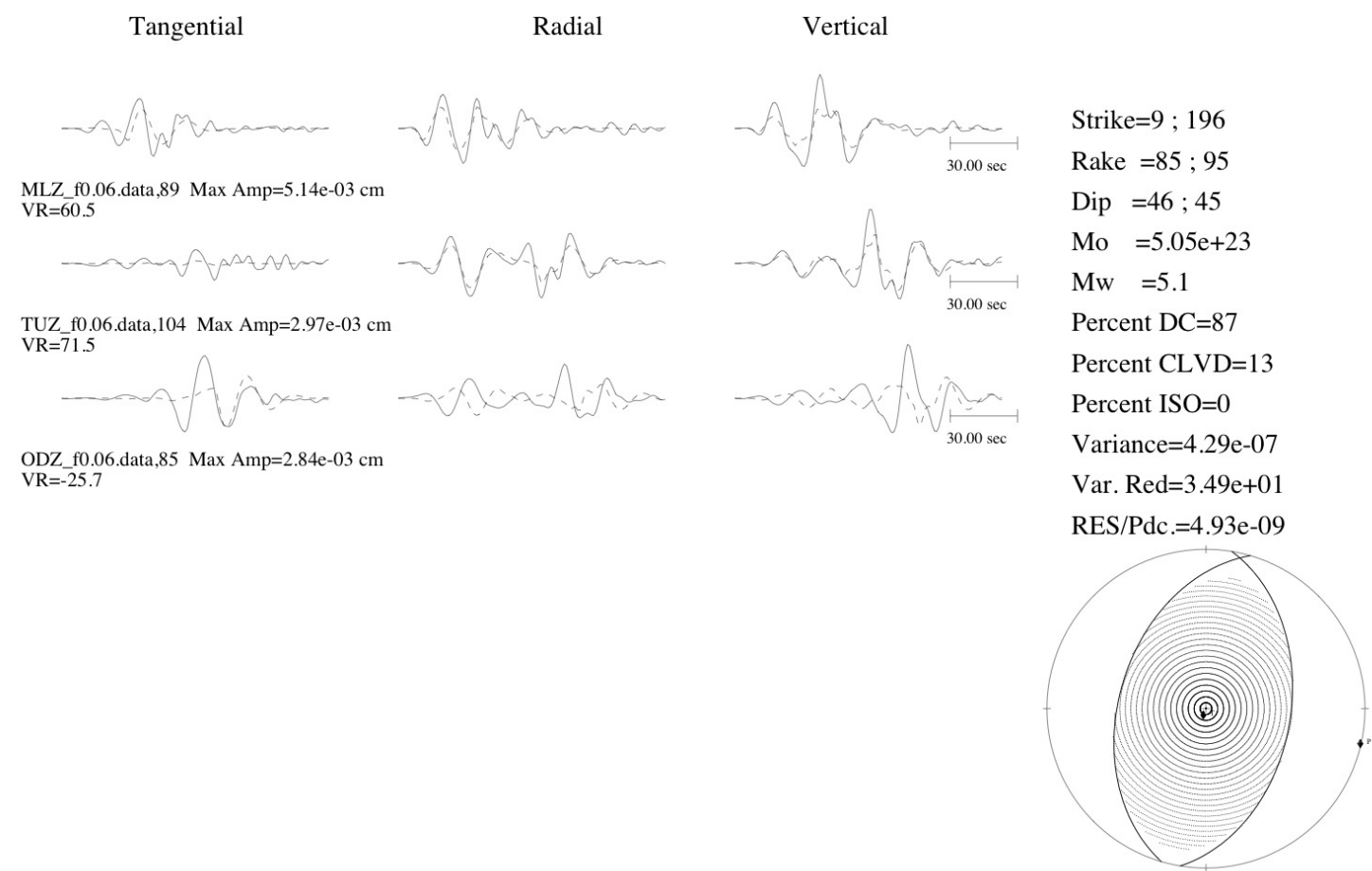

Figure A1.8. The best solution calculated for event 2137186, $5 \mathrm{~km}$ deep.

\section{Three stations: WHZ, MLZ \& ODZ}

The three stations WHZ, MLZ and ODZ lie at distances of $150-360 \mathrm{~km}$ and at azimuths of $85^{\circ}-111^{\circ}$ from the earthquake epicentre. Magnitudes calculated using these stations range from $\mathrm{Mw} 4.9$ (for a depth of $10 \mathrm{~km}$ ) to $\mathrm{Mw} 5.3$ (for depths of $40-50 \mathrm{~km}$ ). Focal mechanisms are normal/strike-slip for the $5 \mathrm{~km}$ deep solution, reverse/strike-slip for the 10 $\mathrm{km}$ deep solution, normal/strike-slip for the $15-20 \mathrm{~km}$ deep solutions, and reverse/strike-slip for the $25-45 \mathrm{~km}$ deep solutions. The fits of the synthetic seismograms to the data are reasonable for the $5-20 \mathrm{~km}$ deep solutions and poor for the $25-45 \mathrm{~km}$ deep solutions. The $5-20 \mathrm{~km}$ deep solutions have magnitudes of $\mathrm{Mw} 4.9-\mathrm{Mw} 5.1$. The $20 \mathrm{~km}$ deep solution has the best fit of the synthetic seismograms to the data, the maximum variance reduction, a magnitude of Mw 5.0, and a normal/strike-slip mechanism.

\section{Three stations: WHZ, TUZ \& ODZ}

The three stations WHZ, TUZ and ODZ lie at distances of $150-360 \mathrm{~km}$ and at azimuths of $85^{\circ}-111^{\circ}$ from the earthquake epicentre. Magnitudes calculated using these stations range from $\mathrm{Mw} 4.9$ (for depths of $10-15 \mathrm{~km}$ ) to $\mathrm{Mw} 5.4$ (for depths of $40-45 \mathrm{~km}$ ). Focal mechanisms are normal/strike-slip for the $5-10 \mathrm{~km}$ deep solutions, strike-slip for the $15 \mathrm{~km}$ deep solution, normal/strike-slip for the $20 \mathrm{~km}$ deep solution, strike-slip/reverse for the 25 $30 \mathrm{~km}$ deep solutions, strike-slip for the $35 \mathrm{~km}$ deep solution, and normal/strike-slip for the $40-45 \mathrm{~km}$ deep solutions. The fits of the synthetic seismograms to the data are fairly poor, with some reasonably fitting traces. 


\section{Three stations: MLZ, TUZ \& ODZ}

The three stations MLZ, TUZ and ODZ lie at distances of $155-360 \mathrm{~km}$ and at azimuths of $85^{\circ}-104^{\circ}$ from the earthquake epicentre. Magnitudes calculated using these stations range from $\mathrm{Mw} 4.9$ (for a depth of $15 \mathrm{~km}$ ) to $\mathrm{Mw} 5.3$ (for a depth of $40 \mathrm{~km}$ ). Focal mechanisms are reverse/strike-slip for the $5 \mathrm{~km}$ deep solution, mostly strike-slip for the $10-20 \mathrm{~km}$ deep solutions, normal/strike-slip for the $25-40 \mathrm{~km}$ deep solutions, and reverse/strike-slip for the $45 \mathrm{~km}$ deep solution. The fits of the synthetic seismograms to the data are good for the 5 and $10 \mathrm{~km}$ deep solutions. These solutions both have a magnitude of $\mathrm{Mw}$ 5.1.

\section{Summary}

Magnitudes of Mw 4.7 - Mw 5.4 were calculated for this earthquake. Reasonable solutions have magnitudes of Mw 4.9- Mw 5.3. The best solution was calculated using the three stations MLZ, TUZ and ODZ and a depth of $5 \mathrm{~km}$. The best solution has a magnitude of Mw 5.1 and a reverse-slip mechanism. The best magnitude is lower than the Global CMT Mw 5.2, but the Global CMT value is within the range of reasonable magnitudes calculated. The focal mechanism was not constrained by this analysis. 
Appendix 1: Case studies 


\section{A1.8. Event 2228901 - Gisborne}

11 May 2004, 2322 UT

Latitude -38.02, Longitude 178.18, depth $5 \mathrm{~km}$ (restricted) (GNS)

Depth $21.1 \mathrm{~km}$ (Global CMT)

ML 4.8 (GNS), Mw 4.9 (Global CMT)

Global CMT focal plane 1: $\quad$ strike 205

Global CMT focal plane 2: $\quad$ strike 354

$\begin{array}{lrlr}\text { rake } & -64 & \text { dip } & 37 \\ \text { rake } & -108 & \text { dip } & 57\end{array}$

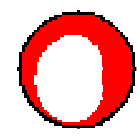

Data from seven stations, at distances of $195-320 \mathrm{~km}$ and azimuths of $207^{\circ}-302^{\circ}$ from the epicentre, and listed in Table A1.8, were used to compute seismic moment tensor solutions for this earthquake.

Table A1.8:

\begin{tabular}{|l|l|c|c|}
\hline $\begin{array}{l}\text { Station } \\
\text { code }\end{array}$ & Station name & $\begin{array}{l}\text { Distance from } \\
\text { earthquake }\end{array}$ & $\begin{array}{l}\text { Azimuth from } \\
\text { earthquake }\end{array}$ \\
\hline BKZ & Black Stump Farm & $195 \mathrm{~km}$ & $229^{\circ}$ \\
\hline TOZ & Tahuroa Road & $240 \mathrm{~km}$ & $277^{\circ}$ \\
\hline PWZ & Pawanui & $250 \mathrm{~km}$ & $207^{\circ}$ \\
\hline KUZ & Kuaotunu & $260 \mathrm{~km}$ & $302^{\circ}$ \\
\hline HIZ & Hauiti & $295 \mathrm{~km}$ & $258^{\circ}$ \\
\hline TSZ & Takapari Road & $295 \mathrm{~km}$ & $220^{\circ}$ \\
\hline VRZ & Vera Road & $320 \mathrm{~km}$ & $247^{\circ}$ \\
\hline
\end{tabular}

This earthquake was processed using the New Zealand standard velocity model. Two frequency pass-band filters were used, $0.03-0.06 \mathrm{~Hz}$ and $0.05-0.10 \mathrm{~Hz}$. Solutions were calculated for various depths between 0 and $35 \mathrm{~km}$. The best solution for each depth was chosen as the solution with the maximum variance reduction. Solutions were also calculated using the $0.05-0.10 \mathrm{~Hz}$ filter with the best solution for each depth being the solution with the maximum double-couple component.

The best solution calculated was calculated using the three stations BKZ, TOZ and KUZ, a $0.05-0.10 \mathrm{~Hz}$ frequency band-pass filter, maximising the double-couple component, and a depth of $25 \mathrm{~km}$. This solution is shown in Figure A1.9, has a magnitude of Mw 4.8 and a normal/strike-slip mechanism.

\section{$0.03-0.06 \mathrm{~Hz}$ filter, 7 stations}

Solutions were calculated using the seven stations listed in Table A1.8 using a $0.03-0.06 \mathrm{~Hz}$ frequency band-pass filter. Solutions were calculated for depths of $0-25 \mathrm{~km}$ at an interval of $5 \mathrm{~km}$. Solutions were also calculated for depths of 8,11,12 and $13 \mathrm{~km}$. The best solution for each depth was chosen as the solution with the greatest variance reduction.

The calculated moment magnitudes range from $\mathrm{Mw} 4.5$ (with depths of 10 and $11 \mathrm{~km}$ ) to $\mathrm{Mw}$ 4.8 (with a depth of $0 \mathrm{~km}$ ). Focal mechanisms are reverse/strike-slip faulting for the solution with a depth of $0 \mathrm{~km}$, normal/strike-slip faulting for solutions with depths of $5-8 \mathrm{~km}$, reverse/strike-slip faulting for solutions with depths of $10-8 \mathrm{~km}$, and strike-slip/normal faulting for solutions with depths of $15-25 \mathrm{~km}$. Double-couple components range from $39 \%$ (with a depth of $25 \mathrm{~km}$ ) to $98 \%$ (with a depth of $11 \mathrm{~km}$ ). The fits of the synthetic seismograms to the data are all poor. 


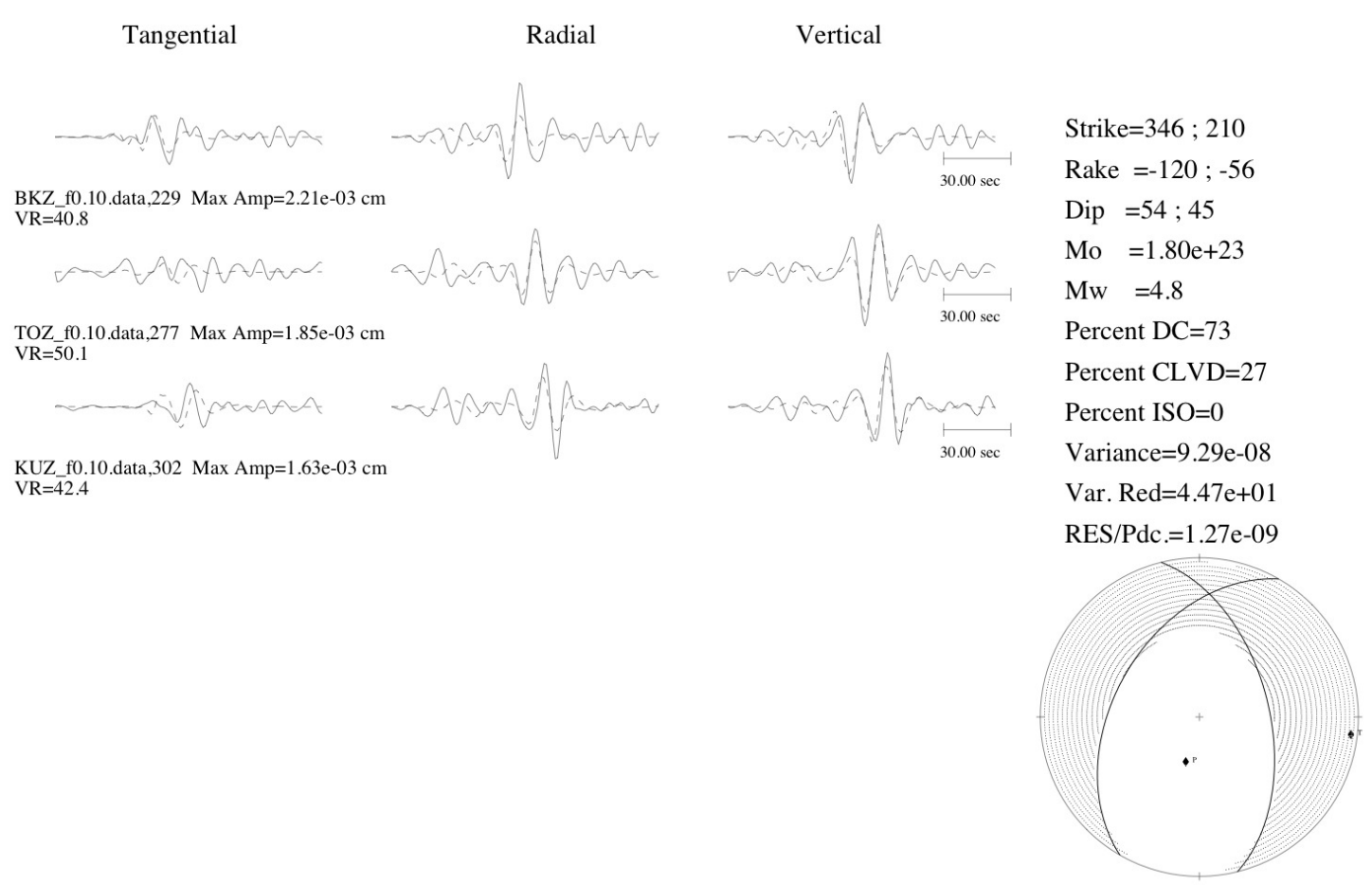

Figure A1.9. The best solution calculated for event 2228901; depth $25 \mathrm{~km}$, using $0.05-0.10$ $\mathrm{Hz}$ frequency band-pass filter and maximising double-couple component.

\subsection{3 - $0.06 \mathrm{~Hz}$ filter, 3 stations}

Solutions were also calculated using the $0.03-0.06 \mathrm{~Hz}$ frequency band-pass filter and the three stations BKZ, TOZ and KUZ. The stations BKZ, TOZ and KUZ lie at distances of 195 $-260 \mathrm{~km}$ and at azimuths of $229^{\circ}-302^{\circ}$ from the earthquake epicentre. Solutions were calculated for depths of $0-30 \mathrm{~km}$ with a $5 \mathrm{~km}$ increment, and also at depths of 3, 4, 6, 7, 22, 23, 24 and $27 \mathrm{~km}$. The best solution for each depth was chosen as the solution with the highest variance reduction.

Calculated moment magnitudes range from $\mathrm{Mw} 4.6$ (with depths of 0 and $5 \mathrm{~km}$ ) to $\mathrm{Mw} 4.8$ (with depths of $3-5 \mathrm{~km}$ ). The $0 \mathrm{~km}$ deep solution shows reverse/strike-slip faulting, the $3-$ $10 \mathrm{~km}$ deep solutions show normal/strike-slip faulting, the $15-20 \mathrm{~km}$ deep solutions show strike-slip/reverse faulting, and the $22-30 \mathrm{~km}$ deep solutions show normal/strike-slip faulting. Double-couple components range from 5\% (for a depth of $15 \mathrm{~km}$ ) to $92 \%$ (for a depth of $5 \mathrm{~km}$ ). The fits of the synthetic seismograms to the data are all fairly poor, with some reasonably fitting traces.

\section{$0.05-0.10 \mathrm{~Hz}$ filter, 3 stations, maximising variance reduction}

Solutions were calculated using the three stations BKZ, TOZ, and KUZ, and a $0.05-0.10 \mathrm{~Hz}$ frequency band-pass filter. Solutions were calculated for a depth of $1 \mathrm{~km}$, for depths of 3 $10 \mathrm{~km}$ at intervals of $1 \mathrm{~km}$, for depths of $10-30 \mathrm{~km}$ at a $5 \mathrm{~km}$ interval, and for a depth of 32 $\mathrm{km}$. The best solution for each depth was chosen as the solution with the highest variance reduction. 
Calculated moment magnitudes range from Mw 4.6 (for depths of $6-10 \mathrm{~km}$ ) to $\mathrm{Mw} 4.9$ (for a depth of $32 \mathrm{~km}$ ). The $1 \mathrm{~km}$ deep solution shows reverse faulting, the $3 \mathrm{~km}$ deep solution shows strike-slip/normal faulting, the $4-7 \mathrm{~km}$ deep solutions show reverse/strike-slip faulting (with various fault orientations), the $8-10 \mathrm{~km}$ deep solutions show vertical dipslip/strike-slip faulting, and the $15-32 \mathrm{~km}$ deep solutions show normal faulting. Doublecouple components range from $19 \%$ (for a depth of $1 \mathrm{~km}$ ) to $100 \%$ (for a depth of $7 \mathrm{~km}$ ). The fits of the synthetic seismograms to the data are mostly reasonable, so the best solution is chosen as the solution with the highest double-couple component; with a depth of $7 \mathrm{~km}, \mathrm{Mw}$ 4.6, and a reverse/strike-slip faulting mechanism.

\subsection{5 - 0.10 Hz filter, 3 stations, maximising double-couple component}

Solutions were calculated using the three stations BKZ, TOZ and KUZ (at distances of 195 $260 \mathrm{~km}$ and azimuths of $229^{\circ}-302^{\circ}$ from the earthquake epicentre) and a $0.05-0.10 \mathrm{~Hz}$ frequency band-pass filter. Solutions were calculated for depths of $1 \mathrm{~km}, 5-30 \mathrm{~km}$ with a 5 $\mathrm{km}$ increment, and also for depths of 12, 17, 18, 21, 22, and $32 \mathrm{~km}$. The best solution for each depth was chosen as that with the highest double-couple component.

The moment magnitudes calculated range from Mw 4.4 (for a depth of $10 \mathrm{~km}$ ) to $\mathrm{Mw} 4.9$ (for depths of $30-32 \mathrm{~km}$ ). The $1-12 \mathrm{~km}$ deep solutions show reverse/strike-slip faulting, with various fault orientations, and the $15-32 \mathrm{~km}$ deep solutions show normal/strike-slip faulting, with various fault orientations. The fits of the synthetic seismograms to the data are mostly reasonable, and the variance reduction is highest for solutions with depths of $17-18 \mathrm{~km}$ and $21-32 \mathrm{~km}$. The best solution, with the highest variance reduction, is the $25 \mathrm{~km}$ deep solution, which has a magnitude of $\mathrm{Mw} 4.8$ and normal/strike-slip faulting. This solution is shown in Figure A1.9.

\section{Summary}

The moment magnitudes calculated for this event are in the range Mw 4.4- Mw 4.9.

The $0.03-0.06 \mathrm{~Hz}$ frequency band-pass filter did not produce good solutions for this earthquake. The solutions calculated using the $0.05-0.10 \mathrm{~Hz}$ frequency band pass filter have magnitudes of Mw 4.4 - Mw 4.9.

The best solution calculated was calculated using three stations, the $0.05-0.10$ frequency band-pass filter, and picking the solution with the highest double-couple component for each depth. It has a depth of $25 \mathrm{~km}$, a moment magnitude of Mw 4.8 and a normal/strike-slip faulting mechanism.

The moment magnitudes calculated are less than the Mw 4.9 calculated by the Global CMT project. 
Appendix 1: Case studies 


\section{A1.9. Event 2266782 - Bay of Plenty}

18 July 2004, 0358 UT

Latitude -38.01, Longitude 176.50, depth $5 \mathrm{~km}$ (restricted) (GNS)

Depth $12 \mathrm{~km}$ (Global CMT)

ML 4.8 (GNS), Mw 5.0 (Global CMT)

Global CMT focal plane 1: $\quad$ strike 54 rake -26 dip 55

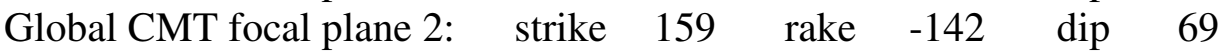

Data from six stations, at distances of $130-230 \mathrm{~km}$ and azimuths of $73^{\circ}-334^{\circ}$, and listed in Table A1.9, were used to compute seismic moment tensor solutions for this earthquake.

Table A1.9:

\begin{tabular}{|l|l|c|c|}
\hline $\begin{array}{l}\text { Station } \\
\text { code }\end{array}$ & Station name & $\begin{array}{l}\text { Distance from } \\
\text { earthquake }\end{array}$ & $\begin{array}{l}\text { Azimuth from } \\
\text { earthquake }\end{array}$ \\
\hline BKZ & Black Stump Farm & $130 \mathrm{~km}$ & $180^{\circ}$ \\
\hline HIZ & Hauiti & $155 \mathrm{~km}$ & $248^{\circ}$ \\
\hline PUZ & Puketiti & $155 \mathrm{~km}$ & $93^{\circ}$ \\
\hline KUZ & Kuaotunu & $155 \mathrm{~km}$ & $334^{\circ}$ \\
\hline MXZ & Matakaoa Point & $165 \mathrm{~km}$ & $73^{\circ}$ \\
\hline TSZ & Takapari Road & $230 \mathrm{~km}$ & $191^{\circ}$ \\
\hline
\end{tabular}

This event was processed using the New Zealand standard velocity model, and a band-pass frequency filter of $0.03-0.06 \mathrm{~Hz}$. Solutions were calculated using various station combinations for depths of $5-35 \mathrm{~km}$ at intervals of $5 \mathrm{~km}$. The solution with the highest double-couple component was chosen as the best solution for each depth.

None of the solutions produced have very good fits between the synthetic seismograms and the data, and neither the moment magnitude nor the mechanism could be constrained by this analysis. One of the solutions calculated (calculated with the four stations BKZ, HIZ, PUZ, and KUZ and a depth of $5 \mathrm{~km}$ ) is shown in Figure A1.10.

\section{6 stations}

Magnitudes for the solutions calculated using all six stations given in Table A1.9 range from Mw 4.6 (for depths of $5-15 \mathrm{~km}$ ) to Mw 4.9 (for a depth of $35 \mathrm{~km}$ ). Focal mechanisms are normal-slip/strike-slip for a depth of $5 \mathrm{~km}$, strike-slip/reverse-slip for a depth of $10 \mathrm{~km}$, strike-slip/normal-slip for a depth of $15 \mathrm{~km}$, and strike-slip/reverse-slip for depths of $20-35$ $\mathrm{km}$. The fits of the synthetic seismograms to the data are all fairly poor.

\section{5 stations}

The five stations BKZ, HIZ, PUZ, KUZ and MXZ lie at distances of $130-165 \mathrm{~km}$ and azimuths of $73^{\circ}-334^{\circ}$ from the epicentre. Magnitudes calculated using these stations range from $\mathrm{Mw} 4.6$ (for depths of $5-10 \mathrm{~km}$ ) to Mw 5.1 (for a depth of $35 \mathrm{~km}$ ). Focal mechanisms are normal/strike-slip for the $5-10 \mathrm{~km}$ deep solutions and strike-slip/reverse for the $15-35$ $\mathrm{km}$ deep solutions. The fits of the synthetic seismograms to the data are all fairly poor. 


\section{4 stations}

The four stations BKZ, HIZ, PUZ, and KUZ lie at distances of $130-155 \mathrm{~km}$ and azimuths of $93^{\circ}-334^{\circ}$ from the epicentre. Magnitudes calculated using these stations range from Mw 4.4 (for the $10 \mathrm{~km}$ deep solution) to Mw 5.0 (for the $35 \mathrm{~km}$ deep solution). Focal mechanisms are normal/strike-slip for the $5-10 \mathrm{~km}$ deep solutions, reverse/strike-slip for the $15-30 \mathrm{~km}$ deep solutions, and strike-slip/normal for the $35 \mathrm{~km}$ deep solution. The fits of the synthetic seismograms to the data are all fairly poor. The $5 \mathrm{~km}$ deep solution is shown in Figure A1.10.

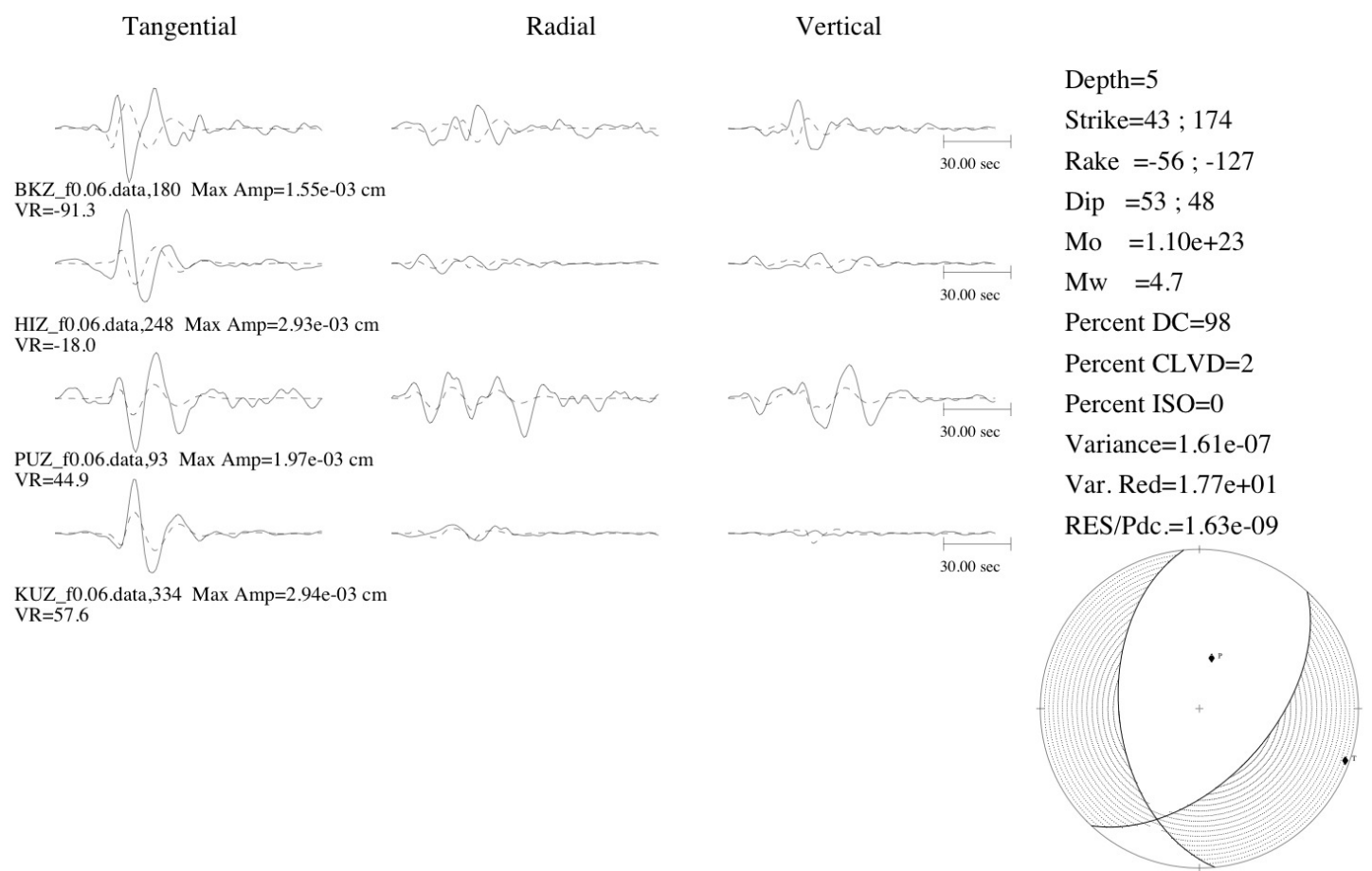

Figure A1.10. An example of the solutions calculated for event 2266782.

\section{3 stations}

The three stations BKZ, HIZ and PUZ lie at distances of $130-155 \mathrm{~km}$ and azimuths of $93^{\circ}$ $248^{\circ}$ from the epicentre. Magnitudes calculated using these stations range from Mw 4.7 (for the $5 \mathrm{~km}$ deep solution) to Mw 4.8 (for the $10-35 \mathrm{~km}$ deep solutions). Focal mechanisms are normal/strike-slip for the $5 \mathrm{~km}$ deep solution, strike-slip with very small dip-slip components for $10-20 \mathrm{~km}$ deep solutions, strike-slip/normal for the $25 \mathrm{~km}$ deep solution, strike-slip/reverse for the $35 \mathrm{~km}$ deep solution. The fits of the synthetic seismograms to the data are fairly poor, with some reasonably fitting traces.

\section{Summary}

None of the solutions calculated had good fits between the synthetic seismograms and the data. Calculated moment magnitudes are between $\mathrm{Mw} 4.4$ and $\mathrm{Mw}$ 5.1, a range that includes the value of Mw 5.0 calculated by the Global CMT project. The focal mechanism of this earthquake was not constrained. 


\section{A1.10. Event 2266243 - Bay of Plenty}

18 July 2004, 0422 UT

Latitude -38.01, Longitude 176.51, depth $5 \mathrm{~km}$ (restricted) (GNS)

Depth $12 \mathrm{~km}$ (Global CMT)

ML 5.1 (GNS), Mw 5.4 (Global CMT)

Global CMT focal plane 1: strike 55

Global CMT focal plane 2: $\quad$ strike 157

$\begin{array}{rrr}\text { rake } & -24 & \operatorname{dip} \\ \text { rake } & -149 & \text { dip }\end{array}$

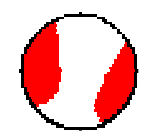

Global CMT mechanism

Data from nine stations, at distances of $130-235 \mathrm{~km}$ and azimuths of $73^{\circ}-333^{\circ}$ from the epicentre, and listed in Table A1.10, were used to compute seismic moment tensor solutions for this earthquake.

Table A1.10:

\begin{tabular}{|l|l|c|c|}
\hline $\begin{array}{l}\text { Station } \\
\text { code }\end{array}$ & Station name & $\begin{array}{l}\text { Distance from } \\
\text { earthquake }\end{array}$ & $\begin{array}{l}\text { Azimuth from } \\
\text { earthquake }\end{array}$ \\
\hline BKZ & Black Stump Farm & $130 \mathrm{~km}$ & $181^{\circ}$ \\
\hline PUZ & Puketiti & $155 \mathrm{~km}$ & $93^{\circ}$ \\
\hline HIZ & Hauiti & $155 \mathrm{~km}$ & $248^{\circ}$ \\
\hline KUZ & Kuaotunu & $155 \mathrm{~km}$ & $333^{\circ}$ \\
\hline MXZ & Matakaoa Point & $165 \mathrm{~km}$ & $73^{\circ}$ \\
\hline VRZ & Vera Road & $195 \mathrm{~km}$ & $230^{\circ}$ \\
\hline PWZ & Pawanui & $225 \mathrm{~km}$ & $172^{\circ}$ \\
\hline TSZ & Takapari Road & $235 \mathrm{~km}$ & $192^{\circ}$ \\
\hline WAZ & Wanganui & $235 \mathrm{~km}$ & $214^{\circ}$ \\
\hline
\end{tabular}

This event was processed using the New Zealand standard velocity model and a frequency pass-band filter of $0.03-0.06 \mathrm{~Hz}$. Solutions were calculated for depths of $5-35 \mathrm{~km}$ at $5 \mathrm{~km}$ intervals. The solution with the highest double-couple component for each depth was chosen as the best solution for that depth. Five combinations of stations were tested.

The best solution was calculated with the three stations BKZ, PUZ and HIZ and a depth of 15 $\mathrm{km}$. This solution has a magnitude of Mw 5.4 and a mostly strike-slip focal mechanism and is shown in Figure A1.11.

\section{9 stations BKZ, PUZ, HIZ, KUZ, MXZ, VRZ, PWZ, TSZ \& WAZ}

The nine stations BKZ, PUZ, HIZ, KUZ, MXZ, VRZ, PWZ, TSZ and WAZ lie at distances of $130-235 \mathrm{~km}$ from the earthquake epicentre, and at azimuths of $73^{\circ}-333^{\circ}$. The moment magnitudes calculated using these stations range from Mw 5.2 (with depths of $5 \mathrm{~km}, 10 \mathrm{~km}$, and $30 \mathrm{~km}$ ) to Mw 5.4 (with a depth of $35 \mathrm{~km}$ ). Focal mechanisms are all strike-slip. The fits of the synthetic seismograms to the data are all fairly poor, with some reasonably fitting traces.

\section{8 stations BKZ, PUZ, HIZ, KUZ, MXZ, VRZ, PWZ \& TSZ}

The eight stations BKZ, PUZ, HIZ, KUZ, MXZ, VRZ, PWZ and TSZ lie at distances of 130 $-235 \mathrm{~km}$ from the earthquake epicentre, and at azimuths of $73^{\circ}-333^{\circ}$. The moment magnitudes calculated using these stations range from Mw 5.2 (with depths of $5-20 \mathrm{~km}$ ) to 
Mw 5.5 (with a depth of $35 \mathrm{~km}$ ). Focal mechanisms are all mostly strike-slip. The fits of the synthetic seismograms to the data are all fairly poor, with some reasonably fitting traces.

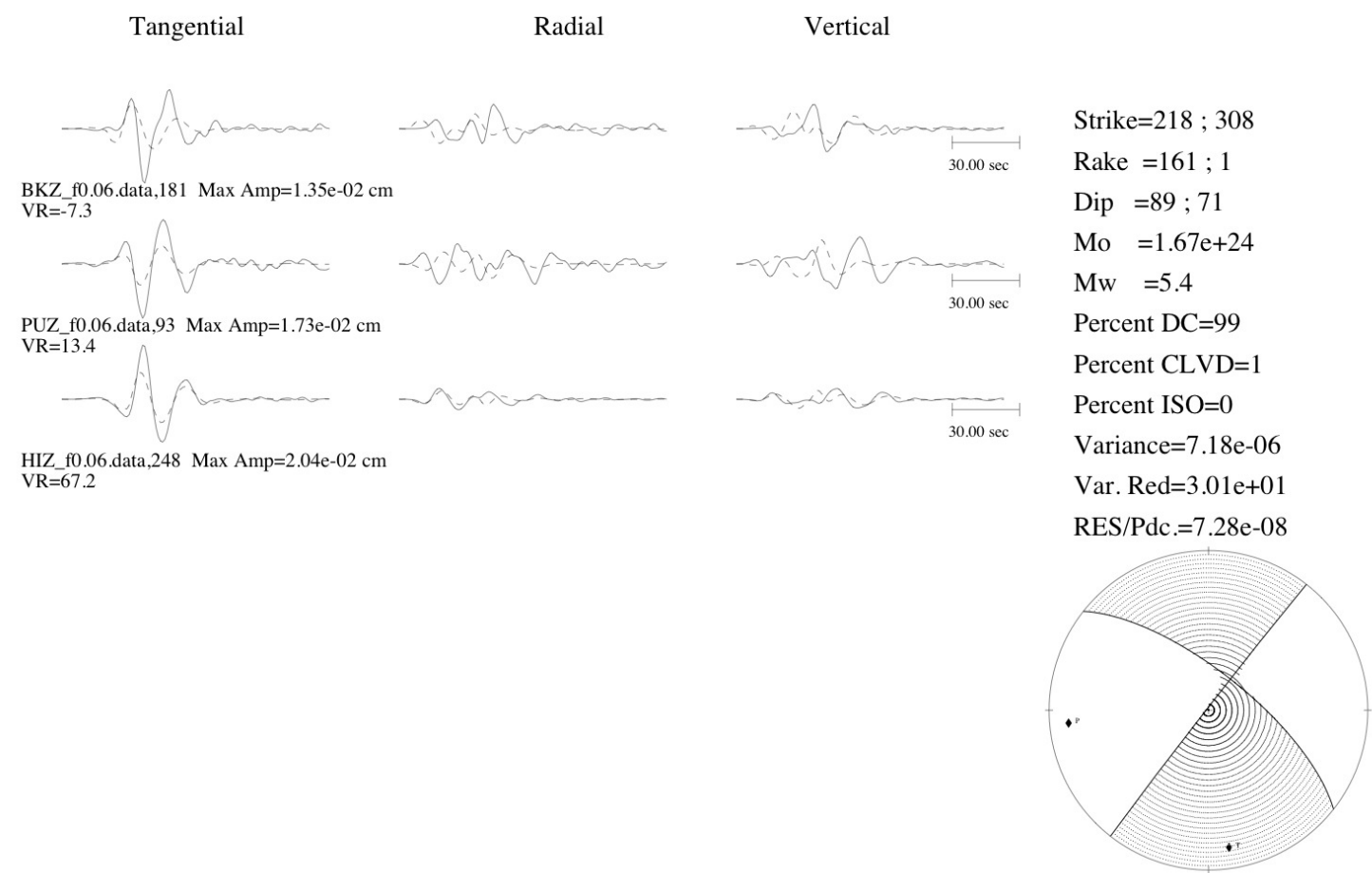

Figure A1.11. The best solution calculated for event 2266243, $15 \mathrm{~km}$ deep.

\section{4 stations BKZ, PUZ, HIZ \& KUZ}

The four stations BKZ, PUZ, HIZ and KUZ lie at distances of $130-155 \mathrm{~km}$ from the earthquake epicentre, and at azimuths of $93^{\circ}-333^{\circ}$. Calculated moment magnitudes range from $\mathrm{Mw} 5.1$ (for depths of $5-30 \mathrm{~km}$ ) to $\mathrm{Mw} 5.3$ (for the $35 \mathrm{~km}$ deep solution). The $5 \mathrm{~km}$ deep solution shows normal/strike-slip, the $10 \mathrm{~km}$ deep solution shows strike-slip, and the 15 $-35 \mathrm{~km}$ deep solutions show reverse/strike-slip. The fits of the synthetic seismograms to the data are all poor.

\section{3 stations BKZ, PUZ \& HIZ}

The three stations BKZ, PUZ and HIZ lie at distances of $130-155 \mathrm{~km}$ from the earthquake epicentre, and at azimuths of $93^{\circ}-248^{\circ}$. Calculated moment magnitudes range from Mw 5.3 (with a depth of $5 \mathrm{~km}$ ) to Mw 5.6 (with a depth of $35 \mathrm{~km}$ ). The $5 \mathrm{~km}$ deep solution shows strike-slip/normal-slip, and the $10-35 \mathrm{~km}$ deep solutions show mostly strike-slip. The fits of the synthetic seismograms to the data are all fairly poor, with some reasonably fitting traces. The variance reduction peaks with a depth of $15 \mathrm{~km}$ and a moment magnitude of $\mathrm{Mw}$ 5.4. This is the best solution, as shown in Figure A1.11.

\section{3 stations HIZ, KUZ \& MXZ}

The three stations HIZ, KUZ and MXZ lie at distances of $155-165 \mathrm{~km}$ from the earthquake epicentre, and at azimuths of $73^{\circ}-333^{\circ}$. The calculated moment magnitudes range from $\mathrm{Mw}$ 5.3 (with depths of $5-20 \mathrm{~km}$ ) to Mw 5.5 (with a depth of $35 \mathrm{~km}$ ). The focal mechanisms are 
all mostly strike-slip. The fits of the synthetic seismograms to the data are all fairly poor, with some reasonably fitting traces.

\section{Summary}

The magnitudes calculated for this event range from $\mathrm{Mw} 5.1$ to $\mathrm{Mw}$ 5.6. The calculated focal mechanisms are mostly strike-slip, with some dip-slip components. None of the fits of the synthetic seismograms to the data were particularly good. The best solution was calculated with the three stations BKZ, PUZ and HIZ and a depth of $15 \mathrm{~km}$. This solution has a magnitude of Mw 5.4 and a mostly strike-slip focal mechanism.

The best magnitude of Mw 5.4 agrees with that calculated by the Global CMT project, however the focal mechanisms do not match. 
Appendix 1: Case studies 


\section{A1.11. Event 2326055 - Puysegur Trench}

22 November 2004, 2026 UT

Latitude -46.61, Longitude 165.32, depth $12 \mathrm{~km}$ (restricted) (GNS)

Depth $40 \mathrm{~km}$ (Global CMT)

ML 7.1 (GNS), Mw 7.1 (Global CMT)

Global CMT focal plane 1: $\quad$ strike 43 rake 103 dip 36

Global CMT focal plane 2: $\quad$ strike 208 rake 81 dip 55

Data from six stations, at distances of $220-390 \mathrm{~km}$ and azimuths of $45^{\circ}-79^{\circ}$ from the epicentre, and listed in Table A1.11, were used to compute seismic moment tensor solutions for this earthquake.

Table A1.11:

\begin{tabular}{|l|l|c|c|}
\hline $\begin{array}{l}\text { Station } \\
\text { code }\end{array}$ & Station name & $\begin{array}{l}\text { Distance from } \\
\text { earthquake }\end{array}$ & $\begin{array}{l}\text { Azimuth from } \\
\text { earthquake }\end{array}$ \\
\hline WHZ & Wether Hill Road & $220 \mathrm{~km}$ & $70^{\circ}$ \\
\hline MLZ & Mavora Lakes & $255 \mathrm{~km}$ & $59^{\circ}$ \\
\hline TUZ & Tuapeka & $340 \mathrm{~km}$ & $79^{\circ}$ \\
\hline EAZ & Earnscleugh & $345 \mathrm{~km}$ & $65^{\circ}$ \\
\hline WKZ & Wanaka & $350 \mathrm{~km}$ & $57^{\circ}$ \\
\hline JCZ & Jackson Bay & $390 \mathrm{~km}$ & $45^{\circ}$ \\
\hline
\end{tabular}

Seismic moment tensors for this earthquake were initially calculated using 4 seconds of data before the arrival of the P-wave, consistent with the other earthquakes. The data was processed using the New Zealand standard velocity model. Frequency pass-bands of $0.03-$ $0.06 \mathrm{~Hz}, 0.01-0.05 \mathrm{~Hz}$, and $0.02-0.05 \mathrm{~Hz}$ were used. The best solution for each depth was usually chosen to be the solution with the highest double-couple component, although solutions were also calculated using 4 seconds of data before the arrival of the P-wave and maximising the variance reduction. Seismic moment tensors were produced for various depths, mostly for depths of $5-60 \mathrm{~km}$ with depth increments of $5 \mathrm{~km}$. Seismic moment tensors were produced using all six stations in the $100-400 \mathrm{~km}$ distance range. Seismic moment tensors were also produced using the $0.03-0.06 \mathrm{~Hz}$ frequency pass-band filter and maximising the double-couple component for the closest five stations (WHZ, MLZ, TUZ, EAZ and WKZ), the five stations WHZ, MLZ, TUZ, EAZ and JCZ, the closest four stations (WHZ, MLZ, TUZ and EAZ), and the closest three stations (WHZ, MLZ and TUZ).

Further processing was done by varying the amount of data before the arrival of the P-wave, and by changing the initial offset of the seismograms and the synthetic seismograms to match. Amounts of 10 seconds, 30 seconds, 1 minute and 2 minutes were chosen. The seismic moment tensors calculated with 10 seconds of data before the P-wave arrival were calculated with an initial offset of zero seconds. Seismic moment tensors calculated with 30 seconds of data before the P-wave arrival were calculated with an initial offset of zero seconds and with an initial offset of 30 seconds. Seismic moment tensors calculated with one minute (60 seconds) of data before the P-wave arrival were calculated with an initial offset of zero seconds and with an initial offset of 60 seconds. Seismic moment tensors calculated with two minutes (120 seconds) of data before the P-wave arrival were calculated with an initial offset of zero seconds and with an initial offset of 120 seconds. Frequency pass-bands of $0.03-0.06 \mathrm{~Hz}, 0.01-0.05 \mathrm{~Hz}$, and $0.02-0.05 \mathrm{~Hz}$ were used. Seismic moment tensors 
were calculated using all six stations in the $100-400 \mathrm{~km}$ distance range, the closest five of those stations, the closest four stations, and the closest three stations. Solutions were calculated for depths of $5-60 \mathrm{~km}$, usually with an increment of $5 \mathrm{~km}$.

The best solution for each depth was chosen to be the solution with the highest double-couple component. The best solution was produced using the four stations WHZ, MLZ, TUZ and EAZ, the $0.03-0.06 \mathrm{~Hz}$ frequency band-pass filter, maximising the double-couple component, two minutes of data before the P-wave arrival, an initial offset between the real and synthetic seismograms of 120 seconds and a depth of $35 \mathrm{~km}$. This solution is shown in Figure A1.12, has a magnitude of $\mathrm{Mw} 7.0$ and shows normal/strike-slip faulting.

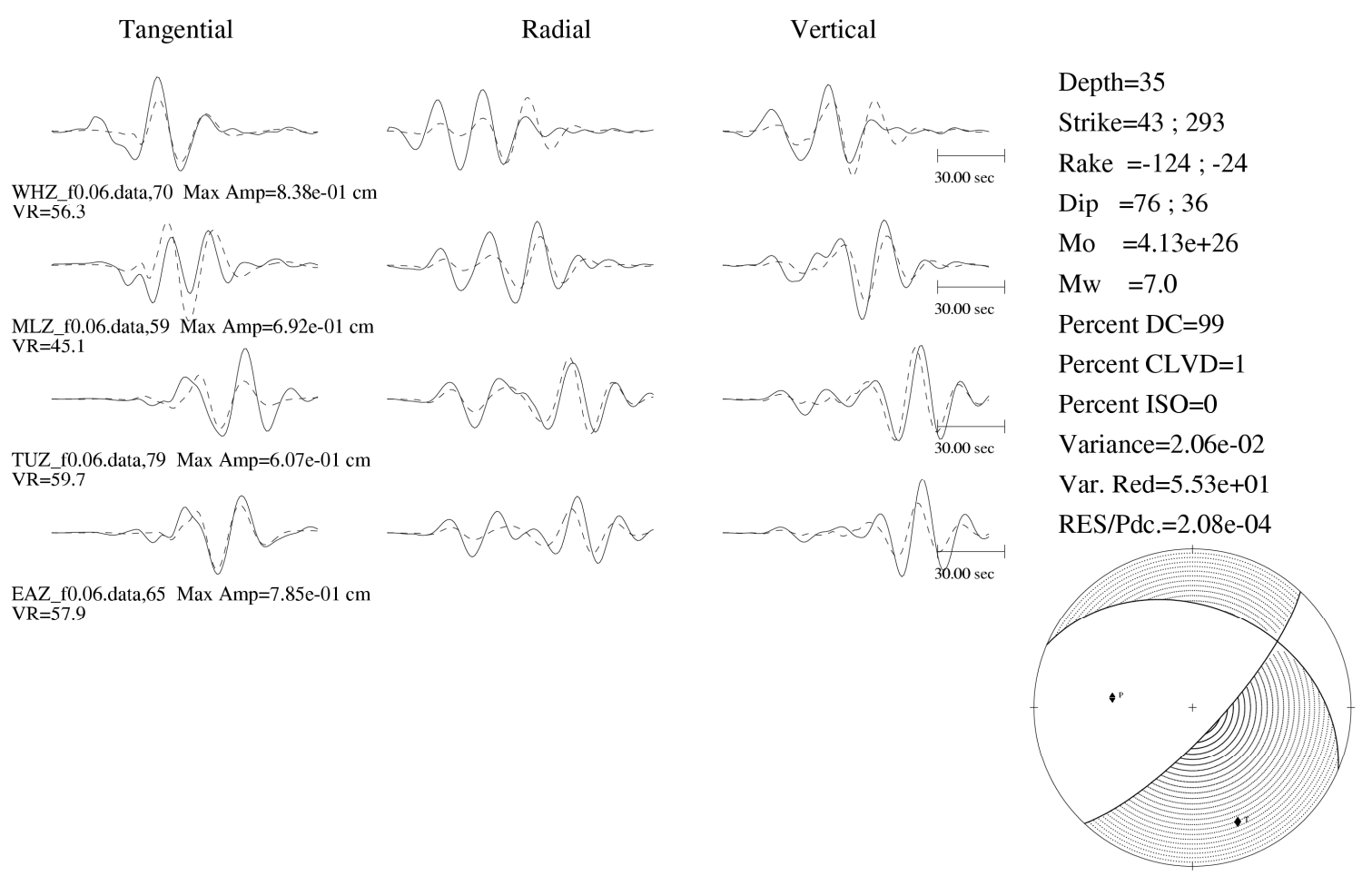

Figure A1.12. The best solution produced for the Puysegur Trench event, event 2326055, using two minutes of data before the arrival of the P-wave, an initial offset between the real and synthetic seismograms of 120 seconds, a $0.03-0.06 \mathrm{~Hz}$ frequency band-pass filter, a source depth of $35 \mathrm{~km}$, the four stations WHZ, MLZ, TUZ and EAZ, and maximising the double-couple component.

\section{With 4 seconds of data before the P-wave arrival}

\section{Six stations WHZ, MLZ, TUZ, EAZ, WKZ \& JCZ, $0.03-0.06$ Hz filter, optimising double-couple component}

With all six stations, a $0.03-0.06 \mathrm{~Hz}$ frequency band-pass filter and optimising the doublecouple component, the moment magnitudes calculated range from Mw 6.5 at $20 \mathrm{~km}$ depth, to Mw 7.1 at $56 \mathrm{~km}$, and the double-couple components of the solutions range from $92 \%$ to $100 \%$. Various focal mechanisms were computed, from normal/strike-slip for depths of 5 $12 \mathrm{~km}$, to reverse/strike-slip for a depth of $13 \mathrm{~km}$, to normal/strike-slip for depths of $14-15$ 
$\mathrm{km}$, to reverse/strike-slip for depths of $16-18 \mathrm{~km}$, to strike-slip for depths of $20-30 \mathrm{~km}$, to reverse/strike-slip for depths of $35-38 \mathrm{~km}$ to normal/strike-slip for depths of $39-56 \mathrm{~km}$, to reverse/strike-slip at $57 \mathrm{~km}$, to strike-slip at $60 \mathrm{~km}$. The higher Mw (Mw 6.8- Mw 7.1) values between 35 and $56 \mathrm{~km}$, suggest that the depth is in that range, which agrees with the Global CMT depth of $40 \mathrm{~km}$. The variance reduction peaks at $35 \mathrm{~km}$, with a moment magnitude of Mw 6.9.

\section{Six stations WHZ, MLZ, TUZ, EAZ, WKZ \& JCZ, $0.03-0.06$ Hz filter, optimising variance reduction}

Using the six stations WHZ, MLZ, TUZ, EAZ, WKZ, and JCZ, a $0.03-0.06 \mathrm{~Hz}$ frequency band-pass filter, and optimising the variance reduction, the calculated magnitudes range from Mw 6.6 (at 5 and $10 \mathrm{~km}$ deep) to Mw 7.2 (at 55 and $60 \mathrm{~km}$ ). Mw generally increases with depth. Double-couple components are between $38 \%$ at $55 \mathrm{~km}$ depth and $99 \%$ at $30 \mathrm{~km}$ depth. The highest double-couple components are in the depth range $20-40 \mathrm{~km}$, with moment magnitudes of Mw 6.8 to Mw 6.9. Focal mechanisms range from reverse/strike-slip for depths of $5-15 \mathrm{~km}$, to normal/strike-slip for depths of $20-30 \mathrm{~km}$, to reverse /strike-slip at $35 \mathrm{~km}$, to strike-slip/normal at $40 \mathrm{~km}$, to normal-slip at $45 \mathrm{~km}$, to normal/strike-slip at 50 $55 \mathrm{~km}$, and back to reverse/strike-slip at $60 \mathrm{~km}$. Optimising the variance reduction using this frequency range and this set of stations does not give a good indication of either the depth or the focal mechanism for this earthquake.

\section{Six stations, WHZ, MLZ, TUZ, EAZ, WKZ \& JCZ, $0.01-0.05$ Hz filter, optimising double-couple component}

Using the six stations WHZ, MLZ, TUZ, EAZ, WKZ, and JCZ, a $0.01-0.05 \mathrm{~Hz}$ frequency band-pass filter, and optimising the double-couple component, solutions were calculated for depths of $5-50 \mathrm{~km}$ at intervals of $5 \mathrm{~km}$. Magnitudes calculated range from Mw 6.4 (at 10 $\mathrm{km}$ deep) to $\mathrm{Mw} 6.9$ (at 35 - $50 \mathrm{~km}$ deep). Double-couple components are between $93 \%$ and $100 \%$, and the highest variance reduction is at $30 \mathrm{~km}$ deep. The fit of the synthetic seismograms to the data are very poor for all depths. Focal mechanisms are reverse/strikeslip for a depth of $5 \mathrm{~km}$, strike-slip/normal for the $10-25 \mathrm{~km}$ deep solutions, strikeslip/reverse for the $30 \mathrm{~km}$ deep solution, and strike-slip/normal for the $35-50 \mathrm{~km}$ deep solutions.

\section{Six stations, WHZ, MLZ, TUZ, EAZ, WKZ \& JCZ, $0.01-0.05$ Hz filter, optimising variance reduction}

Using the six stations WHZ, MLZ, TUZ, EAZ, WKZ, and JCZ, a $0.01-0.05 \mathrm{~Hz}$ frequency band-pass filter, and optimising the variance reduction, the calculated magnitudes range from Mw 6.6 (at $5 \mathrm{~km}$ deep) to Mw 7.1 (at $50-60 \mathrm{~km}$ ). Magnitude increases with depth. The double-couple components range from $36 \%$ at $35 \mathrm{~km}$ deep to $99 \%$ at $10 \mathrm{~km}$. The fit of the synthetic seismograms to the data is generally very poor for all depths. There are two stations, TUZ and EAZ, for which the synthetics at some depths have quite good fits to the data, but the fits for all the other stations are very poor. Focal mechanisms are reverse/strikeslip for the $5-35 \mathrm{~km}$ deep solutions, strike-slip/normal-slip for the $40 \mathrm{~km}$ deep solution, strike-slip/vertical dip-slip for the $45-50 \mathrm{~km}$ deep solutions, and strike-slip/normal-slip for the $55-60 \mathrm{~km}$ deep solutions. 


\section{Six stations, WHZ, MLZ, TUZ, EAZ, WKZ \& JCZ, $0.02-0.05$ Hz filter, optimising double-couple component}

Using the six stations WHZ, MLZ, TUZ, EAZ, WKZ, and JCZ, a $0.02-0.05 \mathrm{~Hz}$ frequency band-pass filter, and optimising the double-couple component, the calculated magnitudes range from $\mathrm{Mw} 6.6$ (at 10 and $20 \mathrm{~km}$ deep) to $\mathrm{Mw} 7.0$ (at $60 \mathrm{~km}$ deep). Magnitude generally increases with depth. Double-couple components are between $96 \%$ and $100 \%$, with the highest double-couple components in the depth range of $10-30 \mathrm{~km}$. The $25 \mathrm{~km}$ deep solution has the maximum variance reduction and a moment magnitude of $\mathrm{Mw}$ 6.8. The focal-mechanisms are mostly reverse/strike-slip for the $5-15 \mathrm{~km}$ deep solutions, mostly strike-slip for the $20 \mathrm{~km}$ deep solution, reverse/strike-slip for the $25 \mathrm{~km}$ deep solution, strikeslip/normal-slip for the $30 \mathrm{~km}$ deep solution, reverse/strike-slip for the $35-40 \mathrm{~km}$ deep solutions, strike-slip/normal-slip for the $45 \mathrm{~km}$ deep solution, reverse/strike-slip for the 50 $55 \mathrm{~km}$ deep solutions, and mostly strike-slip for the $60 \mathrm{~km}$ deep solution.

\section{Six stations, WHZ, MLZ, TUZ, EAZ, WKZ \& JCZ, $0.02-0.05$ Hz filter, optimising variance reduction}

Using the six stations WHZ, MLZ, TUZ, EAZ, WKZ, and JCZ, a $0.02-0.05 \mathrm{~Hz}$ frequency band-pass filter, and optimising the variance reduction, the calculated magnitudes range from Mw 6.7 (at $5-15 \mathrm{~km}$ deep) to Mw 7.1 (at $60 \mathrm{~km}$ deep). Magnitude increases with depth. Double-couple components are between $28 \%$ and $98 \%$, with the maximums at the depths of 35 and $40 \mathrm{~km}$. Magnitudes are Mw $6.9-\mathrm{Mw} 7.0$ for these depths. The focal mechanisms are all reverse/strike-slip.

\section{Five stations WHZ, MLZ, TUZ, EAZ \& WKZ, $0.03-0.06 \mathrm{~Hz}$ filter, optimising double-couple component}

The closest 5 stations within the 100 - $400 \mathrm{~km}$ range are WHZ, MLZ, TUZ, EAZ, and WKZ, at distances of $220 \mathrm{~km}$ to $350 \mathrm{~km}$, and with azimuths of $57^{\circ}-79^{\circ}$. Seismic moment tensor solutions were calculated using a $0.03-0.06 \mathrm{~Hz}$ frequency band-pass filter and optimising the double-couple component. The moment magnitudes of the seismic moment tensor solutions range from $\mathrm{Mw} 6.5$ at $8 \mathrm{~km}$ depth, to $\mathrm{Mw} 7.2$ at depths of $45 \mathrm{~km}-55 \mathrm{~km}$. Double couple components range from $75 \%$ to $100 \%$. Focal mechanisms are strike-slip/normal for the $5 \mathrm{~km}$ deep solution, strike-slip/reverse for the $8-9 \mathrm{~km}$ deep solutions, strike-slip/normal for the $10-11 \mathrm{~km}$ deep solutions, strike-slip/reverse for the $12 \mathrm{~km}$ deep solution, strike-slip for the $20-30 \mathrm{~km}$ deep solutions, normal/strike-slip for the $40-55 \mathrm{~km}$ deep solutions, and strike-slip/normal for the $60 \mathrm{~km}$ deep solution. The high double couple components for depths of $40-50 \mathrm{~km}$ suggests that the depth is in this range. The variance reduction is also high in this depth range.

\section{Five stations WHZ, MLZ, TUZ, EAZ \& JCZ, $0.03-0.06 \mathrm{~Hz}$ filter, optimising double-couple component}

Another set of five stations, WHZ, MLZ, TUZ, EAZ, and JCZ, lie in the distance range of $220-390 \mathrm{~km}$, and are at azimuths of $45^{\circ}$ to $79^{\circ}$. Seismic moment tensor solutions were calculated using a $0.03-0.06 \mathrm{~Hz}$ frequency band-pass filter and optimising the doublecouple component. The moment magnitudes of the seismic moment tensor solutions range from Mw 6.4 at a depth of $20 \mathrm{~km}$ to $\mathrm{Mw} 7.1$ at $60 \mathrm{~km}$. Double couple components range from $83 \%$ to $100 \%$. Focal mechanism solutions are strike-slip/vertical dip-slip at $5 \mathrm{~km}$ deep, reverse/strike-slip faulting at $10 \mathrm{~km}$, strike-slip at $20 \mathrm{~km}$, strike-slip/vertical dip-slip for the $23 \mathrm{~km}$ deep solution, normal/strike-slip faulting for the $25-27 \mathrm{~km}$ deep solutions, strike-slip 
for the $30 \mathrm{~km}$ deep solution, reverse/strike-slip for the $35-40 \mathrm{~km}$ deep solutions, normal/strike-slip for the 43 - $55 \mathrm{~km}$ deep solutions, and normal/strike-slip for the $60 \mathrm{~km}$ deep solution. The best solutions, with the highest variance reductions have depths of $35-$ $47 \mathrm{~km}$, and moment magnitudes of Mw 6.8 - Mw 7.0.

\section{Four stations WHZ, MLZ, TUZ \& EAZ, $0.03-0.06 \mathrm{~Hz}$ filter, optimising double- couple component}

The closest four stations within the 100 - $400 \mathrm{~km}$ distance range are WHZ, MLZ, TUZ, and EAZ. Seismic moment tensor solutions were calculated using a $0.03-0.06 \mathrm{~Hz}$ frequency band-pass filter and optimising the double-couple component. These stations lie at distances of $220 \mathrm{~km}-345 \mathrm{~km}$ from the epicentre, with azimuths of $59^{\circ}-79^{\circ}$. Moment magnitudes of the seismic moment tensor solutions range from $\mathrm{Mw} 6.6$ at $10 \mathrm{~km}$ deep to $\mathrm{Mw} 7.0$ at $35 \mathrm{~km}$ and $50 \mathrm{~km}$ deep. Double-couple components range from $87 \%$ to $100 \%$. Focal mechanisms are normal/strike-slip for the $5 \mathrm{~km}$ deep solution, reverse/strike-slip for the $10 \mathrm{~km}$ deep solution, strike-slip/normal for the $15 \mathrm{~km}$ deep solution, strike-slip for the $18 \mathrm{~km}$ deep solution, normal/strike-slip for the $20-30 \mathrm{~km}$ deep solutions, strike-slip/normal for the 32 $\mathrm{km}$ deep solution, reverse/strike-slip for the $35 \mathrm{~km}$ deep solution, strike-slip for the $40 \mathrm{~km}$ deep solution, and normal/strike-slip for the $50-60 \mathrm{~km}$ deep solutions. There is a lot of variation between the fault plane orientations with depth. The $30 \mathrm{~km}$ deep solution has the best fit of the synthetics to the data, and a moment magnitude of Mw 6.9.

\section{Three stations WHZ, MLZ \& TUZ, $0.03-0.06 \mathrm{~Hz}$ filter, optimising double- couple component}

The closest three stations within the $100-400 \mathrm{~km}$ distance range are WHZ, MLZ, and TUZ. These stations lie within $220 \mathrm{~km}$ and $340 \mathrm{~km}$, and at azimuths of $59^{\circ}-79^{\circ}$. Seismic moment tensor solutions were calculated using a $0.03-0.06 \mathrm{~Hz}$ frequency band-pass filter and optimising the double-couple component. Moment magnitudes range from Mw 6.5 (at $15 \mathrm{~km}$ and $25 \mathrm{~km}$ deep) to $\mathrm{Mw} 7.1$ at a depth of $60 \mathrm{~km}$. Double-couple components range from $82 \%$ to $99 \%$. The $50 \mathrm{~km}$ deep solution has the best fit of the synthetics to the data, and a moment magnitude of Mw 7.0. Focal mechanisms are normal-slip for the $5 \mathrm{~km}$ deep solution, reverse/strike-slip for the $10 \mathrm{~km}$ deep solution, strike-slip/normal-slip for the 15 $20 \mathrm{~km}$ deep solutions, normal/strike-slip for the $25 \mathrm{~km}$ deep solution, strike-slip/normal-slip for the $30 \mathrm{~km}$ deep solution, strike-slip/vertical dip-slip for the $40-45 \mathrm{~km}$ deep solutions, normal/strike-slip for the $50-55 \mathrm{~km}$ deep solutions, and reverse/strike-slip for the $60 \mathrm{~km}$ deep solution. There is a lot of variation between the fault plane orientations with depth.

\section{0 seconds of data before $P$-wave arrival, $0.03-0.06 \mathrm{~Hz}$ filter, maximising double-couple component, zero seconds initial offset between seismograms and synthetic seismograms}

\section{Six stations}

Seismic moment tensor solutions were produced for depths of $5-60 \mathrm{~km}$ (with an interval of $5 \mathrm{~km}$ ) using the six stations WHZ, MLZ, TUZ, EAZ, WKZ, and JCZ (at distances of $220-$ $390 \mathrm{~km}$ and azimuths of $45^{\circ}-79^{\circ}$ from the epicentre), 10 seconds of data before the P-wave arrival, a frequency passband of $0.03-0.06 \mathrm{~Hz}$, and maximising the double-couple component. These moment tensors gave moment magnitudes of Mw 6.4- Mw 7.0. The fits of the synthetic seismograms to the data were poor for all depths. The focal mechanisms were all combinations of normal and strike-slip. 


\section{Five stations}

Seismic moment tensor solutions were produced for depths of $5-60 \mathrm{~km}$ (with an interval of $5 \mathrm{~km}$ ) using the five stations WHZ, MLZ, TUZ, EAZ and WKZ (at distances of $220-350$ $\mathrm{km}$ and azimuths of $57^{\circ}-79^{\circ}$ from the epicentre), 10 seconds of data before the P-wave arrival, a frequency passband of $0.03-0.06 \mathrm{~Hz}$, and maximising the double-couple component. These moment tensors gave moment magnitudes of Mw 6.6- Mw 7.2. The fits of the synthetic seismograms to the data were poor for all depths. Focal mechanisms had elements of strike-slip, normal, and reverse slip.

\section{Four stations}

Seismic moment tensor solutions were produced for depths of 5-60 km (with an interval of $5 \mathrm{~km}$ ) using the four stations WHZ, MLZ, TUZ and EAZ (at distances of $220-345 \mathrm{~km}$ and azimuths of $59^{\circ}-79^{\circ}$ from the epicentre), 10 seconds of data before the P-wave arrival, a frequency passband of $0.03-0.06 \mathrm{~Hz}$, and maximising the double-couple component. These moment tensors gave moment magnitudes of $\mathrm{Mw}$ 6.5- Mw 7.0. The fits of the synthetic seismograms to the data were poor for all depths. Focal mechanisms had elements of strikeslip, normal, and reverse slip.

\section{Three stations}

Seismic moment tensor solutions were produced for depths of $5-60 \mathrm{~km}$ (with an interval of $5 \mathrm{~km}$ ) using the three stations WHZ, MLZ and TUZ (at distances of $220-340 \mathrm{~km}$ and azimuths of $59^{\circ}-79^{\circ}$ from the epicentre), 10 seconds of data before the P-wave arrival, a frequency passband of $0.03-0.06 \mathrm{~Hz}$, and maximising the double-couple component. These moment tensors gave moment magnitudes of $\mathrm{Mw}$ 6.5- Mw 7.0. The fits of the synthetic seismograms to the data were poor for all depths. Focal mechanisms had elements of strikeslip, normal, and reverse slip.

\section{0 seconds of data before P-wave arrival, 0.03-0.06Hz filter, maximising double-couple component, zero seconds initial offset between seismograms and synthetic seismograms}

\section{Six stations}

Seismic moment tensor solutions were produced for depths of $5-60 \mathrm{~km}$ (with an interval of $5 \mathrm{~km}$ ) using the six stations WHZ, MLZ, TUZ, EAZ, WKZ, and JCZ (at distances of $220-$ $390 \mathrm{~km}$ and azimuths of $45^{\circ}-79^{\circ}$ from the epicentre), 30 seconds of data before the P-wave arrival, a frequency passband of $0.03-0.06 \mathrm{~Hz}$, and maximising the double-couple component. The initial value of the offset between the seismograms and the synthetic seismograms was set to zero. These moment tensors have moment magnitudes of $\mathrm{Mw} 6.3$ Mw 7.0. The fits of the synthetic seismograms to the data were poor for all depths. Focal mechanisms had elements of strike-slip, normal, and reverse slip.

\section{Five stations}

Seismic moment tensor solutions were produced for depths of $5-60 \mathrm{~km}$ (with an interval of $5 \mathrm{~km}$ ) using the five stations WHZ, MLZ, TUZ, EAZ and WKZ (at distances of $220-350$ $\mathrm{km}$ and azimuths of $57^{\circ}-79^{\circ}$ from the epicentre), 30 seconds of data before the P-wave arrival, a frequency pass-band of $0.03-0.06 \mathrm{~Hz}$, and maximising the double-couple component. The initial value of the offset between the seismograms and the synthetic seismograms was set to zero. The moment magnitudes of these solutions are $\mathrm{Mw} 6.3-\mathrm{Mw}$ 
7.1. The fits of the synthetic seismograms to the data were poor for all depths. Focal mechanisms had elements of strike-slip, normal, and reverse slip.

\section{Four stations}

Seismic moment tensor solutions were produced for depths of $5-60 \mathrm{~km}$ (with an interval of $5 \mathrm{~km}$ ) using the four stations WHZ, MLZ, TUZ and EAZ (at distances of $220-345 \mathrm{~km}$ and azimuths of $59^{\circ}-79^{\circ}$ from the epicentre), 30 seconds of data before the P-wave arrival, a frequency pass-band of $0.03-0.06 \mathrm{~Hz}$, and maximising the double-couple component. The initial value of the offset between the seismograms and the synthetic seismograms was set to zero. The moment magnitudes of these solutions are Mw 6.4-Mw 7.0. The fits of the synthetic seismograms to the data were poor for all depths. Focal mechanisms had elements of strike-slip, normal, and reverse slip.

\section{Three stations}

Seismic moment tensor solutions were produced for depths of $5-60 \mathrm{~km}$ (with an interval of $5 \mathrm{~km}$ ) using the three stations WHZ, MLZ and TUZ (at distances of $220-340 \mathrm{~km}$ and azimuths of $59^{\circ}-79^{\circ}$ from the epicentre), 30 seconds of data before the P-wave arrival, a frequency pass-band of $0.03-0.06 \mathrm{~Hz}$, and maximising the double-couple component. The initial value of the offset between the seismograms and the synthetic seismograms was set to zero. The moment magnitudes of these solutions are Mw 6.2-Mw 7.1. The fits of the synthetic seismograms to the data were poor for all depths. Focal mechanisms had elements of strike-slip, normal, and reverse slip.

\section{0 seconds of data before $P$-wave arrival, 0.03-0.06Hz filter, maximising double-couple component, thirty seconds initial offset between seismograms and synthetic seismograms, six stations}

Seismic moment tensor solutions were produced for depths of $5-60 \mathrm{~km}$ (with an interval of $5 \mathrm{~km}$ ) using the six stations WHZ, MLZ, TUZ, EAZ, WKZ, and JCZ (at distances of $220-$ $390 \mathrm{~km}$ and azimuths of $45^{\circ}-79^{\circ}$ from the epicentre), 30 seconds of data before the P-wave arrival, a frequency passband of $0.03-0.06 \mathrm{~Hz}$, and maximising the double-couple component. The initial value of the offset between the seismograms and the synthetic seismograms was set to thirty seconds. These moment tensors have moment magnitudes of Mw 6.6-Mw 7.1. The fits of the synthetic seismograms to the data are good at depths of 5 and $10 \mathrm{~km}$. The $5 \mathrm{~km}$ deep solution is the best solution and has a reverse slip focal mechanism and a moment magnitude of $\mathrm{Mw}$ 6.8. The $10 \mathrm{~km}$ deep solution has a normal/strike-slip solution and a moment magnitude of Mw 6.7. The focal mechanisms for the $15-60 \mathrm{~km}$ deep solutions are all reverse/strike-slip, and the fits of the synthetic seismograms to the data are reasonable for these depths.

\section{One minute of data before P-wave arrival, $0.03-0.06 \mathrm{~Hz}$ filter, maximising double-couple component, zero seconds initial offset between seismograms and synthetic seismograms}

\section{Six stations}

Seismic moment tensor solutions were produced for depths of $5-60 \mathrm{~km}$ (with an interval of $5 \mathrm{~km}$ ) using the six stations WHZ, MLZ, TUZ, EAZ, WKZ, and JCZ (at distances of $220-$ $390 \mathrm{~km}$ and azimuths of $45^{\circ}-79^{\circ}$ from the epicentre), one minute of data before the P-wave arrival, a frequency passband of $0.03-0.06 \mathrm{~Hz}$, and maximising the double-couple component. The initial value of the offset between the seismograms and the synthetic 
seismograms was set to zero. These moment tensors have moment magnitudes of Mw $6.4-$ Mw 7.0. The fits of the synthetic seismograms to the data are poor for all depths. Focal mechanisms for the solutions with various depths have elements of strike-slip, normal-slip and reverse-slip.

\section{Five stations}

Seismic moment tensor solutions were produced for depths of $5-60 \mathrm{~km}$ (with an interval of $5 \mathrm{~km}$ ) using the five stations WHZ, MLZ, TUZ, EAZ and WKZ (at distances of $220-350$ $\mathrm{km}$ and azimuths of $57^{\circ}-79^{\circ}$ from the epicentre), one minute of data before the P-wave arrival, a frequency passband of $0.03-0.06 \mathrm{~Hz}$, and maximising the double-couple component. The initial value of the offset between the seismograms and the synthetic seismograms was set to zero. These moment tensors have moment magnitudes of Mw $6.4-$ Mw 7.2. The fits of the synthetic seismograms to the data are poor for all depths. Focal mechanisms for the solutions with various depths have elements of strike-slip, normal-slip and reverse-slip.

\section{Four stations}

Seismic moment tensor solutions were produced for depths of $5-60 \mathrm{~km}$ (with an interval of $5 \mathrm{~km}$ ) using the four stations WHZ, MLZ, TUZ and EAZ (at distances of $220-345 \mathrm{~km}$ and azimuths of $59^{\circ}-79^{\circ}$ from the epicentre), one minute of data before the P-wave arrival, a frequency passband of $0.03-0.06 \mathrm{~Hz}$, and maximising the double-couple component. The initial value of the offset between the seismograms and the synthetic seismograms was set to zero. These moment tensors have moment magnitudes of Mw 6.6-Mw 7.1. The fits of the synthetic seismograms to the data are poor for all depths. Focal mechanisms for the solutions with various depths have elements of strike-slip, normal-slip and reverse-slip.

\section{Three stations}

Seismic moment tensor solutions were produced for depths of $5-60 \mathrm{~km}$ (with an interval of $5 \mathrm{~km}$ ) using the three stations WHZ, MLZ and TUZ (at distances of $220-340 \mathrm{~km}$ and azimuths of $59^{\circ}-79^{\circ}$ from the epicentre), one minute of data before the P-wave arrival, a frequency passband of $0.03-0.06 \mathrm{~Hz}$, and maximising the double-couple component. The initial value of the offset between the seismograms and the synthetic seismograms was set to zero. These moment tensors have moment magnitudes of Mw 5.9-Mw 6.9. The fits of the synthetic seismograms to the data are poor for all depths. Focal mechanisms for the solutions with various depths have elements of strike-slip, normal-slip and reverse-slip.

\section{One minute of data before P-wave arrival, 0.03-0.06Hz filter, maximising double-couple component, sixty seconds initial offset between seismograms and synthetic seismograms, six stations}

Seismic moment tensor solutions were produced for depths of $5-60 \mathrm{~km}$ (with an interval of $5 \mathrm{~km}$ ) using the six stations WHZ, MLZ, TUZ, EAZ, WKZ, and JCZ (at distances of $220-$ $390 \mathrm{~km}$ and azimuths of $45^{\circ}-79^{\circ}$ from the epicentre), one minute of data before the P-wave arrival, a frequency passband of $0.03-0.06 \mathrm{~Hz}$, and maximising the double-couple component. The initial value of the offset between the seismograms and the synthetic seismograms was set to sixty seconds. These moment tensors have moment magnitudes of Mw 6.6 - Mw 7.0. The fits of the synthetic seismograms to the data are good for the $5 \mathrm{~km}$ deep solution, and reasonable for all other depths. The $5 \mathrm{~km}$ deep solution has a moment magnitude of $\mathrm{Mw} 6.8$, and a reverse-slip focal mechanism. The $10-60 \mathrm{~km}$ deep solutions have normal/strike-slip focal mechanisms. 


\section{One minute of data before P-wave arrival, 0.02-0.05Hz filter, maximising double-couple component, zero seconds initial offset between seismograms and synthetic seismograms}

\section{Six stations}

Seismic moment tensor solutions were produced for depths of $5-60 \mathrm{~km}$ (with an interval of $5 \mathrm{~km}$ ) using the six stations WHZ, MLZ, TUZ, EAZ, WKZ, and JCZ (at distances of $220-$ $390 \mathrm{~km}$ and azimuths of $45^{\circ}-79^{\circ}$ from the epicentre), one minute of data before the P-wave arrival, a frequency passband of $0.02-0.05 \mathrm{~Hz}$, and maximising the double-couple component. The initial value of the offset between the seismograms and the synthetic seismograms was set to zero. These moment tensors have moment magnitudes of Mw 6.4 Mw 7.2. The fits of the synthetic seismograms to the data are poor for all depths. Focal mechanisms for the solutions with various depths have elements of strike-slip, normal-slip and reverse-slip.

\section{Five stations}

Seismic moment tensor solutions were produced for depths of $5-60 \mathrm{~km}$ (with an interval of $5 \mathrm{~km}$ ) using the five stations WHZ, MLZ, TUZ, EAZ and WKZ (at distances of $220-350$ $\mathrm{km}$ and azimuths of $57^{\circ}-79^{\circ}$ from the epicentre), one minute of data before the $\mathrm{P}$-wave arrival, a frequency passband of $0.02-0.05 \mathrm{~Hz}$, and maximising the double-couple component. The initial value of the offset between the seismograms and the synthetic seismograms was set to zero. These moment tensors have moment magnitudes of Mw $6.4-$ Mw 7.1. The fits of the synthetic seismograms to the data are poor for all depths. Focal mechanisms for the solutions with various depths have elements of strike-slip, normal-slip and reverse-slip.

\section{Four stations}

Seismic moment tensor solutions were produced for depths of $5-60 \mathrm{~km}$ (with an interval of $5 \mathrm{~km}$ ) using the four stations WHZ, MLZ, TUZ and EAZ (at distances of $220-345 \mathrm{~km}$ and azimuths of $59^{\circ}-79^{\circ}$ from the epicentre), one minute of data before the P-wave arrival, a frequency passband of $0.02-0.05 \mathrm{~Hz}$, and maximising the double-couple component. The initial value of the offset between the seismograms and the synthetic seismograms was set to zero. These moment tensors have moment magnitudes of Mw 6.4-Mw 7.2. The fits of the synthetic seismograms to the data are poor for all depths. Focal mechanisms for the solutions with various depths have elements of strike-slip, normal-slip and reverse-slip.

\section{Three stations}

Seismic moment tensor solutions were produced for depths of $5-60 \mathrm{~km}$ (with an interval of $5 \mathrm{~km}$ ) using the three stations WHZ, MLZ and TUZ (at distances of $220-340 \mathrm{~km}$ and azimuths of $59^{\circ}-79^{\circ}$ from the epicentre), one minute of data before the P-wave arrival, a frequency passband of $0.02-0.05 \mathrm{~Hz}$, and maximising the double-couple component. The initial value of the offset between the seismograms and the synthetic seismograms was set to zero. These moment tensors have moment magnitudes of Mw 6.3-Mw 6.9. The fits of the synthetic seismograms to the data are poor for all depths. Focal mechanisms for the solutions with various depths have elements of strike-slip, normal-slip and reverse-slip. 


\section{One minute of data before P-wave arrival, 0.02-0.05Hz filter, maximising double-couple component, sixty seconds initial offset between seismograms and synthetic seismograms}

\section{Six stations}

Seismic moment tensor solutions were produced for depths of $5-60 \mathrm{~km}$ (with an interval of $5 \mathrm{~km}$ ) using the six stations WHZ, MLZ, TUZ, EAZ, WKZ, and JCZ (at distances of $220-$ $390 \mathrm{~km}$ and azimuths of $45^{\circ}-79^{\circ}$ from the epicentre), one minute of data before the P-wave arrival, a frequency passband of $0.02-0.05 \mathrm{~Hz}$, and maximising the double-couple component. The initial value of the offset between the seismograms and the synthetic seismograms was set to sixty seconds. These moment tensors have moment magnitudes of Mw 6.7 - Mw 7.1. The fits of the synthetic seismograms to the data are poor for all depths. Focal mechanisms for the solutions with various depths have elements of strike-slip, normalslip and reverse-slip.

\section{Three stations}

Seismic moment tensor solutions were produced for depths of 5-60 km (with an interval of $5 \mathrm{~km}$ ) using the three stations WHZ, MLZ and TUZ (at distances of $220-340 \mathrm{~km}$ and azimuths of $59^{\circ}-79^{\circ}$ from the epicentre), one minute of data before the P-wave arrival, a frequency passband of $0.02-0.05 \mathrm{~Hz}$, and maximising the double-couple component. The initial value of the offset between the seismograms and the synthetic seismograms was set to sixty seconds. These moment tensors have moment magnitudes of Mw 6.4-Mw 7.0. The fits of the synthetic seismograms to the data are poor for all depths. Focal mechanisms for the solutions with various depths have elements of strike-slip, normal-slip and reverse-slip.

\section{Two minutes of data before P-wave arrival, 0.03-0.06Hz filter, maximising double-couple component, zero seconds initial offset between seismograms and synthetic seismograms}

\section{Six stations}

Seismic moment tensor solutions were produced for depths of $5-60 \mathrm{~km}$ (with an interval of $5 \mathrm{~km}$ ) using the six stations WHZ, MLZ, TUZ, EAZ, WKZ, and JCZ (at distances of $220-$ $390 \mathrm{~km}$ and azimuths of $45^{\circ}-79^{\circ}$ from the epicentre), two minutes of data before the Pwave arrival, a frequency passband of $0.03-0.06 \mathrm{~Hz}$, and maximising the double-couple component. The initial value of the offset between the seismograms and the synthetic seismograms was set to zero. These moment tensors have moment magnitudes of $\mathrm{Mw} 6.5$ Mw 6.9. The fits of the synthetic seismograms to the data are poor for all depths. Focal mechanisms for the solutions with various depths have elements of strike-slip, normal-slip and reverse-slip.

\section{Five stations}

Seismic moment tensor solutions were produced for depths of $5-60 \mathrm{~km}$ (with an interval of $5 \mathrm{~km}$ ) using the five stations WHZ, MLZ, TUZ, EAZ and WKZ (at distances of $220-350$ $\mathrm{km}$ and azimuths of $57^{\circ}-79^{\circ}$ from the epicentre), two minutes of data before the P-wave arrival, a frequency passband of $0.03-0.06 \mathrm{~Hz}$, and maximising the double-couple component. The initial value of the offset between the seismograms and the synthetic seismograms was set to zero. These moment tensors have moment magnitudes of Mw $6.4-$ Mw 7.1. The fits of the synthetic seismograms to the data are poor for all depths. Focal 
mechanisms for the solutions with various depths have elements of strike-slip, normal-slip and reverse-slip.

\section{Four stations}

Seismic moment tensor solutions were produced for depths of $5-60 \mathrm{~km}$ (with an interval of $5 \mathrm{~km}$ ) using the four stations WHZ, MLZ, TUZ and EAZ (at distances of $220-345 \mathrm{~km}$ and azimuths of $59^{\circ}-79^{\circ}$ from the epicentre), two minutes of data before the P-wave arrival, a frequency passband of $0.03-0.06 \mathrm{~Hz}$, and maximising the double-couple component. The initial value of the offset between the seismograms and the synthetic seismograms was set to zero. These moment tensors have moment magnitudes of Mw 5.1-Mw 7.1. The fits of the synthetic seismograms to the data are poor for all depths. Focal mechanisms for the solutions with various depths have elements of strike-slip, normal-slip and reverse-slip.

\section{Three stations}

Seismic moment tensor solutions were produced for depths of $5-60 \mathrm{~km}$ (with an interval of $5 \mathrm{~km}$ ) using the three stations WHZ, MLZ and TUZ (at distances of $220-340 \mathrm{~km}$ and azimuths of $59^{\circ}-79^{\circ}$ from the epicentre), two minutes of data before the P-wave arrival, a frequency passband of $0.03-0.06 \mathrm{~Hz}$, and maximising the double-couple component. The initial value of the offset between the seismograms and the synthetic seismograms was set to zero. These moment tensors have moment magnitudes of Mw 6.3-Mw 7.0. The fits of the synthetic seismograms to the data are poor for all depths. Focal mechanisms for the solutions with various depths have elements of strike-slip, normal-slip and reverse-slip.

\section{Two minutes of data before P-wave arrival, 0.03-0.06Hz filter, maximising double-couple component, one hundred and twenty seconds initial offset between seismograms and synthetic seismograms}

\section{Six stations}

Seismic moment tensor solutions were produced for depths of $10-60 \mathrm{~km}$ (with an interval of $10 \mathrm{~km}$ ) using the six stations WHZ, MLZ, TUZ, EAZ, WKZ, and JCZ (at distances of 220 $390 \mathrm{~km}$ and azimuths of $45^{\circ}-79^{\circ}$ from the epicentre), two minutes of data before the Pwave arrival, a frequency passband of $0.03-0.06 \mathrm{~Hz}$, and maximising the double-couple component. The initial value of the offset between the seismograms and the synthetic seismograms was set to one hundred and twenty seconds. These moment tensors have moment magnitudes of Mw 6.7 - Mw 7.0. The fits of the synthetic seismograms to the data are fairly good for the $10 \mathrm{~km}$ deep solution, and poor for the other depths. The $10 \mathrm{~km}$ deep solution has a moment magnitude of 6.7. Focal mechanisms are normal/strike-slip for all depths.

\section{Five stations}

Seismic moment tensor solutions were produced for depths of $5-60 \mathrm{~km}$ (with an interval of $5 \mathrm{~km}$ ) using the five stations WHZ, MLZ, TUZ, EAZ and WKZ (at distances of $220-350$ $\mathrm{km}$ and azimuths of $57^{\circ}-79^{\circ}$ from the epicentre), two minutes of data before the P-wave arrival, a frequency passband of $0.03-0.06 \mathrm{~Hz}$, and maximising the double-couple component. The initial value of the offset between the seismograms and the synthetic seismograms was set to one hundred and twenty seconds. These moment tensors have moment magnitudes of $\mathrm{Mw} 6.7-\mathrm{Mw}$ 7.2. The fits of the synthetic seismograms to the data are good for all depths. The best solution is the $55 \mathrm{~km}$ deep solution, with a moment magnitude of 7.2. Focal mechanisms are strike-slip/normal-slip for all depths. 


\section{Four stations}

Seismic moment tensor solutions were produced for depths of $5-60 \mathrm{~km}$ (with an interval of $5 \mathrm{~km}$ ) using the four stations WHZ, MLZ, TUZ and EAZ (at distances of $220-345 \mathrm{~km}$ and azimuths of $59^{\circ}-79^{\circ}$ from the epicentre), two minutes of data before the P-wave arrival, a frequency passband of $0.03-0.06 \mathrm{~Hz}$, and maximising the double-couple component. The initial value of the offset between the seismograms and the synthetic seismograms was set to one hundred and twenty seconds. These moment tensors have moment magnitudes of Mw 6.6 - Mw 7.1. The fits of the synthetic seismograms to the data are good for the $5-50 \mathrm{~km}$ deep solutions, which have magnitudes of Mw 6.6- Mw 7.1. Focal mechanisms are strikeslip/reverse-slip for the $5 \mathrm{~km}$ deep solution and strike-slip/normal-slip for the $10-60 \mathrm{~km}$ deep solutions. The best solution is the $35 \mathrm{~km}$ deep solution, with a moment magnitude of 7.0. This is the best solution produced for this event, and is shown in Figure A1.12.

\section{Three stations}

Seismic moment tensor solutions were produced for depths of 5-60 km (with an interval of $5 \mathrm{~km}$ ) using the three stations WHZ, MLZ, and TUZ (at distances of $220-340 \mathrm{~km}$ and azimuths of $59^{\circ}-79^{\circ}$ from the epicentre), two minutes of data before the P-wave arrival, a frequency passband of $0.03-0.06 \mathrm{~Hz}$, and maximising the double-couple component. The initial value of the offset between the seismograms and the synthetic seismograms was set to one hundred and twenty seconds. These moment tensors have moment magnitudes of Mw 6.4 - Mw 7.0. The fits of the synthetic seismograms to the data are good for the $10-15 \mathrm{~km}$ and $40-45 \mathrm{~km}$ deep solutions, with magnitudes of Mw 6.7-Mw 7.0. The best solution is the 15 $\mathrm{km}$ deep solution, with a moment magnitude of 6.8. Focal mechanisms are strike-slip for the $5 \mathrm{~km}$ deep solution, normal-slip for the $10 \mathrm{~km}$ deep solution, strike-slip for the $15 \mathrm{~km}$ deep solution, normal-slip for the $20 \mathrm{~km}$ deep solution, and normal/strike-slip for the $25-60 \mathrm{~km}$ deep solutions.

\section{Two minutes of data before P-wave arrival, 0.02-0.05Hz filter, maximising double-couple component, zero seconds initial offset between seismograms and synthetic seismograms}

\section{Six stations}

Seismic moment tensor solutions were produced for depths of $5-60 \mathrm{~km}$ (with an interval of $5 \mathrm{~km}$ ) using the six stations WHZ, MLZ, TUZ, EAZ, WKZ, and JCZ (at distances of $220-$ $390 \mathrm{~km}$ and azimuths of $45^{\circ}-79^{\circ}$ from the epicentre), two minutes of data before the Pwave arrival, a frequency passband of $0.02-0.05 \mathrm{~Hz}$, and maximising the double-couple component. The initial value of the offset between the seismograms and the synthetic seismograms was set to zero. These moment tensors have moment magnitudes of Mw $6.4-$ $\mathrm{Mw}$ 7.0. The fits of the synthetic seismograms to the data are poor for all depths. Focal mechanisms are strike-slip and reverse-slip.

\section{Five stations}

Seismic moment tensor solutions were produced for depths of $5-60 \mathrm{~km}$ (with an interval of $5 \mathrm{~km}$ ) using the five stations WHZ, MLZ, TUZ, EAZ and WKZ (at distances of $220-350$ $\mathrm{km}$ and azimuths of $57^{\circ}-79^{\circ}$ from the epicentre), two minutes of data before the P-wave arrival, a frequency passband of $0.02-0.05 \mathrm{~Hz}$, and maximising the double-couple component. The initial value of the offset between the seismograms and the synthetic seismograms was set to zero. These moment tensors have moment magnitudes of $\mathrm{Mw} 6.3$ - 
Mw 7.2. The fits of the synthetic seismograms to the data are poor for all depths. Focal mechanisms for the solutions with various depths have elements of strike-slip, normal-slip and reverse-slip.

\section{Four stations}

Seismic moment tensor solutions were produced for depths of $5-60 \mathrm{~km}$ (with an interval of $5 \mathrm{~km}$ ) using the four stations WHZ, MLZ, TUZ and EAZ (at distances of $220-345 \mathrm{~km}$ and azimuths of $59^{\circ}-79^{\circ}$ from the epicentre), two minutes of data before the P-wave arrival, a frequency passband of $0.02-0.05 \mathrm{~Hz}$, and maximising the double-couple component. The initial value of the offset between the seismograms and the synthetic seismograms was set to zero. These moment tensors have moment magnitudes of Mw 6.3-Mw 7.0. The fits of the synthetic seismograms to the data are poor for all depths. Focal mechanisms for the solutions with various depths have elements of strike-slip, normal-slip and reverse-slip.

\section{Three stations}

Seismic moment tensor solutions were produced for depths of $5 \mathrm{~km}$ and $10-60 \mathrm{~km}$ (with an interval of $10 \mathrm{~km}$ ) using the three stations WHZ, MLZ, and TUZ (at distances of $220-340$ $\mathrm{km}$ and azimuths of $59^{\circ}-79^{\circ}$ from the epicentre), two minutes of data before the P-wave arrival, a frequency passband of $0.02-0.05 \mathrm{~Hz}$, and maximising the double-couple component. The initial value of the offset between the seismograms and the synthetic seismograms was set to zero. These moment tensors have moment magnitudes of Mw 6.2 Mw 7.0. The fits of the synthetic seismograms to the data are poor for all depths. Focal mechanisms for the solutions with various depths have elements of strike-slip, normal-slip and reverse-slip.

\section{Two minutes of data before P-wave arrival, 0.02-0.05Hz filter, maximising double-couple component, one hundred and twenty seconds initial offset between seismograms and synthetic seismograms}

\section{Six stations}

Seismic moment tensor solutions were produced for depths of $5-60 \mathrm{~km}$ (with an interval of $5 \mathrm{~km}$ ) using the six stations WHZ, MLZ, TUZ, EAZ, WKZ, and JCZ (at distances of 220 $390 \mathrm{~km}$ and azimuths of $45^{\circ}-79^{\circ}$ from the epicentre), two minutes of data before the Pwave arrival, a frequency passband of $0.02-0.05 \mathrm{~Hz}$, and maximising the double-couple component. The initial value of the offset between the seismograms and the synthetic seismograms was set to one hundred and twenty seconds. These moment tensors have moment magnitudes of Mw 6.6 - Mw 7.0. The fits of the synthetic seismograms to the data are poor for all depths. Focal mechanisms are strike-slip/reverse-slip for the $5 \mathrm{~km}$ deep solution and strike-slip/normal-slip for the $10-60 \mathrm{~km}$ deep solutions.

\section{Five stations}

Seismic moment tensor solutions were produced for depths of $5-60 \mathrm{~km}$ (with an interval of $5 \mathrm{~km}$ ) using the five stations WHZ, MLZ, TUZ, EAZ and WKZ (at distances of $220-350$ $\mathrm{km}$ and azimuths of $57^{\circ}-79^{\circ}$ from the epicentre), two minutes of data before the P-wave arrival, a frequency passband of $0.02-0.05 \mathrm{~Hz}$, and maximising the double-couple component. The initial value of the offset between the seismograms and the synthetic seismograms was set to one hundred and twenty seconds. These moment tensors have moment magnitudes of Mw 6.7-Mw 7.2. The fits of the synthetic seismograms to the data 
are mostly reasonable. The best solution is the $55 \mathrm{~km}$ deep solution, which has a moment magnitude of 7.2. Focal mechanisms are normal/strike-slip for all solutions.

\section{Four stations}

Seismic moment tensor solutions were produced for depths of $5-60 \mathrm{~km}$ (with an interval of $5 \mathrm{~km}$ ) using the four stations WHZ, MLZ, TUZ and EAZ (at distances of $220-345 \mathrm{~km}$ and azimuths of $59^{\circ}-79^{\circ}$ from the epicentre), two minutes of data before the P-wave arrival, a frequency passband of $0.02-0.05 \mathrm{~Hz}$, and maximising the double-couple component. The initial value of the offset between the seismograms and the synthetic seismograms was set to one hundred and twenty seconds. These moment tensors have moment magnitudes of Mw 6.5 - Mw 7.1. The fits of the synthetic seismograms to the data are poor for all depths. Focal mechanisms for the solutions with various depths have elements of strike-slip, normal-slip and reverse-slip.

\section{Three stations}

Seismic moment tensor solutions were produced for depths of $5-60 \mathrm{~km}$ (with an interval of $5 \mathrm{~km}$ ) using the three stations WHZ, MLZ and TUZ (at distances of $220-340 \mathrm{~km}$ and azimuths of $59^{\circ}-79^{\circ}$ from the epicentre), two minutes of data before the P-wave arrival, a frequency passband of $0.02-0.05 \mathrm{~Hz}$, and maximising the double-couple component. The initial value of the offset between the seismograms and the synthetic seismograms was set to one hundred and twenty seconds. These moment tensors have moment magnitudes of Mw 6.5 - Mw 7.1. The fits of the synthetic seismograms to the data are poor for all depths. Focal mechanisms are reverse/strike-slip for the $5-40 \mathrm{~km}$ deep solutions, strike-slip/normal-slip for the $45-50 \mathrm{~km}$ deep solutions, and strike-slip/reverse-slip for the $55-60 \mathrm{~km}$ deep solutions.

\section{Two minutes of data before P-wave arrival, 0.01-0.05Hz filter, maximising double-couple component, zero seconds initial offset between seismograms and synthetic seismograms}

\section{Six stations}

Seismic moment tensor solutions were produced for depths of $5-60 \mathrm{~km}$ (with an interval of $5 \mathrm{~km}$ ) using the six stations WHZ, MLZ, TUZ, EAZ, WKZ, and JCZ (at distances of $220-$ $390 \mathrm{~km}$ and azimuths of $45^{\circ}-79^{\circ}$ from the epicentre), two minutes of data before the Pwave arrival, a frequency passband of $0.01-0.05 \mathrm{~Hz}$, and maximising the double-couple component. The initial value of the offset between the seismograms and the synthetic seismograms was set to zero. These moment tensors have moment magnitudes of $\mathrm{Mw} 6.5-$ Mw 7.0. The fits of the synthetic seismograms to the data are poor for all depths. Focal mechanisms for the solutions with various depths have elements of strike-slip, normal-slip and reverse-slip.

\section{Five stations}

Seismic moment tensor solutions were produced for depths of $5-60 \mathrm{~km}$ (with an interval of $5 \mathrm{~km}$ ) using the five stations WHZ, MLZ, TUZ, EAZ and WKZ (at distances of $220-350$ $\mathrm{km}$ and azimuths of $57^{\circ}-79^{\circ}$ from the epicentre), two minutes of data before the P-wave arrival, a frequency passband of $0.01-0.05 \mathrm{~Hz}$, and maximising the double-couple component. The initial value of the offset between the seismograms and the synthetic seismograms was set to zero. These moment tensors have moment magnitudes of Mw $6.4-$ Mw 7.1. The fits of the synthetic seismograms to the data are poor for all depths. Focal 
mechanisms for the solutions with various depths have elements of strike-slip, normal-slip and reverse-slip.

\section{Four stations}

Seismic moment tensor solutions were produced for depths of $5-60 \mathrm{~km}$ (with an interval of $5 \mathrm{~km}$ ) using the four stations WHZ, MLZ, TUZ and EAZ (at distances of $220-345 \mathrm{~km}$ and azimuths of $59^{\circ}-79^{\circ}$ from the epicentre), two minutes of data before the P-wave arrival, a frequency passband of $0.01-0.05 \mathrm{~Hz}$, and maximising the double-couple component. The initial value of the offset between the seismograms and the synthetic seismograms was set to zero. These moment tensors have moment magnitudes of Mw 6.6-Mw 7.1. The fits of the synthetic seismograms to the data are poor for all depths. Focal mechanisms are reverse/strike-slip for all depths.

\section{Three stations}

Seismic moment tensor solutions were produced for depths of 5 and $10-60 \mathrm{~km}$ (with an interval of $10 \mathrm{~km}$ ) using the three stations WHZ, MLZ and TUZ (at distances of $220-340$ $\mathrm{km}$ and azimuths of $59^{\circ}-79^{\circ}$ from the epicentre), two minutes of data before the P-wave arrival, a frequency passband of $0.01-0.05 \mathrm{~Hz}$, and maximising the double-couple component. The initial value of the offset between the seismograms and the synthetic seismograms was set to zero. These moment tensors have moment magnitudes of Mw 5.9 Mw 7.1. The fits of the synthetic seismograms to the data are poor for all depths. Focal mechanisms are reverse/strike-slip for the $5-50 \mathrm{~km}$ deep solutions, and strike-slip for the 60 $\mathrm{km}$ deep solution.

\section{Two minutes of data before P-wave arrival, 0.01-0.05Hz filter, maximising double-couple component, one hundred and twenty seconds initial offset between seismograms and synthetic seismograms}

\section{Six stations}

Seismic moment tensor solutions were produced for depths of $5-60 \mathrm{~km}$ (with an interval of $5 \mathrm{~km}$ ) using the six stations WHZ, MLZ, TUZ, EAZ, WKZ, and JCZ (at distances of 220 $390 \mathrm{~km}$ and azimuths of $45^{\circ}-79^{\circ}$ from the epicentre), two minutes of data before the Pwave arrival, a frequency passband of $0.01-0.05 \mathrm{~Hz}$, and maximising the double-couple component. The initial value of the offset between the seismograms and the synthetic seismograms was set to one hundred and twenty seconds. These moment tensors have moment magnitudes of Mw 6.7 - Mw 7.0. The fits of the synthetic seismograms to the data are okay for all depths. The best solution, with the highest variance reduction, is the $45 \mathrm{~km}$ deep solution, with a magnitude of Mw 7.0 and a normal/strike-slip mechanism. The $5 \mathrm{~km}$ deep solution has a strike-slip mechanism, and the $10-60 \mathrm{~km}$ deep solutions have normal/strike-slip mechanisms.

\section{Five stations}

Seismic moment tensor solutions were produced for depths of $5-60 \mathrm{~km}$ (with an interval of $5 \mathrm{~km}$ ) using the five stations WHZ, MLZ, TUZ, EAZ and WKZ (at distances of $220-350$ $\mathrm{km}$ and azimuths of $57^{\circ}-79^{\circ}$ from the epicentre), two minutes of data before the P-wave arrival, a frequency passband of $0.01-0.05 \mathrm{~Hz}$, and maximising the double-couple component. The initial value of the offset between the seismograms and the synthetic seismograms was set to one hundred and twenty seconds. These moment tensors have moment magnitudes of Mw 6.8 - Mw 7.2. Focal mechanisms are normal/strike-slip for all 
depths. The fits of the synthetic seismograms to the data are good for all depths. The best solution is the $40 \mathrm{~km}$ deep solution, which has a magnitude of $\mathrm{Mw} 7.1$.

\section{Four stations}

Seismic moment tensor solutions were produced for depths of $5-60 \mathrm{~km}$ (with an interval of $5 \mathrm{~km}$ ) using the four stations WHZ, MLZ, TUZ and EAZ (at distances of $220-345 \mathrm{~km}$ and azimuths of $59^{\circ}-79^{\circ}$ from the epicentre), two minutes of data before the P-wave arrival, a frequency passband of $0.01-0.05 \mathrm{~Hz}$, and maximising the double-couple component. The initial value of the offset between the seismograms and the synthetic seismograms was set to one hundred and twenty seconds. These moment tensors have moment magnitudes of Mw 6.5 - Mw 7.0. The $5 \mathrm{~km}$ deep solution has a reverse/strike-slip focal mechanism, the $10-30 \mathrm{~km}$ deep solutions have strike-slip/normal focal mechanisms, the $35-40 \mathrm{~km}$ deep solutions have reverse/strike-slip mechanisms, the $45 \mathrm{~km}$ deep solution has a strike-slip/normal focal mechanism, and the 50-60 km deep solutions have strike-slip mechanisms. The fits of the synthetic seismograms to the data are good for the solutions with depths of $15-25 \mathrm{~km}$, and poor for all other depths. The best solution, is the $20 \mathrm{~km}$ deep solution, with a moment magnitude of Mw 6.8 and a strike-slip/normal focal mechanism. The $15-25 \mathrm{~km}$ deep solutions all have a moment magnitude of $\mathrm{Mw} 6.8$.

\section{Three stations}

Seismic moment tensor solutions were produced for depths of depths of $5-60 \mathrm{~km}$ (with an interval of $5 \mathrm{~km}$ ) using the three stations WHZ, MLZ and TUZ (at distances of $220-340 \mathrm{~km}$ and azimuths of $59^{\circ}-79^{\circ}$ from the epicentre), two minutes of data before the P-wave arrival, a frequency passband of $0.01-0.05 \mathrm{~Hz}$, and maximising the double-couple component. The initial value of the offset between the seismograms and the synthetic seismograms was set to one hundred and twenty seconds. These moment tensors have moment magnitudes of Mw 6.4 - Mw 7.0. The fits of the synthetic seismograms to the data are poor for all depths. Focal mechanisms are reverse for the $5 \mathrm{~km}$ deep solution, normal for the $10-15 \mathrm{~km}$ deep solutions, reverse/strike-slip for the $20-50 \mathrm{~km}$ deep solutions, and strike-slip for the $55-60$ $\mathrm{km}$ deep solutions.

\section{Summary}

Calculated magnitudes for this earthquake range from $\mathrm{Mw} 5.1$ to $\mathrm{Mw}$ 7.2. The best solutions have magnitudes of Mw 6.6-Mw 7.2. The depth can not be constrained. The most likely focal mechanism is a mostly strike-slip mechanism.

The best solution was produced using the four stations WHZ, MLZ, TUZ and EAZ, the 0.03 $-0.06 \mathrm{~Hz}$ frequency band-pass filter, maximising the double-couple component, two minutes of data before the P-wave arrival, an initial offset between the real and synthetic seismograms of 120 seconds and a depth of $35 \mathrm{~km}$. This solution is shown in Figure A1.1212, has a magnitude of $\mathrm{Mw} 7.0$ and shows normal/strike-slip faulting.

When using more than a few seconds of data before the P-wave arrival, the offset between the real and the synthetic seismograms should be increased from zero to match the amount of data before the P-wave arrival. 


\section{A1.12. Event 2352986 - Wairarapa}

18 January 2005, 0836 UT

Latitude -41.46, Longitude 175.79, depth $18.8 \pm 0.9 \mathrm{~km}$ (GNS)

Depth $18.7 \mathrm{~km}$ (Global CMT)

ML 5.3 (GNS), Mw 5.2 (Global CMT)

Global CMT focal plane 1: $\quad$ strike 218

Global CMT focal plane 2: $\quad$ strike 353

$\begin{array}{rrrr}\text { rake } & 133 & \text { dip } & \text { Glob } \\ \text { rake } & 74 & \text { dip } & 74\end{array}$

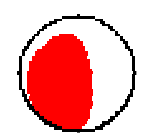

Global CMT mechanism

Data from five stations, at distances of $155-245 \mathrm{~km}$ and azimuths of $5^{\circ}-277^{\circ}$ from the epicentre, and listed in Table A1.12, were used to compute seismic moment tensor solutions for this earthquake.

Table A1.12:

\begin{tabular}{|l|l|c|c|}
\hline $\begin{array}{l}\text { Station } \\
\text { code }\end{array}$ & Station name & $\begin{array}{l}\text { Distance from } \\
\text { earthquake }\end{array}$ & $\begin{array}{l}\text { Azimuth from } \\
\text { earthquake }\end{array}$ \\
\hline TSZ & Takapari Road & $155 \mathrm{~km}$ & $5^{\circ}$ \\
\hline PWZ & Pawanui & $185 \mathrm{~km}$ & $30^{\circ}$ \\
\hline NNZ & Nelson & $205 \mathrm{~km}$ & $277^{\circ}$ \\
\hline KHZ & Kahutara & $215 \mathrm{~km}$ & $240^{\circ}$ \\
\hline THZ & Top House & $245 \mathrm{~km}$ & $261^{\circ}$ \\
\hline
\end{tabular}

This event was processed using the New Zealand standard velocity model and with frequency pass-band filters of $0.02-0.05 \mathrm{~Hz}, 0.02-0.10 \mathrm{~Hz}, 0.03-0.06 \mathrm{~Hz}$ and $0.04-0.10 \mathrm{~Hz}$.

Solutions were calculated for depths of $5-35 \mathrm{~km}$ with a $5 \mathrm{~km}$ depth interval, and also for a depth of $19 \mathrm{~km}$. The solution with the highest double-couple component was chosen as the best solution for that depth.

None of the solutions produced good fits between the synthetic seismograms and the data, so neither the moment magnitude nor the mechanism of this earthquake could be constrained. An example of the solutions produced (produced using the $0.03-0.06 \mathrm{~Hz}$ frequency bandpass filter and a depth of $15 \mathrm{~km}$ ) is shown in Figure A1.13.

\section{$0.02-0.05 \mathrm{~Hz}$ filter}

Using the $0.02-0.05 \mathrm{~Hz}$ frequency band-pass filter, the calculated moment magnitudes range from $\mathrm{Mw} 4.7$ (with a depth of $25 \mathrm{~km}$ ) to Mw 5.0 (with a depth of $35 \mathrm{~km}$ ). Focal mechanisms are all reverse/strike-slip. The $15 \mathrm{~km}$ deep solution has the highest variance reduction of 10.59, and a moment magnitude of $\mathrm{Mw} 4.9$. The fits of the synthetic seismograms to the data are poor for all solutions.

\section{$0.02-0.10 \mathrm{~Hz}$ filter}

Using the $0.02-0.10 \mathrm{~Hz}$ frequency band-pass filter, the calculated moment magnitudes range from Mw 4.4 (with a depth of $5 \mathrm{~km}$ ) to Mw 5.1 (with a depth of $35 \mathrm{~km}$ ). Focal mechanisms are reverse/strike-slip with a variety of focal plane orientations. The $19 \mathrm{~km}$ deep solution has the highest variance reduction of 9.78 and a moment magnitude of $\mathrm{Mw}$ 4.9. The fits of the synthetic seismograms to the data are poor for all solutions. 


\section{$0.03-0.06 \mathrm{~Hz}$ filter}

Using the $0.03-0.06 \mathrm{~Hz}$ frequency band-pass filter, the calculated moment magnitudes range from $\mathrm{Mw} 4.9$ (with depths of $5-25 \mathrm{~km}$ ) to $\mathrm{Mw} 5.1$ (with a depth of $35 \mathrm{~km}$ ). Focal mechanisms are all mostly strike-slip with some dip-slip (reverse or normal) components, and a variety of focal plane orientations. The $10 \mathrm{~km}$ deep solution has the highest variance reduction of 13.72 and a moment magnitude of $\mathrm{Mw}$ 4.9. The fits of the synthetic seismograms to the data are poor for all solutions. The $15 \mathrm{~km}$ solution is shown in Figure A1.13.
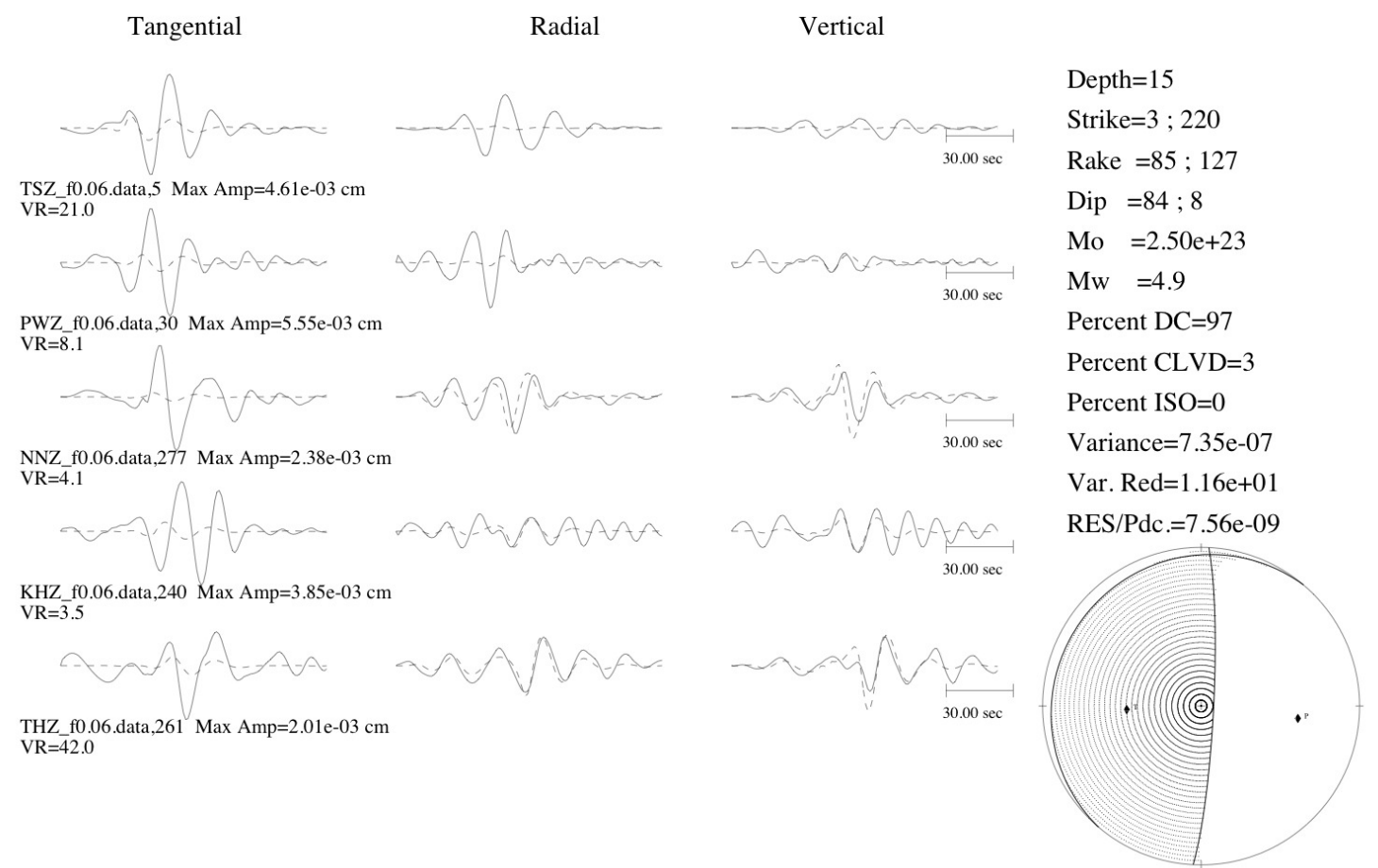

Figure A1.13. One of the solutions calculated for event 2352986. Processed using the 0.03 $-0.06 \mathrm{~Hz}$ frequency band-pass filter and a depth of $15 \mathrm{~km}$.

\section{$0.04-0.10 \mathrm{~Hz}$ filter}

Using the $0.04-0.10 \mathrm{~Hz}$ frequency band-pass filter, the calculated moment magnitudes range from Mw 4.8 (with a depth of $15 \mathrm{~km}$ ) to Mw 5.1 (with a depth of $35 \mathrm{~km}$ ). Focal mechanisms are strike-slip for solutions with depths of $5-10 \mathrm{~km}$, reverse-slip with various fault-plane orientations for solutions with depths of $15-25 \mathrm{~km}$, strike-slip for the $30 \mathrm{~km}$ deep solution, and reverse-slip for the $35 \mathrm{~km}$ deep solution. The $10 \mathrm{~km}$ deep solution has the highest variance reduction of 19.76 and a moment magnitude of $\mathrm{Mw}$ 4.9. The fits of the synthetic seismograms to the data are poor for all solutions.

\section{Summary}

None of the solutions produced a good fit of synthetic seismograms to the data. The range of calculated magnitudes is Mw 4.4-Mw 5.1. All of these magnitudes are lower than the Mw 5.2 calculated by the Global CMT project. The focal mechanism was not accurately determined using the TDMT_INVC method. 


\section{A1.13. Event 2353002 - Wairarapa}

18 January 2005, 0926 UT

Latitude -41.46, Longitude 175.80, depth $18.0 \pm 0.9 \mathrm{~km}$ (GNS)

Depth $26.6 \mathrm{~km}$ (Global CMT)

ML 5.2 (GNS), Mw 5.0 (Global CMT)

Global CMT focal plane 1: $\quad$ strike 200 rake 105 dip 28

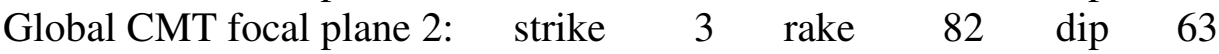

Data from five stations, at distances of $155-245 \mathrm{~km}$ and azimuths of $5^{\circ}-340^{\circ}$ from the epicentre, and listed in Table A1.13, were used to compute seismic moment tensor solutions for this earthquake.

Table A1.13:

\begin{tabular}{|l|l|c|c|}
\hline $\begin{array}{l}\text { Station } \\
\text { code }\end{array}$ & Station name & $\begin{array}{l}\text { Distance from } \\
\text { earthquake }\end{array}$ & $\begin{array}{l}\text { Azimuth from } \\
\text { earthquake }\end{array}$ \\
\hline TSZ & Takapari Road & $155 \mathrm{~km}$ & $5^{\circ}$ \\
\hline PWZ & Pawanui & $180 \mathrm{~km}$ & $30^{\circ}$ \\
\hline NNZ & Nelson & $205 \mathrm{~km}$ & $277^{\circ}$ \\
\hline KHZ & Kahutara & $215 \mathrm{~km}$ & $240^{\circ}$ \\
\hline THZ & Top House & $245 \mathrm{~km}$ & $261^{\circ}$ \\
\hline
\end{tabular}

This event was processed using the New Zealand standard velocity model. Frequency passband filters of $0.02-0.05 \mathrm{~Hz}, 0.02-0.10 \mathrm{~Hz}, 0.03-0.06 \mathrm{~Hz}$, and $0.04-0.10 \mathrm{~Hz}$ were used. Solutions were calculated for depths of $5-35 \mathrm{~km}$ at $5 \mathrm{~km}$ intervals and also for a depth of 18 $\mathrm{km}$. The solution with the highest double-couple component was chosen as the best solution for each depth.

None of the solutions produced good fits between the synthetic seismograms and the data, so neither the moment magnitude nor the mechanism of this earthquake could be constrained. An example of the solutions produced (produced using the $0.03-0.06 \mathrm{~Hz}$ frequency bandpass filter and a depth of $15 \mathrm{~km}$ ) is shown in Figure A1.14.

\section{$0.02-0.05 \mathrm{~Hz}$ filter}

Solutions calculated using the $0.02-0.05 \mathrm{~Hz}$ frequency band-pass filter have magnitudes of Mw 4.7 (for depths of $5-15 \mathrm{~km}$ and $25-30 \mathrm{~km}$ ) to $\mathrm{Mw} 5.1$ (for a depth of $35 \mathrm{~km}$ ). Focal mechanisms are vertical dip-slip/strike-slip for the $5 \mathrm{~km}$ deep solution and reverse/strike-slip for the $10-35 \mathrm{~km}$ deep solutions. The fits of the synthetic seismograms to the data are all poor.

\section{$0.02-0.10 \mathrm{~Hz}$ filter}

Solutions calculated using the $0.02-0.10 \mathrm{~Hz}$ frequency band-pass filter have magnitudes of Mw 4.5 (for a depth of $10 \mathrm{~km}$ ) to Mw 5.1 (for a depth of $35 \mathrm{~km}$ ). Focal mechanisms are strike-slip/normal for the $5-10 \mathrm{~km}$ deep solutions, reverse/strike-slip for the $15-20 \mathrm{~km}$ deep solutions, strike-slip/normal for the $25 \mathrm{~km}$ deep solution, and reverse/strike-slip for the $30-35 \mathrm{~km}$ deep solutions. The fits of the synthetic seismograms to the data are all poor. 


\section{$0.03-0.06 \mathrm{~Hz}$ filter}

Solutions calculated using the $0.03-0.06 \mathrm{~Hz}$ frequency band-pass filter have magnitudes of Mw 4.7 (for depths of $10-30 \mathrm{~km}$ ) to $\mathrm{Mw} 4.9$ (for a depth of $35 \mathrm{~km}$ ). Focal mechanisms are reverse/strike-slip for the $5-25 \mathrm{~km}$ deep solutions, strike-slip/normal for the $30 \mathrm{~km}$ deep solution, and reverse/strike-slip for the $35 \mathrm{~km}$ deep solution. The fits of the synthetic seismograms to the data are all poor. The $15 \mathrm{~km}$ deep solution is shown in Figure A1.14.

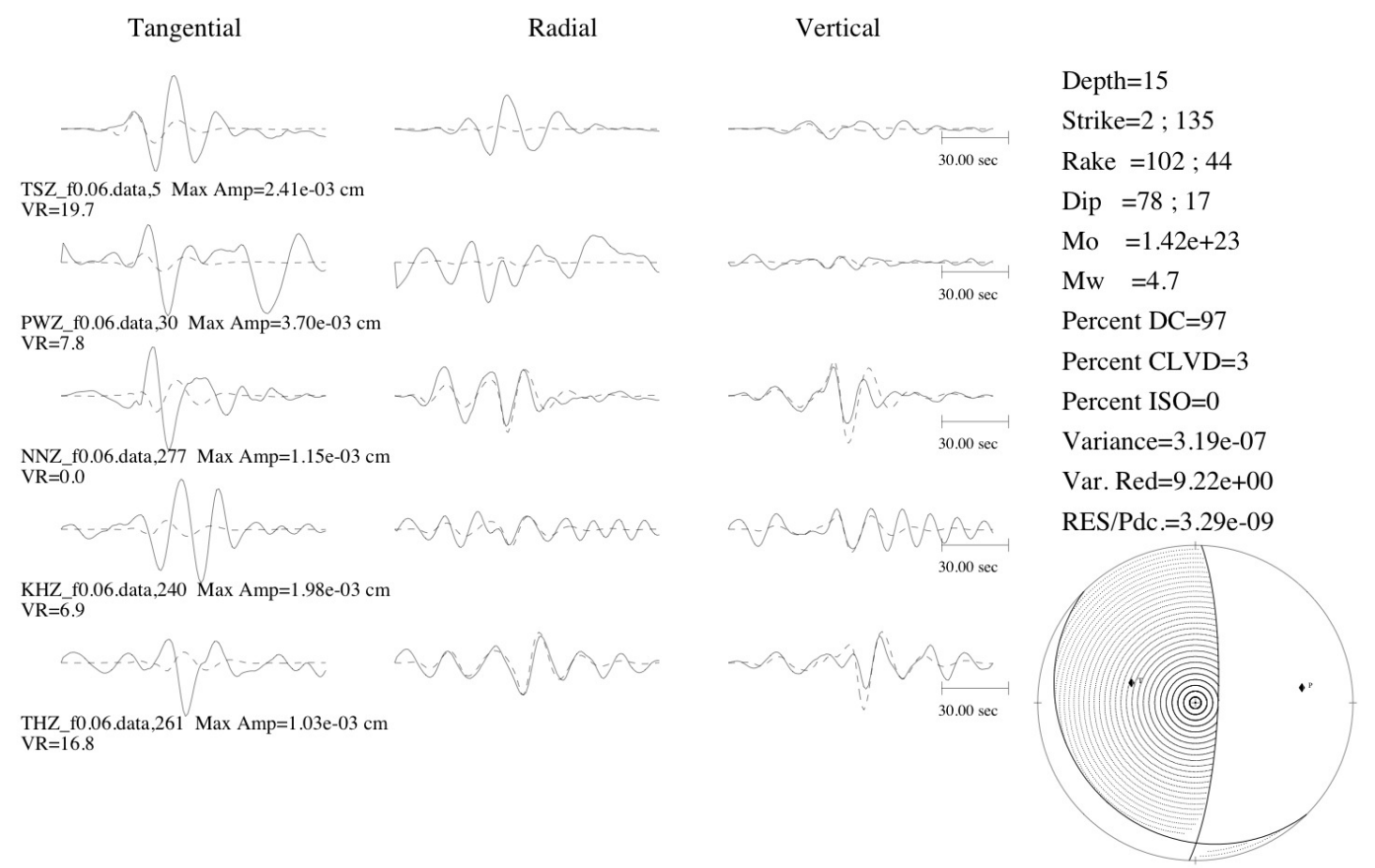

Figure A1.14. An example of the solutions calculated for event 2353002. Processed using a $0.03-0.06 \mathrm{~Hz}$ frequency band-pass filter and a depth of $15 \mathrm{~km}$.

\section{$0.04-0.10 \mathrm{~Hz}$ filter}

Solutions calculated using the $0.04-0.10 \mathrm{~Hz}$ frequency band-pass filter have magnitudes of Mw 4.6 (for depths of $10-15 \mathrm{~km}$ ) to Mw 4.9 (for depths of $25-30 \mathrm{~km}$ ). Focal mechanisms are reverse for the $5 \mathrm{~km}$ deep solution, strike-slip/normal for the $10 \mathrm{~km}$ deep solution, reverse/strike-slip for the $15-18 \mathrm{~km}$ deep solutions, normal/strike-slip for the $20-30 \mathrm{~km}$ deep solutions, and reverse/strike-slip for the $35 \mathrm{~km}$ deep solution. The fits of the synthetic seismograms to the data are all poor.

\section{Summary}

None of the solutions calculated for this event have good fits between the synthetic seismograms and the data.

Magnitudes of Mw 4.5 - Mw 5.1 were calculated for this event. The magnitude calculated by the Global CMT project of Mw 5.0 is in this range.

The correct focal mechanism for this event can not be determined from the calculated solutions. 


\section{A1.14. Event 2354133 - Upper Hutt}

20 January 2005, 1856 UT

Latitude -41.09, Longitude 175.05, depth $30.8 \pm 0.3 \mathrm{~km}$ (GNS)

Depth $30.9 \mathrm{~km}$ (Global CMT)

ML 5.6 (GNS), Mw 5.3 (Global CMT)

Global CMT focal plane 1: strike 223

Global CMT focal plane 2: $\quad$ strike 76

$\begin{array}{lr}\text { rake } & -116 \\ \text { rake } & -69\end{array}$

$\begin{array}{ll} & \text { Glob } \\ \text { dip } & 42 \\ \text { dip } & 55\end{array}$

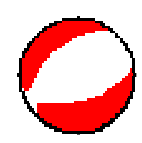

Data from eight stations, at distances of $110-215 \mathrm{~km}$ and azimuths of $34^{\circ}-358^{\circ}$ from the epicentre, and listed in Table A1.14, were used to compute seismic moment tensor solutions for this earthquake.

Table A1.14:

\begin{tabular}{|l|l|c|c|}
\hline $\begin{array}{l}\text { Station } \\
\text { code }\end{array}$ & Station name & $\begin{array}{l}\text { Distance from } \\
\text { earthquake }\end{array}$ & $\begin{array}{l}\text { Azimuth from } \\
\text { earthquake }\end{array}$ \\
\hline BFZ & Birch Farm & $110 \mathrm{~km}$ & $66^{\circ}$ \\
\hline TSZ & Takapari Road & $140 \mathrm{~km}$ & $34^{\circ}$ \\
\hline NNZ & Nelson & $140 \mathrm{~km}$ & $264^{\circ}$ \\
\hline WAZ & Wanganui & $150 \mathrm{~km}$ & $358^{\circ}$ \\
\hline PWZ & Pawanui & $195 \mathrm{~km}$ & $53^{\circ}$ \\
\hline KHZ & Kahutara & $195 \mathrm{~km}$ & $220^{\circ}$ \\
\hline THZ & Top House & $195 \mathrm{~km}$ & $247^{\circ}$ \\
\hline QRZ & Quartz Range & $215 \mathrm{~km}$ & $277^{\circ}$ \\
\hline
\end{tabular}

This earthquake was processed with the New Zealand standard velocity model and frequency band-pass filters of $0.02-0.05 \mathrm{~Hz}$ and $0.03-0.06 \mathrm{~Hz}$. Solutions were calculated for depths of $5-50 \mathrm{~km}$ at intervals of $5 \mathrm{~km}$ and also for a depth of $31 \mathrm{~km}$. Solutions were also computed using the Wellington velocity model and a frequency pass-band filter of 0.03 $0.06 \mathrm{~Hz}$, for depths of $5-40 \mathrm{~km}$ at intervals of $5 \mathrm{~km}$ and for a depth of $31 \mathrm{~km}$. The solution with the highest double-couple component was chosen as the best solution for each depth. Various combinations of stations were used.

The best solution was produced using the New Zealand velocity model, the $0.02-0.05 \mathrm{~Hz}$ frequency band-pass filter, the three stations BFZ, TSZ and NNZ, and a depth of $31 \mathrm{~km}$. This solution is shown in Figure A1.15, and has a magnitude of Mw 5.3 and a normal/strikeslip mechanism.

\section{New Zealand velocity model, $0.02-0.05 \mathrm{~Hz}, 8$ stations}

Solutions calculated with data from the eight stations listed in Table A1.14, the New Zealand velocity model and the $0.02-0.05 \mathrm{~Hz}$ frequency pass-band filter have magnitudes of Mw 4.8 (for depths of 10 and $31 \mathrm{~km}$ ) to Mw 5.2 (for a depth of $40 \mathrm{~km}$ ). Focal mechanisms are reverse/strike-slip for the $5-10 \mathrm{~km}$ deep solutions, normal/strike-slip for the $15-30 \mathrm{~km}$ deep solutions, strike-slip/reverse for the $31 \mathrm{~km}$ deep solution, normal/strike-slip for the 35 $40 \mathrm{~km}$ deep solutions, and normal-strike-slip with different fault orientations for the $45-50$ $\mathrm{km}$ deep solutions. The fits of the synthetic seismograms to the data are poor for all solutions. 

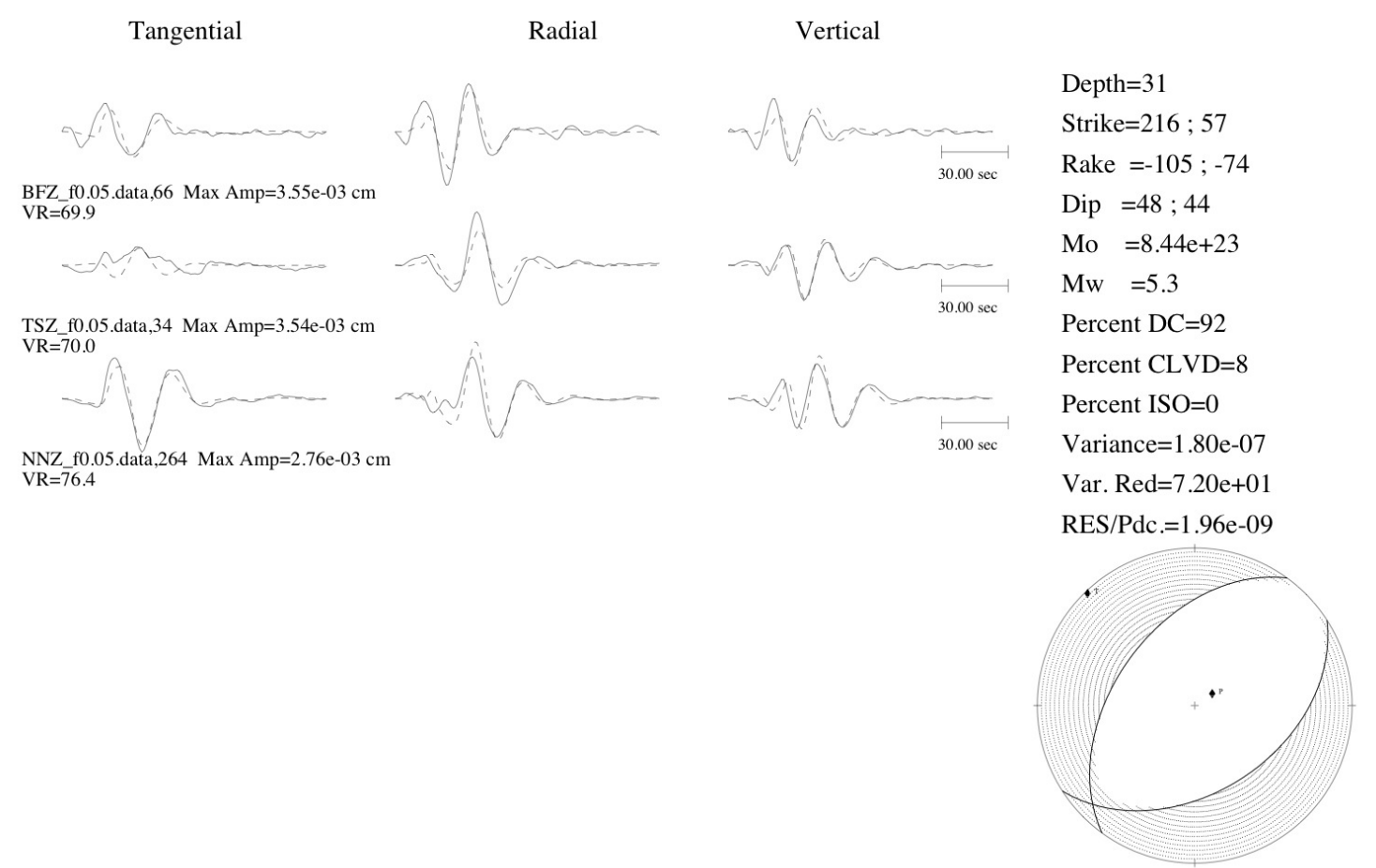

Figure A1.15. The best solution calculated for event 2354133. Produced using the New Zealand velocity model, the $0.02-0.05 \mathrm{~Hz}$ frequency band-pass filter, and a $31 \mathrm{~km}$ source depth.

\section{New Zealand velocity model, $0.02-0.05 \mathrm{~Hz}, 5$ stations}

The five stations BFZ, TSZ, NNZ, WAZ and PWZ lie at distances of $110-195 \mathrm{~km}$ and azimuths of $34^{\circ}-358^{\circ}$ from the epicentre. Solutions calculated with data from these stations, the New Zealand velocity model and with a $0.02-0.05 \mathrm{~Hz}$ frequency band-pass filter have magnitudes of Mw 4.9 (for a depth of $31 \mathrm{~km}$ ) to Mw 5.3 (for depths of $35-40$ $\mathrm{km})$. Focal mechanisms are normal/strike-slip for the $5-30 \mathrm{~km}$ deep solutions, reverse/strike-slip for the $31 \mathrm{~km}$ deep solution, and normal/strike-slip for the $35-50 \mathrm{~km}$ deep solutions, with a change in orientation between $35 \mathrm{~km}$ and $40 \mathrm{~km}$. Fits between the synthetic seismograms and the data are reasonable for all solutions except the $31 \mathrm{~km}$ deep solution. Excluding the $31 \mathrm{~km}$ deep solution, magnitudes range from $\mathrm{Mw} 5.0-\mathrm{Mw} 5.3$. The $30 \mathrm{~km}$ deep solution has the best fit between the synthetic seismograms and the data, the maximum variance reduction, a magnitude of $\mathrm{Mw} 5.2$ and a normal/strike-slip mechanism.

\section{New Zealand velocity model, $0.02-0.05 \mathrm{~Hz}, 4$ stations}

The four stations BFZ, TSZ, NNZ and WAZ lie at distances of $110-150 \mathrm{~km}$ and azimuths of $34^{\circ}-358^{\circ}$ from the epicentre. Solutions calculated with data from these stations, the New Zealand velocity model and with a $0.02-0.05 \mathrm{~Hz}$ frequency band-pass filter have magnitudes of Mw 4.6 (for the $31 \mathrm{~km}$ deep solution) to Mw 5.3 (for depths of $35-40 \mathrm{~km}$ ). Focal mechanisms are reverse/strike-slip for the $5 \mathrm{~km}$ deep solution, normal/strike-slip for depths of $10-30 \mathrm{~km}$, strike-slip/reverse for a depth of $31 \mathrm{~km}$, normal/strike-slip for depths of $35-40 \mathrm{~km}$, and reverse for depths of $45-50 \mathrm{~km}$. The fits of the synthetic seismograms to the data are good for solutions with depths of $10-30 \mathrm{~km}$ and $35-40 \mathrm{~km}$, and poor for the other solutions. Magnitudes for solutions with good fits of the synthetic seismograms to the data are $\mathrm{Mw} 5.0-\mathrm{Mw}$ 5.3. The $25 \mathrm{~km}$ deep solution has the best fit between the synthetic 
seismograms and the data, the maximum variance reduction, a magnitude of Mw 5.2 and a normal/strike-slip mechanism.

\section{New Zealand velocity model, $0.02-0.05 \mathrm{~Hz}, 3$ stations}

The three stations BFZ, TSZ and NNZ lie at distances of $110-140 \mathrm{~km}$ and azimuths of $34^{\circ}-$ $264^{\circ}$ from the epicentre. Solutions calculated using data from these stations, the New Zealand velocity model and a $0.02-0.05 \mathrm{~Hz}$ frequency band-pass filter have magnitudes of Mw 5.0 (for depths of $5-15 \mathrm{~km}$ ) to Mw 5.3 (for depths of 31, 40 and $50 \mathrm{~km}$ ). Focal mechanisms are reverse/strike-slip for the $5 \mathrm{~km}$ deep solution and normal/strike-slip for the $10-50 \mathrm{~km}$ deep solutions. The fits of the synthetic seismograms to the data are all mostly good. The $31 \mathrm{~km}$ deep solution has the best fit between the synthetic seismograms and the data, the maximum variance reduction, a magnitude of 5.3 and a normal/strike-slip mechanism. This solution is the best solution produced for this earthquake and is shown in Figure A1.15.

\section{New Zealand velocity model, $0.03-0.06$ Hz, 8 stations}

Solutions calculated with data from the eight stations listed in Table A1.14, the New Zealand velocity model and the $0.03-0.06 \mathrm{~Hz}$ frequency pass-band filter have magnitudes of $\mathrm{Mw} 4.8$ (for a depth of $20 \mathrm{~km}$ ) to $\mathrm{Mw} 5.1$ (for depths of $35-50 \mathrm{~km}$ ). Focal mechanisms are reverse/strike-slip for the $5 \mathrm{~km}$ deep solution, normal/strike-slip for the $10-35 \mathrm{~km}$ deep solutions, reverse/strike-slip for the $40 \mathrm{~km}$ deep solution, normal/strike-slip for the $45 \mathrm{~km}$ deep solution, and strike-slip for the $50 \mathrm{~km}$ deep solution. The fits of the synthetic seismograms to the data are poor for all solutions.

\section{New Zealand velocity model, $0.03-0.06 \mathrm{~Hz}, 5$ stations}

The five stations BFZ, TSZ, NNZ, WAZ and PWZ lie at distances of $110-195 \mathrm{~km}$ and azimuths of $34^{\circ}-358^{\circ}$ from the epicentre. Solutions calculated with data from these stations, the New Zealand velocity model and with a $0.03-0.06 \mathrm{~Hz}$ frequency band-pass filter have magnitudes of Mw 5.0 (for depths of 5, 10, 31 and $45 \mathrm{~km}$ ) to Mw 5.4 (for a depth of $50 \mathrm{~km}$ ). Focal mechanisms are vertical dip-slip/strike-slip for the $5 \mathrm{~km}$ deep solution, normal/strike-slip for the $10-35 \mathrm{~km}$ deep solutions, reverse/strike-slip for the $40 \mathrm{~km}$ deep solution, and normal/strike-slip for the $45-50 \mathrm{~km}$ deep solutions. The fits of the synthetic seismograms to the data are good for the $10-35 \mathrm{~km}$ and $50 \mathrm{~km}$ deep solutions and poor for the other solutions. Magnitudes for the solutions with good fits between the synthetic seismograms and the data are $\mathrm{Mw} 5.0$ - Mw 5.4. The $30 \mathrm{~km}$ deep solution has the best fit between the synthetic seismograms and the data, the maximum variance reduction, a magnitude of Mw 5.2 and a normal/strike-slip mechanism.

\section{New Zealand velocity model, $0.03-0.06$ Hz, 4 stations}

The four stations BFZ, TSZ, NNZ and WAZ lie at distances of $110-150 \mathrm{~km}$ and azimuths of $34^{\circ}-358^{\circ}$ from the epicentre. Solutions calculated with data from these stations, the New Zealand velocity model and with a $0.03-0.06 \mathrm{~Hz}$ frequency band-pass filter have magnitudes of $\mathrm{Mw} 4.9$ (for a depth of $40 \mathrm{~km}$ ) to $\mathrm{Mw} 5.4$ (for a depth of $35 \mathrm{~km}$ ). Focal mechanisms are reverse/strike-slip for the $5 \mathrm{~km}$ deep solution, normal/strike-slip for the 10 $35 \mathrm{~km}$ deep solutions, reverse/strike-slip for the $40-50 \mathrm{~km}$ deep solutions. The fits of the synthetic seismograms to the data are good for the $10-35 \mathrm{~km}$ deep solutions, and poor for the $5 \mathrm{~km}$ deep and the $40-50 \mathrm{~km}$ deep solutions. Magnitudes of the $10-35 \mathrm{~km}$ deep solutions are $\mathrm{Mw} 5.1-\mathrm{Mw}$ 5.3. The $30 \mathrm{~km}$ deep solution has the best fit between the 
synthetic seismograms and the data, the maximum variance reduction, a magnitude of $\mathrm{Mw}$ 5.3 and a normal/strike-slip mechanism.

\section{New Zealand velocity model, $0.03-0.06 \mathrm{~Hz}, 3$ stations}

The three stations BFZ, TSZ and NNZ lie at distances of $110-140 \mathrm{~km}$ and azimuths of $34^{\circ}-$ $264^{\circ}$ from the epicentre. Solutions calculated using data from these stations, the New Zealand velocity model and a $0.03-0.06 \mathrm{~Hz}$ frequency band-pass filter have magnitudes of Mw 4.8 (for a depth of $5 \mathrm{~km}$ ) to Mw 5.4 (for a depth of $50 \mathrm{~km}$ ). Focal mechanisms are normal/strike-slip for all solutions. The fits of the synthetic seismograms to the data are mostly good. The $31 \mathrm{~km}$ deep solution has the best fit between the synthetic seismograms and the data, the maximum variance reduction, a magnitude of Mw 5.2 and a normal/strikeslip mechanism.

\section{Wellington velocity model, $0.03-0.06 \mathrm{~Hz}, 5$ stations}

Seismic moment tensor solutions calculated using data from the five stations BFZ, TSZ, NNZ, WAZ and PWZ (at distances of $110-195 \mathrm{~km}$ and azimuths of $34^{\circ}-358^{\circ}$ from the epicentre), the Wellington velocity model, and a $0.03-0.06 \mathrm{~Hz}$ frequency band-pass filter have magnitudes of Mw 4.9 (for depths of 5 and $10 \mathrm{~km}$ ) to Mw 5.3 (for a depth of $40 \mathrm{~km}$ ). Focal mechanisms are reverse/strike-slip for the $5 \mathrm{~km}$ deep solution, normal-slip for the 10 $\mathrm{km}$ deep solution, strike-slip/normal for the $15 \mathrm{~km}$ deep solution, and normal/strike-slip for the $20-40 \mathrm{~km}$ deep solutions. The fits of the synthetic seismograms to the data are mostly good, and the best solution (with the highest variance reduction) is the $35 \mathrm{~km}$ deep solution, with a magnitude of Mw 5.3 and a normal/strike-slip mechanism.

\section{Wellington velocity model, $0.03-0.06 \mathrm{~Hz}, 4$ stations}

Seismic moment tensor solutions calculated using data from the four stations BFZ, TSZ, $\mathrm{NNZ}$ and WAZ (at distances of $110-150 \mathrm{~km}$ and azimuths of $34^{\circ}-358^{\circ}$ from the epicentre), the Wellington velocity model, and a $0.03-0.06 \mathrm{~Hz}$ frequency band-pass filter have magnitudes of $\mathrm{Mw} 4.9$ (for a depth of $40 \mathrm{~km}$ ) to Mw 5.3 (for depths of $31-35 \mathrm{~km}$ ). Focal mechanisms are reverse-slip for the $5 \mathrm{~km}$ deep solution, normal/strike-slip for the 10 $35 \mathrm{~km}$ deep solutions, and reverse-slip for the $40 \mathrm{~km}$ deep solution. The fits of the synthetic seismograms to the data are good for depths of $5-35 \mathrm{~km}$. Magnitudes for this depth range are Mw 5.1 - Mw 5.3. The best solutions (with the highest variance reduction) are the $30-$ $35 \mathrm{~km}$ deep solutions, with magnitudes of Mw $5.2-5.3$ normal/strike-slip mechanisms.

\section{Wellington velocity model, $0.03-0.06 \mathrm{~Hz}, 3$ stations}

Seismic moment tensor solutions calculated using data from the three stations BFZ, TSZ and NNZ (at distances of $110-140 \mathrm{~km}$ and azimuths of $34^{\circ}-264^{\circ}$ from the epicentre), the Wellington velocity model, and a $0.03-0.06 \mathrm{~Hz}$ frequency band-pass filter have magnitudes of Mw 4.9 (for a depth of $10 \mathrm{~km}$ ) to Mw 5.4 (for a depth of $40 \mathrm{~km}$ ). Focal mechanisms are normal/strike-slip for all solutions. The fits of the synthetic seismograms to the data are mostly good, and the best solution (with the highest variance reduction) is the $40 \mathrm{~km}$ deep solution, with a magnitude of Mw 5.4 and a normal/strike-slip mechanism.

\section{Summary}

Calculated magnitudes for this event using the New Zealand standard velocity model range from Mw 4.6 to Mw 5.4. Magnitudes for solutions with good fits between the synthetic seismograms and the data are Mw 4.8 - Mw 5.4. 
Appendix 1: Case studies

A1.14 Event 2354133 - Upper Hutt

Using the Wellington velocity model, the magnitudes calculated are Mw 4.9 - Mw 5.4, and the best magnitudes are Mw 5.2 - Mw 5.4.

The magnitudes calculated match the Mw 5.3 calculated by the Global CMT project.

The best solutions all have normal/strike-slip faulting mechanisms which match the mechanism calculated by the Global CMT project.

There were no significant differences between the solutions calculated using the two frequency filters or the two velocity models.

The best solution was calculated with the New Zealand velocity model, a $0.02-0.05 \mathrm{~Hz}$ frequency band-pass filter and the three stations BFZ, TSZ and NNZ. It has a depth of 31 $\mathrm{km}$, a magnitude of Mw 5.3 and a normal/strike-slip faulting mechanism. 
Appendix 1: Case studies 


\section{A1.15. Event 2354877 - Upper Hutt}

22 January 2005, 0814 UT

Latitude -41.08 , Longitude 175.06, depth $29.1 \pm 0.03 \mathrm{~km}$ (GNS)

ML 4.2 (GNS)

There was no Global CMT solution for this earthquake. Data from five stations, at distances of $110-190 \mathrm{~km}$ and azimuths of $34^{\circ}-358^{\circ}$ from the epicentre and listed in Table A1.15, were used to compute seismic moment tensor solutions for this event.

\section{Table A1.15:}

\begin{tabular}{|l|l|c|c|}
\hline $\begin{array}{l}\text { Station } \\
\text { code }\end{array}$ & Station name & $\begin{array}{l}\text { Distance from } \\
\text { earthquake }\end{array}$ & $\begin{array}{l}\text { Azimuth from } \\
\text { earthquake }\end{array}$ \\
\hline BFZ & Birch Farm & $110 \mathrm{~km}$ & $66^{\circ}$ \\
\hline TSZ & Takapari Road & $140 \mathrm{~km}$ & $34^{\circ}$ \\
\hline NNZ & Nelson & $140 \mathrm{~km}$ & $264^{\circ}$ \\
\hline WAZ & Wanganui & $150 \mathrm{~km}$ & $358^{\circ}$ \\
\hline PWZ & Pawanui & $195 \mathrm{~km}$ & $53^{\circ}$ \\
\hline
\end{tabular}

This earthquake was processed with the New Zealand standard velocity model and frequency band-pass filters of $0.02-0.05 \mathrm{~Hz}, 0.03-0.06 \mathrm{~Hz}$, and $0.04-0.10 \mathrm{~Hz}$. Solutions were calculated for depths of $10-40 \mathrm{~km}$ at intervals of $5 \mathrm{~km}$. The solution with the highest double-couple component was chosen as the best solution for each depth.

None of the solutions produced good fits between the synthetic seismograms and the data, so neither the moment magnitude nor the mechanism of this earthquake could be constrained. An example of the solutions produced (produced using the $0.03-0.06 \mathrm{~Hz}$ frequency bandpass filter and a depth of $10 \mathrm{~km}$ ) is shown in Figure A1.16.

\section{$0.02-0.05 \mathrm{~Hz}$}

Solutions calculated with the five stations listed in Table A1.15 and the $0.02-0.05 \mathrm{~Hz}$ frequency pass-band filter have magnitudes of Mw 3.8 (for depths of 10 and $20 \mathrm{~km}$ ) to Mw 4.1 (for depths of $35-40 \mathrm{~km}$ ). Focal mechanisms show mostly reverse-slip for the $10-25$ $\mathrm{km}$ deep solutions, strike-slip/normal-slip for the $30 \mathrm{~km}$ deep solution, and reverse-slip for the $35-40 \mathrm{~km}$ deep solutions. The fits of the synthetic seismograms to the data are extremely poor for all solutions.

\section{$0.03-0.06 \mathrm{~Hz}$}

Solutions calculated with the five stations listed in Table A1.15 and the $0.03-0.06 \mathrm{~Hz}$ frequency pass-band filter have magnitudes of $\mathrm{Mw} 3.6$ (for a depth of $10 \mathrm{~km}$ ) to $\mathrm{Mw} 4.3$ (for a depth of $40 \mathrm{~km}$ ). Focal mechanisms show mostly reverse-slip for the $10-35 \mathrm{~km}$ deep solutions, and normal-slip for the $40 \mathrm{~km}$ deep solution. The fits of the synthetic seismograms to the data are extremely poor for all solutions. The $10 \mathrm{~km}$ deep solution is shown in Figure A1.16.

\section{$0.04-0.10 \mathrm{~Hz}$}

Solutions calculated with the five stations listed in Table A1.15 and the $0.04-0.10 \mathrm{~Hz}$ frequency pass-band filter have magnitudes of $\mathrm{Mw} 3.5$ (for a depths of $10 \mathrm{~km}$ ) to $\mathrm{Mw} 4.1$ (for 
a depth of $40 \mathrm{~km}$ ). All of the focal mechanisms show mostly reverse-slip. The fits of the synthetic seismograms to the data are extremely poor for all solutions.

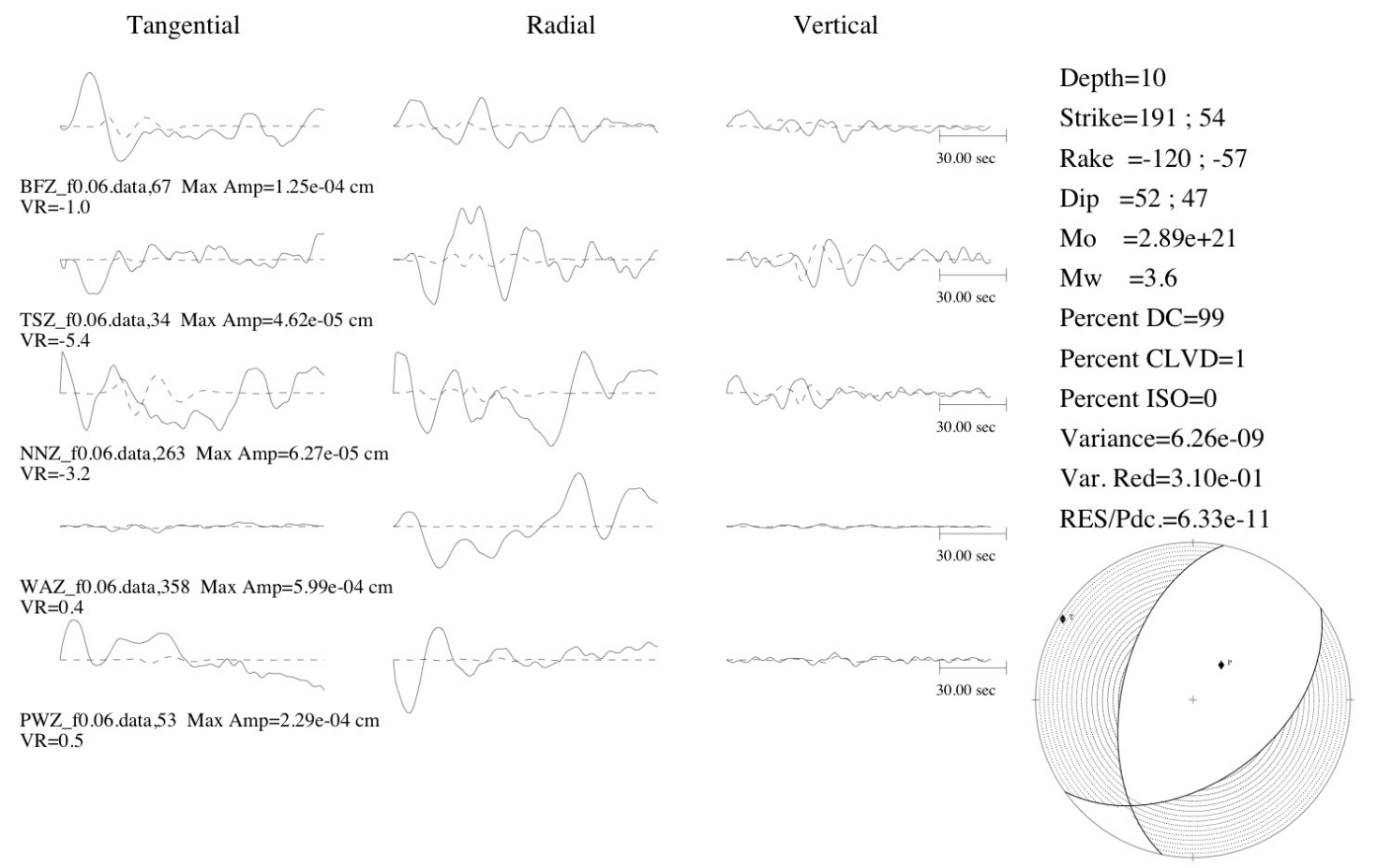

Figure A1.16. An example of the solutions calculated for event 2354877. Produced with the $0.03-0.06 \mathrm{~Hz}$ frequency band-pass filter and a $10 \mathrm{~km}$ source depth.

\section{Summary}

Magnitudes of Mw 3.5 - Mw 4.3 were calculated for this event. Fits between the synthetic seismograms and the data were extremely poor for all solutions. 


\section{A1.16. Event 2359081 - Wairarapa}

31 January 2005, 1731 UT

Latitude -41.46, Longitude 175.76, depth $19.9 \pm 1.5 \mathrm{~km}$ (GNS)

Depth $17.7 \mathrm{~km}$ (Global CMT)

ML 5.3 (GNS), Mw 5.0 (Global CMT)

Global CMT focal plane 1: $\quad$ strike 267 rake 164 dip 38

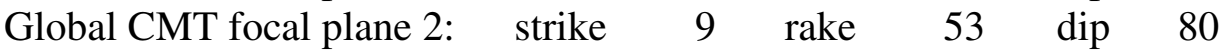

Data from five stations, at distances of $155-240 \mathrm{~km}$ and azimuths of $6^{\circ}-339^{\circ}$ from the epicentre, and listed in Table A1.16, were used to compute seismic moment tensor solutions for this earthquake.

Table A1.16:

\begin{tabular}{|l|l|c|c|}
\hline $\begin{array}{l}\text { Station } \\
\text { code }\end{array}$ & Station name & $\begin{array}{l}\text { Distance from } \\
\text { earthquake }\end{array}$ & $\begin{array}{l}\text { Azimuth from } \\
\text { earthquake }\end{array}$ \\
\hline TSZ & Takapari Road & $155 \mathrm{~km}$ & $6^{\circ}$ \\
\hline PWZ & Pawanui & $185 \mathrm{~km}$ & $31^{\circ}$ \\
\hline NNZ & Nelson & $200 \mathrm{~km}$ & $277^{\circ}$ \\
\hline KHZ & Kahutara & $210 \mathrm{~km}$ & $339^{\circ}$ \\
\hline THZ & Top House & $240 \mathrm{~km}$ & $261^{\circ}$ \\
\hline
\end{tabular}

This event was processed using the New Zealand standard velocity model and a $0.03-0.06$ $\mathrm{Hz}$ frequency pass-band filter. Solutions were calculated with depths of $15 \mathrm{~km}, 17-29 \mathrm{~km}$ with an interval of $1 \mathrm{~km}$, and $33 \mathrm{~km}$. For each depth the solution with the highest variance reduction was chosen as the best solution for that depth.

The calculated magnitudes range from Mw 5.1 (with depths of $15-27 \mathrm{~km}$ ) to $\mathrm{Mw} 5.3$ (with a depth of $33 \mathrm{~km}$ ). Focal mechanisms are all strike-slip. Double-couple components range from $46 \%$ (for depths of 25 and $26 \mathrm{~km}$ ) to $91 \%$ for the $24 \mathrm{~km}$ deep solution. The fits of the synthetic seismograms to the data were good for all solutions. The high double-couple component for the $24 \mathrm{~km}$ deep solution suggests that this is the best solution, and this is shown in Figure A1.17. The $24 \mathrm{~km}$ deep solution has a magnitude of Mw 5.1 and a strikeslip focal mechanism.

The magnitude calculated by the Global CMT project of Mw 5.0 is slightly below the best and minimum magnitude calculated using the TCMT_INVC method, of Mw 5.1. The focal mechanism calculated by the Global CMT project is similar but not identical to the focal mechanisms calculated using the TDMT_INVC method. 


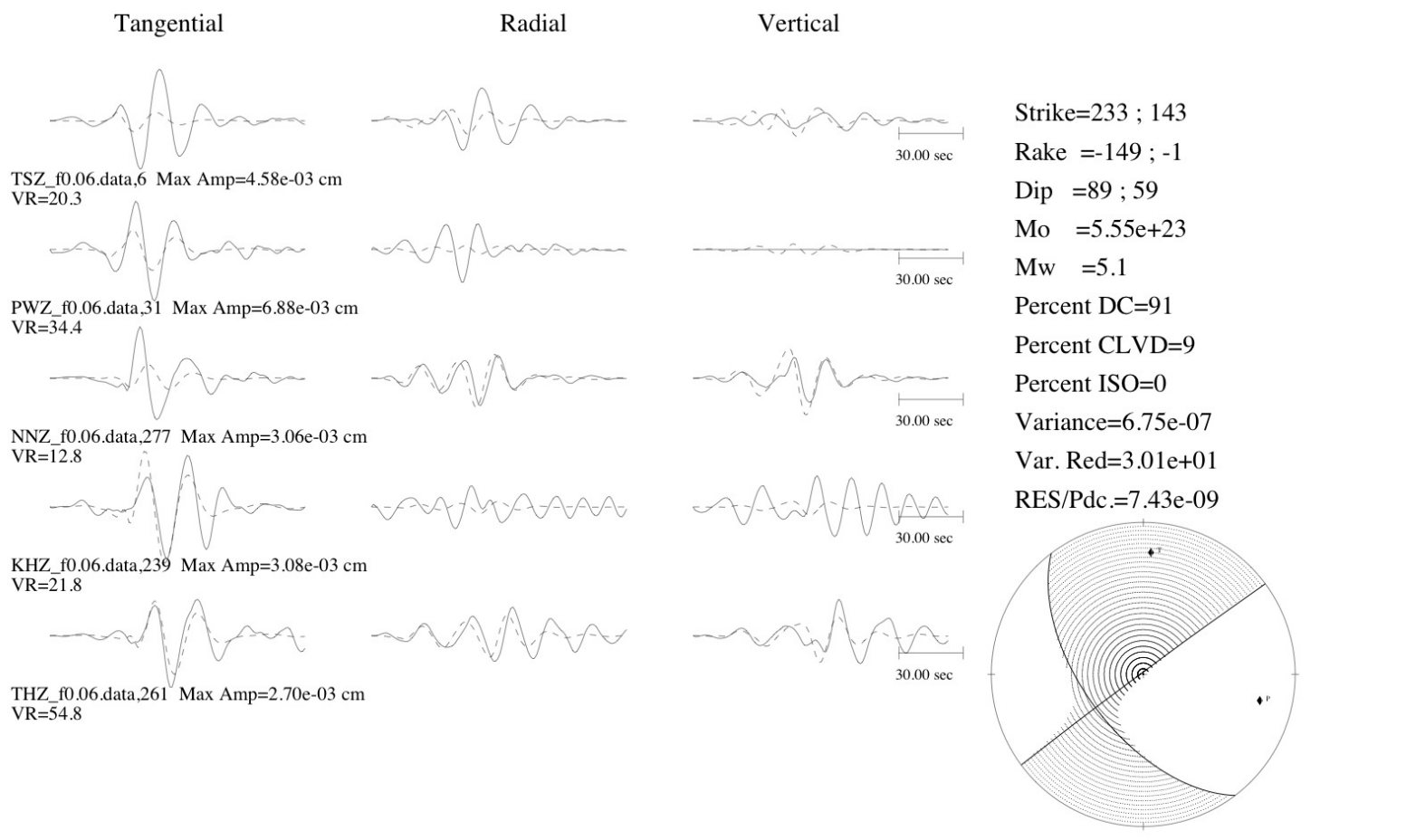

Figure A1.17. The best solution produced for event 2359081 with a source depth of $24 \mathrm{~km}$. 


\section{A1.17. Event 2569288 - Wairarapa}

31 January 2005, 1734 UT

Latitude -41.42 , Longitude 175.75, depth $12.4 \pm 1.3 \mathrm{~km}(\mathrm{GNS})$

ML 4.2 (GNS)

There was no Global CMT solution for this earthquake. Data from four stations, at distances of $150-200 \mathrm{~km}$ and azimuths of $7^{\circ}-340^{\circ}$ from the epicentre and listed in Table A1.17, were used to compute seismic moment tensor solutions for this event.

Table A1.17:

\begin{tabular}{|l|l|c|c|}
\hline $\begin{array}{l}\text { Station } \\
\text { code }\end{array}$ & Station name & $\begin{array}{l}\text { Distance from } \\
\text { earthquake }\end{array}$ & $\begin{array}{l}\text { Azimuth from } \\
\text { earthquake }\end{array}$ \\
\hline TSZ & Takapari Road & $150 \mathrm{~km}$ & $7^{\circ}$ \\
\hline PWZ & Pawanui & $180 \mathrm{~km}$ & $32^{\circ}$ \\
\hline WAZ & Wanganui & $195 \mathrm{~km}$ & $340^{\circ}$ \\
\hline NNZ & Nelson & $200 \mathrm{~km}$ & $276^{\circ}$ \\
\hline
\end{tabular}

This earthquake was processed with the New Zealand standard velocity model and a 0.03 $0.06 \mathrm{~Hz}$ frequency band-pass filter. Solutions were calculated for depths of $5-20 \mathrm{~km}$ at intervals of $5 \mathrm{~km}$, and for a depth of $12 \mathrm{~km}$. The solution with the highest double-couple component was chosen as the best solution for each depth.

Magnitudes of Mw 4.0 (with a depth of $12 \mathrm{~km}$ ) to Mw 4.2 (with a depth of $20 \mathrm{~km}$ ) were calculated. Focal mechanisms are reverse-slip for depths of $5-10 \mathrm{~km}$, strike-slip for a depth of $12 \mathrm{~km}$, and strike-slip/normal-slip for depths of $15-20 \mathrm{~km}$. The fits between the data and the synthetics are extremely poor for all solutions. Neither the moment magnitude nor the focal mechanism can be constrained by this analysis. The $12 \mathrm{~km}$ deep solution is shown in Figure A1.18. 
Appendix 1: Case studies

A1.17 Event 2569288 - Wairarapa

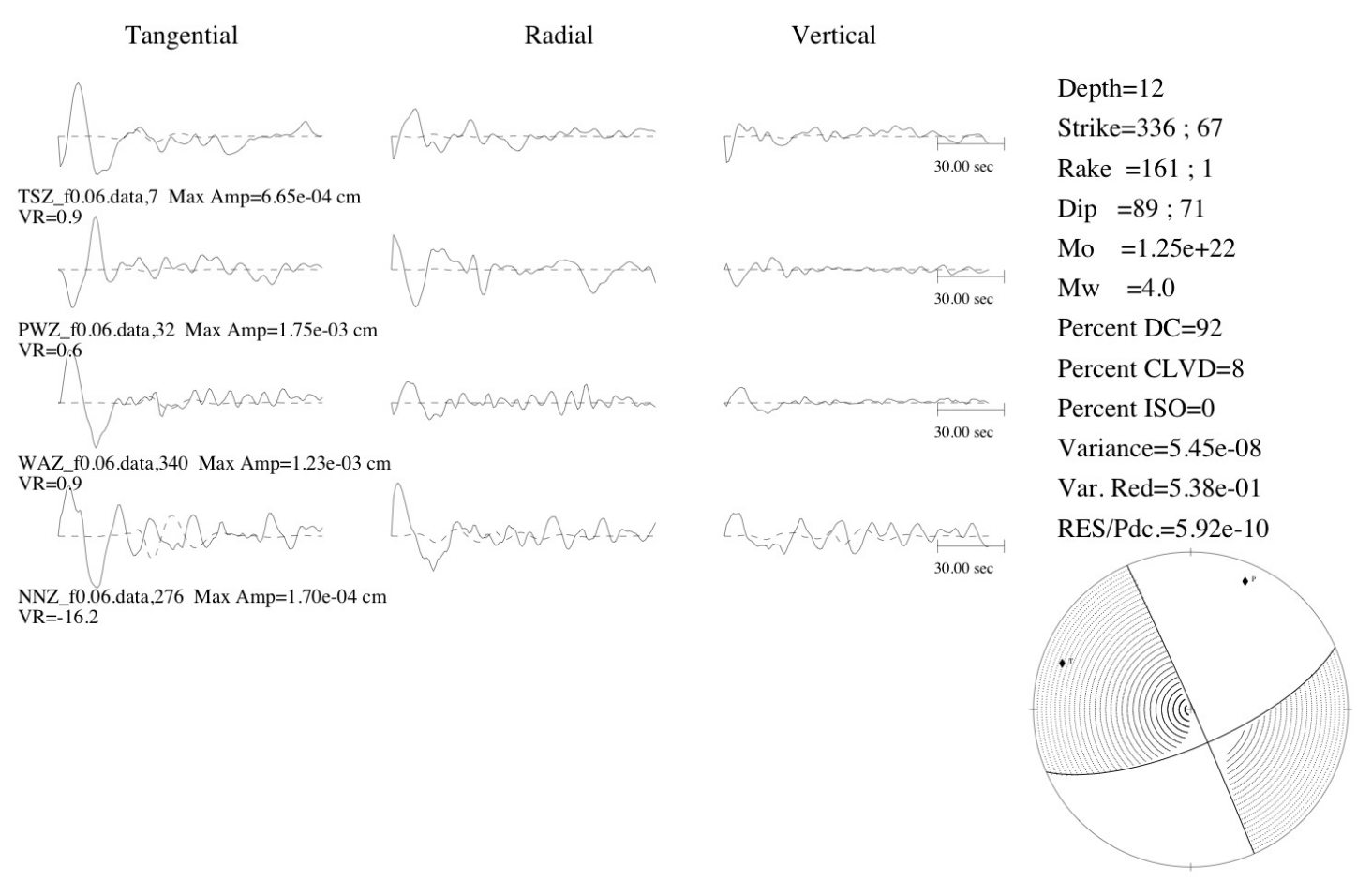

Figure A1.18. The $12 \mathrm{~km}$ deep solution for event 2569288 . 


\section{A1.18. Event 2376455 - South of Taranaki}

13 March 2005, 1508 UT

Latitude -40.18 , Longitude 173.67, depth $142.9 \pm 2.3 \mathrm{~km}$ (GNS)

Depth $152.9 \mathrm{~km}$ (Global CMT)

ML 6.4 (GNS), Mw 5.4 (Global CMT)

$\begin{array}{llllll}\text { Global CMT focal plane 1: } & \text { strike } 68 \text { rake } & -155 & \text { dip } & 23\end{array}$

Global CMT focal plane 2: $\quad$ strike 315 rake $\quad-69$ dip 81

Data from thirteen stations, at distances of $120-270 \mathrm{~km}$ and azimuths of $29^{\circ}-233^{\circ}$ from the epicentre, and listed in Table A1.18, were used to compute seismic moment tensor solutions for this earthquake.

Table A1.18:

\begin{tabular}{|l|l|c|c|}
\hline $\begin{array}{l}\text { Station } \\
\text { code }\end{array}$ & Station name & $\begin{array}{l}\text { Distance from } \\
\text { earthquake }\end{array}$ & $\begin{array}{l}\text { Azimuth from } \\
\text { earthquake }\end{array}$ \\
\hline NNZ & Nelson & $120 \mathrm{~km}$ & $192^{\circ}$ \\
\hline QRZ & Quartz Range & $120 \mathrm{~km}$ & $233^{\circ}$ \\
\hline WAZ & Wanganui & $150 \mathrm{~km}$ & $68^{\circ}$ \\
\hline VRZ & Vera Road & $170 \mathrm{~km}$ & $109^{\circ}$ \\
\hline MRZ & Mangatainoka River & $185 \mathrm{~km}$ & $200^{\circ}$ \\
\hline THZ & Top House & $195 \mathrm{~km}$ & $57^{\circ}$ \\
\hline WPVZ & Whakapapa & $195 \mathrm{~km}$ & $87^{\circ}$ \\
\hline TSZ & Takapari Road & $210 \mathrm{~km}$ & $29^{\circ}$ \\
\hline HIZ & Hauiti & $225 \mathrm{~km}$ & $105^{\circ}$ \\
\hline BFZ & Birch Farm & $250 \mathrm{~km}$ & $182^{\circ}$ \\
\hline KHZ & Kahutara & $265 \mathrm{~km}$ & $66^{\circ}$ \\
\hline BKZ & Black Stump Farm & $270 \mathrm{~km}$ & $88^{\circ}$ \\
\hline PWZ & Pawanui & & \\
\hline
\end{tabular}

This event was processed with the New Zealand Standard velocity model, with a $0.03-0.06$ $\mathrm{Hz}$ frequency pass-band filter, and with varying numbers of stations. Depths of $100-200$ $\mathrm{km}$ were tested with an increment of $10 \mathrm{~km}$. For each depth the solution with the highest double-couple component was chosen as the best solution for that depth.

The best solution was produced using the three stations NNZ, QRZ and VRZ and a depth of $130 \mathrm{~km}$. This solution has a magnitude of Mw 5.2 and a normal/strike-slip mechanism, and is shown in Figure A1.19.

\section{Stations NNZ, QRZ, WAZ, VRZ, MRZ, THZ, WPVZ, TSZ, HIZ, BFZ, KHZ, BKZ \& PWZ}

Initially this event was processed with all thirteen stations listed in Table A1.18, and with groups of the closest of these. 


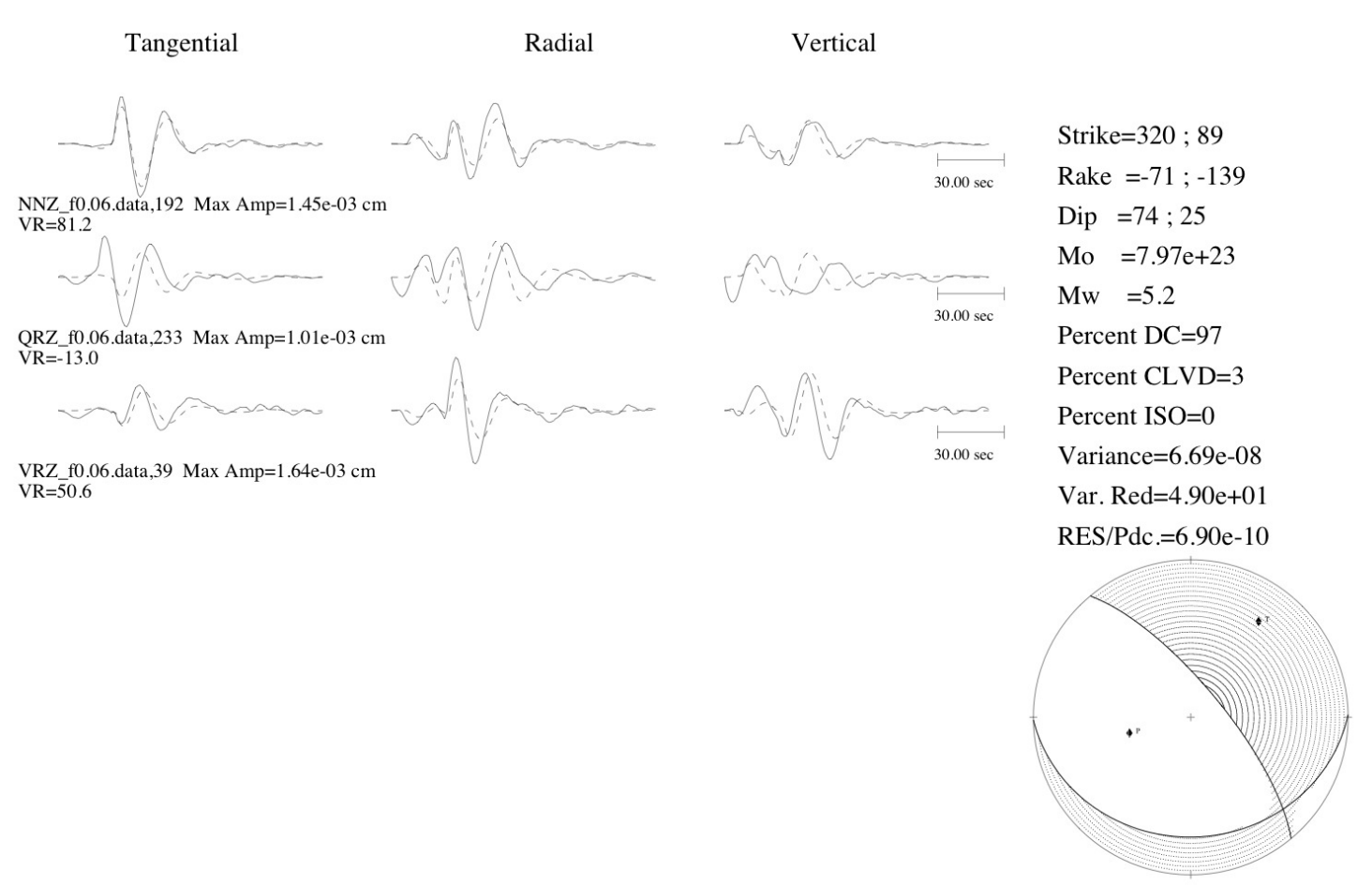

Figure A1.19. The best solution calculated for event 2376455, with a source depth of 130 $\mathrm{km}$.

\section{3 stations NNZ, QRZ, WAZ, VRZ, MRZ, THZ, WPVZ, TSZ, HIZ, BFZ, KHZ, BKZ \& PWZ}

The stations NNZ, QRZ, WAZ, VRZ, MRZ, THZ, WPVZ, TSZ, HIZ, BFZ, KHZ, BKZ and PWZ lie at distances of $120 \mathrm{~km}-270 \mathrm{~km}$ from the earthquake epicentre, and have an azimuthal range of $204^{\circ}$. With thirteen sets of seismograms and synthetic seismograms on the plots of the seismograms and synthetic it is very hard to see which is which. The fits between the synthetic seismograms and the seismograms are all very poor. Calculated moment magnitudes range from Mw 5.3 (with a depth of $140 \mathrm{~km}$ ) to Mw 5.6 (with a depth of $110 \mathrm{~km}$ ). The $100-140 \mathrm{~km}$ deep solutions show strike-slip/normal faulting, the $150 \mathrm{~km}$ deep solution shows normal faulting, and the $160-200 \mathrm{~km}$ deep solutions show strikeslip/reverse faulting.

\section{2 stations NNZ, QRZ, WAZ, VRZ, MRZ, THZ, WPVZ, TSZ, HIZ, BFZ, KHZ \& BKZ}

The twelve stations NNZ, QRZ, WAZ, VRZ, MRZ, THZ, WPVZ, TSZ, HIZ, BFZ, KHZ, and $B K Z$ lie at distances of $120 \mathrm{~km}-265 \mathrm{~km}$ from the earthquake epicentre, and have an azimuthal range of $204^{\circ}$. Twelve sets of seismograms and synthetic seismograms on the plots are again too cramped. The fits between the synthetic seismograms and the seismograms are again all very poor. Moment magnitudes of these solutions range from $\mathrm{Mw}$ 5.3 (with a depth of $140 \mathrm{~km}$ ) to Mw 5.7 (with depths of 100 and $110 \mathrm{~km}$ ). The $100 \mathrm{~km}-140$ $\mathrm{km}$ deep solutions show strike-slip/normal faulting, and the $150-200 \mathrm{~km}$ deep solutions show reverse/strike-slip faulting. 


\section{1 stations NNZ, QRZ, WAZ, VRZ, MRZ, THZ, WPVZ, TSZ, HIZ, BFZ \& KHZ}

The eleven stations NNZ, QRZ, WAZ, VRZ, MRZ, THZ, WPVZ, TSZ, HIZ, BFZ and KHZ lie at distances of $120 \mathrm{~km}-250 \mathrm{~km}$ from the earthquake epicentre, and with an azimuthal range of $204^{\circ}$. Again, eleven sets of seismograms and synthetic seismograms on the plots make the plots too cramped to read easily. The fits between the synthetic seismograms and the seismograms are again all very poor. Moment magnitudes of these solutions range from Mw 5.3 (with a depth of $140 \mathrm{~km}$ ) to Mw 5.7 (with depths of 100 and $110 \mathrm{~km}$ ). The $100-$ $130 \mathrm{~km}$ deep solutions show strike-slip/normal faulting and the $140-200 \mathrm{~km}$ deep solutions show reverse/strike-slip faulting.

\section{0 stations NNZ, QRZ, WAZ, VRZ, MRZ, THZ, WPVZ, TSZ, HIZ \& BFZ}

The ten stations NNZ, QRZ, WAZ, VRZ, MRZ, THZ, WPVZ, TSZ, HIZ and BFZ lie at distances of $120 \mathrm{~km}$ to $225 \mathrm{~km}$ from the earthquake epicentre, and with an azimuthal range of $204^{\circ}$. Again, ten sets of seismograms and synthetic seismograms on the plots make the plots too cramped to read easily. The fits between the synthetic seismograms and the seismograms are again all very poor. Moment magnitudes of these solutions range from $\mathrm{Mw} 5.4$ (with depths of 130 and $140 \mathrm{~km}$ ) to Mw 5.7 (with a depth of $100 \mathrm{~km}$ ). The $100-120 \mathrm{~km}$ deep solutions show strike-slip/normal faulting, the $130-140 \mathrm{~km}$ deep solutions show mostly strike-slip faulting, and the $150-200 \mathrm{~km}$ deep solutions show reverse/strike-slip faulting.

\section{9 stations NNZ, QRZ, WAZ, VRZ, MRZ, THZ, WPVZ, TSZ \& HIZ}

The nine stations NNZ, QRZ, WAZ, VRZ, MRZ, THZ, WPVZ, TSZ and HIZ lie at distances of $120 \mathrm{~km}$ to $210 \mathrm{~km}$ from the earthquake epicentre, and with an azimuthal range of $204^{\circ}$. The plots of the seismograms and synthetic seismograms are too cramped to read easily, but this may be just because of the very poor fits between the synthetic seismograms and the data. Moment magnitudes of these solutions range from Mw 5.4 (with a depth of $140 \mathrm{~km}$ ) to Mw 5.7 (with depths of $100-120 \mathrm{~km}$ ). The solutions show strike-slip/normal faulting for depths of $100-140 \mathrm{~km}$ and reverse/strike-slip faulting for depths of $150-200 \mathrm{~km}$.

\section{8 stations NNZ, QRZ, WAZ, VRZ, MRZ, THZ, WPVZ \& TSZ}

The eight stations NNZ, QRZ, WAZ, VRZ, MRZ, THZ, WPVZ and TSZ lie at distances of $120 \mathrm{~km}$ to $195 \mathrm{~km}$ from the earthquake epicentre, and with an azimuthal range of $194^{\circ}$. The plots showing the seismograms and the synthetic seismograms are too cramped to read easily, probably because of the very large differences between some of the synthetic seismograms and the corresponding seismograms. The moment magnitudes calculated with these eight stations range from Mw 5.4 (with a depth of $140 \mathrm{~km}$ ) to Mw 5.8 (with a depth of $110 \mathrm{~km}$ ). The 100 - $120 \mathrm{~km}$ deep solutions show strike-slip/normal faulting, the $130-140 \mathrm{~km}$ deep solutions show strike-slip/reverse faulting, and the $150-200 \mathrm{~km}$ deep solutions show reverse/strike-slip faulting.

\section{7 stations NNZ, QRZ, WAZ, VRZ, MRZ, THZ \& WPVZ}

The seven stations NNZ, QRZ, WAZ, VRZ, MRZ, THZ and WPVZ lie at distances of 120 $\mathrm{km}$ to $195 \mathrm{~km}$ from the earthquake epicentre, and with an azimuthal range of $194^{\circ}$. The plots showing the seismograms and the synthetic seismograms are too cramped to read easily because of the very large differences between some of the synthetic seismograms and the corresponding seismograms. The moment magnitudes calculated with these seven stations range from $\mathrm{Mw} 5.5$ (with a depth of $140 \mathrm{~km}$ ) to Mw 5.8 (with a depth of $100 \mathrm{~km}$ ). The $100-$ 
$140 \mathrm{~km}$ deep solutions show strike-slip/normal faulting and the $150-200 \mathrm{~km}$ deep solutions show reverse/strike-slip faulting.

\section{6 stations NNZ, QRZ, WAZ, VRZ, MRZ \& THZ}

The six stations NNZ, QRZ, WAZ, VRZ, MRZ and THZ lie at distances of $120 \mathrm{~km}$ to 185 $\mathrm{km}$ from the earthquake epicentre, and with an azimuthal range of $194^{\circ}$. The fits between the synthetic seismograms and the data are much better than in the sets of solutions using more stations, but are still poor. The moment magnitudes calculated with these stations range from Mw 4.7 (with a depth of $130 \mathrm{~km}$ ) to Mw 5.2 (with depths of 100, 120, and $140 \mathrm{~km}$ ). The 100 - $110 \mathrm{~km}$ deep solutions show normal/strike-slip faulting, the $120 \mathrm{~km}$ and $140 \mathrm{~km}$ deep solutions also show normal/strike-slip faulting but with different fault plane orientations, the $130 \mathrm{~km}$ and $150-160 \mathrm{~km}$ deep solutions show reverse/strike-slip faulting, and the $170-200$ $\mathrm{km}$ deep solutions show mostly reverse-slip faulting.

\section{5 stations NNZ, QRZ, WAZ, VRZ \& MRZ}

The five stations NNZ, QRZ, WAZ, VRZ and MRZ lie at distances of $120 \mathrm{~km}$ to $170 \mathrm{~km}$ from the earthquake epicentre, and with an azimuthal range of $194^{\circ}$. The fits between the data and the synthetic seismograms are fairly poor, but some traces fit reasonably for the 100 $\mathrm{km}$ and $110 \mathrm{~km}$ deep solutions. Moment magnitudes range from Mw 5.1 (with depths of 150 $-200 \mathrm{~km}$ ) to $\mathrm{Mw} 5.2$ (with depths of $100-140 \mathrm{~km}$ ). The solutions show normal/strike-slip faulting for depths of $100-140 \mathrm{~km}$, reverse/strike-slip faulting and a complete change of fault-plane orientation for a depth of $150 \mathrm{~km}$, and mostly reverse faulting (with similar orientations to the normal/strike-slip faulting for depths of $100-140 \mathrm{~km}$ ) for depths of $160-$ $200 \mathrm{~km}$.

\section{4 stations NNZ, QRZ, WAZ \& VRZ}

The four stations NNZ, QRZ, WAZ and VRZ lie at distances of $120 \mathrm{~km}$ to $150 \mathrm{~km}$ from the earthquake epicentre, and with an azimuthal range of $194^{\circ}$. Fits between the data and the synthetic seismograms are mostly reasonable for depths of $100-170 \mathrm{~km}$, and the variance reduction peaks at $140 \mathrm{~km}$, making this the most likely depth using this set of solutions. Moment magnitudes range from Mw 5.0 (with a depth of $200 \mathrm{~km}$ ) to Mw 5.3 (with depths of $110 \mathrm{~km}$ and $140 \mathrm{~km}$ ). In the $100-170 \mathrm{~km}$ depth range moment magnitudes range from $\mathrm{Mw}$ 5.1 - Mw 5.3. Focal mechanisms are normal/strike-slip for depths of $100-140 \mathrm{~km}$ with a change in fault plane orientation between the $110 \mathrm{~km}$ deep and $120 \mathrm{~km}$ deep solutions, and reverse/strike-slip for depths of $150-200 \mathrm{~km}$, with various different fault-plane orientations.

\section{3 stations NNZ, QRZ \& WAZ}

The three stations NNZ, QRZ and WAZ are approximately equidistant from the earthquake, at a distance of about $120 \mathrm{~km}$, and with an azimuthal range of $165^{\circ}$. Fits between the data and the synthetic seismograms are reasonable for the $100 \mathrm{~km}$ depth solution, which is the solution with the highest variance reduction. Moment magnitudes range from Mw 5.0 (with a depth of $140 \mathrm{~km}$ ) to Mw 5.2 (with depths of $130 \mathrm{~km}$ and $160 \mathrm{~km}$ ). The moment magnitude of the $100 \mathrm{~km}$ deep solution is Mw 5.1. Focal mechanisms are normal/strike-slip for depths of $100-140 \mathrm{~km}$ (with significantly different fault plane orientations for the $120 \mathrm{~km}$ deep solution) and reverse/strike-slip for depths of $150-200 \mathrm{~km}$. 


\section{Summary}

The moment magnitudes calculated for this earthquake using these station combinations range from $\mathrm{Mw} 4.8$ to $\mathrm{Mw}$ 5.8.

Only the five-station set, four-station set and three-station set produced any reasonable solutions for this earthquake, with depths of $100 \mathrm{~km}$ or $110 \mathrm{~km}$ for the five-station set, 100 $170 \mathrm{~km}$ for the four-station set or $100 \mathrm{~km}$ for the three-station set. Reasonable solutions have moment magnitudes of $\mathrm{Mw} 5.1$ to $\mathrm{Mw}$ 5.3. The best solution, calculated using four stations and a depth of $140 \mathrm{~km}$, has a magnitude of $\mathrm{Mw}$ 5.3. These magnitudes are lower than the Mw 5.4 calculated by the Global CMT project.

Neither the five-station set nor the three-station set produced reasonable solutions for depths near that calculated by the Global CMT project $(152.9 \mathrm{~km})$. The best solution (with the highest variance reduction) of the four-station set has a depth of $140 \mathrm{~km}$, which is close to that calculated by the Global CMT project, and closer to that calculated by GNS Science $(142.9 \mathrm{~km})$. This is the best solution calculated using these station combinations.

The mechanism of the $140 \mathrm{~km}$ deep solution for the four-station set is similar to the Global CMT solution.

The fits of the synthetic seismograms to the data for stations WPVZ and WAZ were bad for all station combinations and depths. Solutions were therefore calculated for sets of stations that did not include these two stations.

\section{Without WPVZ or WAZ}

Because of the poor fits of the synthetic seismograms to the data for stations WPVZ and WAZ, these stations were removed from the pool and solutions for different combinations of stations were calculated. A maximum of nine stations were used, because of the difficulty of plotting the seismograms and synthetic seismograms for lots of stations.

\section{9 stations NNZ, QRZ, VRZ, MRZ, THZ, TSZ, HIZ, BFZ \& KHZ}

The nine stations NNZ, QRZ, VRZ, MRZ, THZ, TSZ, HIZ, BFZ and KHZ lie at distances of $120-250 \mathrm{~km}$ from the earthquake epicentre with an azimuthal range of $204^{\circ}$. The fits of the synthetic seismograms to the data are all pretty poor. Calculated moment magnitudes range from Mw 4.8 (with depths of 190 and $200 \mathrm{~km}$ ) and Mw 5.1 (with depths of $100-140 \mathrm{~km}$ ). The $100-140 \mathrm{~km}$ deep solutions show normal/strike-slip faulting and the $150-200 \mathrm{~km}$ deep solutions show reverse/strike-slip faulting with various fault-plane orientations.

\section{8 stations NNZ, QRZ, VRZ, MRZ, THZ, TSZ, HIZ \& BFZ}

The eight stations NNZ, QRZ, VRZ, MRZ, THZ, TSZ, HIZ and BFZ lie at distances of 120 $225 \mathrm{~km}$ from the earthquake epicentre with an azimuthal range of $204^{\circ}$. The fits of the synthetic seismograms to the data are all fairly poor. Calculated moment magnitudes range from $\mathrm{Mw} 4.8$ (with a depth of $140 \mathrm{~km}$ ) to Mw 5.1 (with depths of $110-140 \mathrm{~km}$ and $160 \mathrm{~km}$ ). The $100 \mathrm{~km}$ deep solution shows mostly normal faulting, the $110-140 \mathrm{~km}$ deep solutions show strike-slip/normal faulting, and the 150 - $200 \mathrm{~km}$ deep solutions show reverse/strikeslip faulting. 


\section{7 stations NNZ, QRZ, VRZ, MRZ, THZ, TSZ \& HIZ}

The seven stations NNZ, QRZ, VRZ, MRZ, THZ, TSZ and HIZ lie at distances of $120-210$ $\mathrm{km}$ from the earthquake epicentre with an azimuthal range of $204^{\circ}$. The fits of the synthetic seismograms to the data are all very poor. Calculated moment magnitudes range from $\mathrm{Mw}$ 4.9 (with depths of $180 \mathrm{~km}$ and $200 \mathrm{~km}$ ) to $\mathrm{Mw} 5.1$ (with depths of $110-150 \mathrm{~km}$ and 170 $\mathrm{km}$ ). Focal mechanisms are normal/strike-slip for depths of $100-140 \mathrm{~km}$ and reverse/strikeslip with various fault plane orientations for depths of $150-200 \mathrm{~km}$.

\section{6 stations NNZ, QRZ, VRZ, MRZ, THZ \& TSZ}

The six stations NNZ, QRZ, VRZ, MRZ, THZ and TSZ lie at distances of $120-195 \mathrm{~km}$ from the earthquake epicentre with an azimuthal range of $194^{\circ}$. The fits of the synthetic seismograms to the data are fairly poor, but some traces fit reasonably for depths of $100-$ $140 \mathrm{~km}$, and the highest variance reduction is at $130 \mathrm{~km}$ deep. Calculated moment magnitudes range from $\mathrm{Mw} 4.9$ (with a depth of $170 \mathrm{~km}$ ) to Mw 5.2 (with depths of 100 $140 \mathrm{~km}$ ). Focal mechanisms are normal/strike-slip for depths of $100-150 \mathrm{~km}$ and mostly reverse-slip for depths of $160-200 \mathrm{~km}$.

\section{5 stations NNZ, QRZ, VRZ, MRZ \& THZ}

The five stations NNZ, QRZ, VRZ, MRZ and THZ lie at distances of $120-185 \mathrm{~km}$ from the earthquake epicentre with an azimuthal range of $194^{\circ}$. The fits of the synthetic seismograms to the data are mostly reasonable for solutions with depths of $100-180 \mathrm{~km}$, with the best solution, and the highest variance reduction, having a depth of $100 \mathrm{~km}$. Calculated moment magnitudes range from Mw 5.0 (with a depth of $190 \mathrm{~km}$ ) to Mw 5.3 (with a depth of 100 $\mathrm{km}$ ). Within the depth range $100-180 \mathrm{~km}$, the magnitudes range from $\mathrm{Mw} 5.1$ (with depths of $110-120 \mathrm{~km}$ and $150-180 \mathrm{~km})$ to $\mathrm{Mw} 5.3(100 \mathrm{~km})$. Focal mechanisms are normal/strike-slip with various fault plane orientations for depths of $100-140 \mathrm{~km}$ and reverse/strike-slip for depths of $150-200 \mathrm{~km}$. There is a lot of variation in fault plane orientations.

\section{4 stations NNZ, QRZ, VRZ \& MRZ}

The four stations NNZ, QRZ, VRZ and MRZ lie at distances of $120-170 \mathrm{~km}$ from the earthquake epicentre with an azimuthal range of $194^{\circ}$. The fits of the synthetic seismograms to the data are mostly reasonable for solutions with depths of $100-110 \mathrm{~km}$, with the highest variance reduction at $110 \mathrm{~km}$. Calculated moment magnitudes range from $\mathrm{Mw} 5.0$ (with a depth of $190 \mathrm{~km}$ ) to Mw 5.3 (with a depth of $110 \mathrm{~km}$ ). The $100 \mathrm{~km}$ deep solution has a magnitude of $\mathrm{Mw}$ 5.2. The $100-140 \mathrm{~km}$ deep solutions show normal/strike-slip faulting, the $150 \mathrm{~km}$ deep solution shows mostly strike-slip faulting, and the $160-200 \mathrm{~km}$ deep solutions show reverse/strike-slip faulting. There is a lot of variation in fault plane orientations.

\section{3 stations NNZ, QRZ \& VRZ}

The three stations NNZ, QRZ and VRZ lie at distances of 120 - $150 \mathrm{~km}$ from the earthquake epicentre with an azimuthal range of $194^{\circ}$. The fits of the synthetic seismograms to the data are mostly reasonable for solutions with depths of $100-140 \mathrm{~km}$, and the variance reduction peaks at $130 \mathrm{~km}$. Calculated moment magnitudes range from Mw 4.9 (with a depth of 160 $\mathrm{km}$ ) to Mw 5.3 (with depths of $100-110 \mathrm{~km}$ ). Calculated moment magnitudes for solutions with depths of $100-140 \mathrm{~km}$ range from Mw $5.1(120 \mathrm{~km})$ to $\mathrm{Mw} 5.3(100-110 \mathrm{~km})$, with Mw 5.2 for the $130 \mathrm{~km}$ deep solution (shown in Figure A1.19). Focal mechanisms are normal/strike-slip for depths of $100-140 \mathrm{~km}$ with a change in fault plane orientations at 120 
$\mathrm{km}$, reverse/strike-slip for a depth of $150 \mathrm{~km}$, mostly normal-slip for a depth of $160 \mathrm{~km}$, and mostly reverse-slip for depths of $170-200 \mathrm{~km}$.

\section{Summary}

Using these combinations of stations, calculated moment magnitudes range from $\mathrm{Mw} 4.8$ Mw 5.3.

None of the nine-station, eight-station or seven-station sets produced any solutions with reasonable fits of the synthetic seismograms to the data. The six-station set produced some reasonable solutions with depths of $100-140 \mathrm{~km}$, the five-station set with depths of $100-$ $180 \mathrm{~km}$, the four station-set with depths of $100-110 \mathrm{~km}$, and the three-station set with depths of $100-140 \mathrm{~km}$.

The reasonable solutions have moment magnitudes of $\mathrm{Mw} 5.1$ to $\mathrm{Mw}$ 5.3. The best solution, calculated using three stations and a depth of $130 \mathrm{~km}$, has a magnitude of $\mathrm{Mw}$ 5.2. These magnitudes are all below the Mw 5.4 calculated by the Global CMT project.

Only the five-station set produced a reasonable solution for a depth close to the depth calculated by the Global CMT project of $152.9 \mathrm{~km}$. The six-station set, five-station set and three-station set produced reasonable solutions close to the depth of $142.9 \mathrm{~km}$ calculated by GNS Science. The solutions with the highest variance reductions have depths of $130 \mathrm{~km}$ for the six-station set, $100 \mathrm{~km}$ for the five-station set, $110 \mathrm{~km}$ for the four-station set, and $130 \mathrm{~km}$ for the three-station set. These depths are all shallower than the depths calculated by either the Global CMT project or GNS Science.

The focal mechanisms were unable to be resolved over the range of possible depths, although the peaks in the variance reductions suggest that a normal/strike-slip mechanism is the most likely. The best solution, produced using the three stations NNZ, QRZ and VRZ and a depth of $130 \mathrm{~km}$, has a normal/strike-slip mechanism.

\section{Summary of all solutions}

Calculated moment magnitudes for this event range from Mw 4.8 to Mw 5.8, depending on the depth and combination of stations used. Reasonable solutions had moment magnitudes of Mw $5.1-5.3$.

There were a lot of very poor solutions produced, with very poor fits of the synthetic seismograms to the data, and the focal mechanism could not be constrained.

Using more than nine stations results in difficult to see plots of seismograms and synthetic seismograms.

The best solution was produced using the three stations NNZ, QRZ and VRZ and a depth of $130 \mathrm{~km}$. This solution has a magnitude of Mw 5.2 and a normal/strike-slip mechanism. 
Appendix 1: Case studies 


\section{A1.19. Event 2376763 - Fiordland}

14 March 2005, 0804 UT

Latitude -45.08, Longitude 166.81, depth $5 \mathrm{~km}$ (restricted) (GNS)

Depth $12 \mathrm{~km}$ (Global CMT)

ML 5.3 (GNS), Mw 5.2 (Global CMT)

Global CMT focal plane 1: $\quad$ strike 23

Global CMT focal plane 2: $\quad$ strike 233

rake 64

rake 105

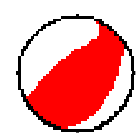

Global CMT mechanism

Data from ten stations, at distances of $110-385 \mathrm{~km}$ and azimuths of $55^{\circ}-136^{\circ}$ from the epicentre, and listed in Table A1.19, were used to compute seismic moment tensor solutions for this earthquake.

Table A1.19:

\begin{tabular}{|l|l|c|c|}
\hline $\begin{array}{l}\text { Station } \\
\text { code }\end{array}$ & Station name & $\begin{array}{l}\text { Distance from } \\
\text { earthquake }\end{array}$ & $\begin{array}{l}\text { Azimuth from } \\
\text { earthquake }\end{array}$ \\
\hline MLZ & Mavora Lakes & $110 \mathrm{~km}$ & $108^{\circ}$ \\
\hline WHZ & Wether Hill Road & $125 \mathrm{~km}$ & $136^{\circ}$ \\
\hline WKZ & Wanaka & $175 \mathrm{~km}$ & $82^{\circ}$ \\
\hline JCZ & Jackson Bay & $190 \mathrm{~km}$ & $55^{\circ}$ \\
\hline EAZ & Earnscleugh & $195 \mathrm{~km}$ & $96^{\circ}$ \\
\hline TUZ & Tuapeka & $240 \mathrm{~km}$ & $115^{\circ}$ \\
\hline LBZ & Lake Benmore & $280 \mathrm{~km}$ & $75^{\circ}$ \\
\hline FOZ & Fox Glacier & $295 \mathrm{~km}$ & $55^{\circ}$ \\
\hline ODZ & Otahua Downs & $300 \mathrm{~km}$ & $91^{\circ}$ \\
\hline WVZ & Waitaha Valley & $385 \mathrm{~km}$ & $56^{\circ}$ \\
\hline
\end{tabular}

This event was analysed using the New Zealand standard velocity model, and a frequency band-pass filter of $0.03-0.06 \mathrm{~Hz}$. Depths of $5-60 \mathrm{~km}$ were tested, with a depth interval of $5 \mathrm{~km}$. The solution with the highest double-couple component at each depth was chosen to be the best. Various numbers of stations were used for analysis.

The best solutions are produced using the five stations MLZ, WHZ, WKZ, JCZ and EAZ; the six stations MLZ, WHZ, WKZ, JCZ, EAZ and TUZ; and the eight stations MLZ, WHZ, WKZ, JCZ, EAZ, TUZ, LBZ and FOZ. The best solutions have depths of $15 \mathrm{~km}$, magnitudes Mw 5.1, and reverse/strike-slip mechanisms. The eight-station solution is shown in Figure A1.20.

\section{Ten stations}

With ten stations the moment magnitude ranges from $\mathrm{Mw} 4.9$ (at $5 \mathrm{~km}$ ) to $\mathrm{Mw} 5.2$ (at 35 $\mathrm{km}$ ). The double-couple component is high for depths up to $40 \mathrm{~km}$, and of these solutions, the variance reduction peaks at $15 \mathrm{~km}$. The magnitude at $15 \mathrm{~km}$ is Mw 5.1. Solutions are reverse/strike-slip for solutions with depths of $5-40 \mathrm{~km}$, normal/strike-slip for a depth of 50 $\mathrm{km}$, and strike-slip for a depth of $60 \mathrm{~km}$. 


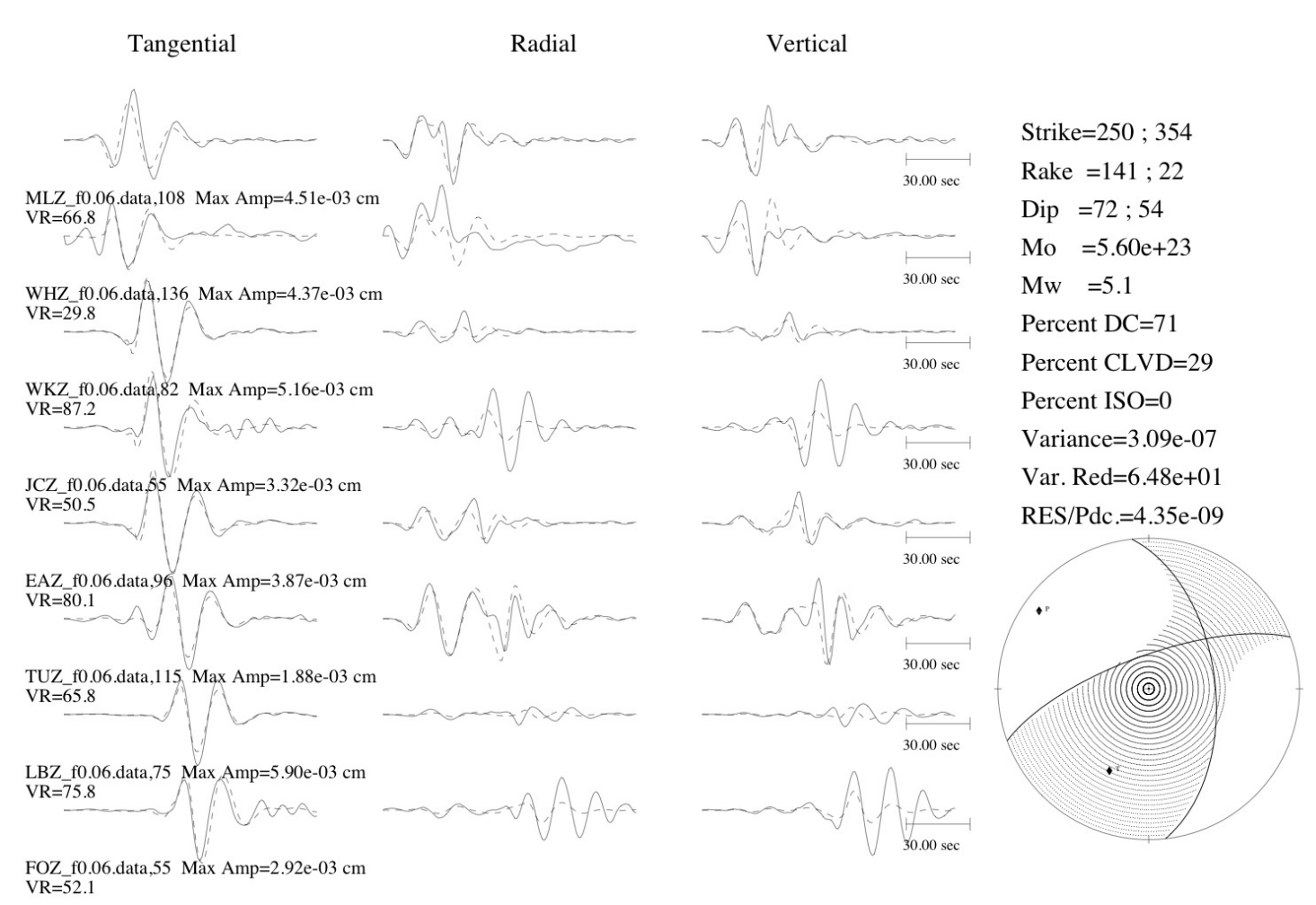

Figure A1.20. The best solution for event 2376763, using a source depth of $15 \mathrm{~km}$.

\section{Nine stations}

The closest nine stations in the suitable distance range are MLZ, WHZ, WKZ, JCZ, EAZ, TUZ, LBZ, FOZ and ODZ, at distances of $110-300 \mathrm{~km}$, and at azimuths of $55^{\circ}-136^{\circ}$ (an azimuthal range of $81^{\circ}$ ), from the earthquake epicentre. The moment magnitude of the seismic moment tensor solutions ranges from Mw 4.8 (at $20 \mathrm{~km}$ depth) to Mw 5.2 (at $45 \mathrm{~km}$ depth). The double-couple component is $89-100 \%$ for solutions at depths up to $45 \mathrm{~km}$, and the variance reduction peaks at $10 \mathrm{~km}$, with a magnitude of $\mathrm{Mw} 5.0$. Solutions are strikeslip/normal-slip for solutions with depths of $5-25 \mathrm{~km}$, strike-slip for the $30-45 \mathrm{~km}$ deep solutions, normal/strike-slip for the $50-55 \mathrm{~km}$ deep solutions, and reverse/strike-slip for the $60 \mathrm{~km}$ deep solution.

\section{Eight stations}

The closest eight stations in the $100-400 \mathrm{~km}$ distance range are MLZ, WHZ, WKZ, JCZ, EAZ, TUZ, LBZ and FOZ, at distances of $110-295 \mathrm{~km}$, and at azimuths of $55^{\circ}-136^{\circ}$ (an azimuthal range of $81^{\circ}$ ), from the earthquake epicentre. The moment magnitudes of the seismic moment tensor solutions range from $\mathrm{Mw} 4.9$ (at $50 \mathrm{~km}$ ) to $\mathrm{Mw} 5.3$ (at $45 \mathrm{~km}$ ). Double-couple components are $71 \%-100 \%$ for depths of $5-20 \mathrm{~km}$, and increase to $97 \%$ $100 \%$ for depths of $20-60 \mathrm{~km}$. The highest variance reduction is at $15 \mathrm{~km}$, where the double-couple component is only $71 \%$ and the magnitude is $\mathrm{Mw}$ 5.1. This solution is shown in Figure A1.20. Fault plane mechanisms are mostly strike-slip for the $5 \mathrm{~km}$ deep solution, reverse/strike-slip for the $10-15 \mathrm{~km}$ deep solutions, strike-slip/reverse for the $20-30 \mathrm{~km}$ deep solutions, strike-slip for the $35 \mathrm{~km}$ deep solution, strike-slip/reverse for the $40 \mathrm{~km}$ deep solution, strike-slip/vertical dip-slip for the $45 \mathrm{~km}$ deep solution, vertical dip-slip/strike-slip for the $50 \mathrm{~km}$ deep solution, and reverse/strike-slip for the $55-60 \mathrm{~km}$ deep solutions. 


\section{Seven stations}

The closest seven stations in the $100-400 \mathrm{~km}$ distance range are MLZ, WHZ, WKZ, JCZ, EAZ, TUZ and LBZ, at distances of $110-280 \mathrm{~km}$, and at azimuths of $55^{\circ}-136^{\circ}$ (an azimuthal range of $81^{\circ}$ ), from the earthquake epicentre. Moment magnitudes range from $\mathrm{Mw}$ 4.9 (at $10 \mathrm{~km}$ deep) to Mw 5.3 (at $45 \mathrm{~km}$ deep). Double-couple components are over $85 \%$ for all depths, and the variance reduction peaks at a depth of $20 \mathrm{~km}$, with a magnitude of $\mathrm{Mw}$ 5.1. Fault plane mechanisms are strike-slip/reverse-slip for the $5-30 \mathrm{~km}$ deep solutions, strike-slip/normal-slip for the $35 \mathrm{~km}$ deep solution, strike-slip/reverse-slip for the $40-45 \mathrm{~km}$ deep solutions, normal/strike-slip for the $50 \mathrm{~km}$ deep solution, and strike-slip/reverse for the $55-60 \mathrm{~km}$ deep solutions.

\section{Six stations}

The closest six stations in the $100-400 \mathrm{~km}$ distance range are MLZ, WHZ, WKZ, JCZ, EAZ and TUZ, at distances of $110-240 \mathrm{~km}$, and at azimuths of $55^{\circ}-136^{\circ}$ (an azimuthal range of $81^{\circ}$ ), from the earthquake epicentre. Moment magnitudes range from Mw 4.9 (at 5 and 10 $\mathrm{km}$ depth) to $\mathrm{Mw} 5.3$ (at depths of 45 and $60 \mathrm{~km}$ ). Double-couple components are over 65\% for depths of $5-60 \mathrm{~km}$, with a minimum of $66 \%$ at $15 \mathrm{~km}$ depth. For depths of $35-60 \mathrm{~km}$, the double-couple components are all over $97 \%$. The peak in the variance reduction is at 15 $\mathrm{km}$ depth, matching the minimum in the double-couple component. The magnitude at this depth is Mw 5.1. Fault-plane solutions range are mostly strike-slip/reverse-slip for solutions with depths of $5-15 \mathrm{~km}$, strike-slip/normal-slip for the $20-30 \mathrm{~km}$ deep solutions, reverse/strike-slip for the $35-45 \mathrm{~km}$ deep solutions, strike-slip/normal-slip for the $50-55$ $\mathrm{km}$ deep solutions, and reverse/strike-slip for the $60 \mathrm{~km}$ deep solution.

\section{Five stations}

The closest five stations in the $100-400 \mathrm{~km}$ distance range are MLZ, WHZ, WKZ, JCZ and EAZ, at distances of $110-195 \mathrm{~km}$, and at azimuths of $55^{\circ}-136^{\circ}$ (an azimuthal range of $81^{\circ}$ ), from the earthquake epicentre. Magnitudes are from $\mathrm{Mw} 4.9$ (at 5 and $10 \mathrm{~km} \mathrm{depth}$ ) to Mw 5.3 (at $35 \mathrm{~km}$ ). Double-couple components are at least $60 \%$ for all calculated solutions at depths of $5-60 \mathrm{~km}$, and are consistently over $95 \%$ for depths of $35-60 \mathrm{~km}$. The maximum variance reduction occurs at a depth of $15 \mathrm{~km}$, where the double-couple component is at its minimum of $61 \%$. By eye, the best fit between the synthetics and the data also occurs at $15 \mathrm{~km}$. The magnitude is Mw 5.1 for the $15 \mathrm{~km}$ depth solution. Focal mechanisms are strike-slip for the $5 \mathrm{~km}$ deep solution, reverse/strike-slip for the $10-15 \mathrm{~km}$ deep solutions, strike-slip/normal for the $20-30 \mathrm{~km}$ deep solutions, reverse/strike-slip for the $35-45 \mathrm{~km}$ deep solutions, normal/strike-slip for the $50-55 \mathrm{~km}$ deep solutions, and reverse/strike-slip for the $60 \mathrm{~km}$ deep solution.

\section{Four stations}

The closest four stations in the $100-400 \mathrm{~km}$ distance range are MLZ, WHZ, WKZ and JCZ, at distances of $110-190 \mathrm{~km}$, and at azimuths of $55^{\circ}-136^{\circ}$ (an azimuthal range of $81^{\circ}$ ), from the earthquake epicentre. The calculated magnitudes are between Mw 4.9 (at a depth of $10 \mathrm{~km}$ ) and $\mathrm{Mw} 5.3$ (at a depth of $45 \mathrm{~km}$ ). The minimum double-couple component is $69 \%$ at a depth of $15 \mathrm{~km}$, where the maximum variance reduction occurs, and the only solution that has a good correlation between the synthetic seismograms and the observed seismograms. The magnitude for the $15 \mathrm{~km}$ depth solution is $\mathrm{Mw}$ 5.1. The focal mechanisms are strike-slip/reverse-slip for solutions with depths of $5-20 \mathrm{~km}$, mostly strikeslip with some normal-slip for 25 - $30 \mathrm{~km}$ depths, reverse/strike-slip for $35-45 \mathrm{~km}$ depths, normal/strike-slip for $50-55 \mathrm{~km}$ depths, and reverse/strike-slip for the $60 \mathrm{~km}$ depth solution. 


\section{Three stations}

The closest three stations in the $100-400 \mathrm{~km}$ distance range are MLZ, WHZ and WKZ, at distances of $110-175 \mathrm{~km}$, and at azimuths of $55^{\circ}-82^{\circ}$ (an azimuthal range of $27^{\circ}$ ), from the earthquake epicentre. Solutions were calculated for $5 \mathrm{~km}$ depth increments for depths of $5-40 \mathrm{~km}$, and at $10 \mathrm{~km}$ increments for depths of $40 \mathrm{~km}-60 \mathrm{~km}$. Magnitudes range from Mw 4.9 (at a depth of $10 \mathrm{~km}$ ), to Mw 5.3 (for the $35 \mathrm{~km}$ depth solution). The double-couple components are at least $95 \%$ for all solutions with depths of $5-60 \mathrm{~km}$. The peak in the variance reduction is much deeper, at $35 \mathrm{~km}$, than it is for sets of solutions calculated with more stations. The focal mechanisms are strike-slip/reverse for solutions with depths of $5-$ $30 \mathrm{~km}$, strike-slip for the $35-40 \mathrm{~km}$ deep solutions, and mostly reverse-slip for depths of 50 and $60 \mathrm{~km}$.

\section{Summary}

Magnitudes of Mw 4.8 - Mw 5.3 were calculated for this earthquake.

The best solutions (calculated with 5, 6 and 8 stations) have depths of $15 \mathrm{~km}$, magnitudes of Mw 5.1 and reverse/strike-slip mechanisms.

The solution calculated by the Global CMT Project has a depth of $12 \mathrm{~km}$, a magnitude of Mw 5.2, and a mostly reverse-slip mechanism. This agrees with the results calculated using most of the station sets.

The results are sensitive to which stations are used in the calculation, and perhaps to the number of stations. The best depth (chosen as the depth with the highest variance reduction from solutions calculated with the highest double-couple component) for the earthquake varies from $10 \mathrm{~km}$ to $35 \mathrm{~km}$, depending on the stations used. Most station sets gave a best result of between 10 and $20 \mathrm{~km}$, which agrees with the Global CMT result of $12 \mathrm{~km}$. The three-station set with the much lower azimuthal range gave the anomalous depth of $35 \mathrm{~km}$. The magnitudes at the best depth are Mw 5.0 - Mw 5.1 for the solutions with best depths of $10-20 \mathrm{~km}$, and Mw 5.3 for the $35 \mathrm{~km}$ solution with only three stations. The magnitude range of Mw 5.0 - Mw 5.1 is a small range and is only slightly less than the Mw 5.2 calculated by the Global CMT project. The mechanisms for these depths (for solutions calculated with four to ten stations) are all mostly reverse-slip, and with similar strikes to the solution calculated by the Global CMT project. 


\section{A1.20. Event 2385032 - Twizel}

2 April 2005, 0207 UT

Latitude -44.37 , Longitude 169.87, depth $10.9 \pm 1.6 \mathrm{~km}$ (GNS)

Depth $12 \mathrm{~km}$ (Global CMT)

ML 5.0 (GNS), Mw 4.9 (Global CMT)

Global CMT focal plane 1: $\quad$ strike 262 rake 174 dip 42

Global CMT focal plane 2: $\quad$ strike 356 rake 48 dip 86

Data from ten stations, at distances of $105-380 \mathrm{~km}$ and azimuths of $26^{\circ}-231^{\circ}$, and listed in

Table A1.20, were used to compute seismic moment tensor solutions for this event.

Table A1.20:

\begin{tabular}{|l|l|c|c|}
\hline $\begin{array}{l}\text { Station } \\
\text { code }\end{array}$ & Station name & $\begin{array}{l}\text { Distance from } \\
\text { earthquake }\end{array}$ & $\begin{array}{l}\text { Azimuth from } \\
\text { earthquake }\end{array}$ \\
\hline EAZ & Earnscleugh & $105 \mathrm{~km}$ & $205^{\circ}$ \\
\hline WVZ & Waitaha Valley & $160 \mathrm{~km}$ & $26^{\circ}$ \\
\hline TUZ & Tuapeka & $175 \mathrm{~km}$ & $186^{\circ}$ \\
\hline MLZ & Mavora Lakes & $175 \mathrm{~km}$ & $231^{\circ}$ \\
\hline WHZ & Wether Hill Road & $225 \mathrm{~km}$ & $221^{\circ}$ \\
\hline MQZ & McQueen's Valley & $235 \mathrm{~km}$ & $73^{\circ}$ \\
\hline CRLZ & Canterbury Ring Laser & $240 \mathrm{~km}$ & $69^{\circ}$ \\
\hline LTZ & Lake Taylor Station & $260 \mathrm{~km}$ & $49^{\circ}$ \\
\hline KHZ & Kahutara & $370 \mathrm{~km}$ & $55^{\circ}$ \\
\hline THZ & Top House & $380 \mathrm{~km}$ & $42^{\circ}$ \\
\hline
\end{tabular}

This event was processed using the New Zealand standard velocity model and a $0.03-0.06$ $\mathrm{Hz}$ frequency band-pass filter. Solutions were calculated for depths of $5-40 \mathrm{~km}$ at intervals of $5 \mathrm{~km}$, and the solution with the highest double-couple component for each depth was chosen as the best solution for that depth. Solutions were calculated using various numbers of stations.

The best solutions are those calculated by the four stations (EAZ, WVZ, TUZ and MLZ) and by the three stations (EAZ, WVZ and TUZ) and a depth of $5 \mathrm{~km}$. These solutions have magnitudes of Mw 4.6 and reverse/strike-slip mechanisms. The best 4 station solution is shown in Figure A1.21.

\section{0 stations}

Magnitudes for the solutions calculated using all ten stations given in Table A1.20 range from $\mathrm{Mw} 4.1$ (for a depth of $10 \mathrm{~km}$ ) to $\mathrm{Mw} 4.6$ (for depths of 5, 35, and $40 \mathrm{~km}$ ). Focal mechanisms are reverse-slip for the $5 \mathrm{~km}$ deep solution, strike-slip/reverse-slip for the $10 \mathrm{~km}$ deep solution, strike-slip/normal-slip for the $15-25 \mathrm{~km}$ deep solutions, strike-slip/reverseslip for the $30 \mathrm{~km}$ deep solution, and strike-slip/normal-slip for the $35-40 \mathrm{~km}$ deep solutions. The fits of the synthetic seismograms to the data are fairly good for the $5 \mathrm{~km}$ deep solution, and poor for the $10-40 \mathrm{~km}$ deep solutions. 


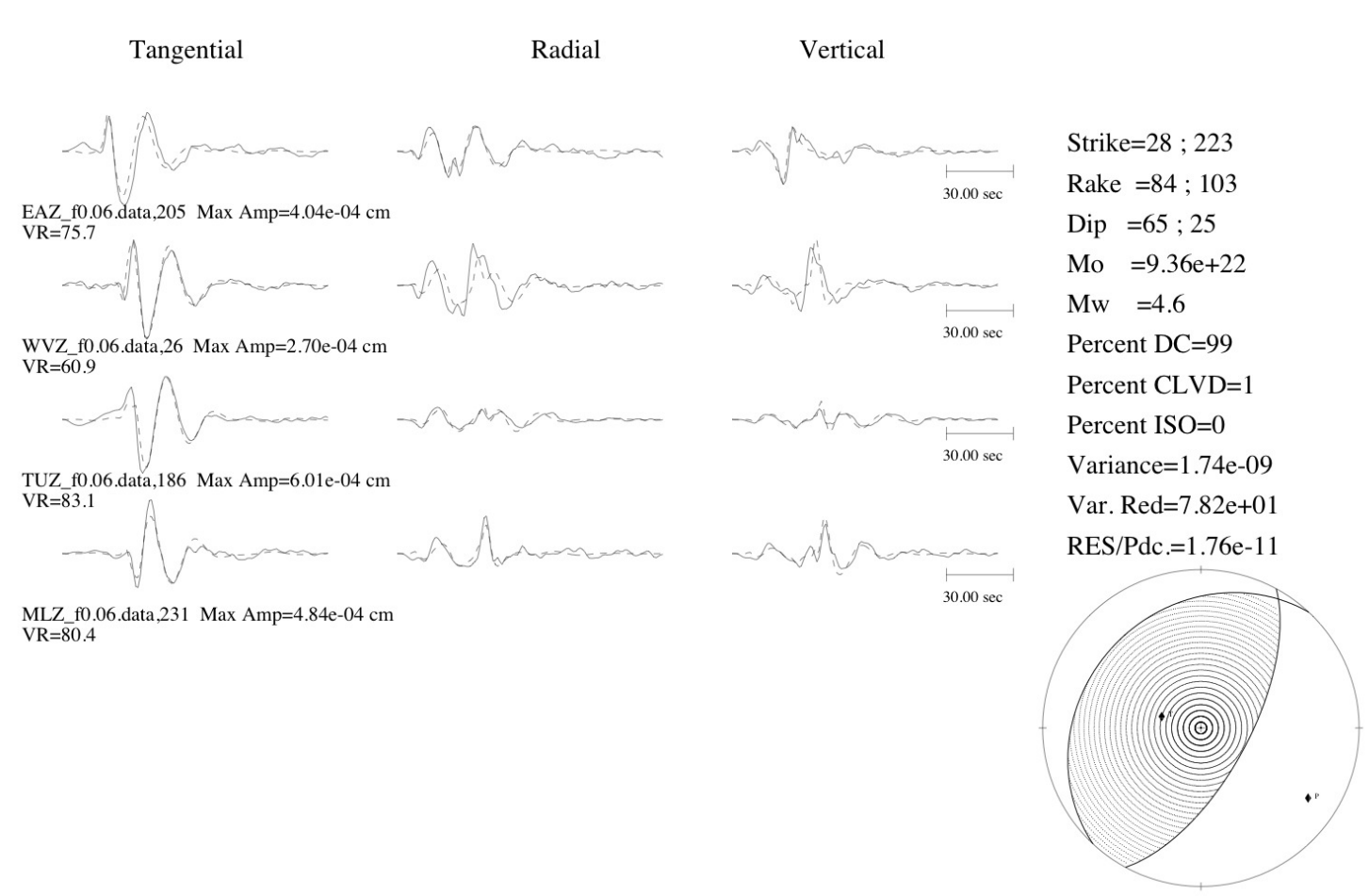

Figure A1.21. The best solution produced for event 2385032, using a source depth of $5 \mathrm{~km}$.

\section{9 stations}

The nine stations EAZ, WVZ, TUZ, WHZ, MQZ, CRLZ, LTZ, KHZ and THZ lie at distances of $105-380 \mathrm{~km}$ and azimuths of $26^{\circ}-221^{\circ}$ from the earthquake epicentre. Magnitudes calculated using these stations range from Mw 4.2 (for a depth of $10 \mathrm{~km}$ ) to $\mathrm{Mw}$ 4.6 (for depths of 5 and $40 \mathrm{~km}$ ). Focal mechanisms are reverse-slip for the $5 \mathrm{~km}$ deep solution, strike-slip/reverse-slip for the $10 \mathrm{~km}$ deep solution, strike-slip/normal-slip for the 15 $\mathrm{km}$ deep solution, strike-slip/reverse-slip for the $20 \mathrm{~km}$ deep solution, strike-slip/normal-slip for the $25 \mathrm{~km}$ deep solution, strike-slip/reverse-slip for the $30 \mathrm{~km}$ deep solution, and strikeslip/normal-slip for the $35-40 \mathrm{~km}$ deep solutions. The fits of the data to the synthetic seismograms to the data are reasonable for the $5 \mathrm{~km}$ deep solution, and poor for the $10-40$ $\mathrm{km}$ deep solutions, with some reasonably fitting traces.

\section{8 stations}

The eight stations EAZ, WVZ, TUZ, MLZ, CRLZ, LTZ, KHZ and THZ lie at distances of $105-380 \mathrm{~km}$ and azimuths of $26^{\circ}-231^{\circ}$ from the earthquake epicentre. Magnitudes calculated using these stations range from $\mathrm{Mw} 4.3$ (for depths of 10 and $15 \mathrm{~km}$ ) to Mw 4.6 (for depths of 35 and $40 \mathrm{~km}$ ). Focal mechanisms are reverse-slip/strike-slip for the $5 \mathrm{~km}$ deep solution, strike-slip/reverse-slip for the $10 \mathrm{~km}$ deep solution, strike-slip/normal-slip for the $15-20 \mathrm{~km}$ deep solutions, strike-slip/reverse-slip for the $25 \mathrm{~km}$ deep solution, strikeslip/normal-slip for the $30 \mathrm{~km}$ deep solution, and strike-slip/reverse-slip for the $35-40 \mathrm{~km}$ deep solutions. The fits of the data to the synthetic seismograms to the data are reasonable for all solutions. The $25 \mathrm{~km}$ deep solution has the maximum variance reduction, a magnitude of Mw 4.5 and a strike-slip/reverse-slip mechanism. 


\section{7 stations}

The seven stations EAZ, WVZ, TUZ, MLZ, CRLZ, LTZ and KHZ lie at distances of 105 $370 \mathrm{~km}$ and azimuths of $26^{\circ}-231^{\circ}$ from the earthquake epicentre. Magnitudes calculated using these stations range from $\mathrm{Mw} 4.3$ (for depths of 10 and $15 \mathrm{~km}$ ) to $\mathrm{Mw} 4.6$ (for depths of 35 and $40 \mathrm{~km}$ ). Focal mechanisms are reverse-slip/strike-slip for the $5-10 \mathrm{~km}$ deep solutions, strike-slip/reverse-slip for the $15 \mathrm{~km}$ deep solution, strike-slip for the $20-30 \mathrm{~km}$ deep solutions, and strike-slip/reverse-slip for the $35-40 \mathrm{~km}$ deep solutions. The fits of the data to the synthetic seismograms to the data are reasonable for all solutions, but there is no best solution.

\section{6 stations}

The six stations EAZ, WVZ, TUZ, MLZ, CRLZ and LTZ lie at distances of $105-260 \mathrm{~km}$ and azimuths of $26^{\circ}-231^{\circ}$ from the earthquake epicentre. Magnitudes calculated using these stations range from $\mathrm{Mw} 4.3$ (for depths of $10-20 \mathrm{~km}$ ) to $\mathrm{Mw} 4.6$ (for a depth of 40 $\mathrm{km}$ ). Focal mechanisms are reverse-slip for the $5 \mathrm{~km}$ deep solution, reverse-slip/strike-slip for the $10 \mathrm{~km}$ deep solution, strike-slip for the $15-20 \mathrm{~km}$ deep solutions, strike-slip/normalslip for the $25 \mathrm{~km}$ deep solution, and strike-slip/reverse-slip for the $30-40 \mathrm{~km}$ deep solutions. The fits of the data to the synthetic seismograms to the data are reasonable for all solutions. The $5 \mathrm{~km}$ deep solution has the maximum variance reduction, a magnitude of $\mathrm{Mw}$ 4.5 and a reverse-slip mechanism.

\section{5 stations}

The five stations EAZ, WVZ, TUZ, MLZ and CRLZ lie at distances of $105-240 \mathrm{~km}$ and azimuths of $26^{\circ}-231^{\circ}$ from the earthquake epicentre. Magnitudes calculated using these stations range from $\mathrm{Mw} 4.2$ (for a depth of $25 \mathrm{~km}$ ) to $\mathrm{Mw} 4.6$ (for a depth of $5 \mathrm{~km}$ ). Focal mechanisms are reverse-slip/strike-slip for the $5-20 \mathrm{~km}$ deep solutions, strike-slip/normalslip for the $25 \mathrm{~km}$ deep solution, and strike-slip/reverse-slip for the $30 \mathrm{~km}$ deep solution, and strike-slip/normal-slip for the $35-40 \mathrm{~km}$ deep solutions. The fits of the data to the synthetic seismograms to the data are reasonable for the $5-20 \mathrm{~km}$ deep solutions. The $5-20 \mathrm{~km}$ deep solutions have magnitudes of $\mathrm{Mw} 4.3$ - Mw 4.6. The $5 \mathrm{~km}$ deep solution has the maximum variance reduction, a magnitude of $\mathrm{Mw} 4.6$ and a reverse-slip mechanism.

\section{4 stations}

The four stations EAZ, WVZ, TUZ and MLZ lie at distances of $105-175 \mathrm{~km}$ and azimuths of $26^{\circ}-231^{\circ}$ from the earthquake epicentre. Magnitudes calculated using these stations range from Mw 4.1 (for a depth of $20 \mathrm{~km}$ ) to Mw 4.6 (for depths of 5 and $40 \mathrm{~km}$ ). Focal mechanisms are reverse-slip/strike-slip for the $5-20 \mathrm{~km}$ deep solutions, normal-slip/strikeslip for the $25 \mathrm{~km}$ deep solution, and strike-slip/reverse-slip for the $30 \mathrm{~km}$ deep solution, reverse-slip/strike-slip for the $35 \mathrm{~km}$ deep solution, and normal-slip/strike-slip for the $40 \mathrm{~km}$ deep solution. The fits of the data to the synthetic seismograms to the data are reasonable for the $5-15 \mathrm{~km}$ deep solutions. The $5-15 \mathrm{~km}$ deep solutions have magnitudes of $\mathrm{Mw} 4.3-$ $\mathrm{Mw}$ 4.6. The $5 \mathrm{~km}$ deep solution has the maximum variance reduction, a magnitude of $\mathrm{Mw}$ 4.6 and a reverse-slip/strike-slip mechanism, and is shown in Figure A1.21.

\section{3 stations}

The three stations EAZ, WVZ and TUZ lie at distances of $105-175 \mathrm{~km}$ and azimuths of $26^{\circ}$ $-205^{\circ}$ from the earthquake epicentre. Magnitudes calculated using these stations range from Mw 4.5 (for depths of $10-30 \mathrm{~km}$ ) to $\mathrm{Mw} 4.7$ (for depths of $35-40 \mathrm{~km}$ ). Focal mechanisms are reverse-slip/strike-slip for the $5-20 \mathrm{~km}$ deep solutions, and normal-slip/strike-slip for the 
$25-40 \mathrm{~km}$ deep solutions. The fits of the data to the synthetic seismograms to the data are good for all solutions. The $5 \mathrm{~km}$ deep solution has the maximum variance reduction, a magnitude of Mw 4.6 and a reverse-slip/strike-slip mechanism.

\section{Summary}

Magnitudes of Mw 4.1 - Mw 4.7 were calculated for this earthquake. Magnitudes of reasonable solutions were $\mathrm{Mw} 4.3$ - Mw 4.7, and the best solutions had magnitudes of Mw 4.6. These magnitudes are all lower than the Mw 4.9 calculated by the Global CMT project.

From the TDMT_INVC solutions it seems most likely that the mechanism for this earthquake is a mostly reverse-slip mechanism.

The best solutions are those calculated by the four stations (EAZ, WVZ, TUZ and MLZ) and by the three stations (EAZ, WVZ and TUZ) and a depth of $5 \mathrm{~km}$. These solutions have magnitudes of $\mathrm{Mw} 4.6$ and reverse/strike-slip mechanisms. 


\section{A1.21. Event 2398629 - Jackson's Bay}

2 May 2005, 1535 UT

Latitude -43.94 , Longitude 168.97, depth $15.0 \pm 1.2 \mathrm{~km}(\mathrm{GNS})$

Depth $12 \mathrm{~km}$ (Global CMT)

ML 5.8 (GNS), Mw 5.4 (Global CMT)

Global CMT focal plane 1: $\quad$ strike 54 rake 153 dip 55

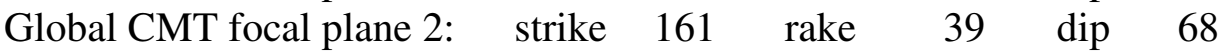

Data from eight stations, at distances of $110-295 \mathrm{~km}$ and azimuths of $57^{\circ}-203^{\circ}$ from the epicentre, were used to calculate seismic moment tensor solutions for this event, and are listed in Table A1.21.

Table A1.21:

\begin{tabular}{|l|l|c|c|}
\hline $\begin{array}{l}\text { Station } \\
\text { code }\end{array}$ & Station name & $\begin{array}{l}\text { Distance from } \\
\text { earthquake }\end{array}$ & $\begin{array}{l}\text { Azimuth from } \\
\text { earthquake }\end{array}$ \\
\hline LBZ & Lake Benmore & $110 \mathrm{~km}$ & $118^{\circ}$ \\
\hline EAZ & Earnscleugh & $145 \mathrm{~km}$ & $170^{\circ}$ \\
\hline WVZ & Waitaha Valley & $170 \mathrm{~km}$ & $57^{\circ}$ \\
\hline MLZ & Mavora Lakes & $170 \mathrm{~km}$ & $203^{\circ}$ \\
\hline ODZ & Otahua Downs & $180 \mathrm{~km}$ & $133^{\circ}$ \\
\hline TUZ & Tuapeka & $230 \mathrm{~km}$ & $167^{\circ}$ \\
\hline WHZ & Wether Hill Road & $230 \mathrm{~km}$ & $200^{\circ}$ \\
\hline MQZ & McQueen's Valley & $295 \mathrm{~km}$ & $86^{\circ}$ \\
\hline
\end{tabular}

This event was processed using the New Zealand standard velocity model and a frequency pass-band filter of $0.03-0.06 \mathrm{~Hz}$. Solutions were calculated for depths of $5-35 \mathrm{~km}$ at intervals of $5 \mathrm{~km}$, and the best solution for each depth was chosen to be the solution with the highest double-couple component. Solutions were calculated using various station combinations.

The best solution was produced using the three stations LBZ, EAZ and WVZ and a depth of $5 \mathrm{~km}$, and has a magnitude of Mw 5.2 and a reverse/strike-slip mechanism. This solution is shown in Figure A1.22.

\section{8 stations}

Magnitudes for the solutions calculated using all eight stations given in Table A1.21 range from $\mathrm{Mw} 4.8$ (for a depth of $10 \mathrm{~km}$ ) to $\mathrm{Mw} 5.3$ (for a depth of $35 \mathrm{~km}$ ). Focal mechanisms are normal/strike-slip for the $5 \mathrm{~km}$ deep solution, reverse/strike-slip for the $10 \mathrm{~km}$ deep solution, normal/strike-slip for the $15 \mathrm{~km}$ deep solution, reverse/strike-slip for the $20 \mathrm{~km}$ deep solution, strike-slip/normal for the $25-30 \mathrm{~km}$ deep solutions, and reverse/strike-slip for the $35 \mathrm{~km}$ deep solution. The fits of the synthetic seismograms to the data are all very poor.

\section{7 stations}

The seven stations LBZ, EAZ, WVZ, MLZ, ODZ, TUZ and WHZ lie at distances of 110 $230 \mathrm{~km}$ and azimuths of $57^{\circ}-203^{\circ}$ from the earthquake epicentre. Magnitudes calculated using these stations range from Mw 5.0 (for the $10 \mathrm{~km}$ deep solution) to Mw 5.3 (for the 30 $\mathrm{km}$ deep solution). Focal mechanisms are strike-slip/normal for the $5 \mathrm{~km}$ deep solution, 
strike-slip/reverse for the $10 \mathrm{~km}$ deep solution, strike-slip/normal for the 15 - $30 \mathrm{~km}$ deep solutions, and strike-slip/reverse for the $35 \mathrm{~km}$ deep solution. The fits of the synthetic seismograms to the data are fairly poor, with some reasonably fitting traces.
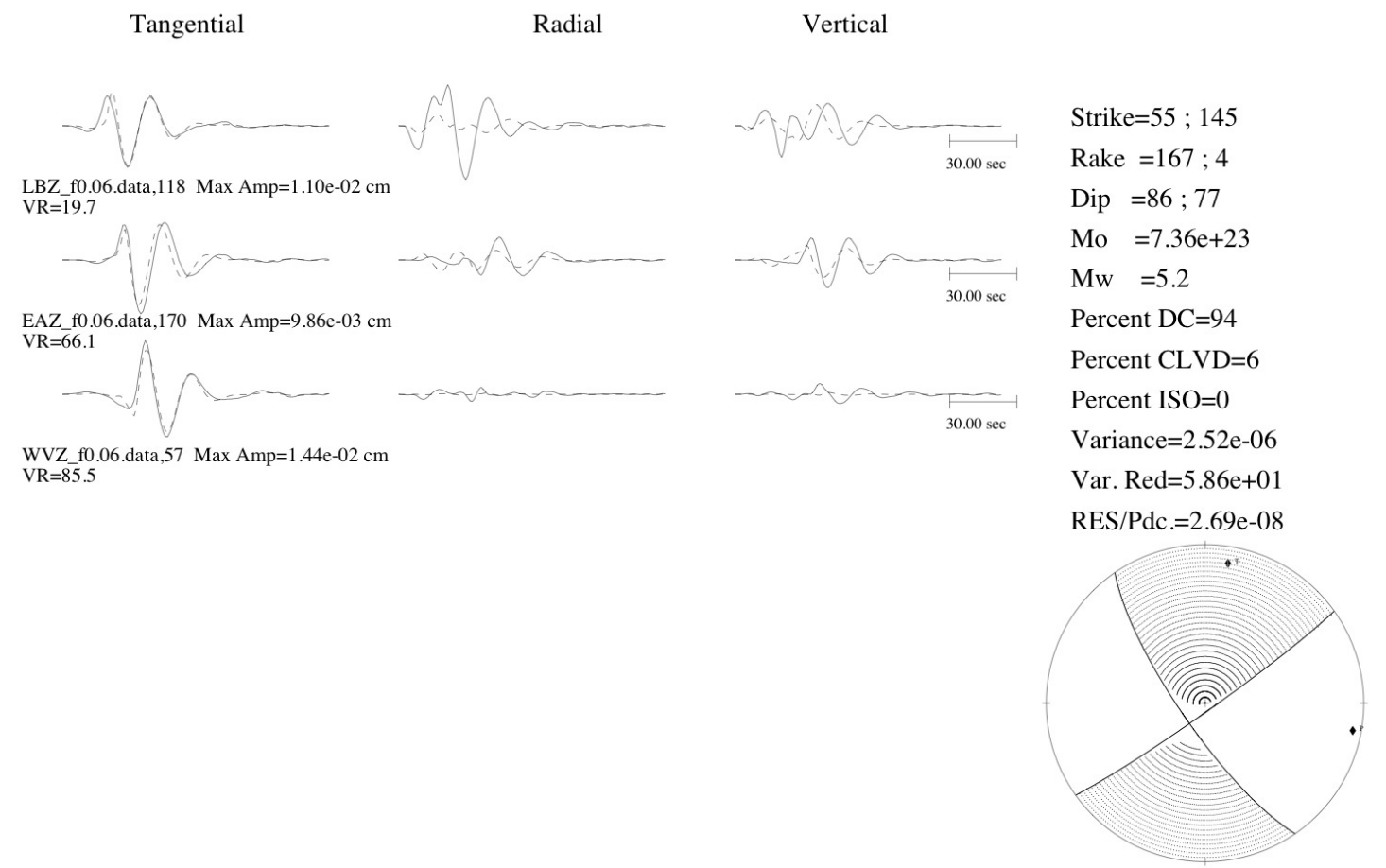

Figure A1.22. The best solution produced for event 2398629, using a depth of $5 \mathrm{~km}$.

\section{4 stations}

The four stations LBZ, EAZ, WVZ and MLZ lie at distances of $110-170 \mathrm{~km}$ and azimuths of $57^{\circ}-203^{\circ}$ from the earthquake epicentre. Magnitudes calculated using these stations range from $\mathrm{Mw} 5.2$ (for the $5 \mathrm{~km}$ and $15 \mathrm{~km}$ deep solutions) to Mw 5.5 (for a depth of 35 $\mathrm{km}$ ). Focal mechanisms are strike-slip/normal for the $5 \mathrm{~km}$ deep solution, reverse/strike-slip for the $10 \mathrm{~km}$ deep solution, and strike-slip/normal for the $15-35 \mathrm{~km}$ deep solutions. The fits of the synthetic seismograms to the data are fairly good, and the $10 \mathrm{~km}$ deep solution has the best fit and highest variance reduction, with a magnitude of Mw 5.3 and a reverse/strikeslip mechanism.

\section{3 stations}

The three stations LBZ, EAZ and WVZ lie at distances of $110-170 \mathrm{~km}$ and azimuths of $57^{\circ}$ $-170^{\circ}$ from the earthquake epicentre. Magnitudes calculated using these stations range from Mw 5.2 (for depths of 5, 10, and $20 \mathrm{~km}$ ) to Mw 5.5 (for a depth of $35 \mathrm{~km}$ ). Focal mechanisms are strike-slip/reverse for depths of $5-15 \mathrm{~km}$, strike-slip/normal for depths of $20-30 \mathrm{~km}$, and strike-slip/reverse for a depth of $35 \mathrm{~km}$. The fits of the data to the synthetic seismograms to the data are fairly good, and the solution with the best fit and highest variance reduction is the $5 \mathrm{~km}$ deep solution, with a magnitude of Mw 5.2 and a strikeslip/reverse mechanism. This solution is shown in Figure A1.22. 


\section{Summary}

Magnitudes calculated for this event range from Mw 4.8 to Mw 5.5. Only the four-station and three-station sets produced good solutions (with good fits between the synthetic seismograms and the data) and these solutions had magnitudes ranging from Mw 5.2 to $\mathrm{Mw}$ 5.5 .

The best solution was produced using the three stations LBZ, EAZ and WVZ and a depth of $5 \mathrm{~km}$, and has a magnitude of Mw 5.2 and a reverse/strike-slip mechanism. This magnitude is less than the Mw 5.4 calculated by the Global CMT project.

The best solutions suggest that the mechanism of this earthquake was strike-slip/reverse faulting, which matches the Global CMT mechanism. 
Appendix 1: Case studies 


\section{A1.22. Event 2626467 - Jackson's Bay}

2 May 2005, 1540 UT

Latitude -43.95, Longitude 169.04, Depth: $10.1 \pm 1.2 \mathrm{~km}(\mathrm{GNS})$

Depth $12 \mathrm{~km}$ (Global CMT)

ML 5.3 (GNS), Mw 5.0 (Global CMT)

Global CMT focal plane 1: $\quad$ strike 62 rake 176 dip 61

Global CMT focal plane 2: $\quad$ strike 154 rake $30 \quad$ dip 86

Data from five stations, at distances of $105-225 \mathrm{~km}$ and azimuths of $55^{\circ}-205^{\circ}$, and listed in Table A1.22, were used to calculate seismic moment tensor solutions for this earthquake.

Table A1.22:

\begin{tabular}{|l|l|c|c|}
\hline $\begin{array}{l}\text { Station } \\
\text { code }\end{array}$ & Station name & $\begin{array}{l}\text { Distance from } \\
\text { earthquake }\end{array}$ & $\begin{array}{l}\text { Azimuth from } \\
\text { earthquake }\end{array}$ \\
\hline LBZ & Lake Benmore & $105 \mathrm{~km}$ & $118^{\circ}$ \\
\hline EAZ & Earnscleugh & $145 \mathrm{~km}$ & $172^{\circ}$ \\
\hline WVZ & Waitaha Valley & $170 \mathrm{~km}$ & $55^{\circ}$ \\
\hline MLZ & Mavora Lakes & $175 \mathrm{~km}$ & $205^{\circ}$ \\
\hline ODZ & Otahua Downs & $225 \mathrm{~km}$ & $168^{\circ}$ \\
\hline
\end{tabular}

This event was processed using the New Zealand standard velocity model and a $0.03-0.06$ $\mathrm{Hz}$ frequency band-pass filter. Solutions were calculated for depths of $5-13 \mathrm{~km}$ with a $1 \mathrm{~km}$ depth increment, and for $15 \mathrm{~km}$. The best solution for each depth was chosen to be the solution with the highest variance reduction.

The moment magnitudes calculated range from Mw 4.8 (for depths of $5-6 \mathrm{~km}$ ) to Mw 5.0 (for a depth of $15 \mathrm{~km}$ ). Focal mechanisms are all mostly strike-slip. The fits of the synthetic seismograms to the data are good for all solutions, so the best solution is chosen as the solution with the highest double-couple component. This is the $7 \mathrm{~km}$ deep solution, which has a double-couple component of $98 \%$ and a moment magnitude of $\mathrm{Mw} 4.9$, and is shown in Figure A1.23.

The moment magnitude calculated for this earthquake is very close to that calculated by the Global CMT project, and the mechanisms match. 


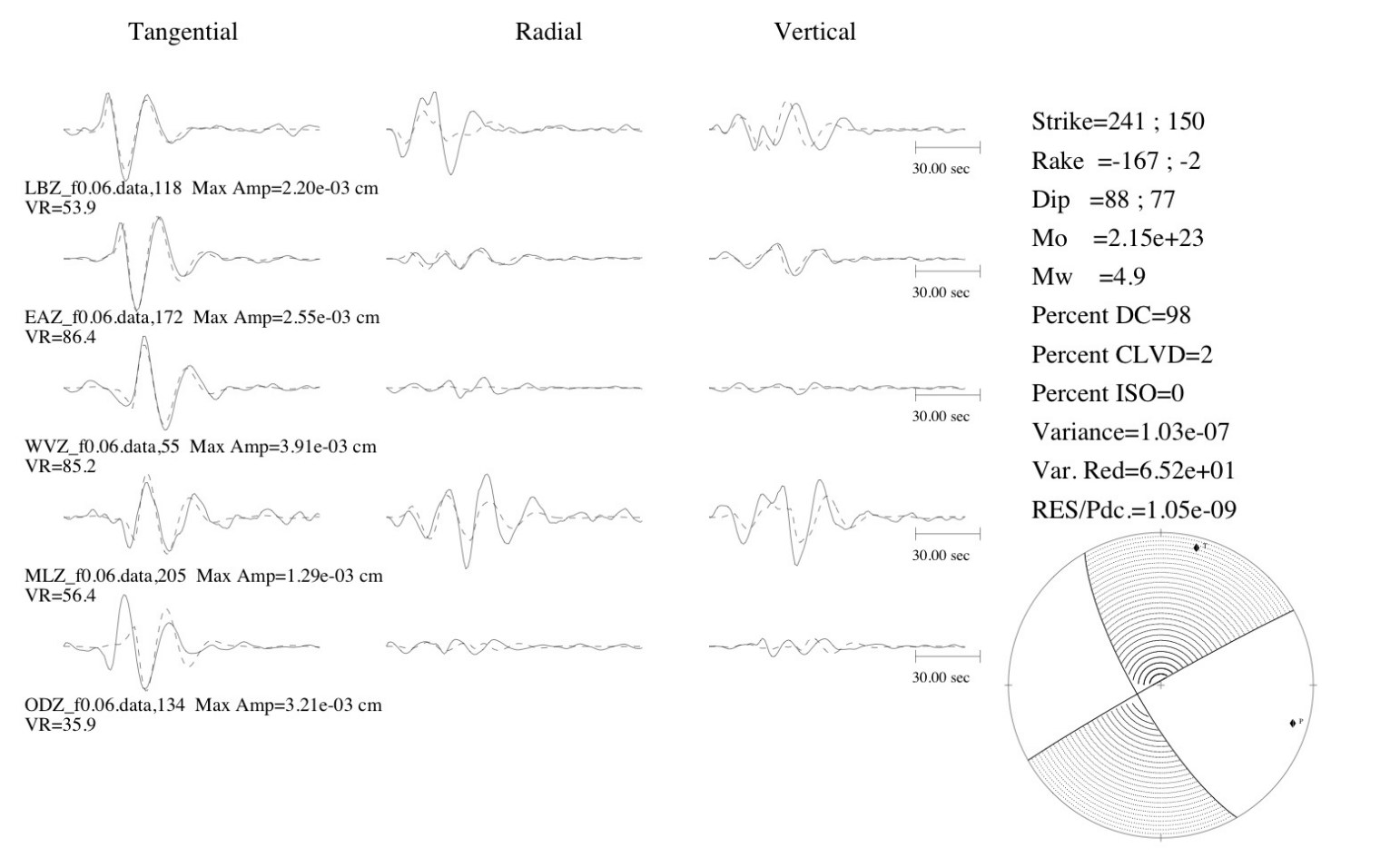

Figure A1.23. The best solution produced for event 2626467, with a depth of $7 \mathrm{~km}$. 


\section{A1.23. Event 2403682 - East of Gisborne}

13 May 2005, 1707 UT

Latitude -38.21, Longitude 179.47, depth $12.0 \mathrm{~km}$ (restricted) (GNS)

Depth $12 \mathrm{~km}$ (Global CMT)

ML 4.8 (GNS), Mw 5.1 (Global CMT)

Global CMT focal plane 1: $\quad$ strike 184 rake 70 dip 16

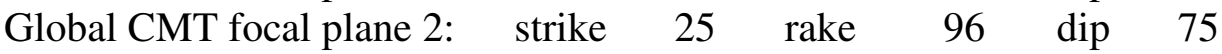

Data from eight stations, at distances of $105-370 \mathrm{~km}$ and azimuths of $235^{\circ}-305^{\circ}$ from the epicentre, and listed in Table A1.23, were used to compute seismic moment tensor solutions for this earthquake.

Table A1.23:

\begin{tabular}{|l|l|c|c|}
\hline $\begin{array}{l}\text { Station } \\
\text { code }\end{array}$ & Station name & $\begin{array}{l}\text { Distance from } \\
\text { earthquake }\end{array}$ & $\begin{array}{l}\text { Azimuth from } \\
\text { earthquake }\end{array}$ \\
\hline PUZ & Puketiti & $105 \mathrm{~km}$ & $278^{\circ}$ \\
\hline MXZ & Matakaoa Point & $125 \mathrm{~km}$ & $305^{\circ}$ \\
\hline MWZ & Matawai & $170 \mathrm{~km}$ & $265^{\circ}$ \\
\hline BKZ & Black Stump Farm & $280 \mathrm{~km}$ & $247^{\circ}$ \\
\hline PWZ & Pawanui & $300 \mathrm{~km}$ & $227^{\circ}$ \\
\hline WPVZ & Whakapapa & $360 \mathrm{~km}$ & $251^{\circ}$ \\
\hline TSZ & Takapari Road & $365 \mathrm{~km}$ & $235^{\circ}$ \\
\hline KUZ & Kuaotunu & $370 \mathrm{~km}$ & $295^{\circ}$ \\
\hline
\end{tabular}

Seismic moment tensor solutions were calculated using the New Zealand standard velocity model and a $0.03-0.06 \mathrm{~Hz}$ frequency pass-band filter. Solutions were calculated for depths of $5-35 \mathrm{~km}$ at intervals of $5 \mathrm{~km}$.

None of the solutions produced good fits between the synthetic seismograms and the data, so neither the moment magnitude nor the mechanism of this earthquake could be constrained. An example of the solutions produced (produced using the three stations PUZ, MXZ and KUZ, maximising the variance reduction and a depth of $25 \mathrm{~km}$ ) is shown in Figure A1.24.

\section{8 stations, maximising double-couple component}

Seismic moment tensor solutions were calculated for depths of $5-35 \mathrm{~km}$ using all eight stations in Table A1.23, and choosing the solution with the highest double-couple component as the best solution for each depth. Moment magnitudes of Mw 5.0 (for a depth of $10 \mathrm{~km}$ ) to Mw 5.4 (with a depth of $35 \mathrm{~km}$ ) were calculated. Focal mechanisms are mostly strike-slip for solutions with depths of $5-25 \mathrm{~km}$, and strike-slip/normal slip for solutions with depths of $30-35 \mathrm{~km}$. The fits of the synthetic seismograms to the data are very poor for all solutions.

\section{8 stations, maximising variance reduction}

Seismic moment tensor solutions were calculated for depths of $5-35 \mathrm{~km}$ using all eight stations in Table A1.23, and choosing the solution with the maximum variance reduction as the best solution for each depth. Moment magnitudes of Mw 5.2 (for depths of $5-15 \mathrm{~km}$ ) to Mw 5.5 (for a depth of $35 \mathrm{~km}$ ) were calculated. Focal mechanisms are mostly strike-slip for solutions with depths of $5-25 \mathrm{~km}$, strike-slip/normal slip for the $30 \mathrm{~km}$ deep solution, and 
normal slip for the $35 \mathrm{~km}$ deep solution. Double-couple components range from $31 \%$ (for the $30 \mathrm{~km}$ deep solution) to $96 \%$ (for the $10 \mathrm{~km}$ deep solution). The fits of the synthetic seismograms to the data are very poor for all solutions.

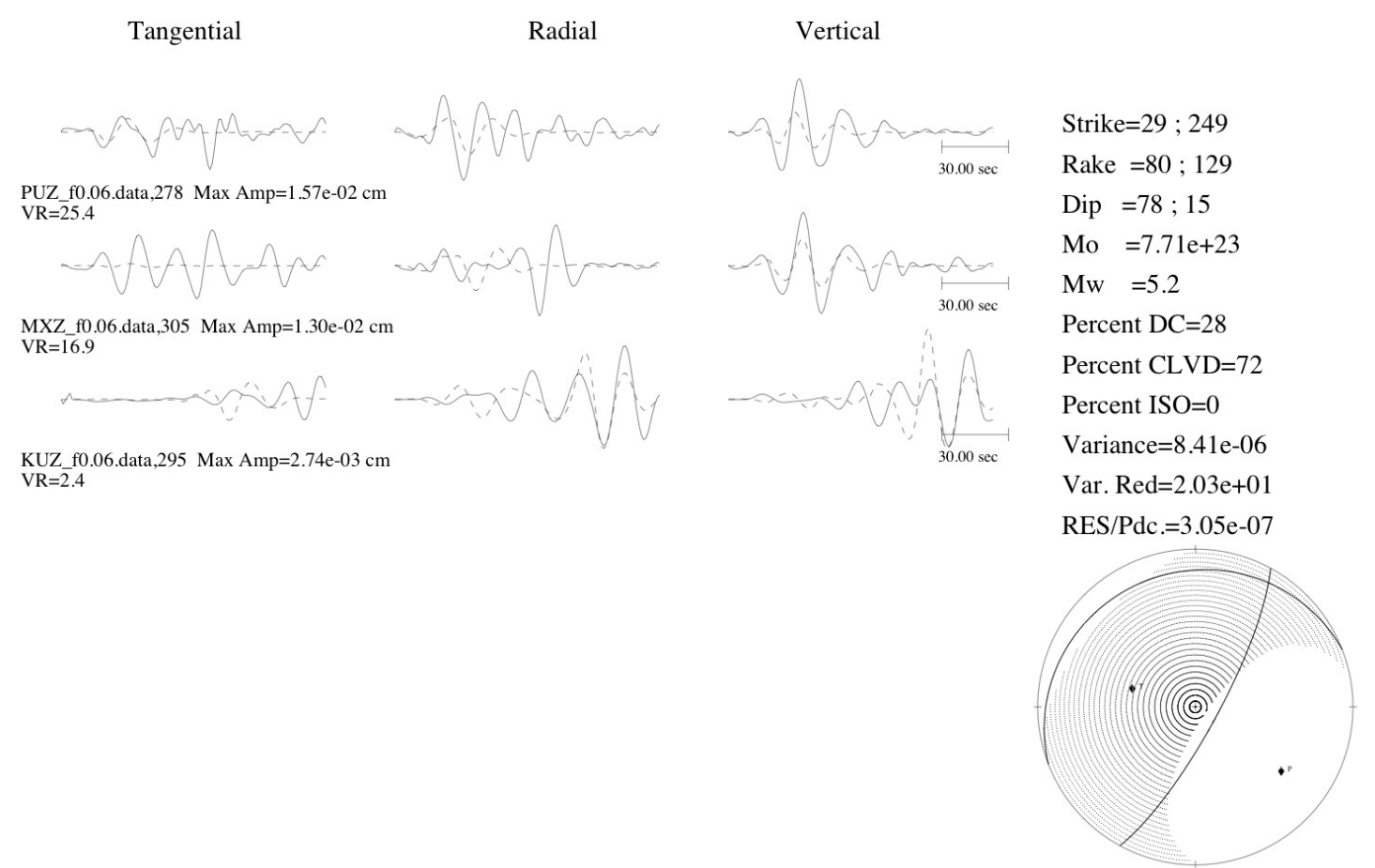

Figure A1.24. An example of a solution produced for event 2403682. Produced using a depth of $35 \mathrm{~km}$ and maximising the variance reduction.

\section{3 stations: PUZ, MXZ \& KUZ, maximising double-couple component}

Seismic moment tensor solutions were calculated using the three stations PUZ, MXZ and $\mathrm{KUZ}$, which lie at distances of $105-370 \mathrm{~km}$ and at azimuths of $278^{\circ}-305^{\circ}$ from the earthquake epicentre. The solution with the highest double-couple component was chosen as the best solution for each depth. Moment magnitudes of Mw 5.1 (for a depth of $20 \mathrm{~km}$ ) to Mw 5.4 (for depths of 5, 25 and $35 \mathrm{~km}$ ) were calculated. Focal mechanisms are normal/strike-slip with various fault plane orientations for the $5-30 \mathrm{~km}$ deep solutions, and reverse/strike-slip for the $35 \mathrm{~km}$ deep solution. Fits of the synthetic seismograms to the data are very poor for all solutions.

\section{3 stations: PUZ, MXZ \& KUZ, maximising variance reduction}

Seismic moment tensor solutions using the stations PUZ, MXZ and KUZ (at distances of 105 $-370 \mathrm{~km}$ and at azimuths of $278^{\circ}-305^{\circ}$ from the earthquake epicentre) were also calculated choosing the solution with the maximum variance reduction as the best solution for each depth. Calculated moment magnitudes range from Mw 5.2 (for depths of 10 and $25 \mathrm{~km}$ ) to Mw 5.4 (for depths of 5, 30 and $35 \mathrm{~km}$ ). Focal mechanisms are normal/strike-slip for the 5 $\mathrm{km}$ deep solution, strike-slip for the $10 \mathrm{~km}$ deep solution, strike-slip/normal slip for the 15 $20 \mathrm{~km}$ deep solutions, reverse/strike-slip for the $25 \mathrm{~km}$ deep solution, and strike-slip/normal slip for the $30-35 \mathrm{~km}$ deep solutions. Double-couple components range from $10 \%$ (for a depth of $10 \mathrm{~km}$ ) to $93 \%$ (for a depth of $20 \mathrm{~km}$ ). Fits of the synthetic seismograms to the data are very poor for all solutions. The $25 \mathrm{~km}$ deep solution is shown in Figure A1.24. 


\section{3 stations: PUZ, MXZ \& MWZ, maximising variance reduction}

The three stations PUZ, MXZ and MWZ lie at distances of $105-170 \mathrm{~km}$ and at azimuths of $265^{\circ}-305^{\circ}$ from the earthquake epicentre. Seismic moment tensor solutions were calculated using these three stations and choosing the solution with the maximum variance reduction as the best solution for each depth. Calculated moment magnitudes range from Mw 5.3 (for depths of $10-25 \mathrm{~km}$ ) to Mw 5.5 (for depths of $30-35 \mathrm{~km}$ ). Focal mechanisms are normal/strike-slip for depths of $5-10 \mathrm{~km}$, reverse/strike-slip for solutions with depths of 15 $-25 \mathrm{~km}$, normal/strike-slip for the solution with a depth of $30 \mathrm{~km}$, and reverse/strike-slip for the $35 \mathrm{~km}$ deep solution. Double-couple components range from $31 \%$ (with a depth of 15 $\mathrm{km}$ ) to $68 \%$ (with depths of 10 and $20 \mathrm{~km}$ ). Fits of the synthetic seismograms to the data are very poor for all solutions.

\section{Summary}

The fits of the synthetic seismograms to the data are poor for all calculated solutions.

Calculated moment magnitudes range from $\mathrm{Mw} 5.0$ to $\mathrm{Mw}$ 5.5, a range that includes the $\mathrm{Mw}$ 5.1 calculated by the Global CMT project. The focal mechanism can not be resolved. 
Appendix 1: Case studies 


\section{A1.24. Event 2418019 - South of Kermadec Islands}

14 June 2005, 2233 UT

Latitude -35.21 , Longitude 178.87, depth $218.0 \pm 7.7 \mathrm{~km}$ (GNS)

Depth $219.8 \mathrm{~km}$ (Global CMT)

ML 5.4 (GNS), Mw 5.3 (Global CMT)

Global CMT focal plane 1: $\quad$ strike 120 rake -139 dip 53

Global CMT focal plane 2: $\begin{array}{llllll}\text { strike } & 2 & \text { rake } & -45 & \text { dip } & 58\end{array}$

Data from four stations, at distances of $265-365 \mathrm{~km}$ and azimuths of $190^{\circ}-238^{\circ}$ from the epicentre, and listed in Table A1.24, were used to compute seismic moment tensor solutions for this earthquake.

Table A1.24:

\begin{tabular}{|l|l|c|c|}
\hline $\begin{array}{l}\text { Station } \\
\text { code }\end{array}$ & Station name & $\begin{array}{l}\text { Distance from } \\
\text { earthquake }\end{array}$ & $\begin{array}{l}\text { Azimuth from } \\
\text { earthquake }\end{array}$ \\
\hline MXZ & Matakaoa Point & $265 \mathrm{~km}$ & $191^{\circ}$ \\
\hline PUZ & Puketiti & $320 \mathrm{~km}$ & $190^{\circ}$ \\
\hline KUZ & Kuaotunu & $330 \mathrm{~km}$ & $238^{\circ}$ \\
\hline MWZ & Matawai & $365 \mathrm{~km}$ & $199^{\circ}$ \\
\hline
\end{tabular}

This event was processed using the New Zealand standard velocity model, a $0.03-0.06 \mathrm{~Hz}$ frequency pass-band filter, and the four stations listed in Table A1.24. Depths of $200-220$ $\mathrm{km}$ with an interval of $5 \mathrm{~km}$ were tested, and also a depth of $240 \mathrm{~km}$. The solution with the highest variance reduction was chosen as the best solution for each depth.

The magnitudes calculated range from Mw 4.8 for the $240 \mathrm{~km}$ deep solution to Mw 5.1 for the solutions with depths of $210 \mathrm{~km}$ and $215 \mathrm{~km}$. Focal mechanisms are mostly normal-slip for depths of $200-220 \mathrm{~km}$, and reverse/strike-slip for the $240 \mathrm{~km}$ depth solution. The fits of the synthetic seismograms to the data are poor for all solutions. The $240 \mathrm{~km}$ deep solution is shown in Figure A1.25 as an example of the solutions obtained.

The calculated magnitudes are significantly lower than the magnitude calculated by the Global CMT project. Although the focal mechanisms of the $200-220 \mathrm{~km}$ deep solutions are normal-slip, as is the Global CMT solution, the fault-plane orientations are quite different. 


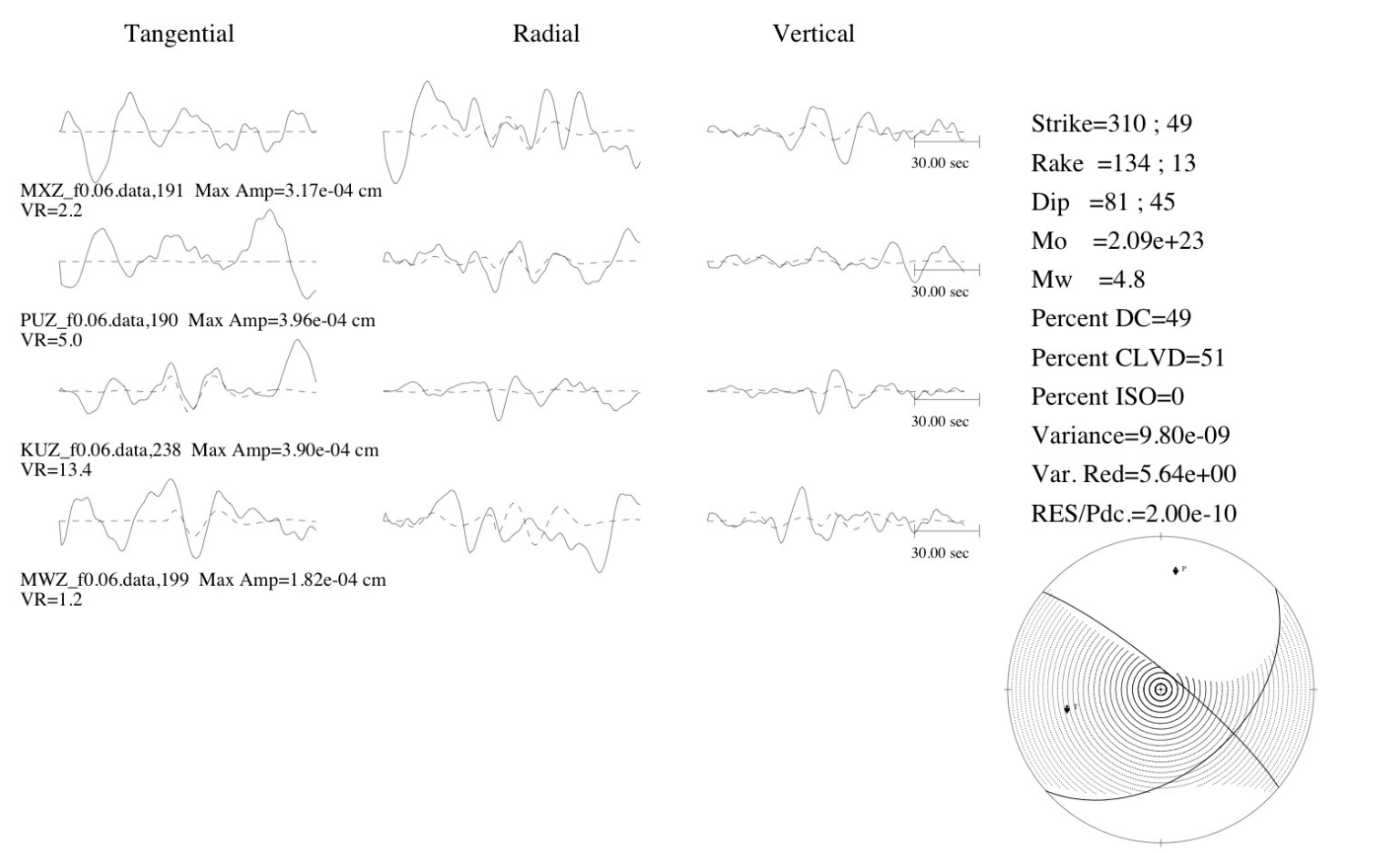

Figure A1.25. The $240 \mathrm{~km}$ deep solution obtained for event 2418019 . 


\section{Appendix 2: All seismic moment tensor solutions}

This Appendix contains all solution output plots produced by the TDMT_INVC algorithm. The plots are on the CD-ROM accompanying this thesis. The plots are Postscript files and are grouped in directories according to the earthquake's cusp ID number. For some earthquakes the directories are divided into sub-directories according to processing parameters. Information on some of the processing parameters is given by the sub-directory names and file-names. The following sections describe the processing parameters given by the file and directory names. More information about the processing parameters applied to each earthquake was given in Appendix 1.

\section{Dpics_1502698}

File-names have the prefix 'pwair', followed by the source-depth and the suffix '.ps'.

\section{Dpics_1597193}

File-names have the prefixes given below, followed by the source-depth and the suffix '.ps'.

- prefix 'pataup' : using the three stations KNZ, TOZ and DSZ.

- prefix 'ptaup' : using the four stations KNZ, TOZ, DSZ and MQZ.

\section{Dpics_1737299}

File-names have the prefix 'pking', followed by the source-depth and the suffix '.ps'.

\section{Dpics_1825324}

File-names have the prefix 'phaa', followed by the source-depth and the suffix '.ps'.

\section{Dpics_2114219}

Dfreq3: Solutions calculated using a $0.03-0.06 \mathrm{~Hz}$ frequency band-pass filter.

File-names have the prefixes given below, followed by the source depth and the suffix '.ps'.

- prefix ' $p f$ ' : using the four stations MLZ, WHZ, TUZ and ODZ.

- prefix 'pf_mto_': using the three stations MLZ, TUZ and ODZ.

- prefix 'pf_mwo_' : using the three stations MLZ, WHZ and ODZ.

- prefix 'pf_mwt_' : using the three stations MLZ, WHZ and TUZ.

- prefix 'pf_wto_' : using the three stations WHZ, TUZ and ODZ.

Dfreq5: Solutions calculated using a $0.05-0.10 \mathrm{~Hz}$ frequency band-pass filter. File-names have the prefix ' $p f$ ', followed by the source depth, a combination of letters relating to the stations used (explained below), and the suffix '.ps'.

- stations '_mwto' : the four stations MLZ, WHZ, TUZ and ODZ.

- stations '_wto' : the three stations WHZ, TUZ and ODZ. 


\section{Dpics_2137041}

Dfreq2: Solutions calculated using a $0.02-0.05 \mathrm{~Hz}$ frequency band-pass filter.

File-names have the prefixes given below, followed by the source depth and the suffix '.ps'.

- prefix 'pfiordl_b' : using the four stations MLZ, WHZ, TUZ and ODZ.

- prefix 'pfiordl_wto_b' : using the three stations WHZ, TUZ and ODZ.

Dfreq3: Solutions calculated using a $0.03-0.06 \mathrm{~Hz}$ frequency band-pass filter.

File-names have the prefixes given below, followed by the source depth and the suffix '.ps'.

- prefix 'pfiordl_' : using the four stations MLZ, WHZ, TUZ and ODZ.

- prefix 'pfiordl_mto': using the three stations MLZ, TUZ and ODZ.

- prefix 'pfiordl_mwo' : using the three stations MLZ, WHZ and ODZ.

- prefix 'pfiordl_mwt' : using the three stations MLZ, WHZ and TUZ.

- prefix 'pfiordl_wto' : using the three stations WHZ, TUZ and ODZ.

\section{Dpics_2137186}

File-names have the prefixes given below, followed by the source depth and the suffix '.ps'.

- prefix 'pfiord_' : using the four stations WHZ, MLZ, TUZ and ODZ.

- prefix 'pfiord_Mto_' : using the three stations MLZ, TUZ and ODZ.

- prefix 'pfiord_wmo_' : using the three stations WHZ, MLZ and ODZ.

- prefix 'pfiord_wmt_' : using the three stations WHZ, MLZ and TUZ.

- prefix 'pfiord_wto_' : using the three stations WHZ, TUZ and ODZ.

\section{Dpics_2228901}

Dfreq3: Solutions calculated using a $0.03-0.06 \mathrm{~Hz}$ frequency band-pass filter.

File-names have the prefixes given below, followed by the source depth and the suffix ‘ps'.

- prefix 'pgis' : using the seven stations BKZ, TOZ, PWZ, KUZ, HIZ, TSZ and VRZ.

- prefix 'pgisb3_' : using the three stations BKZ, TOZ and KUZ.

Dfreq5: Solutions calculated using a $0.05-0.10 \mathrm{~Hz}$ frequency band-pass filter.

File-names have the prefixes given below, followed by the source depth and the suffix 'ps'.

- prefix ' $p g_{-}$' : using the three stations BKZ, TOZ and KUZ, and maximising the variance reduction.

- $\quad$ prefix 'pge' : using the three stations BKZ, TOZ and KUZ, and maximising the double-couple component.

\section{Dpics_2266243}

File-names have the prefixes given below, followed by the source depth and the suffix '.ps'.

- prefix 'pbop_3h_' : using the three stations HIZ, KUZ and MXZ. 
- prefix 'pbop_3s_' : using the three stations BKZ, PUZ and HIZ.

- prefix 'pbop_ $4 s_{-}$' : using the four stations BKZ, PUZ, HIZ and KUZ.

- prefix 'pbop_ $8 s_{-}$' : using the eight stations BKZ, PUZ, HIZ, KUZ, MXZ, VRZ, PWZ and TSZ.

- prefix 'pbop_9s_' : using the nine stations BKZ, PUZ, HIZ, KUZ, MXZ, VRZ, PWZ, TSZ and WAZ.

\section{Dpics_2266782}

File-names have the prefixes given below, followed by the source depth and the suffix '.ps'.

- prefix ' $p b p \_3 s_{-}$' : using the three stations BKZ, HIZ and PUZ.

- prefix ' $p b p \_4 s_{-}$' : using the four stations BKZ, HIZ, PUZ and KUZ.

- prefix ' $p b p \_5 s_{-}$' : using the five stations BKZ, HIZ, PUZ, KUZ and MXZ.

- prefix 'pbp_6s_' : using the six stations BKZ, HIZ, PUZ, KUZ, MXZ and TSZ.

\section{Dpics_2326055}

\section{P4sec:}

Solutions calculated using 4 seconds of data before the arrival of the P-wave. The initial value of the offset between the seismograms and the synthetic seismograms was zero.

Dfreq1: Solutions calculated using a $0.01-0.05 \mathrm{~Hz}$ frequency band-pass filter. File-names have the prefix ' $p b \_p u y$ ', followed by the source-depth and the suffix '.ps'. If there is a ' $j$ ' between the source depth and the '.ps' the solution was calculated by maximising the variance reduction. If there is not, the solution was calculated by maximising the double-couple component.

Dfreq2: Solutions calculated using a $0.02-0.05 \mathrm{~Hz}$ frequency band-pass filter. File-names have the prefix ' $p c \_p u y$ ', followed by the source-depth, a letter ' $e$ ' or ' $j$ ' specifying whether the solution was calculated by maximising the double-couple component (' $e$ ') or the variance reduction (' $j$ '), and the suffix '.ps'.

Dfreq3: Solutions calculated using a $0.03-0.06 \mathrm{~Hz}$ frequency band-pass filter.

File-names have the prefixes given below, followed by the source depth and the suffix '.ps'.

- prefix 'ppuy_' : using the six stations WHZ, MLZ, TUZ, EAZ, WKZ and JCZ, and maximising the variance reduction. These files also have ' $j$ 's between the source depth and the '.ps'.

- prefix 'ppuy' : using the six stations WHZ, MLZ, TUZ, EAZ, WKZ and JCZ, and maximising the double-couple component.

- prefix 'ppuy_wmt' : using the three stations WHZ, MLZ and TUZ, and maximising the double-couple component.

- $\quad$ prefix 'ppuy_wmte' : using the four stations WHZ, MLZ, TUZ and EAZ, and maximising the double-couple component.

- prefix 'ppuy_wmtej' : using the five stations WHZ, MLZ, TUZ, EAZ and JCZ, and maximising the double-couple component. 
- prefix 'ppuy_wmtew' : using the five stations WHZ, MLZ, TUZ, EAZ and WKZ, and maximising the double-couple component.

\section{P10sec:}

Solutions calculated using 10 seconds of data before the arrival of the P-wave. Solutions were calculated using a $0.03-0.06 \mathrm{~Hz}$ frequency band-pass filter and maximising the double-couple component. The initial value of the offset between the seismograms and the synthetic seismograms was zero. File-names have the prefixes given below, followed by the source depth and the suffix '.ps.'

- prefix 'ppuya_' : using the six stations WHZ, MLZ, TUZ, EAZ, WKZ and JCZ.

- prefix ' $p p u y b_{-}$' : using the five stations WHZ, MLZ, TUZ, EAZ and WKZ.

- prefix 'ppuyc_' : using the four stations WHZ, MLZ, TUZ and EAZ.

- prefix 'ppuyd_' : using the three stations WHZ, MLZ and TUZ.

\section{P120sec:}

Solutions calculated using two minutes of data before the arrival of the P-wave. Solutions were calculated by maximising the double-couple component.

\section{Dfreq1:}

Solutions were calculated using a $0.01-0.05 \mathrm{~Hz}$ frequency band-pass filter. Filenames have the prefixes given below, followed by the source depth and the suffix '.ps.

- prefix 'pриуи_' : using the six stations WHZ, MLZ, TUZ, EAZ, WKZ and JCZ, and an initial offset between the seismograms and the synthetic seismograms of zero.

- prefix 'ppuyv_' : using the five stations WHZ, MLZ, TUZ, EAZ and WKZ, and an initial offset between the seismograms and the synthetic seismograms of zero.

- prefix 'ppuyw_' : using the four stations WHZ, MLZ, TUZ and EAZ, and an initial offset between the seismograms and the synthetic seismograms of zero.

- prefix 'ppuyx_' : using the three stations WHZ, MLZ and TUZ, and an initial offset between the seismograms and the synthetic seismograms of zero.

- prefix 'ppuyzi_': using the six stations WHZ, MLZ, TUZ, EAZ, WKZ and JCZ, and an initial offset between the seismograms and the synthetic seismograms of one hundred and twenty seconds.

- prefix 'ppuyzj_' : using the five stations WHZ, MLZ, TUZ, EAZ and WKZ, and an initial offset between the seismograms and the synthetic seismograms of one hundred and twenty seconds.

- prefix 'ppuyzk_' : using the four stations WHZ, MLZ, TUZ and EAZ, and an initial offset between the seismograms and the synthetic seismograms of one hundred and twenty seconds.

- prefix 'ppuyzl_' : using the three stations WHZ, MLZ and TUZ, and an initial offset between the seismograms and the synthetic seismograms of one hundred and twenty seconds. 


\section{Dfreq2:}

Solutions were calculated using a $0.02-0.05 \mathrm{~Hz}$ frequency band-pass filter. Filenames have the prefixes given below, followed by the source depth and the suffix '.ps.

- prefix 'ppuyya_' : using the six stations WHZ, MLZ, TUZ, EAZ, WKZ and JCZ, and an initial offset between the seismograms and the synthetic seismograms of zero.

- prefix 'ppuyyb_' : using the five stations WHZ, MLZ, TUZ, EAZ and WKZ, and an initial offset between the seismograms and the synthetic seismograms of zero.

- prefix 'ppuyyc_' : using the four stations WHZ, MLZ, TUZ and EAZ, and an initial offset between the seismograms and the synthetic seismograms of zero.

- prefix 'ppuyyd_' : using the three stations WHZ, MLZ and TUZ, and an initial offset between the seismograms and the synthetic seismograms of zero.

- prefix 'ppuyzm_' : using the six stations WHZ, MLZ, TUZ, EAZ, WKZ and JCZ, and an initial offset between the seismograms and the synthetic seismograms of one hundred and twenty seconds.

- prefix 'ppuyzn_' : using the five stations WHZ, MLZ, TUZ, EAZ and WKZ, and an initial offset between the seismograms and the synthetic seismograms of one hundred and twenty seconds.

- prefix 'ppuyzo_' : using the four stations WHZ, MLZ, TUZ and EAZ, and an initial offset between the seismograms and the synthetic seismograms of one hundred and twenty seconds.

- prefix 'ppuyzp_' : using the three stations WHZ, MLZ and TUZ, and an initial offset between the seismograms and the synthetic seismograms of one hundred and twenty seconds.

\section{Dfreq3:}

Solutions were calculated using a $0.03-0.06 \mathrm{~Hz}$ frequency band-pass filter. Filenames have the prefixes given below, followed by the source depth and the suffix '.ps.

- prefix 'ppuyq_' : using the six stations WHZ, MLZ, TUZ, EAZ, WKZ and JCZ, and an initial offset between the seismograms and the synthetic seismograms of zero.

- prefix 'ppuyr_' : using the five stations WHZ, MLZ, TUZ, EAZ and WKZ, and an initial offset between the seismograms and the synthetic seismograms of zero.

- prefix 'ppuys_' : using the four stations WHZ, MLZ, TUZ and EAZ, and an initial offset between the seismograms and the synthetic seismograms of zero.

- prefix 'ppuyt_' : using the three stations WHZ, MLZ and TUZ, and an initial offset between the seismograms and the synthetic seismograms of zero.

- prefix 'ppuyzb_' : using the six stations WHZ, MLZ, TUZ, EAZ, WKZ and JCZ, and an initial offset between the seismograms and the synthetic seismograms of one hundred and twenty seconds.

- prefix 'ppuyzc_' : using the five stations WHZ, MLZ, TUZ, EAZ and WKZ, and an initial offset between the seismograms and the synthetic seismograms of one hundred and twenty seconds. 
- prefix 'ppuyzd_' : using the four stations WHZ, MLZ, TUZ and EAZ, and an initial offset between the seismograms and the synthetic seismograms of one hundred and twenty seconds.

- prefix 'ppuyze_' : using the three stations WHZ, MLZ and TUZ, and an initial offset between the seismograms and the synthetic seismograms of one hundred and twenty seconds.

\section{P30sec:}

Solutions calculated using 30 seconds of data before the arrival of the P-wave. Solutions were calculated using a $0.03-0.06 \mathrm{~Hz}$ frequency band-pass filter and maximising the double-couple component. File-names have the prefixes given below, followed by the source depth and the suffix '.ps.'

- prefix 'ppuye_' : using the six stations WHZ, MLZ, TUZ, EAZ, WKZ and JCZ, and an initial offset between the seismograms and the synthetic seismograms of zero.

- prefix 'ppuyf_' : using the five stations WHZ, MLZ, TUZ, EAZ and WKZ, and an initial offset between the seismograms and the synthetic seismograms of zero.

- prefix 'ppuyg_' : using the four stations WHZ, MLZ, TUZ and EAZ, and an initial offset between the seismograms and the synthetic seismograms of zero.

- prefix 'ppuyh_' : using the three stations WHZ, MLZ and TUZ, and an initial offset between the seismograms and the synthetic seismograms of zero.

- prefix 'ppuyzf_' : using the six stations WHZ, MLZ, TUZ, EAZ, WKZ and JCZ, and an initial offset between the seismograms and the synthetic seismograms of thirty seconds.

\section{P60sec:}

Solutions calculated using one minute of data before the arrival of the P-wave. Solutions were calculated by maximising the double-couple component.

\section{Dfreq2:}

Solutions were calculated using a $0.02-0.05 \mathrm{~Hz}$ frequency band-pass filter. Filenames have the prefixes given below, followed by the source depth and the suffix '.ps.

- prefix 'ppuym_' : using the six stations WHZ, MLZ, TUZ, EAZ, WKZ and JCZ, and an initial offset between the seismograms and the synthetic seismograms of zero.

- prefix 'ppuyn_' : using the five stations WHZ, MLZ, TUZ, EAZ and WKZ, and an initial offset between the seismograms and the synthetic seismograms of zero.

- prefix 'ppuyo_' : using the four stations WHZ, MLZ, TUZ and EAZ, and an initial offset between the seismograms and the synthetic seismograms of zero.

- prefix 'ppuyp_': using the three stations WHZ, MLZ and TUZ, and an initial offset between the seismograms and the synthetic seismograms of zero.

- prefix 'ppuyza_' : using the three stations WHZ, MLZ and TUZ, and an initial offset between the seismograms and the synthetic seismograms of sixty seconds. 
- prefix 'ppuyzh_' : using the six stations WHZ, MLZ, TUZ, EAZ, WKZ and JCZ, and an initial offset between the seismograms and the synthetic seismograms of sixty seconds.

\section{Dfreq3:}

Solutions were calculated using a $0.03-0.06 \mathrm{~Hz}$ frequency band-pass filter. Filenames have the prefixes given below, followed by the source depth and the suffix '.ps.

- prefix 'ppuyi_' : using the six stations WHZ, MLZ, TUZ, EAZ, WKZ and JCZ, and an initial offset between the seismograms and the synthetic seismograms of zero.

- prefix 'ppuyj_' : using the five stations WHZ, MLZ, TUZ, EAZ and WKZ, and an initial offset between the seismograms and the synthetic seismograms of zero.

- prefix 'ppuyk_' : using the four stations WHZ, MLZ, TUZ and EAZ, and an initial offset between the seismograms and the synthetic seismograms of zero.

- prefix 'ppuyl_' : using the three stations WHZ, MLZ and TUZ, and an initial offset between the seismograms and the synthetic seismograms of zero.

- prefix 'ppuyzg_' : using the six stations WHZ, MLZ, TUZ, EAZ, WKZ and JCZ, and an initial offset between the seismograms and the synthetic seismograms of sixty seconds.

\section{Dpics_2352986}

Dfreq2a_pics: Solutions calculated using a $0.02-0.05 \mathrm{~Hz}$ frequency band-pass filter.

File-names have the prefix ' $p w f$ ', followed by the source-depth and the suffix '.ps'.

Dfreq2b_pics: Solutions calculated using a $0.02-0.10 \mathrm{~Hz}$ frequency band-pass filter.

File-names have the prefix ' $p w g$ ', followed by the source-depth and the suffix '.ps'.

Dfreq3_pics: Solutions calculated using a $0.03-0.06 \mathrm{~Hz}$ frequency band-pass filter.

File-names have the prefix ' $p w h$ ', followed by the source-depth and the suffix '.ps'.

Dfreq4_pics: Solutions calculated using a $0.04-0.10 \mathrm{~Hz}$ frequency band-pass filter.

File-names have the prefix ' $p w i$ ', followed by the source-depth and the suffix '.ps'.

\section{Dpics_2353002}

Dfreq2a_pics: Solutions calculated using a $0.02-0.05 \mathrm{~Hz}$ frequency band-pass filter.

File-names have the prefix ' $p w b$ ', followed by the source-depth and the suffix '.ps'. 
Dfreq2b_pics: Solutions calculated using a $0.02-0.10 \mathrm{~Hz}$ frequency band-pass filter.

File-names have the prefix ' $p w c$ ', followed by the source-depth and the suffix '.ps'.

Dfreq3_pics: Solutions calculated using a $0.03-0.06 \mathrm{~Hz}$ frequency band-pass filter.

File-names have the prefix ' $p w d$ ', followed by the source-depth and the suffix '.ps'.

Dfreq4_pics: Solutions calculated using a $0.04-0.10 \mathrm{~Hz}$ frequency band-pass filter.

File-names have the prefix ' $p w e$ ', followed by the source-depth and the suffix '.ps'.

\section{Dpics_2354133}

Dfreq2_pics: Solutions calculated using the New Zealand velocity model and a $0.02-0.05 \mathrm{~Hz}$ frequency band-pass filter.

File-names have the prefixes given below, followed by the source-depth and the suffix '.ps'.

- prefix 'puhutt_a' : using the eight stations BFZ, TSZ, NNZ, WAZ, PWZ, KHZ, THZ and QRZ.

- prefix 'puhutt_c' : using the five stations BFZ, TSZ, NNZ, WAZ and PWZ.

- prefix 'puhutt_d' : using the four stations BFZ, TSZ, NNZ and WAZ.

- prefix 'puhutt_e' : using the three stations BFZ, TSZ and NNZ.

Dfreq3_pics: Solutions calculated using the New Zealand velocity model and a $0.03-0.06 \mathrm{~Hz}$ frequency band-pass filter.

File-names have the prefixes given below, followed by the source-depth and the suffix '.ps'.

- prefix 'puhutt_f' : using the eight stations BFZ, TSZ, NNZ, WAZ, PWZ, KHZ, THZ and QRZ.

- prefix 'puhutt_g' : using the five stations BFZ, TSZ, NNZ, WAZ and PWZ.

- prefix 'puhutt_h' : using the four stations BFZ, TSZ, NNZ and WAZ.

- prefix 'puhutt_i' : using the three stations BFZ, TSZ and NNZ.

DWgtn_pics: Solutions calculated using the Wellington velocity model and a 0.03 $0.06 \mathrm{~Hz}$ frequency band-pass filter.

File-names have the prefixes given below, followed by the source-depth and the suffix '.ps'.

- prefix 'puh_w3_' : using the three stations BFZ, TSZ and NNZ.

- prefix 'puh_w4_': using the four stations BFZ, TSZ, NNZ and WAZ.

- prefix 'puh_w5_': using the five stations BFZ, TSZ, NNZ, WAZ and PWZ. 


\section{Dpics_2354877}

Dfreq2a_pics: Solutions calculated using a $0.02-0.05 \mathrm{~Hz}$ frequency band-pass filter.

File-names have the prefix 'puha_', followed by the source-depth and the suffix '.ps'.

Dfreq3_pics: Solutions calculated using a $0.03-0.06 \mathrm{~Hz}$ frequency band-pass filter.

File-names have the prefix 'puhb_', followed by the source-depth and the suffix '.ps'.

Dfreq4_pics: Solutions calculated using a $0.04-0.10 \mathrm{~Hz}$ frequency band-pass filter.

File-names have the prefix 'puhc_', followed by the source-depth and the suffix '.ps'.

\section{Dpics_2359081}

File-names have the prefix 'pwair', followed by the source-depth and the suffix '.ps'.

\section{Dpics_2376455}

File-names have the prefixes given below, followed by the source-depth and the suffix '.ps'.

- prefix 'pst' : using the thirteen stations NNZ, QRZ, WAZ, VRZ, MRZ, THZ, WPVZ, TSZ, HIZ, BFZ, KHZ, BKZ and PWZ.

- prefix 'pst_03s_' : using the three stations NNZ, QRZ and WAZ.

- prefix 'pst_03w_' : using the three stations NNZ, QRZ and VRZ.

- prefix 'pst_04s_' : using the four stations NNZ, QRZ, WAZ and VRZ.

- prefix 'pst_04w_' : using the four stations NNZ, QRZ, VRZ and MRZ.

- prefix 'pst_05s_' : using the five stations NNZ, QRZ, WAZ, VRZ and MRZ.

- prefix 'pst_05w_' : using the five stations NNZ, QRZ, VRZ, MRZ and THZ.

- prefix 'pst_06s_' : using the six stations NNZ, QRZ, WAZ, VRZ, MRZ and THZ.

- prefix 'pst_06w_' : using the six stations NNZ, QRZ, VRZ, MRZ, THZ and TSZ.

- prefix 'pst_07s_' : using the seven stations NNZ, QRZ, WAZ, VRZ, MRZ, THZ and WPVZ.

- prefix 'pst_07w_' : using the seven stations NNZ, QRZ, VRZ, MRZ, THZ, TSZ and HIZ.

- prefix 'pst_08s_' : using the eight stations NNZ, QRZ, WAZ, VRZ, MRZ, THZ, WPVZ and TSZ.

- $\quad$ prefix 'pst_08w_' : using the eight stations NNZ, QRZ, VRZ, MRZ, THZ, TSZ, HIZ and BFZ.

- prefix 'pst_09s_' : using the nine stations NNZ, QRZ, WAZ, VRZ, MRZ, THZ, WPVZ, TSZ and HIZ.

- $\quad$ prefix 'pst_09w_' : using the nine stations NNZ, QRZ, VRZ, MRZ, THZ, TSZ, HIZ, BFZ and KHZ.

- prefix 'pst_10s_' : using the ten stations NNZ, QRZ, WAZ, VRZ, MRZ, THZ, WPVZ, TSZ, HIZ and BFZ.

- prefix 'pst_11s_' : using the eleven stations NNZ, QRZ, WAZ, VRZ, MRZ, THZ, WPVZ, TSZ, HIZ, BFZ and KHZ. 
- prefix 'pst_12s_' : using the twelve stations NNZ, QRZ, WAZ, VRZ, MRZ, THZ, WPVZ, TSZ, HIZ, BFZ, KHZ and BKZ.

\section{Dpics_2376763}

File-names have the prefixes given below, followed by the source-depth and the suffix '.ps'.

- $\quad$ prefix ' $p 237 f_{-}$' : using the ten stations MLZ, WHZ, WKZ, JCZ, EAZ, TUZ, LBZ, FOZ, ODZ and WVZ.

- prefix 'p237f_3stns_' : using the three stations MLZ, WHZ and WKZ.

- prefix 'p237f_4stns_' : using the four stations MLZ, WHZ, WKZ and JCZ.

- prefix ' $p 237 f \_5 s t n s_{-}$' : using the five stations MLZ, WHZ, WKZ, JCZ and EAZ.

- prefix 'p237f_6stns_' : using the six stations MLZ, WHZ, WKZ, JCZ, EAZ and TUZ.

- prefix 'p237f_7stns_' : using the seven stations MLZ, WHZ, WKZ, JCZ, EAZ, TUZ and LBZ.

- $\quad$ prefix 'p237f_8stns_' : using the eight stations MLZ, WHZ, WKZ, JCZ, EAZ, TUZ, LBZ and FOZ.

- prefix 'p237f_9stns_' : using the nine stations MLZ, WHZ, WKZ, JCZ, EAZ, TUZ, LBZ, FOZ and ODZ.

\section{Dpics_2385032}

File-names have the prefixes given below, followed by the source-depth and the suffix '.ps'.

- prefix 'ptwi_': using the ten stations EAZ, WVZ, TUZ, MLZ, WHZ, MQZ, CRLZ, LTZ, KHZ and THZ.

- $\quad$ prefix ' $p t w i_{-} 3 s_{-}$' : using the three stations EAZ, WVZ and TUZ.

- prefix 'ptwi_4s_' : using the four stations EAZ, WVZ, TUZ and MLZ.

- prefix 'ptwi_5s_' : using the five stations EAZ, WVZ, TUZ, MLZ and CRLZ.

- prefix 'ptwi_6s_' : using the six stations EAZ, WVZ, TUZ, MLZ, CRLZ and LTZ.

- prefix 'ptwi_ $7 s_{-}$' : using the seven stations EAZ, WVZ, TUZ, MLZ, CRLZ, LTZ and KHZ.

- prefix 'ptwi_8s_' : using the eight stations EAZ, WVZ, TUZ, MLZ, CRLZ, LTZ, $\mathrm{KHZ}$ and THZ.

- prefix 'ptwi_9s_' : using the nine stations EAZ, WVZ, TUZ, WHZ, MQZ, CRLZ, LTZ, KHZ and THZ.

\section{Dpics_2398629}

File-names have the prefixes given below, followed by the source-depth and the suffix '.ps'.

- prefix 'pjack_3stns_' : using the three stations LBZ, EAZ and WVZ.

- prefix 'pjack_4stns_' : using the four stations LBZ, EAZ, WVZ and MLZ.

- prefix 'pjack_7stns_' : using the seven stations LBZ, EAZ, WVZ, MLZ, ODZ, TUZ, and WHZ.

- prefix 'pjack_8stns_' : using the eight stations LBZ, EAZ, WVZ, MLZ, ODZ, TUZ, WHZ and MQZ.

\section{Dpics_2403682}

File-names have the prefixes given below, followed by the source-depth and the suffix '.ps'. An ' $i$ ' immediately after the source-depth indicates that the solution was obtained by 
Appendix 2: All seismic moment tensor solutions.

maximising the variance reduction. If there is no ' $i$ ' immediately following the source-depth then the solution was obtained by maximising the double-couple component.

- prefix 'p240eofgisb_' : using the eight stations PUZ, MXZ, MWZ, BKZ, PWZ, WPVZ, TSZ and KUZ.

- prefix 'p240eofgisb_pmk' : using the three stations PUZ, MXZ and KUZ.

- prefix 'p240eofgisb_pmm' : using the three stations PUZ, MXZ and MWZ.

\section{Dpics_2418019}

File-names have the prefix 'psk', followed by the source-depth and and the suffix '.ps'.

\section{Dpics_2569288}

File-names have the prefix 'pmt_', followed by the source-depth and and the suffix '.ps'.

\section{Dpics_2626467}

File-names have the prefix ' $p j b$ ', followed by the source-depth and and the suffix '.ps'. 